\title{
Data of Geochemistry
}

Sixth Edition

Chapter B. Cosmochemistry

Part 1. Meteorites

GEOLOGICALSURVEY PROFESSIONAL PAPER 440-B-1
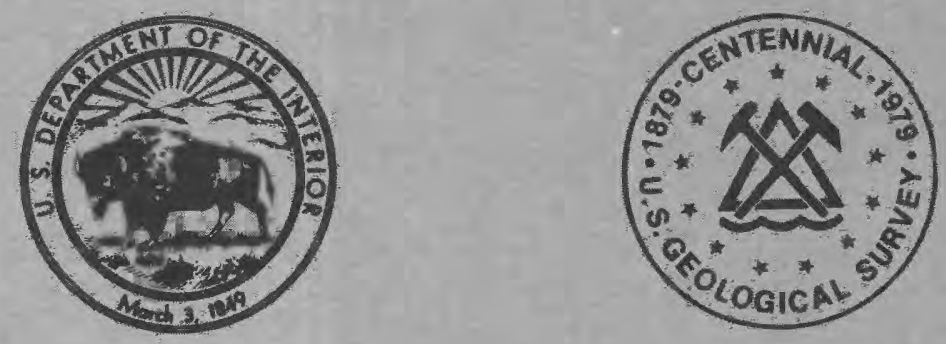


\section{Data of Geochemistry}

Sixth Edition

MICHAEL FLEISCHER, Technical Editor

Chapter B. Cosmochemistry

Part 1. Meteorites

By BRIAN MASON

GEOLOGICAL SURVEY PROFESSIONAL PAPER 440-B-1

Tabulation and discussion of elemental abundances in the different classes of stony and iron meteorites, and in their constituent minerals

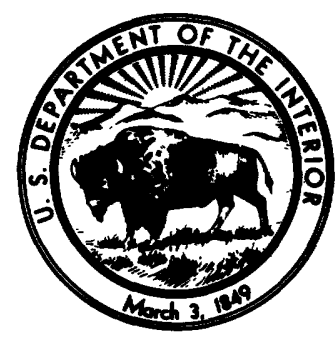


UNITED STATES DEPARTMENT OF THE INTERIOR

CECIL D. ANDRUS, Secretary

\section{GEOLOGICAL SURVEY}

H. William Menard, Director

Library of Congress catalog-card No. 79-64561

For sale by the Superintendent of Documents, U.S. Government Printing Office

Washington, D.C. 20402

Stock Number 024-001-031621 


\title{
DATA OF GEOCHEMISTRY, SIXTH EDITION
}

\author{
Michael Fleischer, Technical Editor
}

The first edition of the Data of Geochemistry, by F. W. Clarke, was published in 1908 as U.S. Geological Survey Bulletin 330. Later editions, also by Clarke, were published in 1911, 1916,1920, and 1924 as Bulletins $491,616,695$, and 770. This, the sixth edition, has been written by several scientists in the Geological Survey and in other institutions in the United States and abroad, each preparing a chapter on his special field. The current edition is being published in individual chapters, titles of which are listed below. Chapters already published are indicated by boldface.

Chapter A. The chemical elements

B. Cosmochemistry Part 1, Meteorites by Brian Mason; Part 2, Cosmochemistry.

C. Internal structure and composition of the earth.

D. Composition of the earth's crust, by R. L. Parker

E. Chemistry of the atmosphere

F. Chemical composition of subsurface waters, by Donald E. White, John D. Hem, and G. A. Waring

G. Chemical composition of rivers and lakes, by Daniel A. Livingstone

H. Chemistry of the oceans

I. Geochemistry of the biosphere

J. Chemistry of rock-forming minerals

K. Voleanic emanations, by Donald E. White and G. A. W aring

L. Phase equilibrium relations of the common rock-forming oxides except water, by G. W. Morey

M. Phase equilibrium relations of the common rock-forming oxides with water and (or) carbon dioxide

N. Chemistry of igneous rocks, Part 1 , The chemistry of the peralkaline oversaturated obsidians, by Ray Macdonald and D. K. Bailey

0. Chemistry of rock weathering and soils

P. Chemistry of bauxites and laterites

Q. Chemistry of nickel silicate deposits

R. Chemistry of manganese oxides

S. Chemical composition of sandstones_excluding carbonate and volcanic sands, by F. J. Pettijohn

T. Nondetrital siliceous sediments, by Earle R. Cressman

U. Chemical composition of shales and related rocks

V. Chemistry of carbonate rocks

W. Chemistry of the iron-rich sedimentary rocks, by H. L. James

X. Chemistry of phosphorites

Y. Marine evaporites, by Frederick H. Stewart

Z. Continental evaporites

AA. Chemistry of coal

BB. Chemistry of petroleum, natural gas, and miscellaneous carbonaceous substances

CC. Chemistry of metamorphic rocks

DD. Abundance and distribution of the chemical elements and their isotopes

EE. Geochemistry of ore deposits

FF. Physical chemistry of sulfide systems

GG. The natural radioactive elements

HH. Geochronology

II. Temperatures of geologic processes

JJ. Composition of fluid inclusions, by Edwin Roedder

KK. Compilation of stable isotope fractionation factors of geochemical interest, by Irving Friedman and James R. O'Neil 


\section{CONTENTS}

Abstract
Introduction
Phistorical background composition of meteorites
Classification of meteorites
Classification of chondrites
Classification of achondrites and stony-irons
$\quad$ Chemical fractionations in chondrites
The geochemical behavior of elements in meteorites
Location of minor and trace elements in meteorites
Tydrogen
Lithium
Beryllium
Boron
Carbon
Nitrogen
Oxygen
Fluorine
Sodium
Magnesium
Aluminum
Silicon
Phosphorus
Sulfur
Chlorine
Potassium
Calcium
Scandium
Titanium
Vanadium
Chromium
Manganese
Iron
Cobalt
Copper
Gine

\begin{tabular}{|c|c|c|}
\hline Ige & & \\
\hline B1 & fermanium -..-- & 853 \\
\hline 1 & Arsenic & 55 \\
\hline 1 & Selenium & 55 \\
\hline 2 & Bromine --1- & $5^{r}$ \\
\hline 4 & m - & \\
\hline 4 & n - & \\
\hline 10 & - & \\
\hline 10 & 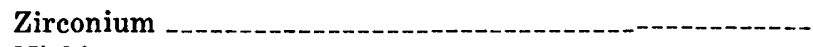 & \\
\hline 13 & - & \\
\hline 14 & $\mathrm{~m}$ & \\
\hline 14 & - & \\
\hline 14 & - & \\
\hline 16 & - & \\
\hline $1 \varepsilon$ & - & \\
\hline 18 & & \\
\hline 20 & & \\
\hline 20 & 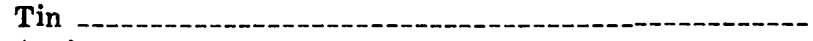 & \\
\hline 21 & - & \\
\hline 28 & ------ & \\
\hline 25 & - & \\
\hline 26 & & \\
\hline 29 & - & \\
\hline 31 & nides & \\
\hline 33 & - & \\
\hline 34 & 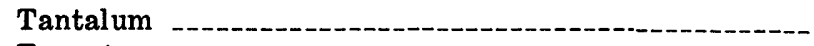 & 86 \\
\hline 36 & 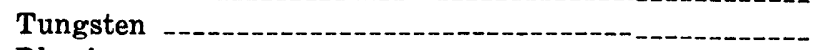 & \\
\hline 37 & - & \\
\hline 39 & $\begin{array}{c}-1 \\
-1\end{array}$ & \\
\hline 39 & - & \\
\hline 40 & & $y$ \\
\hline 41 & n & \\
\hline 44 & - & 9 \\
\hline 44 & 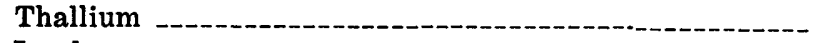 & $9^{r}$ \\
\hline 45 & 'ר- & \\
\hline 46 & & 0 \\
\hline 48 & - & J1 \\
\hline 5 & [-1 & 0 \\
\hline $\mathbf{5}$ & - & \\
\hline 52 & dgments _- & \\
\hline 52 & s cited & \\
\hline
\end{tabular}

\section{ILLUSTRATIONS}

FrguRes 1-3. Graphs showing:

1. Relationship between elemental abundances in Type I carbonaceous chondrites and abundances in the Sun

2. Relationship between oxidized iron and i ron as metal and sulfide in analyses of chondrites

3. Relationship between $\mathrm{CaO}$ and $\mathrm{FeO} /(\mathrm{FeO}+\mathrm{MgO})$ in the achondrites and stony-irons ............ 
FiguRES 4-6. Diagrams showing

4. Relative abundances of selected elements in Type II and III carbonaceous chondrites and in ordinary chondrites, normalized to Type I carbonaceous chondrites $=1.0$

5. Frequency distribution of carbon in chondrites

6. ${ }^{18} \mathrm{O} /{ }^{18} \mathrm{O}$ analyses of whole-rock samples and olivines from carbonaceous chondrites and whole-rock analyses of other meteorites

7. Graph showing relationship between $\mathrm{SiO}_{2}$ and $\mathrm{MgO}$ in chondrites

8. Logarithmic plot showing $\mathrm{Co}-\mathrm{Ni}$ distribution in meteorites

9. Histogram showing the nickel content of analy zed iron meteorites 10-15. Logarithmic plots showing:

10. Ga-Ni distribution in iron meteorites

11. Ge-Ni distribution in iron meteorites

12. As-Ni distribution in iron meteorites

13. Ru-Ni distribution in iron meteorites

14. Pd-Ni distribution in iron meteorites

15. Sb-Ni distribution in iron meteorites

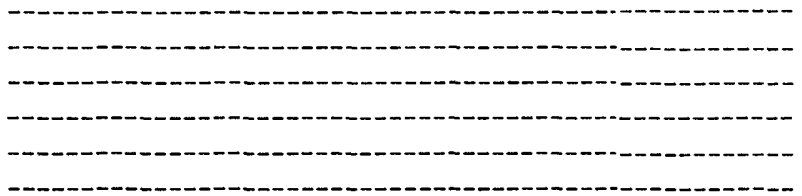

16, 17. Diagrams showing:

16. Lanthanide abundances in $\mathrm{Cl}$ chondrites, $\mathrm{C3}$ chondrites, and the eucrites (calcium-rich achondrites

17. Chondrite-normalized lanthanide abund ances in achondrites

18. Re-Ni distribution in iron meteorites

19. Os-Ni distribution in iron meteorites

20. Ir-Ni distribution in iron meteorites

21. Pt-Ni distribution in iron meteorites

22. $\mathrm{Au}-\mathrm{Ni}$ distribution in iron meteorites

\section{TABLES}

TABLE 1. The common minerals of meteorites

2. Classification of meteorites

3. Chemical analyses of chondritic meteorites -.

4. Petrologic types of chondrites

5. Classification of the chondrites -..............

6. Structural classification of iron meteorites -

7. Structural and compositional properties of iron meteorite groups

8. The geochemical behavior of the elements in chondritic meteorites

9. Hydrogen released as water from carbonaceous chondrites

10. Noble gases in five meteorites ..............

11. Lithium in stony meteorites

12. Beryllium in meteorites

13. Boron in meteorites

14. Carbon in stony meteorites
3

6

9

10

11

12
15. Carbon in iron meteorites

16. Nitrogen in stony meteorites

17. Nitrogen in iron meteorites

18. Oxygen in stony meteorites

19. Comparison of fluorine determinations in chondrites

20. Fluorine in stony meteorites

21. Sodium in stony meteorites

22. Magnesium in stony meteorites

23. Aluminum in stony meteorites

24. Silicon in stony meteorites

25. Phosphorus in stony meteorites

26. Phosphorus in iron meteorites

27. Sulfur in stony meteorites

28. Chlorine in stony meteorites

29. Potassium in stony meteorites 
TABLE 30. Calcium in stony meteorites

B40

31. Scandium in stony meteorites

32. Titanium in stony meteorites

33. Vanadium in stony meteorites

34. Chromium in stony meteorites

35. Manganese in stony meteorites

37. Mean iron content of individual classes of iron meteorites

38. Cobalt in stony meteorites

39. Nickel in stony meteorites

40. Copper in stony meteorites -.-.--.--

41. Zinc in stony meteorites -

42. Zinc in iron meteorites

43. Gallium in stony meteorites

44. Germanium in stony meteorites

45. Arsenic in chondritic meteorites

46. Selenium in stony meteorites

47. Bromine in stony meteorites

49. Strontium in stony meteorites

50. Yttrium in stony meteorites ........................

51. Zirconium in stony meteorites

52. Niobium in meteorites

53. Molybdenum in stony meteorites

54. Ruthenium in stony meteorites

55. Rhodium in stony meteorites (........ 69

56. Palladium in stony meteorites _..._._... 70

57. Silver in stony meteorites 72
58. Cadmium in stony meteorites _........ B73

59. Indium in stony meteorites _........... 74

60. Tin in stony meteorites _..._...... 75

61. Antimony in stony meteorites - 76

62. Tellurium in stony meteorites _...........- 78

63. Iodine in chondrites _._. 79

64. Cesium in stony meteorites - 80

65. Barium in stony meteorites _._._._._._. 81

66. Lanthanides in stony meteorites ...__._. 82

67. Lanthanide abundances in chondrite composites

68. Hafnium in meteorites _................ 87

69. Tantalum in stony meteorites .........- 88

70. Tungsten in stony meteorites ............ 89

71. Rhenium in stony meteorites _._._...- 90

72. Osmium in stony meteorites _... 92

73. Iridium in stony meteorites ......... 93

74. Platinum in chondrites _.............- 95

75. Gold in stony meteorites _....... 96

76. Mercury in stony meteorites ........... 98

77. Thallium in stony meteorites _......... 99

78. Lead in stony meteorites _-_...-.-100

79. Bismuth in stony meteorites _............ 101

80. Thorium in stony meteorites _..........- 102

81. Uranium in stony meteorites ..........-. 103

82. Chondritic and solar abundances ..........- 105

83. Minerals of meteorites _-_._._-_._- 107

84. Analytical data for a selection of stony meteorites _- 111

\section{ABBREVIATIONS}

The following abbreviations for the meteorite classes are used throughout the tables and elsewhere; for the chondrites a digit after the symbol indicates the petrographic type.

Chondrites
C carbonaceous
H bronzite
L
LL ampersthene
E enstatite

Calcium-poor achondrites

Ae aubrites

Ah diogenites

Ac chassignite

Au ureilites

\author{
Calcium-rich achondrites \\ Aa angrite \\ An nakhlites \\ Aho howardites \\ Aeu eucrites
}




\title{
DATA OF GEOCHEMISTRY
}

\section{COSMOCHEMISTRY PART 1. METEORITES}

\author{
By BRIAN MASON ${ }^{1}$
}

\begin{abstract}
Meteorites are the least-differentiated rocks in the solar system, and can thus provide a reasonable approximation to the relative and absolute abundances of the nonvolatile elements. This was first recognized by V. M. Goldschmidt, who in 1937 used data from meteorites to compile the first table of cosmic abundances of the elements in "Geochemische Verteilungsgesetze der Elemente." The great expansion and improvement in analytical techniques, coupled with a growing interest on space research, have resulted in an enormous expansion in the data on elemental abundances in meteorites. These data (to 1976) are summarized herein. An introductory section discusses the phase composition and classification of meteorites, and the factors governing the distribution of the chemical elements within them. This is followed by sections, one for each element (groups of elements for the noble gases and the lanthanides), in which the specific abundances are tabulated and discussed. A concluding section compares meteoritic and solar abundances, using Type I carbonaceous chondrites as the best approximation for average meteoritic matter. In this class of meteorites the order of abundance of the elements (by weight) is: $\mathrm{O}, \mathrm{Si}, \mathrm{Fe}$ ( $>10$ percent); $\mathrm{Mg}$, $\mathrm{S}, \mathrm{Ca}, \mathrm{Ni}$ (1-10 percent); $\mathrm{Al}, \mathrm{Na}, \mathrm{Cr}, \mathrm{Mn}$ (0.1-1 percent); $\mathrm{P}, \mathrm{Cl}, \mathrm{K}, \mathrm{Co}, \mathrm{Ti}, \mathrm{Zn}, \mathrm{Cu}$ (0.01-0.1 percent); all others $(<0.01$ percent $)$. A list of meteorite minerals is provided, and a tabulation of elemental abundances in 35 stony meteorites represents most of the recognized classes.
\end{abstract}

\section{INTRODUCTION}

\section{HISTORICAL BACKGROUND}

The systematic investigation of elemental abundances in meteorites can be said to date from 1923. In that year V. M. Goldschmidt, in the initial part of his great work "Geochemische Verteilungsgestze der Elemente," pointed out the significance of meteorites for elucidating the geochemistry of the elements. He proposed a classification of the elements into siderophile, chalcophile, lithophile, and atmophile groups, according to their affinity for metallic iron, for sulfides, for silicates, and for the atmosphere, respec-

\footnotetext{
${ }^{1}$ Curator, Department of Mineral Sciences, National Museum of Natural History, Smithsonian Institution, Washington, D.C. 20560.
}

tively. He remarked that meteorites, with their nickel-iron, troilite ( $\mathrm{FeS})$, and silicate (plus oxide) phases, provided a readily available "fossilized" experiment in the distribution of the elements among these phases. During the following years, Goldschmidt and his coworkers made many determinations of specific elements in meteorites. These results, and those of other investigations such as I. and W. Noddack and G. von Hevesy, were summarized in the final part of "Geochemische Verteilungsgesetz der Elemente" (1937), and were used by Goldschmidt to prepare the first comprehensive table of elemental abundances in meteoritic matter. In this table (1937, p. 99-101) he introduced the convention of referring atomic abundances to silicon as the reference element, primarily in order to relate terrestrial and meteoritic abundances to solar abundances, a convention which has since become standard practice.

On the basis of the meteoritic data, supplemented by information from solar spectra, Goldschmidt also prepared a table of cosmic abundances of the elements (1937, p. 120-122). This table and many revised versions (such as Cameron, 1973) have formed the basis for theoretical studies of cosmochemistry and for the testing of hypotheses of nucleosynthesis. As Cameron stated (1973, p. 121):

In the field of cosmochemistry, these abundances determine the mineral phases which will condense from the primitive solar nebula under different conditions of temperature and density, so that by examining the bulk compositions and individual mineral phases of planetary and smaller bodies in the solar system, much can be deduced about the conditions in the original primitive solar nebula. As our knowledge of the abundances improves, more stringent boundary conditions can be placed on the mechanisms of nucleosynthesis which produced these elements in stars, particularly in short-lived phases such as supernova explosions, thus allowing better tests of theoretical astrophysical calculations in this field.

For some years the propriety of using data from 
meteorites for establishing cosmic abundances of the elements was questioned, largely on an apparent fivefold to tenfold discrepancy between the iron abundance in the solar photosphere and in chondritic meteorites (Urey, 1967; Arnold and Suess, 1969). This discrepancy has been eliminated by the discovery of a tenfold error in the oscillator strengths of the Fe spectrographic lines used for solar abundance determinations (Garz and Kock, 1969). Anders (1971a) provided a detailed discussion of this problem, and concluded that a particular group of meteorites, the Type I carbonaceous chondrites, closely approximates the condensible fraction of primordial solar-system matter. Figure 1 shows the correlation between solar abundances and those in Type I carbonaceous chondrites for 29 elements for which adequate data are available. If abundances for individual elements were the same in both, the points in figure 1 would lie on the $45^{\circ}$ line. The close approach to this line is the basis for considering Type I carbonaceous chondrites as approximating in composition the unfractionated nonvolatile matter of the solar system.

\section{PHASE COMPOSITION OF METEORITES}

More than 80 minerals are known from meteorites (tables 1 and 83), but many of these are rare acces-

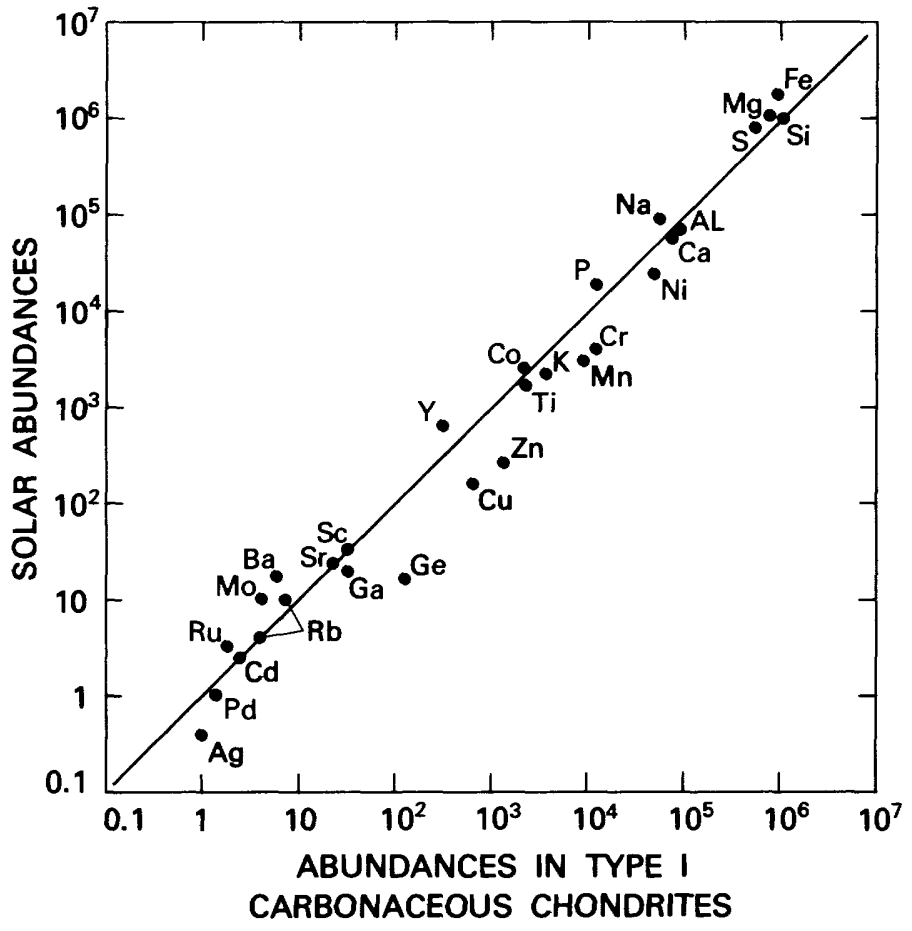

FigURE 1.-Comparison of elemental abundances (normalized to $\mathrm{Si}=10^{6}$ atoms) in Type $\mathrm{I}$ carbonaceous chondrites with abundances in the Sun. Reprinted from Mason (1971) and published with permission.

TABLE 1.-The common minerals of meteorites

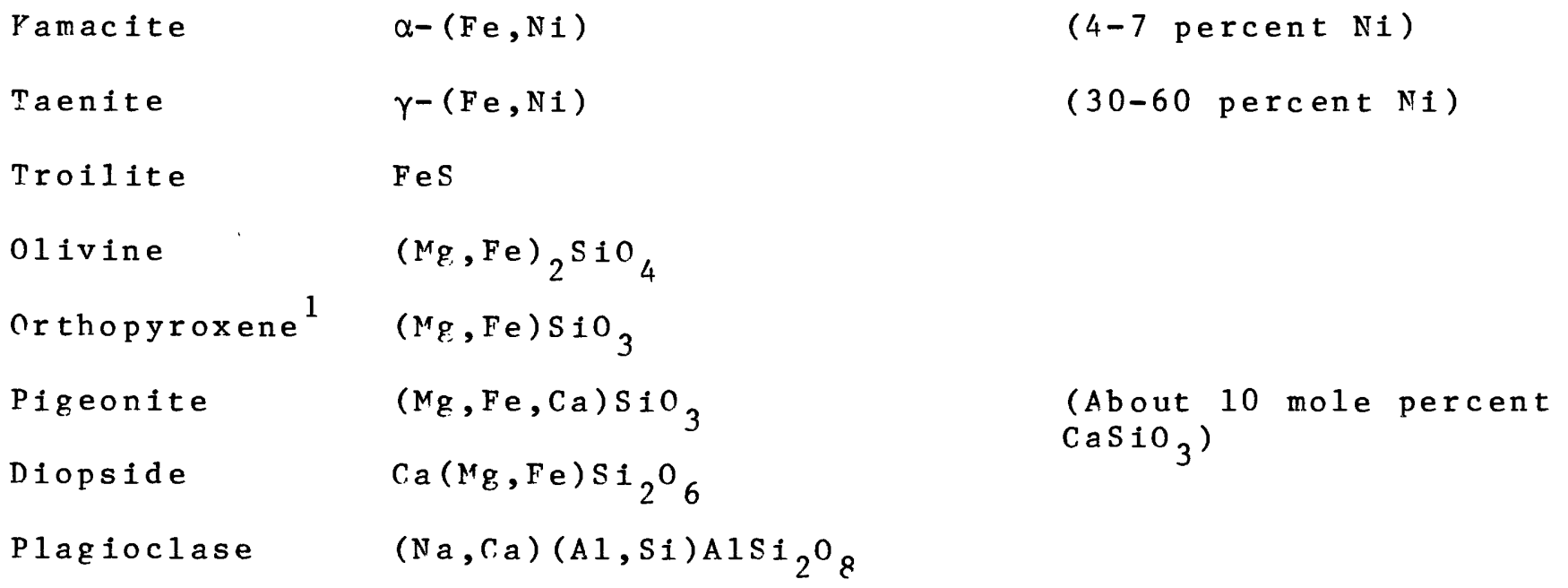

1 Divided into enstatite, with 0-10 mole percent Fesio 3 , bronzite 10-20 percent, and hypersthene, $>20$ percent; these minerals are orthorhombic, and have monoclinic polymorphs known as clinoenstatite, clinobronzite, and clinohypersthene. It should be noted that the boundary between bronzite and hypersthene in meteorites, established by Prior (1920), is not the same as current mineralogical usage ( 30 mole percent $\mathrm{FeSiO}_{3}$ ), following Poldervaart (1947). 


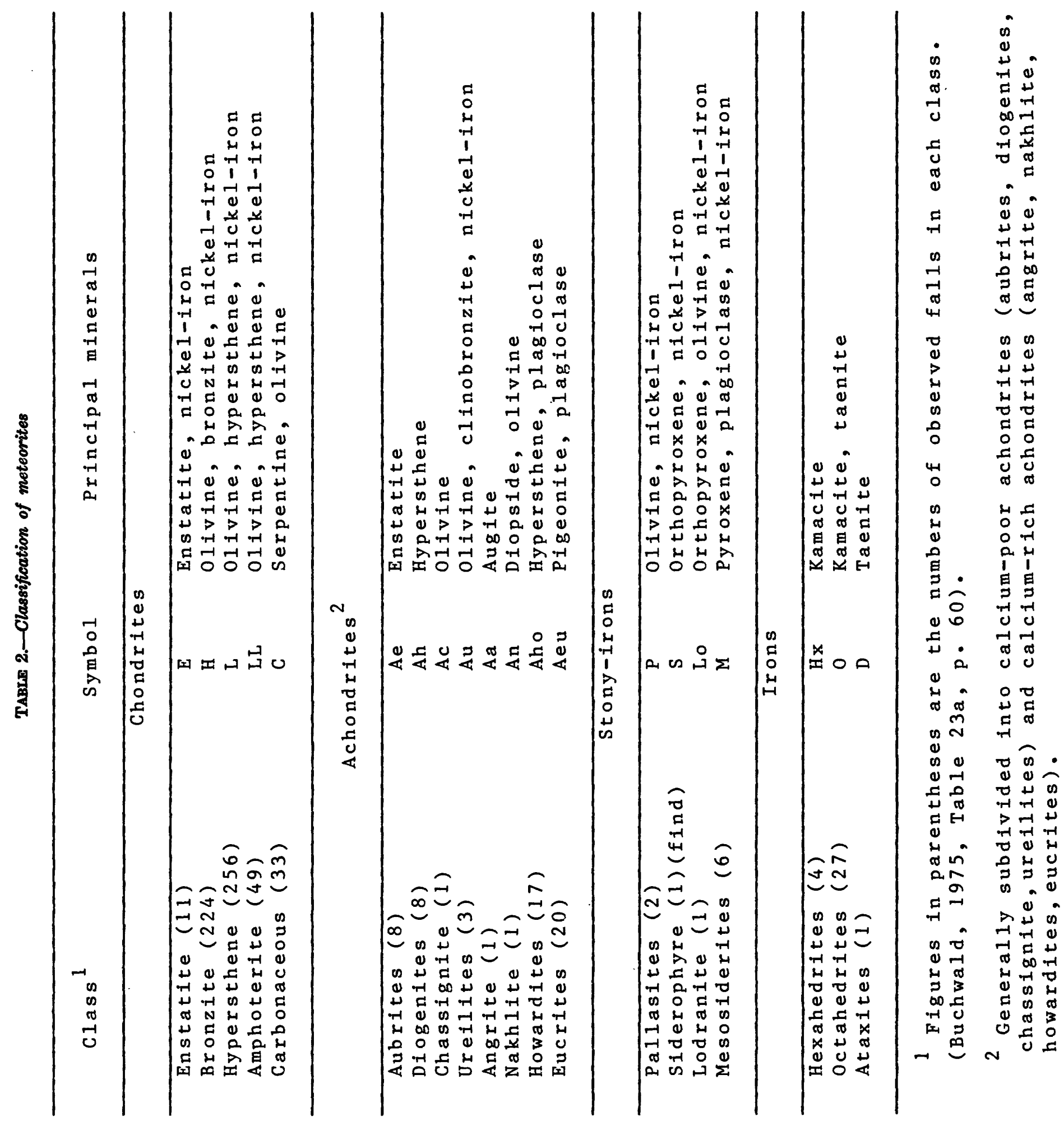


sories. The common and abundant minerals are listed in table 1. Some contrasts to terrestrial mineralogy may be pointed out: nickel-iron is practically absent from terrestrial rocks; the common minerals in meteorites are largely magnesium-iron silicates, whereas, in the Earth's crust, the commonest minerals are quartz and aluminosilicates; the common meteorite minerals are anhydrous, whereas hydrated minerals are common and abundant on Earth. These features indicate that most meteorites formed in a highly reducing environment, in which nickel and iron were largely in the metallic state. The carbonaceous chondrites, a small but remarkable class of meteorites, differ fundamentally: they consist largely of serpentine, $(\mathrm{Mg}, \mathrm{FE})_{6} \mathrm{Si}_{4} \mathrm{O}_{10}(\mathrm{OH})_{8}$ (or related layer-lattice silicates), the nickel is present mainly in silicates and sulfides, and they contain considerable amounts of organic compounds of extraterrestrial origin. A notable feature of the overall mineralogy of meteorites is the absence of phases, such as pyrope garnet and jadeitic pyroxenes, indicative of high pressures (that is, large parent bodies); the origin of the diamond in the Canyon Diablo iron has been plausibly ascribed to the shock of impact with the Earth that formed the Arizona Meteor Crater, and the presence of diamond in the small group of ureilites appears to be due to extraterrestrial shock effects.

\section{CLASSIFICATION OF METEORITES}

Current classifications of meteorites are based on mineralogy and structure. The major groups and classes are listed in table 2 . It is obvious from the figures for observed falls that the populations of the different classes vary widely. The figures for observed falls are used as being the best approach to actual extraterrestrial abundances; irons dominate meteorite finds since they are resistant to weathering and are readily recognized as meteorites or at least as very unusual objects. More than 80 percent of meteorite falls are chondrites, and 84 percent of these belong to two classes, frequently referred to jointly as the ordinary or common chondrites. Of the other classes of meteorites, some are represented by a single fall, which suggests that additional classes, as yet unknown, may well exist.

\section{CLASSIFICATION OF CHONDRITES}

Chondrites are characterized by the presence of chondrules, which are small $(\sim 1 \mathrm{~mm}$ diameter $)$ spheroidal aggregates, usually of olivine and (or) pyroxene. Chondrules are unique to chondritic meteorites ${ }^{2}$, being unknown in terrestrial rocks, which suggests that they were formed by some exotic process. That they originated as molten silicate droplets is generally agreed, although where and under what circumstances is still a controversial subject. Current ideas include volcanism on the meteorite parent bodies, splash droplets formed in collisions between asteroids, condensation of liquid droplets from a hot gas of solar composition, and fusion of dust in the primordial solar nebula.

Not only are the chondrites the most abundant meteorites, but many features indicate a primary origin for them and a derivative origin for the other meteorite groups. As a consequence, compositional data are far more extensive for the chondrites than for any other meteorite group. However, although the chondrites may have originated from comparatively undifferentiated parent material, they can be subdivided into several classes and subclasses, marked off by distinct mineralogical and chemical hiatuses.

This subdivision is illustrated in figure 2, which plots chemical analyses of individual chondrites in the form of weight percent iron as metal and sulfide (that is, reduced iron) against weight percent oxidized iron (essentially iron combined in silicates). The trend is clear, from meteorites in which all the iron is in the reduced form (the enstatite chondrites) to meteorites in which all or nearly all is in the oxidized form (the carbonaceous chondrites). But the sequence is not a continuous one, and the five classes of chondrites form discrete clusters in this diagram. The classes are also distinguished by their total iron content. Urey and Craig (1953), in the original version of figure 2 , noted a bimodal clustering of points corresponding to average total iron contents of approximately 22 percent and 28 percent, and named these the low-iron (L) and high-iron (H) groups respectively. The present figure 2, based on a more rigid selection of analyses and a considerable number of superior analyses made since 1953, shows that the $\mathrm{H}$ group comprises the bronzite chondrites and the L group the hypersthene chondrites. In the enstatite chondrites the iron content ranges from values corresponding to the $\mathrm{L}$ group to higher figures than those characteristic of the $\mathrm{H}$ group. Carbonaceous chondrites cannot be directly compared with the other classes of chondrites, since they contain a large amount of combined water and other volatiles; on a volatile-free basis (used in fig. 1) they belong to the $\mathrm{H}$ group.

2 Chondrite-like structures have been identified in some lunar rocks. 


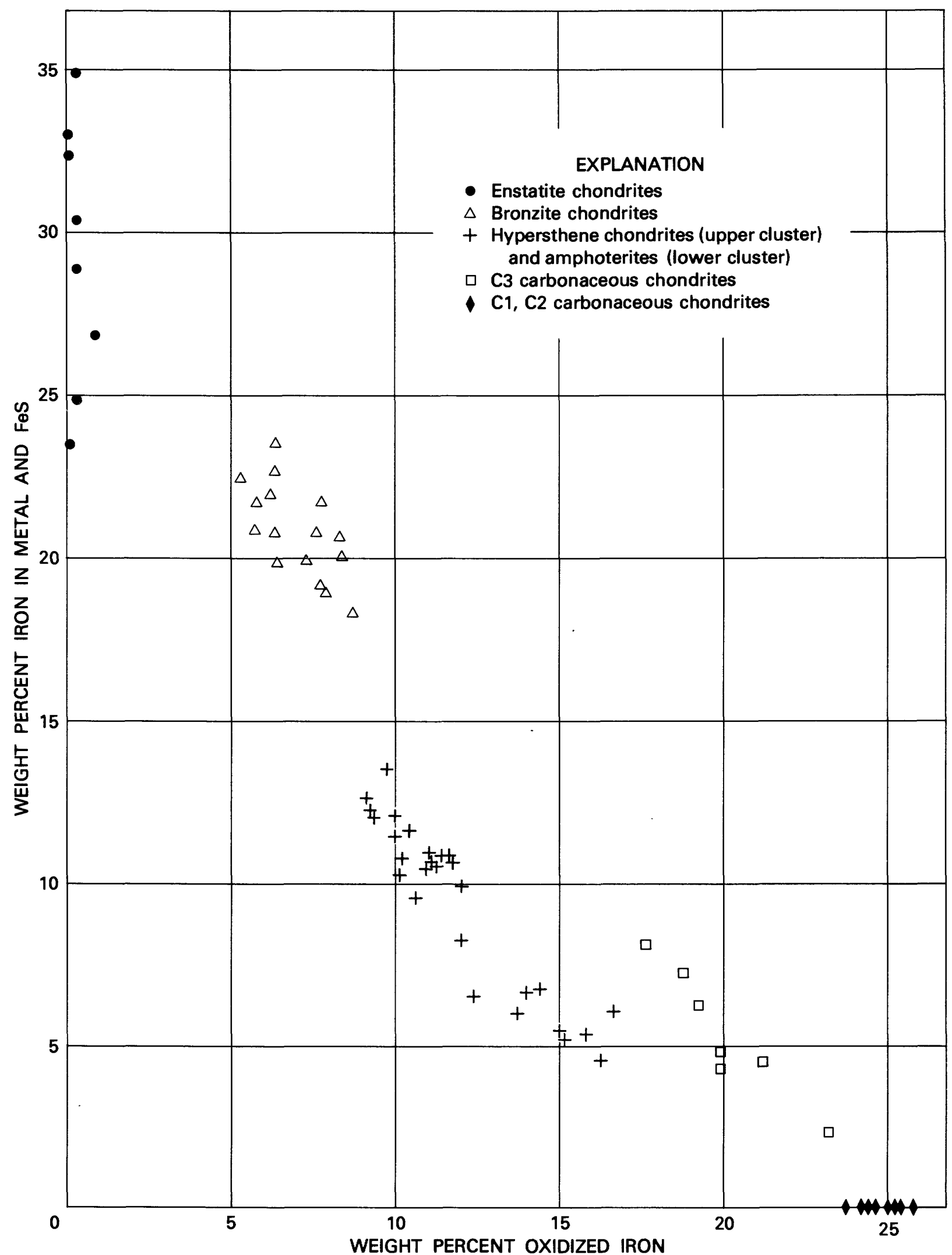

FIGURE 2.-Relationship between oxidized iron and iron as metal and sulfide in analyses of chondrites, illustrating the separation into distinct classes and the variation within the classes. Reprinted from Mason (1967b) and published with permission. 


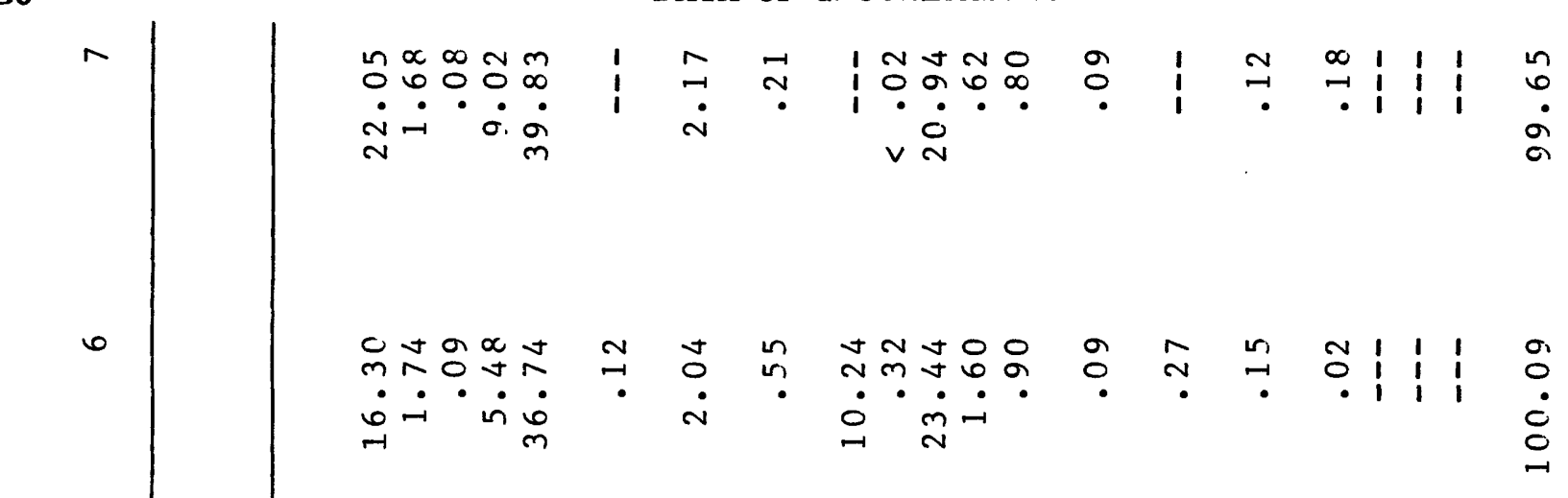

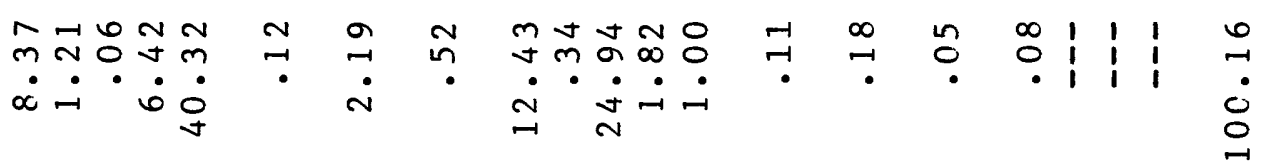

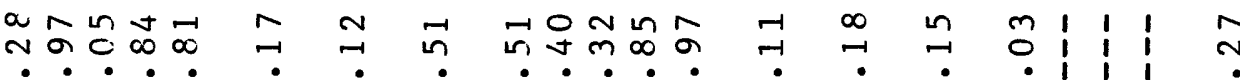

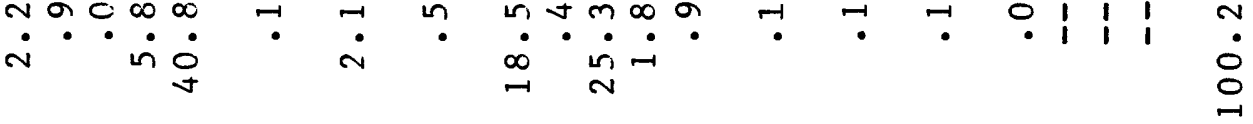

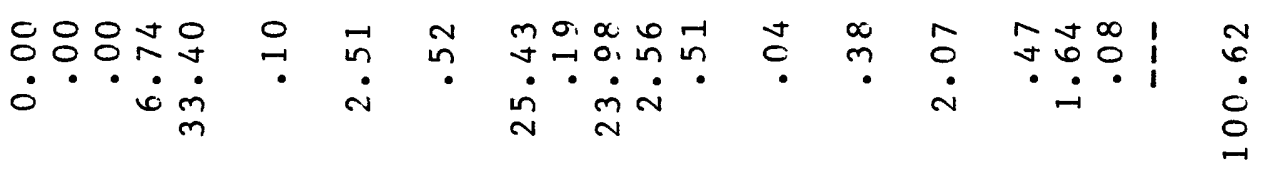

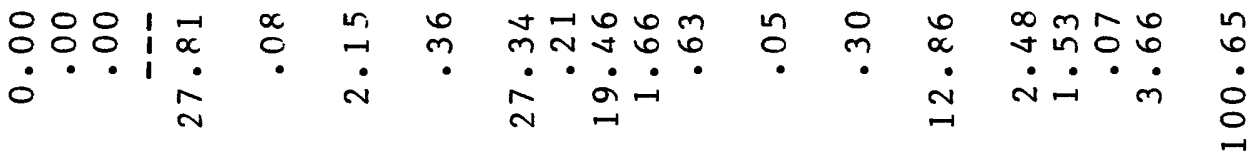

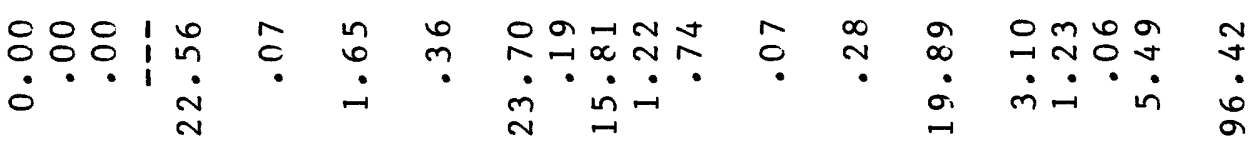

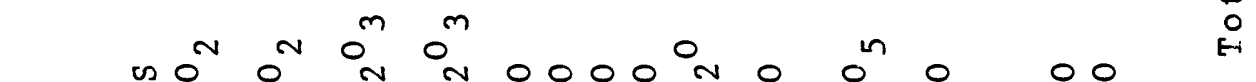


o o o o o o o m andoon O 6 t $m$ in $\sigma m \infty \pi$ t $m m$ N ON $\ln \mathrm{m} \mathrm{m}$

Oñ

$000000004 N m$ in in $0- \pm 6 N \infty N N$ N 0 in $\rightarrow$ ot 0 t ○ं $\infty$

$000000000 \pi, 4 h t$ ป ONa 0 t

○ें in

$00000000 N \infty m, n$ 至 onm ond ०ूं in

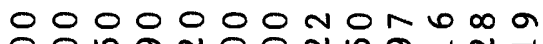

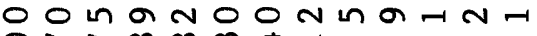
$\infty m+r$ O̊n

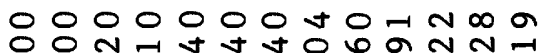

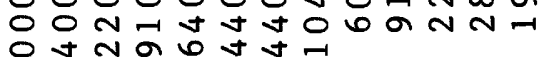
$00 \infty$

$00000000-1,000 \mathrm{~N}$

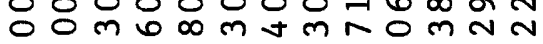
$0+r \infty$ n 6 ×

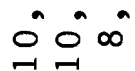

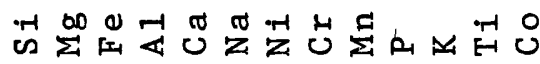

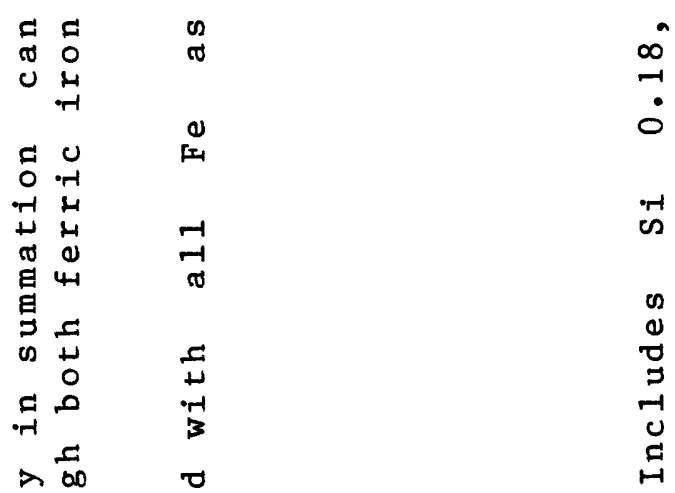

ชิ

(1)

(1)

$\int_{0 \rightarrow+1}^{\pi}$

$+-10$

感

$\begin{array}{lll}2 & 0 \\ 0 & 0\end{array}$

-

के is

in

a $\rightarrow$ in

त

ॠ

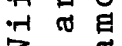

20

$-100$

i) on

$\Rightarrow \pi$

$\begin{array}{lll}4 & 0 & 0 \\ 0 & 0\end{array}$

○ I I :

-1

$\ddot{4}$ त 0

(c) $00 \mathrm{C}$

a

है-

सम

(1)

$\begin{array}{lll}1 & 0 & 0 \\ \sim & 0 & 0 \\ 4 & 11 & 0\end{array}$

त 00

मै H

I 0

ป

D

क 01

ग

(1) क्ष 4

0 ए 0

* 025

घี क

मे

인

$\circ 0$

40

ป

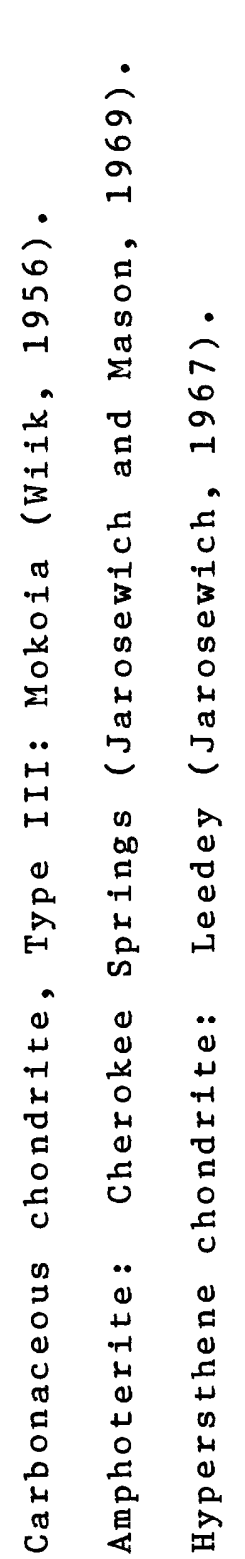

aे
- a

2
0
0
0
-1
0
0
0
0
0
$\Sigma$
0
0
0
0
2
0
$0-1$
3
0
0
0
0
0
2
0

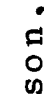

$\infty$

à

ช

$\pi 0$

다

30

o

n

$\circ 0$

年 的

己

(1)

บั

+ .

os 0

常 u

त

त्

.. ลे

iv

$+0$

$\pm$

H $m$

政

O 4

ป

व 5

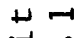

+

$\pi$

戠

on

E

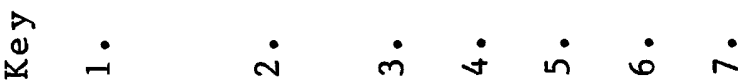


The individual classes can be divided into subclasses by the use of chemical, mineralogical, and structural distinctions. On the basis of his numerous chemical analyses, Wiik (1956) divided the carbonaceous chondrites into Types I, II, and III, some of the principal distinguishing factors being $\mathrm{C}, \mathrm{H}_{2} \mathrm{O}$, total $\mathrm{S}$, and specific gravity, the mean values being:

\begin{tabular}{|c|c|c|c|}
\hline 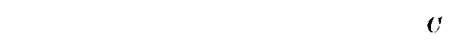 & $\mathrm{H}_{\mathrm{g}} \mathrm{O}$ & $s$ & $s p g r$ \\
\hline - & 20.08 & 6.04 & 2.2 \\
\hline Type II & 13.35 & 3.16 & 2.7 \\
\hline Type III & .99 & 2.21 & 3.4 \\
\hline
\end{tabular}

These three types are clearly demarcated by both chemical and mineralogical criteria, and appear to be discrete groups, meteorites of intermediate composition being unknown. One unique carbonaceous chondrite, Renazzo, cannot be readily classified; its mineralogy resembles that of Type II, except for the presence of 12 percent free nickel-iron. Type III carbonaceous chondrites have been called olivine-pigeonite chondrites, but the mineral identified as pigeonite is now known to be a pyroxene of the clinobronzite-clinohypersthene series, so the term "olivine-pigeonite chondrite" should be abandoned.

The existence of an amphoterite group distinct from the hypersthene chondrites has been the subject of some controversy. Inspection of figure 2 shows a cluster of hypersthene chondrite analyses around 10 percent oxidized iron, and a smaller cluster around 15 percent oxidized iron, with possibly a hiatus between them. This clustering was first perceived by Prior (1916), and he called them the Baroti type and Soko-Banja type respectively, after two analyzed meteorites. In the 1920 paper in which Prior established the current classification, he placed these two types in a single class of hypersthene chondrites; the overall chemical composition of the two types is very similar, except for the degree of oxidation of the iron. As figure 2 shows, the greater amount of oxidized iron in the SokoBanja type is compensated by a concomitant decrease in the amount of iron in the metal phase. Mason and Wiik (1964) studied a number of meteorites of the Soko-Banja type and found that chemically and mineralogically they correspond to the amphoterites, then considered a class of achondrites, evidently because they contain few and poorly defined chondrules; Mason and Wiik therefore considered the amphoterites as a subclass of the hypersthene chondrites. Independently, Keil and Fredriksson (1964) pointed out some distinctive features of the Soko-Banja type chondrites, in particular: "The total iron content of the Soko-Banja group is almost the same as in the L-group chondrites, whereas the mettalic nickel-iron content is considerably lower.
For this reason the group constituted of Soko-Banja chondrites should properly be designated the lowiron-low metal (or LL group) of chondrites" ( $p$. 3493-4). Thus the terms Soko-Banja type (or group), LL group, and amphoterite refer to a single group of meteorites. A compositional hiatus probably exists between this group and the hypersthene chondrites (Fredriksson and others, 1968), but the hiatus is a narrow one, much narrower than those between the other chondrite classes and between the Type I, II, III carbonaceous chondrites.

The bronzite chondrites form a very coherent group and are not readily subdivided on chemical or mineralogical criteria. The enstatite chondrites, however, show a wide spread in chemical composition, their total iron content ranging from 20 to 35 percent. They can be divided into two subclasses, sometimes called Type I and Type II (Anders, 1964). Type I enstatite chondrites contain more than 30 percent Fe and more than 5 percent $S$; the principal mineral is clinoenstatite; and chondritic structure is well developed. Type II enstatite chondrites contain less than 30 percent $\mathrm{Fe}$ and 5 percent $\mathrm{S}$; the principal mineral is enstatite; and chondritic structure is poorly developed. Type I and Type II enstatite chondrites show characteristic differences in minor- and trace-element contents (Larimer and Anders, 1967).

The similarities and differences in overall chemical composition between chondrites of the different classes and subclasses is illustrated in table 3 . The variation in nickel and cobalt are clearly seen. The carbonaceous chondrites, the common chondrites, and the enstatite chondrites have distinctive $\mathrm{Si} / \mathrm{Mg}$ ratios, as pointed out originally by Urey (1961). Fractionation of the major lithophile elements between different classes of chondrites is the subject of a paper by Ahrens and others (1969).

Van Schmus and Wood (1967) developed a classification scheme for the chondrites that has been widely adopted. They distinguished six petrologic types on the basis of mineralogical and structural criteria (table 4). They then constructed two-dimensional classification grid (table 5), using these six petrologic types and five chemical groupings [enstatite chondrites (E), carbonaceous chondrites (C), bronzite chondrites $(\mathrm{H})$, hypersthene chondrites (L), and amphoterites (LL)]. No carbonaceous chondrites of types 5 and 6 are known, and there are no representatives of types 1 and 2 in the remaining chemical groups. Their $\mathrm{C} 1, \mathrm{C} 2$, and C3 classes correspond closely to Wiik's Type I, II, and III carbonaceous chondrites. Their E3 and E4 classes correspond to the Type I enstatite chondrites, E5 and E6 to the Type II. The Van Schmus-Wood clas- 
COSMOCHEMISTRY PART 1. METEORITES

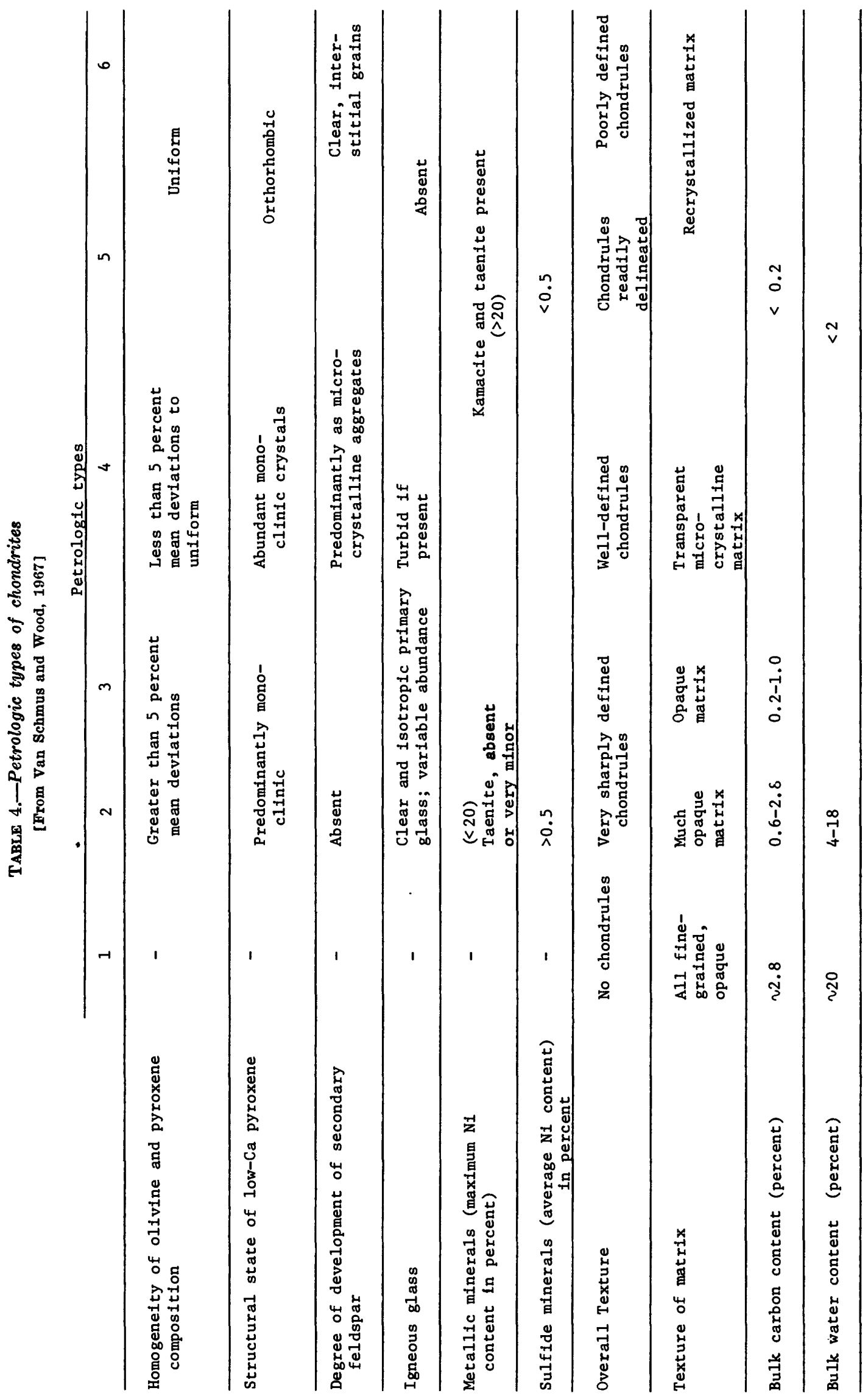


TABLE 5.-Classification of the chondrites

[From Van Schmus and Wood, 1967]

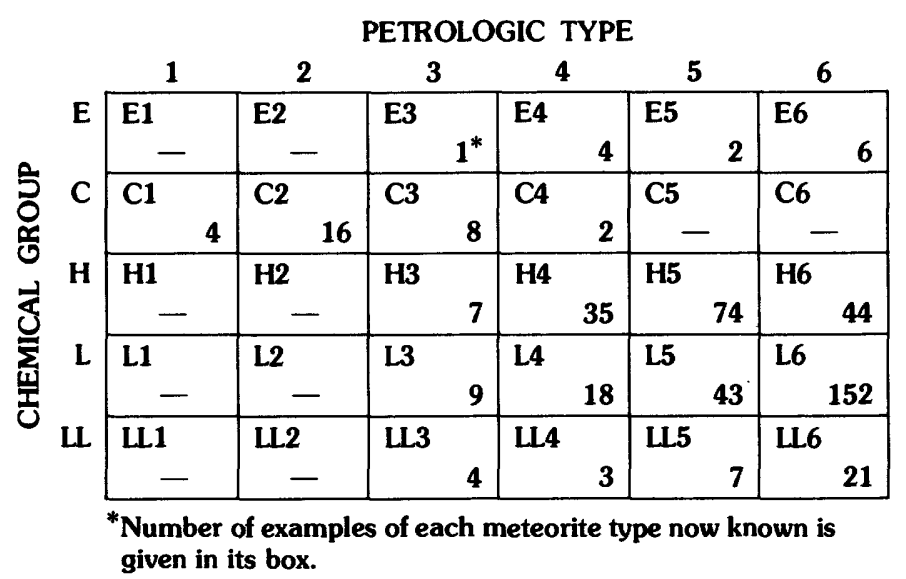

sification implies that each chemical group is essentially an isochemical sequence, and that the classes within each group are genetically related; they suggested that (except for the carbonaceous chondrites) the sequence may represent progressive recrystallization. The interpretation is not universally accepted. However, the classification stands independently of its genetic implications; it provides a workable scheme for subdividing the larger chondrite classes, and has shown its utility in the interpretation of minor- and trace-element data.

\section{CLASSIFICATION OF ACHONDRITES AND STONY-IRONS}

Superficial examination of a collection of achondrites and stony-irons reveals a great diversity and an apparent lack of any unifying features. Some of them, especially the mesosiderites, are obviously breccias made up of fragments of widely different chemical and mineralogical composition, cemented together by a nickel-iron matrix. However, a closer examination does indicate relationships that imply common processes of genesis for most of them. The composition and structure of the silicate material indicate original crystallization from a melt, similar to the magmas that gave rise to terrestrial mafic and ultramafic igneous rocks.

These relationships can be most readily visualized in the form of a diagram (fig. 3). This shows a regular trend, from calcium-poor, magnesium-rich compositions to compositions richer in calcium and ferrous iron. The enstatite achondrites can plausibly be accounted for by the partial melting of a parent body of enstatite chondrite composition, whereby

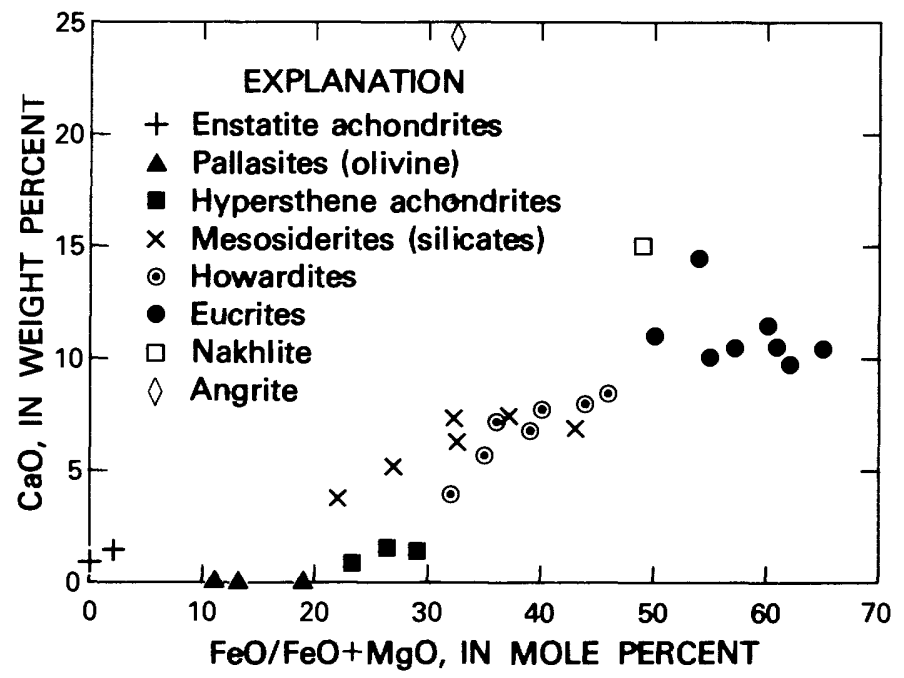

Figure 3.-Plot of $\mathrm{CaO}$ (weight percent) against $\mathrm{FeO}^{\prime}$ $(\mathrm{FeO}+\mathrm{MgO})$ (mole percent) for the achondrites and stony-irons.

metal and sulfide were melted and removed by gravitational forces, leaving a residue of coarsely-crystallized enstatite and a little sodic plagioclase. Most of the other achondrites and stony-iron may have been derived by the melting and fractional crystallization of one or more parent bodies with the overall composition of the common chondrites. Such a melt would begin to crystallize at about $1,500^{\circ} \mathrm{C}$ with the separation of magnesium-rich olivine, similar in composition to that found in pallasites. This olivine together wth the molten nickel-iron would sink and eventually form a core of pallasitic composition. The crystallization of olivine would be followed by that of hypersthene, with a higher $\mathrm{Fe} / \mathrm{Mg}$ ratio, as occurs in the hypersthene achondrites. At a slightly later stage, plagioclase would begin to crystallize, giving the association hypersthene-plagioclase characteristic of the howardites. This fractional crystallization would result in a steady increase in the concentration of calcium and ferrous iron in the melt, and eventually pigeonite, a pyroxene richer in iron and calcium than hypersthene, would be the stable ferromagnesian silicate, producing the association pigeonite-plagioclase characteristic of the eucrites. Mesosiderites appear to be breccias of all these achondrite types, together with nickel-iron and olivine.

\section{CLASSIFICATION OF IRON METEORITES}

The traditional basis for classifying iron meteorites is their structure, specifically the relationship between kamacite, taenite, and plessite (a fine intergrowth of kamacite and taenite). This classification 


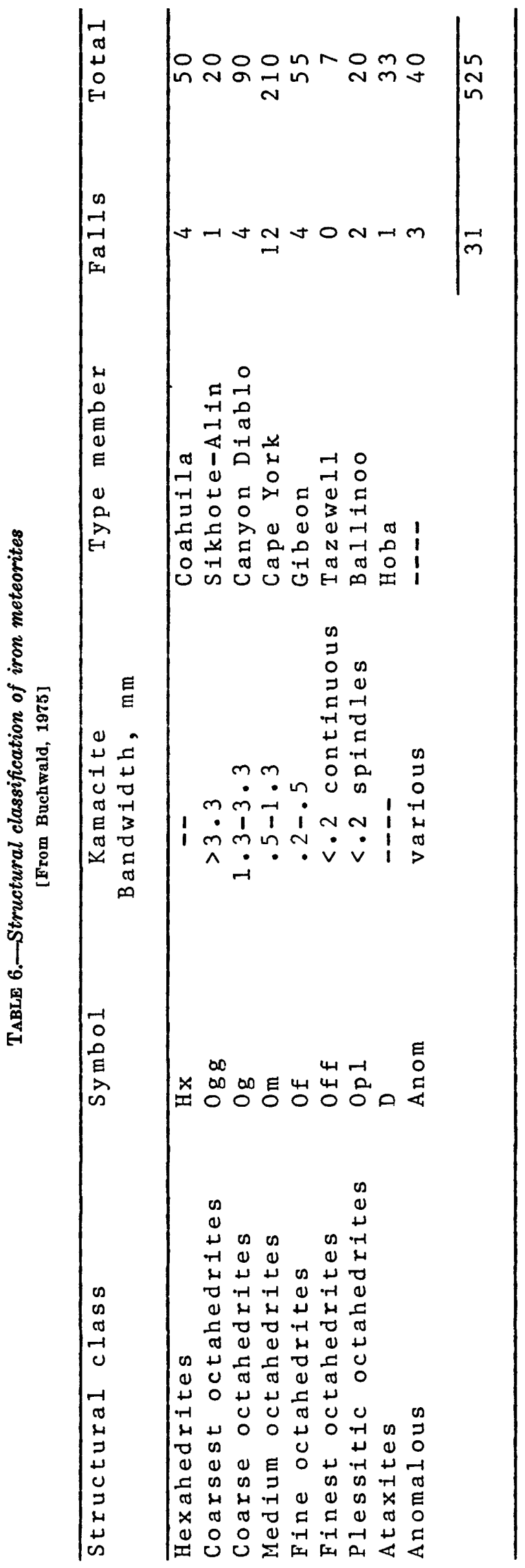




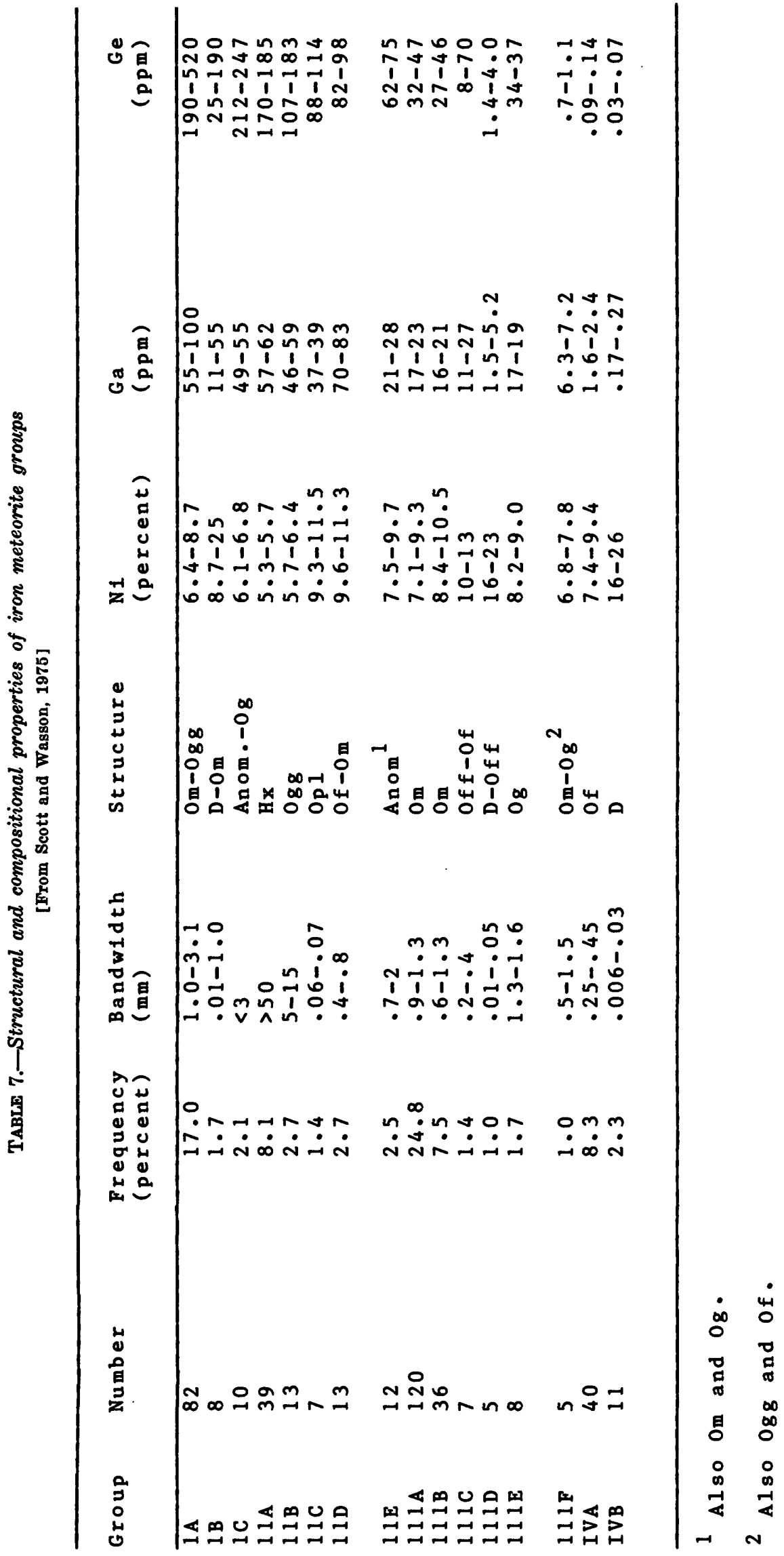


is presented in table 6 , and its significance was discussed in detail by Buckwald (1975).

A more detailed chemical classification of the irons [based on chemical parameters], has been developed by J. T. Wasson and coworkers, and is described by Scott and Wasson (1975). This work is a refinement and extension of the earlier Ga-Ge divisions of Goldberg, Uchiyama, and Brown (1951) and Lovering and others (1957). This classification is based on structural data and accurate analyses for $\mathrm{Ni}, \mathrm{Ga}$, and Ge. Sixteen groups of irons have been defined, each of which shows limited ranges of these and other elements, and very similar structures (table 7). Scott and Wasson believe there is good evidence for genetic relationships between groups IA-IB, IIA-IIB, IIIAIIIB, and IIIC-IIID, and each of these pairs is considered as a single group, giving 12 distinct groups. As can be seen from table 7, the groups are very unevenly populated, two of them (IA and IIIA) comprising over 40 percent of the whole. The relationship of $\mathrm{Co}, \mathrm{Ga}, \mathrm{Ge}, \mathrm{As}, \mathrm{Ru}, \mathrm{Sb}, \mathrm{Re}, \mathrm{Os}, \mathrm{Ir}, \mathrm{Pt}$, and $\mathrm{Au}$ to $\mathrm{Ni}$ is shown in diagrams under each of these elements.

\section{CHEMICAL FRACTIONATIONS IN CHONDRITES}

The abundance variations between different classes and subclasses of chondrites were carefully reviewed by Larimer and Anders (1967). Figure 4, taken from their report, relates the abundances of a considerable number of elements, of differing degree of volatility, in Type I, II, and III carbonaceous chondrites, and in the ordinary chondrites. For the carbonaceous chondrites, abundances decrease from Type I through Type II to Type III by rather constant factors, in the ratio $1.0: 0.6: 0.3$; Type I enstatite chondrites, with a factor 0.7 , resemble Type II carbonaceous chondrites. In ordinary chondrites and Type II enstatite chondrites, 9 elements ( $\mathrm{Au}$, $\mathrm{Cu}, \mathrm{F}, \mathrm{Ga}, \mathrm{Ge}, \mathrm{S}, \mathrm{Sb}, \mathrm{Se}$, and $\mathrm{Sn}$ ) are depleted by factors of $0.2-0.5$, whereas 12 elements ( $\mathrm{Te}, \mathrm{Ag}, \mathrm{Zn}, \mathrm{Cd}$, $\mathrm{Hg}, \mathrm{Cl}, \mathrm{Br}, \mathrm{I}, \mathrm{Pb}, \mathrm{Bi}, \mathrm{In}, \mathrm{Tl}$ ) show more drastic depletions, to factors of 0.002 . Larimer and Anders considered that chondrites are a mixture of two types of material: a low-temperature fraction (=matrix) that retained most of its volatiles, and a high-temperature fraction (=chondrules, metallic grains) that lost them. They concluded that these fractionations occurred in the solar nebula as it cooled from high temperatures, and could not have been produced in the meteorite parent bodies. They correlated the different compositions of the chondrite classes with different regions of aggregation within the ancestral solar nebula: enstatite chondrites come from the inner fringe of the asteroidal belt; ordinary chondrites

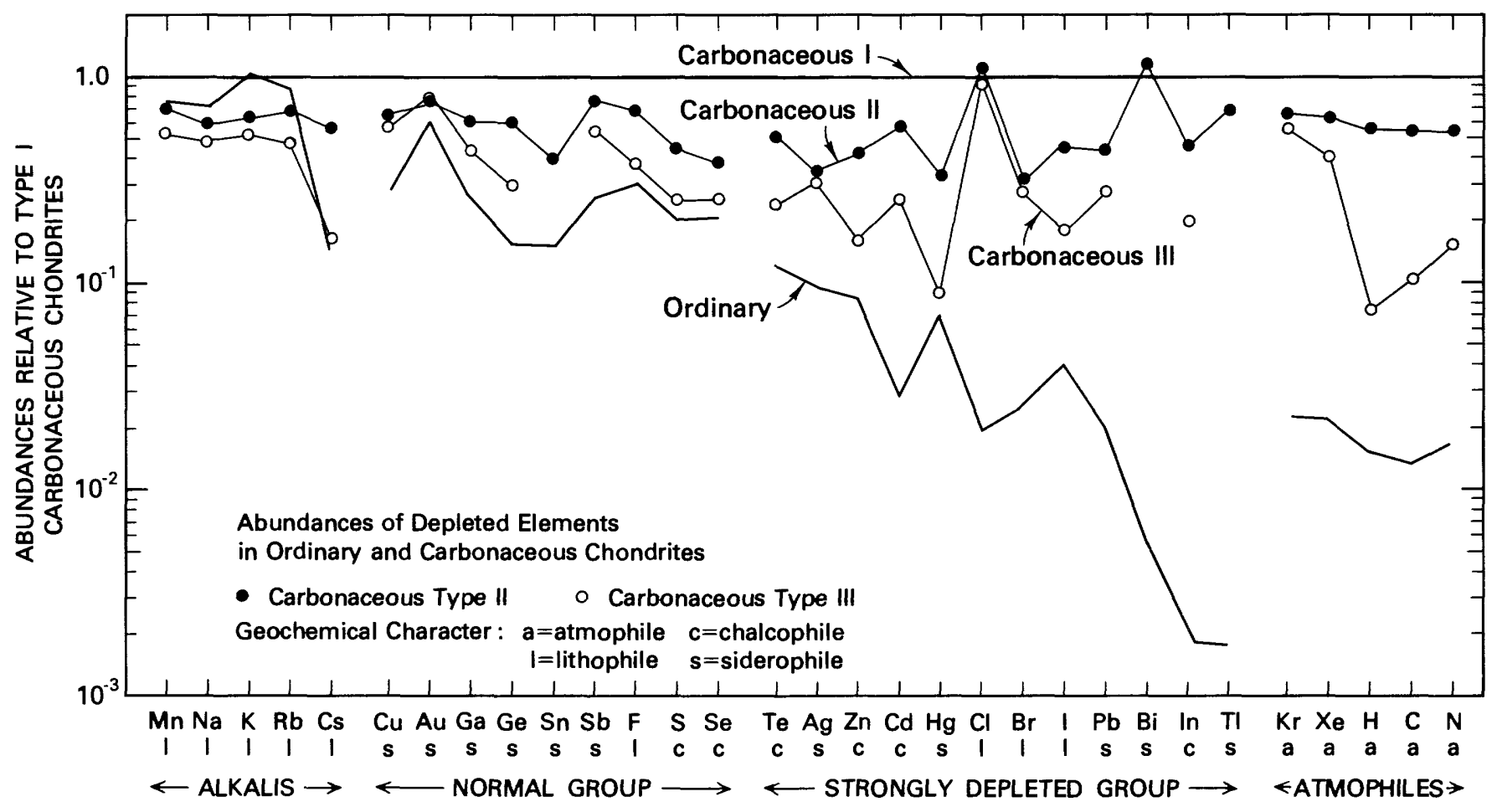

FigrJRE 4.--Relative abundances of selected elements in Type II and III carbonaceous chondrites and in ordinary chondrites, normalized to Type I carbonaceous chondrite abundances=1.0. Reprinted from Larimer and Anders (1967) and published with permission. 
from the center and inner half; carbonaceous chondrites from the outer fringe or from comets.

Goles $(1969$, p. 123) commented: "While the model of Larimer and Anders (1967) is an engagingly simple approach to the systematization and, hopefully, understanding of geochemical fractionations among meteorites, much further work must be done before it can be accepted as valid." This seems to be a reasonable statement of the present situation. The existence of fractionation, both of major and minor elements, between different classes of chondrites is beyond dispute; how and where these fractionations took place, and their significance for the early history of the solar system, are certainly open for further elucidation. Clearly, however, the different classes of chondrites are not a simple genetic sequence in the sense that one class represents the parent material from which the others were derived. Instead, they appear to be samples from different regions of an ancestral nebula which was somewhat differentiated chemically, and possibly mineralogically. Carbonaceous chondrites, usually considered more "primitive" or "undifferentiated" with respect to other chondrites, are so only to the extent that their elemental abundances approximate solar abundances more closely; they are presumably coeval, not ancestral, to the other classes.

\section{THE GEOCHEMICAL BEHAVIOR OF ELEMENTS IN METEORITES}

When Goldschmidt proposed his geochemical classification of the elements in 1923, few data were available for many of the minor and trace elements. This situation has been largely remedied, but thorough investigation has revealed some surprising variations of geochemical behavior under special circumstances, particularly in some of the less common meteorite classes. For example, potassium, normally a completely lithophile element, occurs as an essential component of the sulfide djerfisherite, $\mathrm{K}_{3} \mathrm{CuFe}_{12} \mathrm{~S}_{14}$, in some enstatite chondrites. For many elements, therefore, it is necessary to qualify their geochemical classification according to the specific environment. Table 8 gives the geochemical behavior as seen in the ordinary chondrites, with appropriate qualifications where called for. Some elements show multiple affinity, even in a single class of meteorite. In ordinary chondrites, iron shows lithophile, chalcophile, and siderophile affinities, whereas in the enstatite chondrites it is essentially chalcophile and siderophile, and in the Type I carbonaceous chondrites it is essentially lithophile, because these meteorites contain no free metal and little or no sulfide.
Variations in behavior occur within a single class of meteorites; for example, titanium is progressively more chalcophile and less lithophile in going from the more chondritic to the more recrystallized members of the enstatite chondrites (Easton and Hey, 1968).

\section{LOCATION OF MINOR AND TRACE ELEMENTS IN METEORITES}

The location of a specific element in a meteorite is of course conditioned by its geochemical character. Siderophile elements are present in the nickel-iron, chalcophile elements in the troilite, lithophile elements in the silicates (and accessory minerals such as phosphates and oxides). However, the quantitative expression of this is only partly explored, and is a promising field for further investigation. Some of the possible ways a minor or trace element may be incorporated in a meteorite are: (1) as a minor constituent of a major phase; for example, in the common chondrites the manganese is present in solid solution in the olivine, pyroxene, and chromite, (2) as a major constituent of a minor phase; for example, zirconium has been found to occur as rare grains of zircon $\left(\mathrm{ZrSiO}_{4}\right)$, (3) as a minor constituent of a minor phase; for example, most of the chlorine in stony meteorites is present in chlorapatite $\left(\mathrm{Ca}_{5}\right.$ $\left(\mathrm{PO}_{4}\right)_{3} \mathrm{Cl}$, (4) possibly as a constituent of an intergranular film; for example, water-soluble bromine and iodine. Other mechanisms can be postulated. For example, the noble gases have been found to be concentrated in the surface layers of meteorite minerals, and emplacement by the solar wind has been advanced as an explanation.

\section{HYDROGEN}

The occurrence and distribution of hydrogen in meteorites has been extensively reviewed by I. R. Kaplan, in Mason (1971). Although hydrogen is the most common element in the solar system and in the universe as a whole, it is essentially absent from most meteorites, because of the high-temperature conditions under which they formed. Only the carbonaceous chondrites contain hydrogenated compounds of undoubted extraterrestrial origin-the small amount of $\mathrm{H}_{2} \mathrm{O}$ sometimes reported in analyses of other stony meteorites is probably terrestrial, acquired since the meteorite entered the Earth's atmosphere. The $\mathrm{C} 1$ and $\mathrm{C} 2$ carbonaceous chondrites contain hydrogen in a number of forms: water of crystallization in gypsum and hydrated magnesium sulfate, $\mathrm{OH}$ groups in serpentine or related layerlattice silicates, hydrogen in a variety of organic 


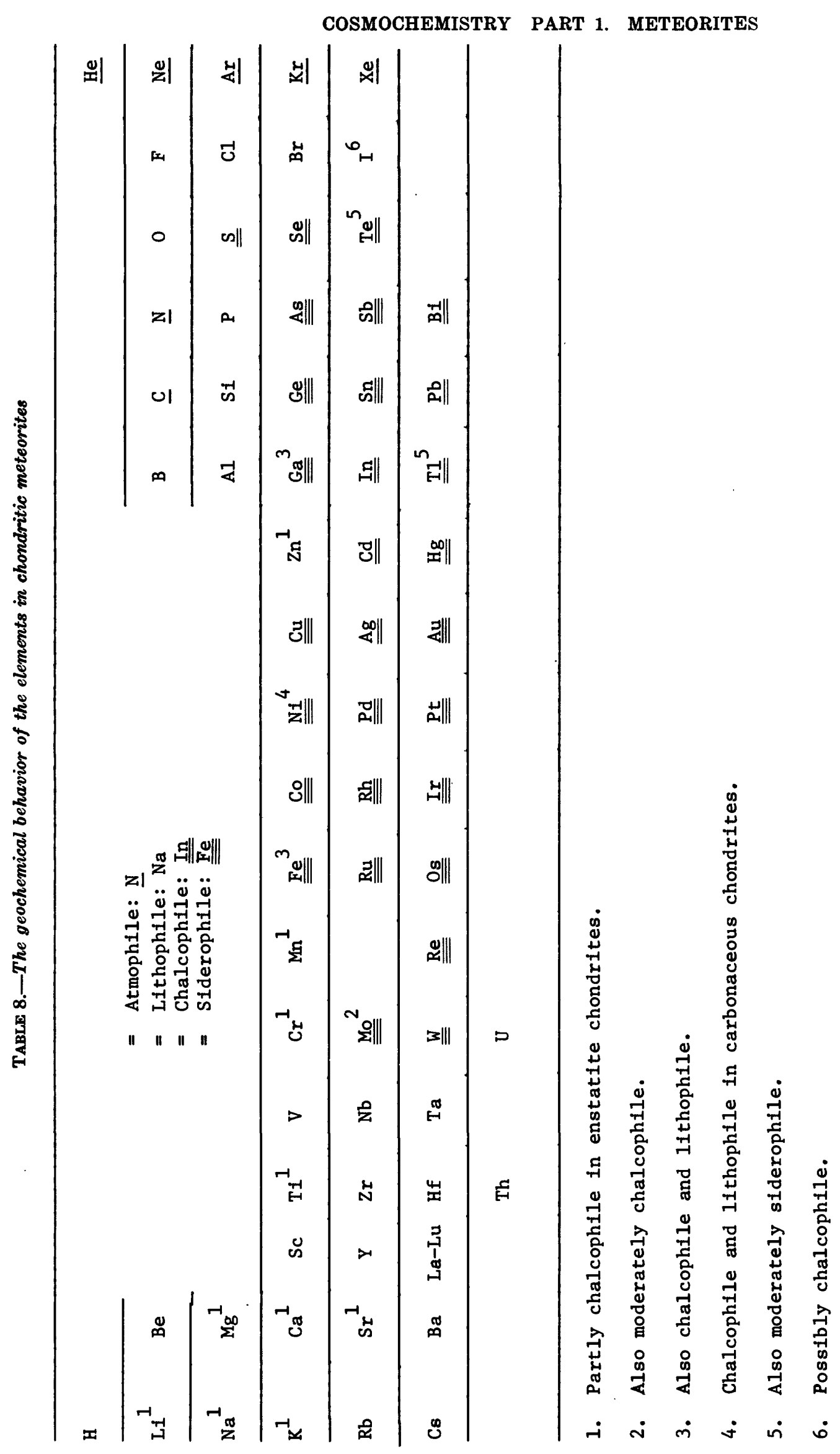


TABLE 9.-Hydrogen released as water from carbonaceous chondrites

[In weight percent]

\begin{tabular}{lrrrl}
\hline Heteorite & Type & $\mathrm{H}_{2}{ }^{\mathrm{O}}$ & $\mathrm{H}_{2} \mathrm{O}+$ & Reference \\
\hline Orgueil & $\mathrm{C} 1$ & 6.10 & 10.55 & Jarosewich, unpub. data \\
Pollen & $\mathrm{C} 2$ & .62 & 12.95 & Wiik, unpub. data \\
Murray & $\mathrm{C} 2$ & 2.44 & 9.98 & Wiik, 1956 \\
Santa Cruz & $\mathrm{C} 2$ & 1.10 & 9.23 & Wiik, 1956 \\
Murchison & $\mathrm{C} 2$ & 1.14 & 8.95 & Jarosewich, 1971 \\
Essebi & $\mathrm{C} 2$ & 3.72 & 7.67 & Wiik, unpub. data \\
Ornans & $\mathrm{C} 3$ & .18 & .25 & Wiik, 1956 \\
Warrenton & $\mathrm{C} 3$ & .00 & .10 & Wiik, 1956 \\
\hline
\end{tabular}

compounds, and presumably acquired terrestrial $\mathrm{H}_{2} \mathrm{O}$ as well. Some analytical data are given in table 9. Many of the C3 chondrites have no detectable combined hydrogen, which is consistent with the absence of hydrated minerals; the small amounts reported in some of them may be partly terrestrial and partly derived from organic compounds.

Boato (1954) concluded from his studies that all $\mathrm{H}_{2} \mathrm{O}$ liberated by heating in a vacuum up to $180^{\circ} \mathrm{C}$ was terrestrial water absorbed by different minerals in the meteorite. This conclusion was reached by measuring the $\mathrm{D} / \mathrm{H}$ ratio of the liberated water at a series of temperatures from $25^{\circ} \mathrm{C}$ to $800^{\circ} \mathrm{C}$. For the Ivuna, Orgueil, and Mokoia meteorites, water released above $180^{\circ} \mathrm{C}$ gave values that fell outside the range of atmospheric water. Some of the $\mathrm{H}_{2} \mathrm{O}$ extracted from the carbonaceous chondrites has the highest deuterium content ever found in natural material.

Edwards (1955) extracted hydrogen from 14 iron meteorites, and found a range of $0.7-54 \mathrm{ppm}$.

\section{THE NOBLE GASES: HELIUM, NEON, ARGON, KRYPTON, XENON}

The noble gases have especial significance in the geochemistry of meteoritic matter. Their gaseous nature and inertness simplify analytical procedures, and the volume of data on their abundance in meteorites exceeds that for most other elements. By using modern techniques, a determination of their concentration and their isotopic composition can be carried out with high precision on small samples. They may have originated from a variety of sources, and the identification of these sources enables significant deductions regarding the origin and evolution of the meteorites.
Neglecting terrestrial atmospheric contamination (usually small and readily removed by gentle heating), the noble-gas content of a meteorite may comprise several different components, as follows:

Trapped.-Divided into two types, (1) solar, implanted in the surface layers of mineral grains directly from the solar wind; (2) planetary, occluded from the primitive solar nebula during the initial condensation of solid matter. The trapped component is sometimes referred to as the primordial component.

Cosmogenic.-Produced by cosmic-ray-induced spallation reactions; dominantly $\mathrm{He}, \mathrm{Ne}$, and $\mathrm{Ar}$ produced by spallation of the abundant elements up to $\mathrm{Fe}$ and $\mathrm{Ni}$. Heavy elements that produce $\mathrm{Kr}$ and Xe by spallation are of low abundance in meteorites, and hence cosmogenic $\mathrm{Kr}$ and $\mathrm{Xe}$ occur only in very minor amounts.

Radiogenic.-Decay products of radioactive isotopes; ${ }^{+} \mathrm{He}$ from $\mathrm{U}$ and $\mathrm{Th},{ }^{40} \mathrm{Ar}$ from ${ }^{+0} \mathrm{Kr}$, and ${ }^{129} \mathrm{Xe}$ from extinct ${ }^{129} \mathrm{I}$.

Fissionogenic.-Isotopes of $\mathrm{Kr}$ and $\mathrm{Xe}$ produced by spontaneous (for example, ${ }^{2+4} \mathrm{Pu}$ ) or neutron-induced (for example, ${ }^{235} \mathrm{U}$ ) fission. Anders and others (1975) have provided evidence that $\mathrm{Xe}$ of peculiar isotopic composition in the Allende meteorite is derived from the fission of an extinct superheavy element, probably element 115 .

An indication of the concentration range of the noble gases in meteorites is provided by the data in table 10 (from Dieter Heymann, in Mason (1971)). Grant is an iron meteorite and contains only cosmogenic gas. Bruderheim contains principally cosmogenic gas and radiogenic ${ }^{4} \mathrm{He}$ and ${ }^{40} \mathrm{Ar}$, and small amounts of trapped ${ }^{36} \mathrm{Ar},{ }^{8} \mathrm{Kr}$, and ${ }^{13}: \mathrm{Xe}$. Chainpur differs from Bruderheim in containing substantial 


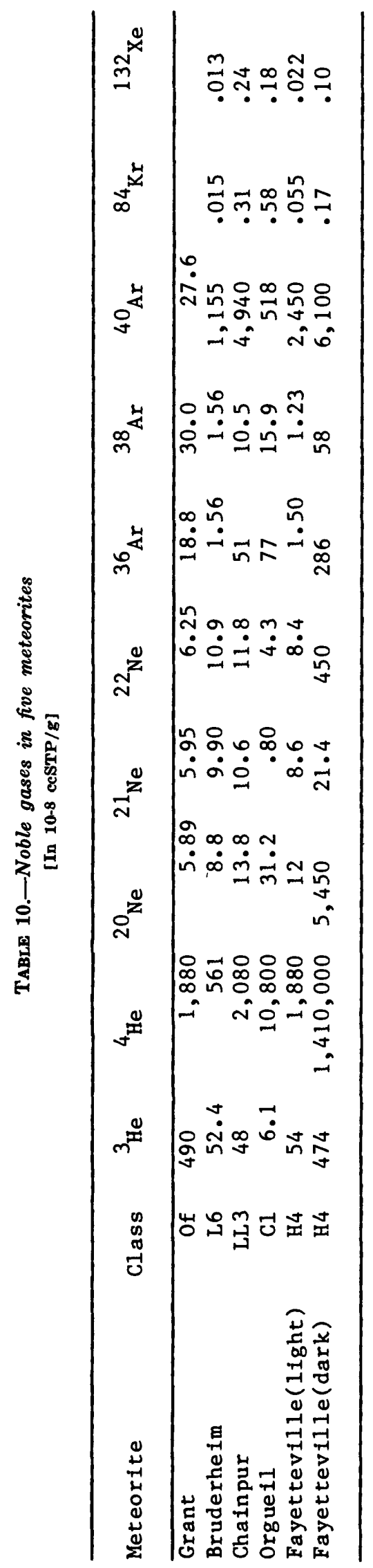


amounts of trapped $\mathrm{Ar}, \mathrm{Kr}$, and $\mathrm{Xe}$; the same is true for Orgueil, which also contains a large amount of trapped He. Fayetteville typifies a small group of chondritic meteorites with light-dark structure (light- and dark-gray areas of essentially the same composition except for their noble-gas content). In Fayetteville, the light parts have gas contents similar to Bruderheim, but the dark part contains vast amounts of trapped $\mathrm{He}, \mathrm{Ne}$, and $\mathrm{Ar}$ of solar wind origin.

This brief review clearly shows that no purpose is served in attempting to give mean concentrations of the noble gases in meteorites since each meteorite is essentially unique, and its noble-gas content reflects its individual history. Cameron (1973) gave the following cosmic atomic abundances for the noble gases (normalized to $\mathrm{Si}=10^{6}$ ): $\mathrm{He}, 2.21 \times 10^{9} ; \mathrm{Ne}$, $3.44 \times 10^{6}$; Ar, $1.172 \times 10^{5} ; \mathrm{Kr}, 46.8$; Xe 5.38.

Wasson (1974) provided a comprehensive account of noble gases in meteorites and their significance in problems of genesis and subsequent history.

\section{LITHIUM}

Lithium is a trace element that shows remarkably little variation in abundance between different classes of chondritic meteorites (table 11), except in the enstatite chondrites of petrologic types 5 and 6 , in which this element is notably diminished. The same is true for the single analysed aubrite (enstatite achondrite). In terms of atoms $/ 10^{6} \mathrm{Si}$, some diminution in abundance is evident in going from $\mathrm{C} 1$ to $\mathrm{C} 2$ to $\mathrm{C} 3$, and thence to the ordinary chondrites. The highest concentrations are found in the eucrites, at about twice chondritic levels.

Lithium is essentially a lithophile element; Fireman and Schwarzer (1957) found less than $0.01 \mathrm{ppm}$ in several iron meteorites. However, Shima and

TABLE 11.-Lithium in stony meteorites

[From Walter Nichiporuk, in Mason, 1971; Nichiporuk and Moore, 1974; Nichiporuk, 1975; and table 84]

\begin{tabular}{|c|c|c|c|c|}
\hline Class & $\begin{array}{c}\text { Number } \\
\text { analyzed }\end{array}$ & $\begin{array}{l}\text { Range } \\
(\mathrm{ppm})\end{array}$ & $\begin{array}{l}\text { Mean } \\
\text { (ppm) }\end{array}$ & Atoms $/ 10^{6} \mathrm{si}$ \\
\hline \multicolumn{5}{|c|}{ Chondrites } \\
\hline $\mathrm{C} 1$ & 2 & $1.52-1.61$ & 1.6 & 60 \\
\hline $\mathrm{C} 2$ & 5 & $1.61-1.86$ & 1.7 & 52 \\
\hline C3 & 11 & $1.43-3.83$ & 1.9 & 49 \\
\hline $\mathrm{H}$ & 13 & $1.2-2.1$ & 1.7 & 40 \\
\hline $\mathrm{L}$ & 19 & $1.3-2 \cdot 6$ & 1.8 & 39 \\
\hline LL & 21 & $1.7-2.7$ & 2.1 & 45 \\
\hline E4 & 2 & $1.3-2 \cdot 9$ & 2.1 & 47 \\
\hline $\mathrm{E} 5,6$ & 2 & $.44-.64$ & $\cdot 58$ & 13 \\
\hline \multicolumn{5}{|c|}{ Calcium-poor achondrites } \\
\hline$\overline{\mathrm{Ae}}$ & 1 & .33 & - & 5.3 \\
\hline $\mathrm{Ah}$ & 1 & 2.20 & -- & 36 \\
\hline $\mathrm{Au}$ & 1 & 1.84 & -- & 40 \\
\hline \multicolumn{5}{|c|}{ Calcium-rich achondrites } \\
\hline $\mathrm{Aa}$ & 1 & 2.02 & - & 40 \\
\hline Aeu & 3 & $5.07-7.27$ & 6.1 & 106 \\
\hline
\end{tabular}


Honda (1967) showed that, in the enstatite chondrite Abee, about two-thirds of the lithium is in the sulfide phases; evidently under conditions of extreme reduction and relatively high sulfur fugacity, lithium, like sodium and potassium, has chalcophile affinities. Shima and Honda also showed that in ordinary chondrites most of the lithium is in the $\mathrm{HCl}-$ soluble fraction (after treatment with bromine water to remove troilite); this indicates that in these meteorites the lithium probably resides in olivine, replacing magnesium. ( $\mathrm{LiFePO}_{4}$ is isostructural with olivine.)

\section{BERYLLIUM}

The limited data on the abundance and distribution of beryllium in meteorites are derived from the work of Sill and Willis (1962) and Quandt and Herr (1974). Sill and Willis analyzed 12 chondrites, 4 achondrites, and 1 iron by a fluorometric procedure; Quandt and Herr analyzed 73 chondrites, 1 achondrite, and 4 irons by photon activation. Their results are generally consistent, although Quandt and Herr recorded some unusually high values for chondrites-those $>100 \mathrm{ppb}$ have been omitted from table 12. The single enstatite chondrite and enstatite achondrite (aubrite) analyzed show relative depletion in this element, as does the Johnstown diogenite; one eucrite, Sioux County, is relatively enriched. Beryllium is a lithophile element; Sill and Willis recorded $<1 \mathrm{ppb}$ in the Aroos iron, Quandt and Herr $<8 \mathrm{ppb}$ in the four irons they analyzed. The abundance of $\mathrm{Be}$ is remarkably low, lower even

TABLE 12.-Beryllium in meteorites

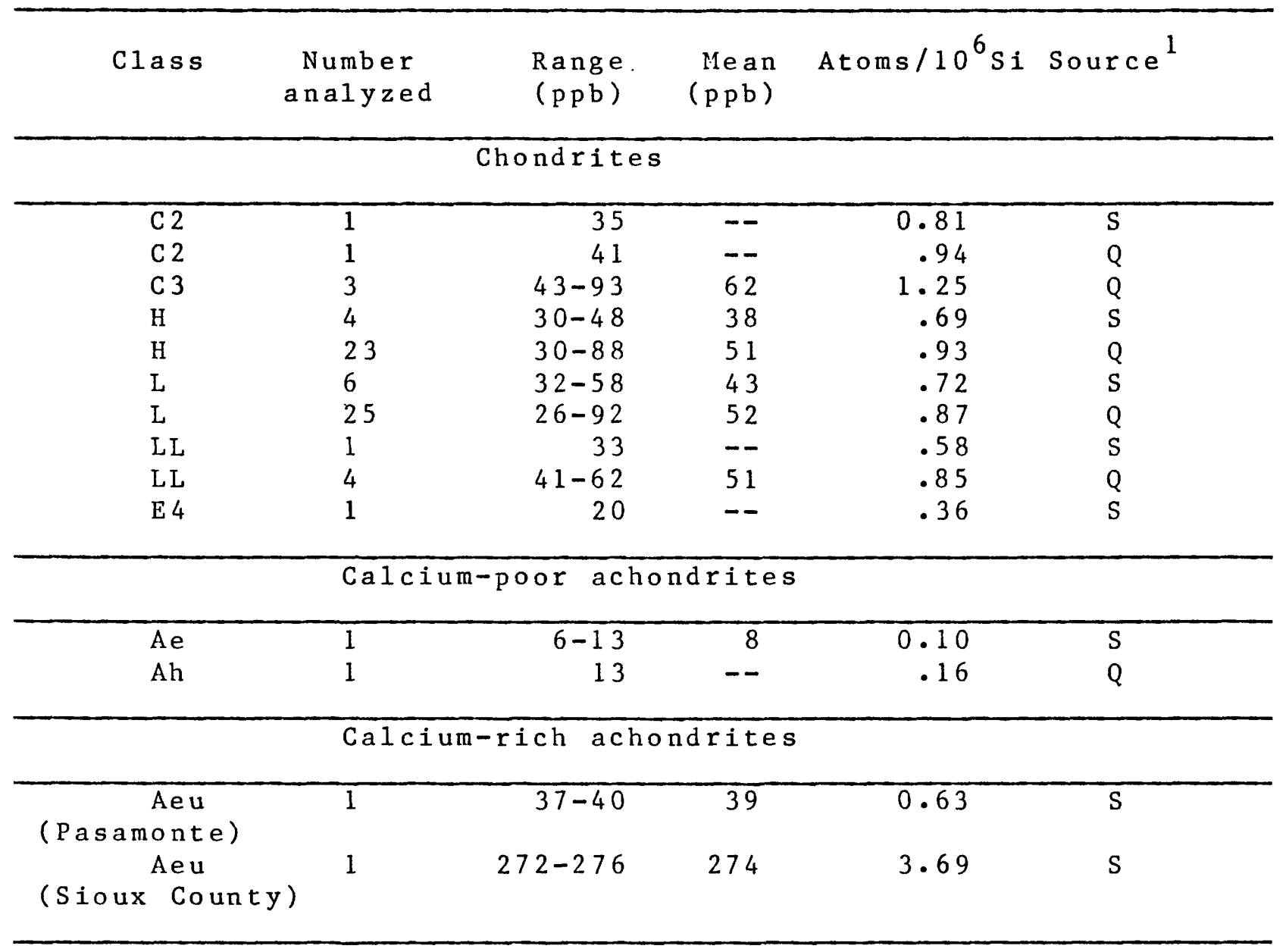

${ }^{1}$ S, Sill and Willis (1962); Q, Quandt and Herr (1974). 
than the abundances of the neighboring odd-numbered elements.

\section{BORON}

Data on the concentration of boron in meteorites are sparse, and have been summarized and discussed by P. A. Baedecker (in Mason, 1971). See table 13. Practically all the data are derived from the work of Quijano-Rico and Wänke (1969), who used a fluorometric method of determination. The concentration in carbonaceous chondrites is notably higher than in most other stones, suggesting that in these meteorites the boron may be associated with the carbonaceous matter, or that it is combined in volatile compounds. Quijano-Rico and Wänke noted a correlation between boron content and petrologic type in chondrites, boron behaving like other volatile elements (and noble gases) by diminishing in concentration with increasing type number. Two iron meteorites, Canyon Diablo and Toluca, contained 0.02 and $0.03 \mathrm{ppm}$ boron, confirming the lithophile nature of this element. Mason and Graham (1970) found that in mineral separates from meteorites boron is concentrated in plagioclase and olivine.

\section{CARBON}

Carbon in small amounts is universally present in meteorites, but until the work of Moore and Lewis $(1965,1966,1967)$ no systematic investigation of a large number of specimens had been undertaken. Their results, along with some additional data, are summarized in table 14 and figure 5 . The carbonaceous chondrites, as implied by their name, are richest in carbon; the abundance ranges of the four types overlap, and the lower limit of C3 and C4 overlaps the higher limits for the ordinary and enstatite chondrites. Thus, the distinction between carbonaceous and other classes of chondrites cannot be based on carbon content alone. Figure 5 illustrates the distribution of carbon in the ordinary chondrites in relation to the petrologic types established by Van Schmus and Wood (1967). High carbon contents are clearly confined to the so-called unequilibrated chondrites, the petrologic type 3 of Van Schmus and

TABLE 13.-Boron in meteorites

[From P. A. Baedecker, in Mason, 1971]

\begin{tabular}{|c|c|c|c|c|}
\hline Class & $\begin{array}{l}\text { Number } \\
\text { analyzed }\end{array}$ & $\begin{array}{l}\text { Range } \\
(\mathrm{ppm})\end{array}$ & $\begin{array}{l}\text { Mean } \\
(\mathrm{ppm})\end{array}$ & Atoms $/ 10^{6}$ \\
\hline \multicolumn{5}{|c|}{ Chondrites } \\
\hline $\mathrm{Cl}$ & 2 & $5.1-7.1$ & 5.7 & 144 \\
\hline $\mathrm{C} 2$ & 1 & 9.4 & -- & 186 \\
\hline C3 & 3 & $5.6-9.6$ & 7.2 & 121 \\
\hline $\mathrm{H}$ & 25 & $.14-6.0$ & 1.0 & 15 \\
\hline $\mathrm{L}$ & 10 & $.14-1.70$ & .74 & 10 \\
\hline LL & 1 & 1.4 & - & 19 \\
\hline E4 & 1 & .77 & - & 12 \\
\hline E6 & 1 & .43 & -- & 5.7 \\
\hline \multicolumn{5}{|c|}{ Calcium-poor achondrites } \\
\hline $\mathrm{Ae}$ & 1 & 0.42 & -- & 3.9 \\
\hline Ah & 1 & .34 & -- & 3.6 \\
\hline \multicolumn{5}{|c|}{ Calcium-rich achondrites } \\
\hline Aeu & 1 & $0.63-1.1$ & 0.83 & 9.4 \\
\hline
\end{tabular}


Wood. A good median figure for the ordinary chondrites is 0.1 percent $\mathrm{C}$.

The carbonaceous material in stony meteorites has been exhaustively discussed in a book by Nagy (1975). In the carbonaceous chondrites, some of the carbon is present as extractable organic compounds, but most is combined in a black insoluble complex of high molecular weight compounds. This complex is probably the carbonaceous material in most of the ordinary chondrites, judging by the results of Hayes and Biemann (1968). They found that the carbonaceous material in Holbrook, a hypersthene chondrite, is largely polymeric, the most abundant compounds being evolved at $200^{\circ}-500^{\circ} \mathrm{C}$. The pyrolysis compounds are predominantly alkylbenzenes, but various aromatic C-H-O, C-H-N, C-H-S compounds are also present, along with some more highly condensed aromatic hydrocarbons.
Carbon contents are low in the achondrites, except for the ureilities, which have carbon contents as high as the carbonaceous chondrites.

The results of Moore, Lewis, and Nava (1969) on iron meteorites (the samples selected to avoid inclusions of graphite and cohenite) show generally low figures for carbon (table 15). Slow cooling has evidently favored the segregation of carbon into specific phases, such as graphite and cohenite. Within the metal phases the carbon is in solid solution in the taenite (0.1-0.5 percent) in preference to the kamacite $(<0.01$ percent), according to Buchwald (1975).

\section{NITROGEN}

Nitrogen in meteorites has been systematically studied by Moore and his coworkers; the total nitrogen contents were determined by an inert gas-

TABLE 14.-Carbon in stony meteorites

[From Vdovykin and Moore, in Mason, 1971]

\begin{tabular}{|c|c|c|c|c|}
\hline Class & $\begin{array}{c}\text { Number of } \\
\text { determinations }\end{array}$ & $\begin{array}{l}\text { Range } \\
\text { (weight percent) }\end{array}$ & $\begin{array}{c}\text { Median } \\
\text { (weight percent) }\end{array}$ & Atoms $/ 10^{6} \mathrm{Si}$ \\
\hline \multicolumn{5}{|c|}{ Chondrites } \\
\hline $\begin{array}{l}\text { C1 } \\
\text { C2 } \\
\text { C3 } \\
\text { C4 } \\
\text { H } \\
\text { L } \\
\text { LL } \\
\text { E4 } \\
\text { E5 } \\
\text { E6 }\end{array}$ & $\begin{array}{l}5 \\
9 \\
9 \\
2 \\
35 \\
43 \\
16 \\
4 \\
2 \\
7\end{array}$ & $\begin{array}{l}2.70-4.83 \\
1.30-4.00 \\
.35-2.49 \\
.07-.20 \\
.02-.35 \\
.03-.53 \\
.03-.44 \\
.36-.56 \\
.37-.54 \\
.06-.43\end{array}$ & $\begin{array}{l}3.19 \\
2.48 \\
.56 \\
.14 \\
.11 \\
.09 \\
.12 \\
.39 \\
.45 \\
.36\end{array}$ & $\begin{array}{r}720,000 \\
440,000 \\
85,000 \\
20,000 \\
15,000 \\
11,000 \\
15,000 \\
53,000 \\
58,000 \\
43,000\end{array}$ \\
\hline \multicolumn{5}{|c|}{ Calcium-poor achondrites } \\
\hline $\begin{array}{l}\mathrm{Ae} \\
\mathrm{Ah} \\
\mathrm{Au}\end{array}$ & $\begin{array}{l}2 \\
1 \\
5\end{array}$ & $\begin{array}{c}0.04-0.10 \\
-- \\
1.94-4.10\end{array}$ & $\begin{array}{r}0.07 \\
.04 \\
3.00\end{array}$ & $\begin{array}{r}59,000 \\
3,800 \\
370,000\end{array}$ \\
\hline \multicolumn{5}{|c|}{ Calcium-rich achondrites } \\
\hline $\begin{array}{l}\text { Aho } \\
\text { Aeu }\end{array}$ & $\begin{array}{l}3 \\
4\end{array}$ & $\begin{array}{r}0.02-0.25 \\
.04-0.47\end{array}$ & $\begin{array}{r}0.11 \\
.06\end{array}$ & $\begin{array}{r}11,000 \\
6,100\end{array}$ \\
\hline
\end{tabular}




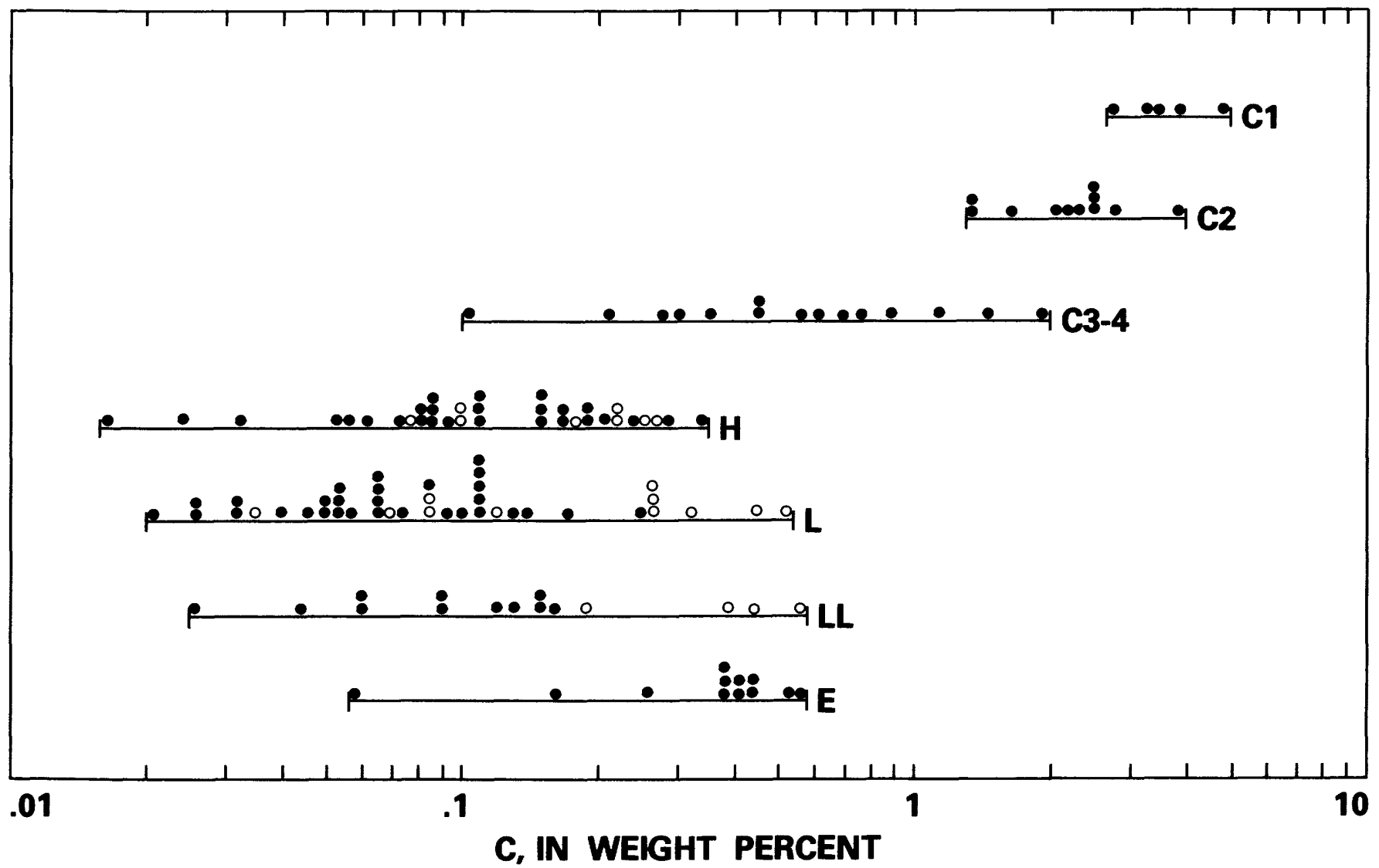

Figure 5.-Frequency distribution of carbon in chondrites; open circles indicate unequilibrated ordinary chondrites, petrologic type 3; solid circles indicate all other chondrites. Reprinted from Vdovykin and Moore in Mason (1971) and published with permission.

TABLE 15.-Carbon in iron meteorites

[In weight percent. From Moore, Lewis, and Nava, 1969]

\begin{tabular}{lccr}
\hline Class & $\begin{array}{l}\text { Number of } \\
\text { meteorites }\end{array}$ & Range & Median \\
\hline $\mathrm{Hx}$ & 8 & $0.005-0.013$ & 0.009 \\
Ogg & 3 & $.009-.022$ & .013 \\
Og & 10 & $.004-.18$ & .012 \\
Om & 42 & $.002-.06$ & .014 \\
Of & 17 & $.005-.046$ & .011 \\
Off & 6 & $.010-.042$ & .030 \\
D & 6 & $.003-.051$ & .007
\end{tabular}

fusion gas chromatographic technique (Gibson and Moore, 1970). Some additional determinations have been provided by Kothari and Goel (1974), who used a neutron activation technique. Results on the same meteorite by the two techniques are fairly consistent, although the figures obtained by Kothari 
and Goel are generally somewhat lower. The data are summarized in tables 16 and 17.

Nitrogen is strongly enriched in $\mathrm{C} 1$ and $\mathrm{C} 2$ carbonaceous chondrites with respect to other classes of stony mateorites. This can be ascribed to the presence in $\mathrm{C} 1$ and $\mathrm{C} 2$ meteorites of nitrogen-bearing organic compounds; Hayatsu and others (1968) have identified the nitrogen-bearing organic compounds adenine, ammeline, guanine, guanylurea, and melamine in the Orgueil (C1) meteorite; and amino acids have been found in several $\mathrm{C} 1$ and $\mathrm{C} 2$ meteorites-more than 30 different amino acids have been identified in the Murchison (C2) meteorite (Lawless, 1973).

The state of combination of the small amounts of nitrogen in noncarbonaceous meteorites is not well known. Kothari and Goel (1974) found that nitrogen is enriched in the nonmagnetic relative to the magnetic (metallic) fractions in ordinary chondrites. Some of the enstatite chondrites contain trace amounts of the minerals osbornite (TiN) and sinoite $\left(\mathrm{Si}_{2} \mathrm{~N}_{2} \mathrm{O}\right)$; sinoite-bearing meteorites have notably enhanced nitrogen contents (Moore, Gibson, and Keil, 1969).

The nitrogen content of iron meteorites is low and variable as shown in table 17 . The mineral carlsbergite $(\mathrm{CrN})$ is an accessory in some irons. Gibson and Moore (1971a) showed that sulfide inclusions in iron meteorites contain notably higher concentrations of nitrogen than the metal itself.

Injerd and Kaplan (1974) determined the isotopic composition of nitrogen in some carbonaceous chondrites, and found that it is enriched in ${ }^{15} \mathrm{~N} ; \delta^{15} \mathrm{~N}$ relative to air ranges from +5.6 to $+46.3(\%)$.

\section{OXYGEN}

Until 1964, no direct measurements had been made on the amount of oxygen in any meteorite, oxygen

TABLE 16.-Nitrogen in stony meteorites

[Data from Moore and Gibson, 1969; Moore, Gibson, and Keil, 1969; Gibson and Moore, 1971; Gibson and others, 1971a, b; Gibson and Moore, 1970 ; Au is from Kothari and Goel, 1974]

\begin{tabular}{|c|c|c|c|c|}
\hline Class & $\begin{array}{c}\text { Number } \\
\text { analyzed }\end{array}$ & $\begin{array}{l}\text { Range } \\
\text { (ppm) }\end{array}$ & $\begin{array}{l}\text { Median } \\
\text { (ppm) }\end{array}$ & Atoms $/ 10^{6} \mathrm{Si}$ \\
\hline \multicolumn{5}{|c|}{ Chondrites } \\
\hline $\mathrm{C} 1$ & 1 & $3,090-3,280$ & 3,185 & 59,000 \\
\hline $\mathrm{C} 2$ & 6 & $950-2,000$ & 1,500 & 22,000 \\
\hline $\mathrm{C} 3$ & 10 & $55-242$ & 105 & 1,200 \\
\hline $\mathrm{H}$ & 20 & $18-121$ & 48 & 570 \\
\hline $\mathrm{L}$ & 28 & $17-109$ & 43 & 480 \\
\hline LL & 11 & $36-298$ & 70 & 740 \\
\hline $\mathrm{E}$ & 9 & $54-780$ & 260 & 3,000 \\
\hline \multicolumn{5}{|c|}{ Calcium-poor achondrites } \\
\hline $\mathrm{Ae}$ & 1 & 44 & -- & 340 \\
\hline $\mathrm{Ah}$ & 1 & 31 & - & 250 \\
\hline $\mathrm{Au}$ & 2 & $13-46$ & 27 & 290 \\
\hline \multicolumn{5}{|c|}{ Calcium-rich achondrites } \\
\hline Aho & 3 & $40-66$ & 56 & 490 \\
\hline Aeu & 3 & $24-45$ & 39 & 360 \\
\hline
\end{tabular}


being a calculated figure, arrived at by difference in a classical chemical analysis ; the oxygen percentages for individual meteorites given in table 84 have been calculated on this basis. This procedure, of course, throws all the errors and omissions of the analysis onto the figure for oxygen. Wing (1964) and Vogt and Ehmann (1965) directly measured oxygen in stony meteorites by neutron-activation analysis. Vogt and Ehmann's work is the more extensive, giving oxygen abundances for 39 meteorites, representing a total of 421 separate analyses; they estimated the absolute accuracy as probably better than \pm 5 percent. Their results for different classes of meteorites are summarized in table 18.

The state of combination of the oxygen presents problems in interpreting analytical data on meteorites. The standard procedure is to allot the requisite amounts to form the standard oxides of those elements more electropositive than iron, and then to add the amount required to form $\mathrm{FeO}$ from the iron not present as sulfide or nickel-iron. This procedure is reasonably satisfactory for most classes of stony and stony-iron meteorites, but may be unsatisfactory for the carbonaceous chodrites (which contain organic compounds, ferric iron, and oxidized sulfur compounds) and the enstatite chondrites (in which some of the $\mathrm{Si}, \mathrm{Ca}, \mathrm{Cr}, \mathrm{Mn}, \mathrm{Mg}$, and $\mathrm{Ti}$ may not be present as oxidic compounds).

Taylor and others (1965) made an extensive series of measurements of oxygen isotopes in stony meteorites, and their results are summarized in figure 6. The common chondrites, the enstatite chondrites and enstatite achondrites, and the nakhlites are isotopically very similar to their terrestrial counterparts, the ultramafic igneous rocks, with $\delta$ values (relative to standard mean ocean water) about 5.7 per mil. Eucrites, howardites, diogenites, and mesosiderites have $\delta$ values about 4.0 per mil. The $\delta$ values of the carbonaceous chondrites are highly variable, showing a range of -2 to +12 per mil. The isotopic relationships among coexisting minerals in meteorites follow the same pattern observed in terrestrial rocks. In the eucrites and howardites, the small differences between pyroxene and plagioclase imply a high temperature of formation, consistent with a magmatic origin for these meteorites.

Intriguing anomalies have been found in the oxygen isotopic composition components of the Allende meteorite (C3). Clayton, Grossman, and Moyeda (1973) found that Ca,Al-rich chondrules and aggregates are strongly depleted in ${ }^{17} \mathrm{O}$ and ${ }^{18} \mathrm{O}$; other carbonaceous chondrites also show this feature. These meteorites have lower ${ }^{18} \mathrm{O} /{ }^{16}$ and ${ }^{17} \mathrm{O} /{ }^{16} \mathrm{O}$ ratios than all other meteorites studied. The depletion pattern is one in which ${ }^{17} \mathrm{O}$ and ${ }^{18} \mathrm{O}$ are equally depleted, whereas chemical processes that produce a 1 percent increase or decrease in the ${ }^{17} \mathrm{O} /{ }^{16} \mathrm{O}$ ratio produce a 2 percent or decrease in the ${ }^{18} \mathrm{O} /{ }^{16} \mathrm{O}$ ratio (since chemical isotope effects are almost linearly proportional to the relative mass difference of the isotopes). This indicates that the depletion pattern is the result of nuclear rather than chemical proc-

TABLE 17.-Nitrogen in iron meteorites

[From Gibson and Moore, 1971a. Median value for 123 meteorites equals 18 ppm nitrogen]

\begin{tabular}{llccc}
\hline Group & $\begin{array}{l}\text { Structure } \\
\text { class }\end{array}$ & $\begin{array}{l}\text { Number } \\
\text { analyzed }\end{array}$ & $\begin{array}{c}\text { Range } \\
\text { (ppm) }\end{array}$ & $\begin{array}{c}\text { Median } \\
\text { (ppm) }\end{array}$ \\
\hline I & Off-Ogg & 17 & $2-131$ & 35 \\
IIA & H & 11 & $4-26$ & 15 \\
IIB & Ogg-Oge & 5 & $16-27$ & 18 \\
IIC & Opl & 3 & $11-16$ & 14 \\
IID & Of-Om & 2 & $32-44$ & 38 \\
IIIA & Om-Og & 33 & $2-80$ & 25 \\
IIIB & Of-Om & 7 & $22-70$ & 46 \\
IVA & Of & 13 & $2-34$ & 4 \\
IVB & D & 4 & $2-9$ & 2 \\
& & & & \\
\hline
\end{tabular}


TABLE 18.-Oxygen in stony meteorites

[From Vogt and Ehmann, 1965; only data from observed falls are used because finds have suffered terrestrial oxidation]

\begin{tabular}{|c|c|c|c|c|}
\hline Class & $\begin{array}{l}\text { Number } \\
\text { analyzed }\end{array}$ & $\begin{array}{c}\text { Range } \\
\text { (weight percent) }\end{array}$ & $\begin{array}{l}\text { Mean } \\
\text { (weight percent) }\end{array}$ & Atoms $/ 10^{6} \mathrm{si}$ \\
\hline \multicolumn{5}{|c|}{ Chondrites } \\
\hline$\overline{\mathrm{Cl}}$ & 1 & -- & 46.2 & $7,870,000$ \\
\hline $\mathrm{C} 2$ & 3 & $42.0-43.8$ & 43.2 & $5,790,000$ \\
\hline C3 & 3 & $35 \cdot 8-38 \cdot 9$ & 37.1 & $4,200,000$ \\
\hline $\mathrm{H}$ & 3 & $34 \cdot 3-37 \cdot 3$ & 35.7 & $3,670,000$ \\
\hline $\mathrm{L}$ & 10 & $35.3-40.0$ & 37.7 & $3,540,000$ \\
\hline LL & 1 & 38.4 & -- & $3,590,000$ \\
\hline$E$ & 2 & $27.0-31.6$ & 29.3 & $2,860,000$ \\
\hline \multicolumn{5}{|c|}{ Calcium-poor achondrites } \\
\hline $\mathrm{Ae}$ & 2 & $47.3-48.0$ & 47.7 & $3,020,000$ \\
\hline $\mathrm{Ah}$ & 1 & 47.7 & --- & $3,400,000$ \\
\hline \multicolumn{5}{|c|}{ Calcium-rich achondrites } \\
\hline Aeu & 1 & 42.4 & -- & $3,260,000$ \\
\hline
\end{tabular}

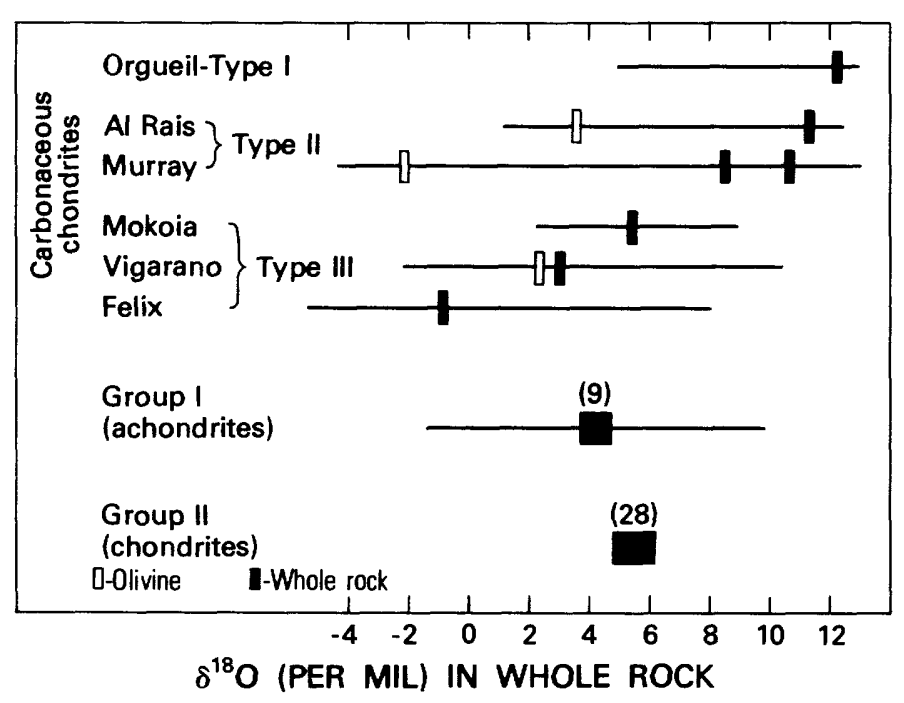

FIGURE 6.-Graphical comparison of ${ }^{18} \mathrm{O} /{ }^{16} \mathrm{O}$ analyses of wholerock samples and olivines from carbonaceaus chondrites with whole-rock analyses of other meteorites. Reprinted from Taylor and others (1965) and published with permission. esses ; Clayton, Grossman, and Mayeda interpreted it as resulting from the admixture of a component of almost pure ${ }^{16} \mathrm{O}$. They suggested that this component may predate the solar system and may represent interstellar dust with a separate history of nucleosynthesis

These investigations of variations in oxygen isotope ratios have been extended to all classes of meteorites (Clayton and others, 1976). On the basis of the data obtained, they presented a classification of meteorites into six categories: (1) $\mathrm{H}$ chondrites ; (2) L and LL chondrites; (3) anhydrous minerals of $\mathrm{C}$ chondrites; (4) hydrous matrix minerals of C2 chondrites; (5) ureilites; (6) stony-irons, achondrites other than ureilites, and $\mathrm{E}$ chondrites (this group also including terrestrial and lunar rocks). They believe that meteorites of one category cannot be derived by fractionation or differentiation from the source materials of any other category.

\section{FLUORINE}

Data on the abundance of fluorine are rather sparse, and the accuracy of many of the data is 
questionable. This is illustrated in table 19, where results obtained by different investigators from the same meteorite are compared. Greenland and Lovering (1965) used emission spectrography; Reed (1964) and Fisher (1963) used different neutronactivation techniques; Goldberg and others (1974) used a proton-activation technique; Sen Gupta (1968b) used a spectrophotometric procedure; and Allen and Clark (1977) used a proton activation technique. Reed determined fluorine in the rock standards G-1 and W-1 by his technique and obtained $1,124 \mathrm{ppm}$ and $490 \mathrm{ppm}$ respectively; these figures are considerably higher than the current recommended values (700 ppm and $250 \mathrm{ppm}$ ), suggesting that his meteorite results may be consistently too high. Therefore, the data provided in table 20 on the average content of fluorine in stony meteorites must be interpreted with caution. However, there is a moderate diminution in fluorine concentration from $\mathrm{C} 1$ through $\mathrm{C} 3$ carbonaceous chondrites to the H, L, LL chondrites is evident; enstatite chondrites are relatively enriched in F. The anchondrites are depleted in fluorine relative to the chondrites, especially the calcium-poor achondrites (aubrites and diogenites).

Little is known about the distribution of fluorine in meteorites. Meteoritic apatite is chlorapatite that has a minor $F$ content ( 0.4 percent), according to Van Schmus and Ribbe (1969). If all the phosphorus in a chondrite is present as apatite, this mineral would amount to 0.6 percent, and thus contribute 24 ppm $\mathrm{F}$ to the meteorite; this is clearly insufficient to account for even the minimum recorded fluorine content. Trace amounts of amphibole are an intriguing possibility. Olsen and others (1973) discovered trace amounts of fluor-richterite (4.6 percent $F)$ in the Abee enstatite chondrite. Reference to table 19 shows that this meteorite has the highest $\mathrm{F}$ content of those analyzed by Greenland and Lovering (1965). Allen and Clark (1977) noted a correlation between $\mathrm{F}$ and $\mathrm{Al}$ in meteorite minerals, and suggested therefore that $\mathrm{F}$ may be enriched in the plagioclase.

\section{SODIUM}

Sodium is determined as a matter of course in most analyses of stony meteorites, but many of these determinations, especially in older analyses, are unreliable. Schmitt and others (1972) made an extensive series of instrumental neutron activation analyses for sodium in meteorites, and their results are summarized in table 21. For the common chondrites $(\mathrm{H}, \mathrm{L}, \mathrm{LL})$, sodium abundances are very uniform. Eugene Jarosewich of the Smithsonian Institution has analyzed a large number of chondrites since 1965 , and for sodium (analyzed by flame photometry) he reported (written commun., 1976) as follows (class, number analyzed, range and mean (weight percent)) : $\mathrm{H}(17), 0.61-0.70,0.62 ; \mathrm{L}(23)$, $0.66-0.78,0.71 ; \mathrm{LL}(4), 0.70-0.74,0.72$. His results show less variability and slightly higher means than those of Schmitt and others (1972) ; the higher variability in the results of Schmitt and others can probably be ascribed to their use in some instances of

TABLE 19.-Comparison of fluorine determinations in chondrites

[In parts per million. 1. Greenland and Lovering, 1965; 2. Reed, 1964; 3. Fisher, 1963; 4. Goldberg and others, 1974; 5 . Sen Gupta, 1968b; 6. Allen and Clark, 1977]

\begin{tabular}{|c|c|c|c|c|c|c|}
\hline Meteorite & 1 & 2 & 3 & 4 & 5 & 6 \\
\hline Orgueil(Cl) & 190 & 206 & 405 & 74 & - & - \\
\hline Mighei(C2) & - & - & 220 & 66 & - & - \\
\hline Abee (E 4) & 280 & 228 & - & - & 275 & - \\
\hline Indarch (E 4$)$ & 220 & 246 & 136 & - & - & - \\
\hline llvittis(E6) & 250 & 122 & - & - & - & - \\
\hline A 11 egan(H5) & 170 & 114 & - & - & - & 32 \\
\hline Holbrook (L6) & 130 & - & 189 & - & - & 43 \\
\hline $\operatorname{llocs}(\mathrm{L} 6)$ & 160 & 119 & 147 & - & - & - \\
\hline
\end{tabular}


COSMOCHEMISTRY PART 1. METEORITES

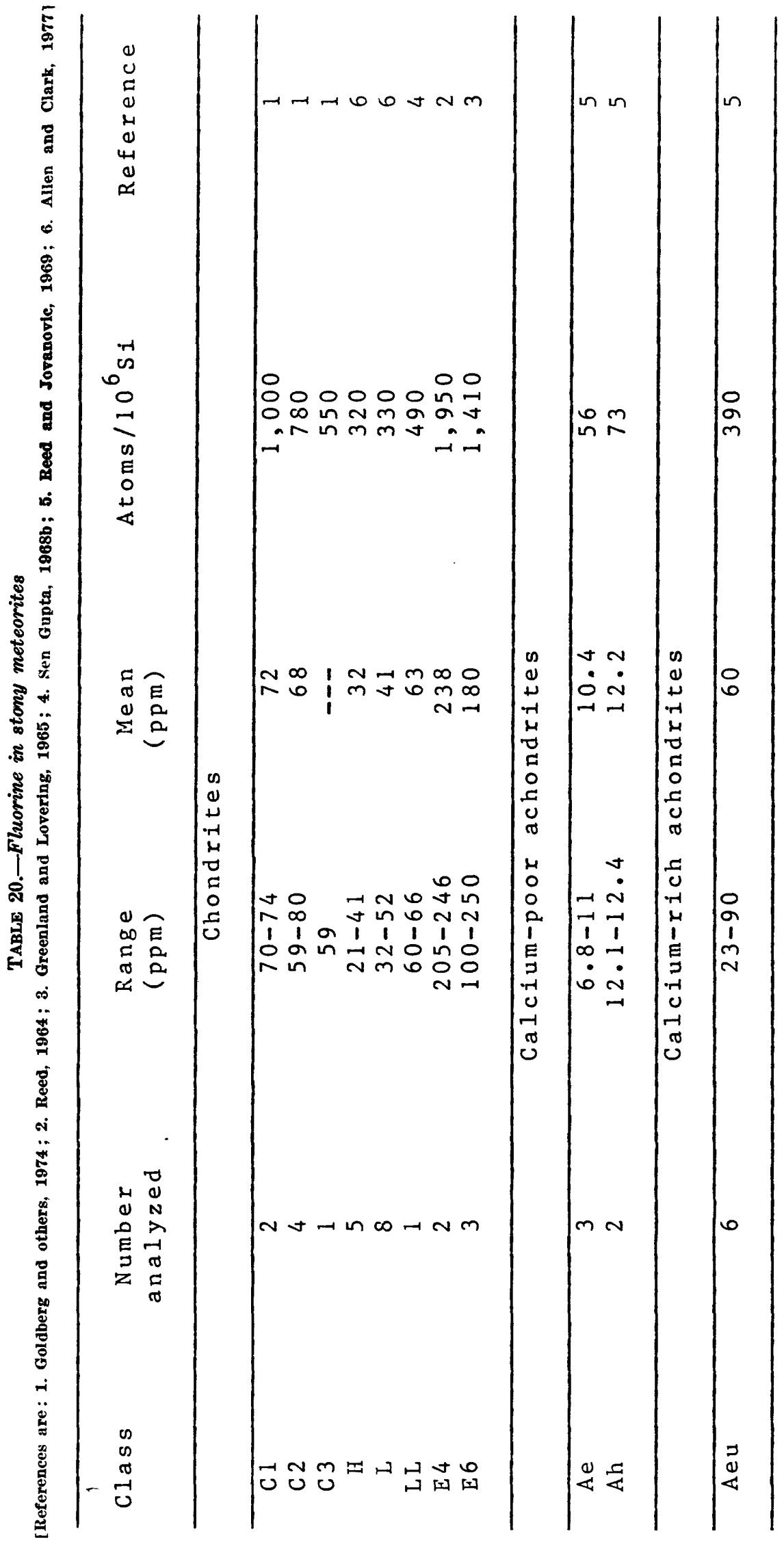




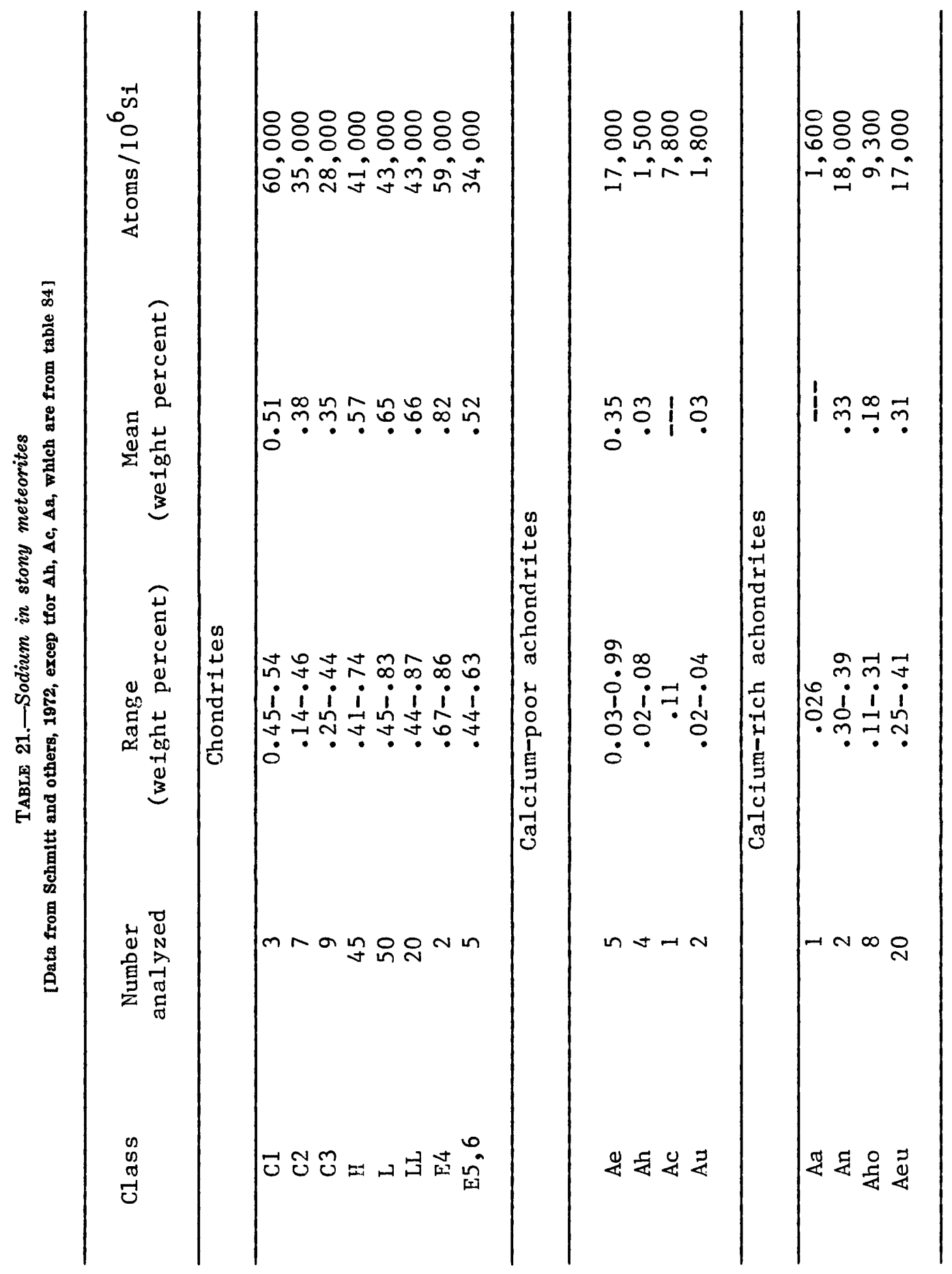


very small samples $(<100 \mathrm{mg}$ ) that may not have been representative. The relative constancy of sodium content is consistent with the relative constancy in the amount ( $\sim 10$ percent) and composition $\left(\mathrm{An}_{10-12}\right)$ of chondrite plagioclase. This mineral (or maskelynite, its glassy equivalent) contains essentially all the sodium in these meteorites.

Carbonaceous chondrites have more variable sodium contents than the common chondrites. The C1 and C2 chondrites contain no feldspar, and the state of combination of the sodium is not well understood. Jarosewich (written commun., 1976) has found that practically all the sodium in Orgueil (C1) and about half that in Murchison (C2) is water soluble (probably as sulfate). Sodium also appears to be very irregularly distributed in some of these meteorites; Fuchs, Olsen, and Jensen (1973) analyzed separate fragments from five different pieces of Murchison and found that the $\mathrm{Na}_{2} \mathrm{O}$ content ranged from 0.19 percent to 0.71 percent. The C3 chondrites contain plagioclase, but it is usually close to anorthite in composition, and most of the sodium must be in other minerals; the Allende meteorite contains both nepheline and sodalite.

The sodium content of enstatite chondrites is comparable to that of the common chondrites. Van Schmus and Ribbe (1968) showed that the plagioclase in enstatite chondrites is slightly more calcic $\left(\mathrm{An}_{15}\right)$ than that in the common chondrites $\left(\mathrm{An}_{10-12}\right)$. Moss and others (1967) detected sodium in the sulfide phases of several enstatite chondrites, demonstrating that this element shows chalcophile tendencies in a highly reducing and sulfide-rich paragenesis.

Achondrites have variable sodium contents, generally considerably lower than in the chondrites. Schaudy, Kiesl, and Hecht (1967) analyzed two irons and found the sodium content to be less than 10 ppm.

\section{MAGNESIUM}

Magnesium is a major element in all classes of stony and stony-iron meteorites, and as a consequence the abundance data are very extensive. Von Michaelis, Ahrens, and Willis (1969) pointed out that the older data on chondrites summarized by Urey and Craig (1953) show a greater spread of values than more recent analyses, indicating an improvement in overall quality in recent years. The figures presented in table 22 are derived as far as possible from recent analyses of observed falls.

The data for the chondrites show that the $\mathrm{Mg} / \mathrm{Si}$ ratio (atomic) is fairly uniform at $0.934-0.965$ for the common $(\mathrm{H}, \mathrm{L}, \mathrm{LL})$ chondrites, although the difference between the $\mathrm{L}$ and $\mathrm{LL}$ groups on the one hand and the $\mathrm{H}$ group on the other is probably greater than the experimental error, and hence may be significant (Ahrens, 1970). The differences between the common chondrites and the carbonaceous and enstatite chondrites are considerably larger than those within the common chondrites. The $\mathrm{Mg} / \mathrm{Si}$ ratio for the carbonaceous chondrites is consistently slightly greater than unity, whereas for the enstatite chondrites this ratio is considerably less than unity and notably lower than for the common chondrites. The difference between the Type I and Type II enstatite chondrites is also significant. The range of values of $\mathrm{Mg} / \mathrm{Si}$ ratios for the enstatite chondrites is considerably wider than for the other classes of chondrites.

The differences between the $\mathrm{Mg} / \mathrm{Si}$ ratios for the different classes of chondrites were first pointed out by Urey (1961), and were further discussed by Ahrens (1964). These differences are illustrated in a simple plot of weight percent $\mathrm{SiO}_{2}$ against weight percent $\mathrm{MgO}$ (fig. 7). The significance of this fractionation remains to be fully elucidated. The close approach to unity of the $\mathrm{Mg} / \mathrm{Si}$ ratio for the carbonaceous and the common chondrites is consistent with their derivation from relatively unfractioned material that still retained the $\mathrm{Mg} / \mathrm{Si}$ ratio established by nucleosynthesis. The fractionation shown by the enstatite chondrites may be related to the high degree of reduction shown by these meteorites, one of the features being the presence of elemental silicon in solid solution in their metal phase. Magnesium is not reduced to the elemental state in any class of meteorites. Thus, the enstatite chondrites may actually be enriched in silicon (incorporated in the metal phase) rather than depleted in magnesium, relative to the common and carbonaceous chondrites.

The calcium-poor achondrites show a considerable range of $\mathrm{Mg} / \mathrm{Si}$ ratios. Since the enstatite achondrites consist almost entirely of enstatite, $\mathrm{MgSiO}_{3}$, this ratio should be close to unity; the exact figure in the table is coincidental owing to the balancing of the contribution of magnesium and silicon by minor minerals such as plagioclase and forsterite. The lower $\mathrm{Mg} / \mathrm{Si}$ ratio for the hypersthene achondrites results from the introduction of ferrous iron partly replacing magnesium in the pyroxene. The chassignite and the ureilites show an enhancement of the $\mathrm{Mg} / \mathrm{Si}$ ratio because of their high content of olivine, $(\mathrm{Mg}, \mathrm{Fe})_{2} \mathrm{SiO}_{4}$.

The calcium-rich achondrites are notably depleted 


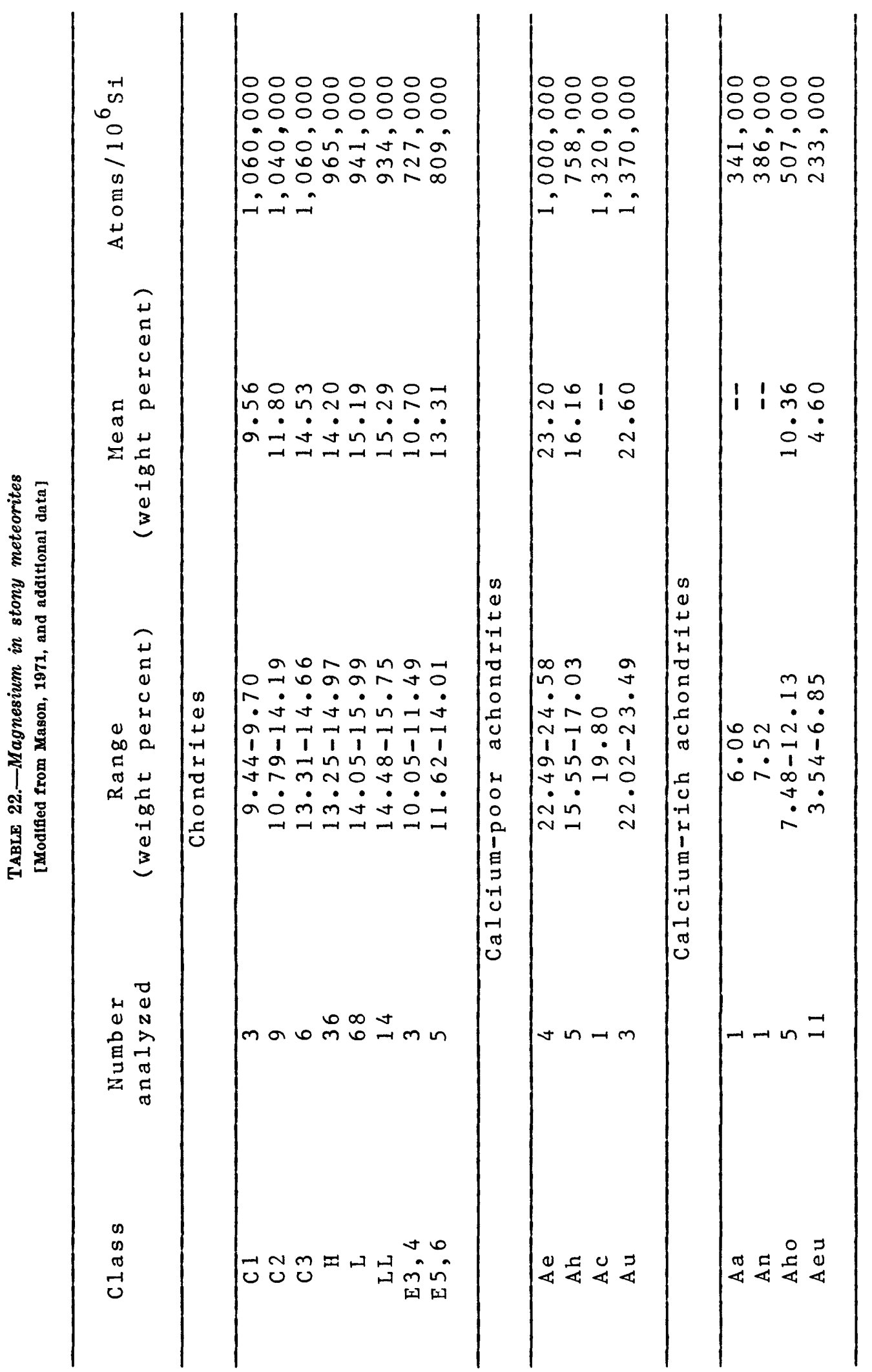




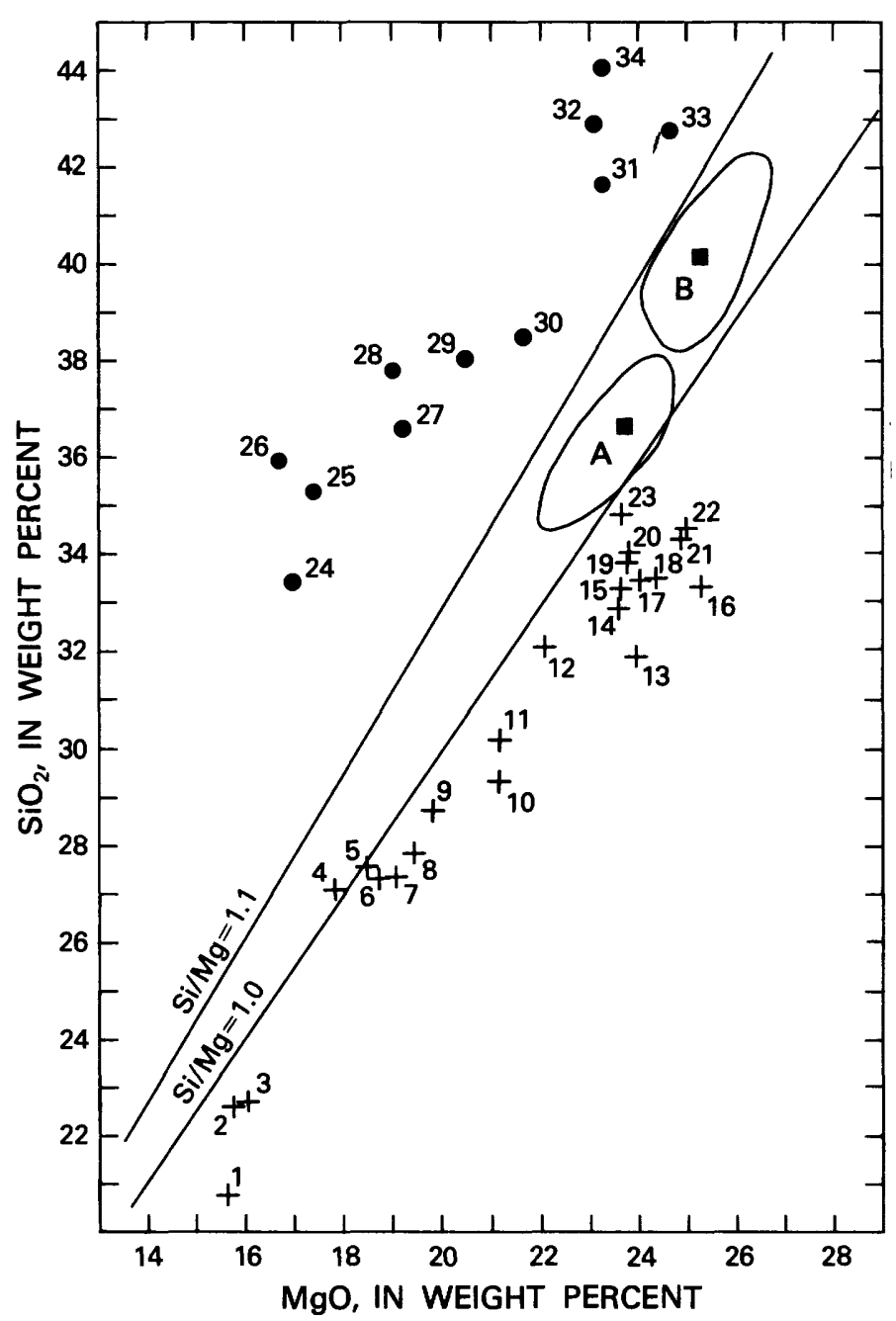

Figure 7.- $\mathrm{SiO}_{2}$ plotted against $\mathrm{MgO}$ (weight percentages) for chemical analyses of chondrites; the diagonal lines are for $\mathrm{Si} / \mathrm{Mg}$ atomic ratios of 1.0 and 1.1. $\mathrm{A}$ is the field for 36 analyses of bronzite $(H)$ chondrites, $B$ the field for 68 analyses of hypersthene ( $\mathrm{L}$ and $\mathrm{LL}$ ) chondrites, the black squares being the means for each group. The analyses of carbonaceous chondrites (1-23) and enstatite chondrites (24-34) are plotted individually. Reprinted from Mason 1967b) and published with permission.

in magnesium relative to the chondrites. The howardites and the eucrites form a sequence in which the silicon and ferrous iron contents remain practically constant and the magnesium content decreases (fig. 3), hence the marked diminution in the $\mathrm{Mg} / \mathrm{Si}$ ratio. Among the stony-irons, the mesosiderite silicates are essentially similar to those in the howardites, hence the similarity in $\mathrm{Mg} / \mathrm{Si}$ ratios between these two classes. The silicate material in the pallasites is magnesium-rich olivine, hence the $\mathrm{Mg} / \mathrm{Si}$ ratio is much higher than in other classes of meteorites and approaches 2:1.
Magnesium is usually considered to be entirely lithophilic in character; however, in the extremely reduced and sulfide-rich enstatite chondrites, a small amount of the total magnesium is present in solid solution in alabandite, $(\mathrm{Mn}, \mathrm{Fe}) \mathrm{S}$, or as niningerite, $(\mathrm{Mg}, \mathrm{Fe}) \mathrm{S}$. In most classes of meteorites the magnesium is combined almost entirely in the minerals olivine and (or) pyroxene. The $\mathrm{C} 1$ and $\mathrm{C} 2$ carbonaceous chondrites are unique in having much of their magnesium present as the hydrated magnesium-iron silicate serpentine (or related layer-lattice silicates) ; C1 carbonaceous chondrites also contain notable amounts of hydrated magnesium sulfate.

\section{ALUMINUM}

Aluminum is a minor constituent in all stony and stony-iron meteorites (except the pallasites, in which it is present in trace amounts only). It has therefore been determined in all complete chemical analyses of these meteorites. However, many of the data in the literature are unreliable, because the accurate determination of small amounts of aluminum (especially in the presence of much iron, as in meteorites) is extremely difficult by standard wet-chemical procedures. To obviate these difficulties, Loveland, Schmitt, and Fisher (1969) applied neutron-activation analysis to the determination of this element in some 120 stony meteorites, and their results are used in table 23, along with selected data for a few classes which they did not analyze.

Loveland, Schmitt, and Fisher reported that their average aluminum abundances were lower, in general, than those previously reported, and that the individual determinations showed a much smaller dispersion around the mean value for each class than earlier determinations. For the common chondrites $(\mathrm{H}, \mathrm{L}, \mathrm{LL})$ they reported relative standard deviations of 6 percent, 7 percent, and 6 respectively, considerably less than earlier dispersion values of 25 percent, 28 percent, and 28 percent. Their low dispersion values indicate that, within specific chondrite classes, aluminum concentrations are remarkably uniform from one meteorite to another. This has been confirmed by Von Michaelis, Ahrens, and Willis (1969), who used X-ray fluorescence to analyze for aluminum and other elements in 69 meteorites.

The data for the chondrites show that the $\mathrm{Al} / \mathrm{Si}$ ratio (atomic) is uniform at $0.061-0.062$ for the common chondrites, whereas it is much greater for the carbonaceous chondrites (average 0.087), and somewhat lower for the enstatite chondrites $(0.048)$. The lower ratio for the latter parallels a corresponding diminution of the $\mathrm{Mg} / \mathrm{Si}$ ratio from the common 
chondrites to the enstatite chondrites, and can probably be ascribed to an absolute enhancement of $\mathrm{Si}$ in the enstatite chondrites. The higher $\mathrm{Al} / \mathrm{Si}$ ratios for the carbonaceous chondrites are significant. The site of the aluminum in $\mathrm{C} 1$ and $\mathrm{C} 2$ chondrites is poorly known, but it is probably combined in the serpentine or other layer-lattice silicates that form the matrix of these meteorites. The C3 chondrites contain a variety of aluminum-rich minerals, the commonest being aluminous pyroxene, spinel $\left(\mathrm{MgAl}_{2} \mathrm{O}_{4}\right)$, anorthite $\left(\mathrm{CaAl}_{2} \mathrm{Si}_{2} \mathrm{O}_{8}\right)$, and melilite $\left(\mathrm{Ca}_{2}(\mathrm{Mg}, \mathrm{Al})\right.$ $(\mathrm{Si}, \mathrm{Al})_{2} \mathrm{O}_{7}$, which are rarely found in other classes of chondrites. Loveland, Schmitt, and Fisher pointed out that the $\mathrm{Al} / \mathrm{Na}$ ratio increases progressively from 1.42 to 2.40 to 3.29 through the $\mathrm{C} 1, \mathrm{C} 2, \mathrm{C} 3$ carbonaceous chondrites, whereas this ratio is very uniform at about $\mathbf{1 . 4 5}$ in the ordinary chondrites.
The calcium-poor achondrites are somewhat lower in aluminum than the chondrites, especially the enstatite achondrites and the ureilites; this can be correlated with their lower content of plagioclase feldspar. The calcium-rich achondrites (except the nakhlite) are notably enriched in aluminum; in the angrite this element is present in an aluminumrich pyroxene, and in the howardites and eucrites as plagioclase.

Ahrens and others (1969) have pointed out that for all the chondrite classes, and for the eucrites and howardites, the $\mathrm{Ca} / \mathrm{Al}$ ratio is remarkably uniform at 1.00-1.19 (by weight), and averages 1.10.

As far as is known, aluminum is entirely lithophilic in meteorites, and lacks chalcophilic or siderophilic tendencies; Fisher (1969b) has shown by activation analysis of 11 iron meteorites that they

TABLE 23.-Aluminum in stony meteorites

[Modified from Loveland and others, 1969 ; and additlonal data]

\begin{tabular}{|c|c|c|c|c|}
\hline Class & $\begin{array}{r}\text { Number } \\
\text { analyzed }\end{array}$ & $\begin{array}{l}\text { Range } \\
\text { (weight percent) }\end{array}$ & $\begin{array}{c}\text { Mean } \\
\text { (weight percent) }\end{array}$ & Atoms $/ 10^{6} \mathrm{Si}$ \\
\hline \multicolumn{5}{|c|}{ Chondrites } \\
\hline $\mathrm{Cl}$ & 3 & $0.80-.87$ & 0.85 & 85,000 \\
\hline $\mathrm{C} 2$ & 7 & $.98-1.21$ & 1.08 & 84,000 \\
\hline C3 & 7 & $1.27-1.64$ & 1.37 & 92,000 \\
\hline $\mathrm{H}$ & 15 & $.89-1.12$ & 1.01 & 61,000 \\
\hline $\mathrm{L}$ & 23 & $1.00-1.31$ & 1.10 & 61,000 \\
\hline LL & 13 & $1.07-1.20$ & 1.12 & 62,000 \\
\hline E3, 4 & 2 & $.71-.84$ & .79 & 48,000 \\
\hline$E 5,6$ & 2 & $.76-.93$ & .85 & 48,000 \\
\hline \multicolumn{5}{|c|}{ Calcium-poor achondrites } \\
\hline $\mathrm{Ae}$ & 5 & $.10-1.40$ & .50 & 20,000 \\
\hline $\mathrm{Ah}$ & 5 & $.27-1.04$ & .55 & 23,000 \\
\hline Ac & 1 & .19 & -- & 17,000 \\
\hline $\mathrm{Au}$ & 3 & $.17-.46$ & $\cdot 30$ & 16,000 \\
\hline \multicolumn{5}{|c|}{ Calcium-rich achondrites } \\
\hline $\mathrm{Aa}$ & 1 & 4.62 & - & 233,000 \\
\hline An & 1 & .77 & -- & 36,000 \\
\hline Aho & 5 & $2.57-5.27$ & 3.71 & 164,000 \\
\hline Aeu & 11 & $6.11-6.88$ & 6.62 & 302,000 \\
\hline
\end{tabular}


contain less than $10 \mathrm{ppm} \mathrm{Al}$. In most meteorites, aluminum is present almost entirely in plagioclase feldspar; meteoritic pyroxenes [except in the angrite and in Allende (C3)] contain only small amounts of aluminum, and olivine only trace amounts. As mentioned above, C3 carbonaceous chondrites are noteworthy for containing aluminum-rich minerals rarely found in other meteorites.

\section{SILICON}

Silicon is a major element in stony and stony-iron meteorites, in which it is present in the common silicate minerals olivine, pyroxene, and plagioclase, and some rarer species. The rare minerals perryite, $(\mathrm{Ni}, \mathrm{Fe})_{5}(\mathrm{Si}, \mathrm{P})_{2}$ and sinoite, $\mathrm{Si}_{2} \mathrm{~N}_{2} \mathrm{O}$, are known as minor constituents in a few enstatite chondrites (and for perryite, in enstatite achondrites also). The con- centration and distribution of silicon in meteorites has been thoroughly covered by C. B. Moore (in Mason, 1971); a selection of his data is provided in table 24.

Because of its high and relatively constant abundance and the availability of high-quality analytical data, silicon is extensively used as the basis for comparison of atomic abundances in stony meteorites. Most of the lithophile elements show relatively small variations with respect to the silicon abundances, but careful evaluation of the data indicates significant fractionation between chondrite classes. The extent of $\mathrm{Mg} / \mathrm{Si}$ fractionation is illustrated in figure 7. Ahrens and Von Michaelis (1968) discussed the variation in the $\mathrm{Mg} / \mathrm{Si}, \mathrm{Ca} / \mathrm{Si}, \mathrm{Al} / \mathrm{Si}$, and $\mathrm{Ti} / \mathrm{Si}$ ratios between the different chondrite classes.

TABLE 24.-Silicon in stony meteorites

[In weight percent. From C. B. Moore, in Mason, 1971; and additional data]

\begin{tabular}{|c|c|c|c|}
\hline Class & $\begin{array}{c}\text { Number } \\
\text { analyzed }\end{array}$ & Range & Mean \\
\hline \multicolumn{4}{|c|}{ Chondrites } \\
\hline $\begin{array}{l}\text { C } 1 \\
\text { C } 2 \\
\text { C } 3 \\
\text { H } \\
\text { L } \\
\text { LL } \\
\text { E } 4 \\
\text { E } 5 \\
\text { E } 6\end{array}$ & $\begin{array}{l}3 \\
9 \\
6 \\
36 \\
68 \\
12 \\
3 \\
2 \\
6\end{array}$ & $\begin{array}{l}9 \cdot 7-10 \cdot 5 \\
12 \cdot 7-13 \cdot 7 \\
14 \cdot 9-15 \cdot 9 \\
16 \cdot 0-17 \cdot 7 \\
17 \cdot 8-19 \cdot 5 \\
18 \cdot 1-19 \cdot 3 \\
15 \cdot 6-17 \cdot 7 \\
17 \cdot 2-17 \cdot 7 \\
18 \cdot 0-20 \cdot 5\end{array}$ & $\begin{array}{l}10 \cdot 3 \\
13 \cdot 1 \\
15 \cdot 5 \\
17 \cdot 1 \\
18 \cdot 7 \\
18 \cdot 8 \\
16 \cdot 6 \\
17 \cdot 4 \\
19.4\end{array}$ \\
\hline \multicolumn{4}{|c|}{ Calcium-poor achondrites } \\
\hline $\begin{array}{l}\mathrm{Ae} \\
\mathrm{Ah} \\
\mathrm{Ac} \\
\mathrm{Au}\end{array}$ & $\begin{array}{l}9 \\
5 \\
1 \\
3\end{array}$ & $\begin{array}{r}27 \cdot 2-28 \cdot 1 \\
24 \cdot 1-25 \cdot 6 \\
17 \cdot 3 \\
18 \cdot 6-19 \cdot 6\end{array}$ & $\begin{array}{r}27.7 \\
24 \cdot 6 \\
--- \\
19.1\end{array}$ \\
\hline \multicolumn{4}{|c|}{ Calcium-rich achondrites } \\
\hline $\begin{array}{r}\text { Aa } \\
\text { An } \\
\text { Aho } \\
\text { Aeu }\end{array}$ & $\begin{array}{l}1 \\
1 \\
5 \\
11\end{array}$ & $\begin{array}{c}20 \cdot 5 \\
22 \cdot 5 \\
23 \cdot 0-24 \cdot 2 \\
22 \cdot 5-23 \cdot 2\end{array}$ & $\begin{array}{l}--- \\
--- \\
23.6 \\
22.8\end{array}$ \\
\hline
\end{tabular}


Silicon is an entirely lithophile element in most meteorites, but in the highly reduced enstatite chondrites and enstatite achondrites minor amounts of the element are present in the metal phase. Detailed investigation of the enstatite chondrites by Keil (1968) showed that the E4, E5, and E6 chondrites have an average of 3.23 .3 , and 1.3 weight percent silicon in their nickel-iron. Most iron meteorites contain only trace amounts of silicon; Moore (in Mason, 1971) reported that of 93 irons, 8 percent contained more than $10 \mathrm{ppm}, 10$ percent contained $5-10 \mathrm{ppm}$, and 2 percent less than $5 \mathrm{ppm}$; the median value was $3 \mathrm{ppm}$.

\section{PHOSPHORUS}

Phosphorus is a ubiquitous element in meteorites, present in minor to trace amounts (tables 25 and 26). Collections of analyses of chondrites, especially older ones, show a considerable variability for this element, which is negated by recent work; the data of Von Michaelis, Ahrens, and Willis (1969), reported

TABLE 25.-Phosphorus in stony meteorites

[From VonMichaelis and others, 1969 ; and additional data]

\begin{tabular}{|c|c|c|c|c|}
\hline Class & $\begin{array}{l}\text { Number } \\
\text { analyzed }\end{array}$ & $\begin{array}{l}\text { Range } \\
\text { (weight percent) }\end{array}$ & $\begin{array}{l}\text { Mean } \\
\text { (weight percent) }\end{array}$ & Atoms $/ 10^{6} \mathrm{Si}$ \\
\hline \multicolumn{5}{|c|}{ Chondrites } \\
\hline $\mathrm{Cl}$ & 1 & 0.080 & -- & 7,000 \\
\hline $\mathrm{C} 2$ & 3 & $.089-.093$ & 0.091 & 6,200 \\
\hline $\mathrm{C} 3$ & 4 & $.102-.107$ & .105 & 6,400 \\
\hline $\mathrm{H}$ & 12 & $.104-.113$ & .108 & 5,800 \\
\hline $\mathrm{L}$ & 20 & $.081-.112$ & .095 & 4,800 \\
\hline LL & 4 & $.044-.13$ & .087 & 4,200 \\
\hline E4 & 2 & $.196-.209$ & .203 & 11,200 \\
\hline E5 & 1 & .193 & -- & 10,200 \\
\hline E6 & 4 & $.105-.134$ & .117 & 5,600 \\
\hline \multicolumn{5}{|c|}{ Calcium-poor achondrites } \\
\hline $\mathrm{Ae}$ & 1 & 0.008 & -- & 290 \\
\hline Ah & 4 & $.001-.006$ & .003 & 110 \\
\hline Ac & 1 & .018 & $-\infty$ & 940 \\
\hline $\mathrm{Au}$ & 4 & $.030-.040$ & .034 & 1,600 \\
\hline \multicolumn{5}{|c|}{ Calcium-rich achondrites } \\
\hline $\mathrm{Aa}$ & 1 & 0.057 & -- & 2,500 \\
\hline An & 1 & .054 & -- & 2,200 \\
\hline Aho & 5 & $.017-.039$ & .024 & 920 \\
\hline Aeu & 11 & $.016-.048$ & .037 & 1,500 \\
\hline
\end{tabular}


in table 25, show that within individual chondrite classes the variability is quite small. Achondrites, especially the calcium-poor achondrites, are notably depleted in phosphorus relative to the chondrites; the nonmetallic part of the mesosiderites appears to be relatively enriched in this element.

Phosphorus is a significant constituent of iron meteorites, but its true abundance is difficult to determine. Much of the phosphorus is present as schreibersite, (Fe,Ni) ${ }_{3} \mathrm{P}$, frequently as macroscopic inclusions; when an iron meteorite is sampled for analysis these inclusions are usually avoided, so the analyses are not representative of the whole meteorite but only of the metallic component (and microscopic inclusions). This selectivity is reflected by the data in table 26. The amount and size of schreibersite inclusions depend on both the bulk phosphorus content and the cooling history, since most if not all schreilbersite in iron meteorites has formed by solidstate diffusion during cooling. Doan and Goldstein (1969) showed that the phosphorus solubility in $\alpha$ (kamacite) and $\gamma$ (taenite) nickel-iron decreases from 2.7 and 1.4 weight percent at $1,000^{\circ} \mathrm{C}$ to 0.25 and 0.08 weight percent at $550^{\circ} \mathrm{C}$; the exsolved phosphorus combines with nickel and iron to form schreibersite. Doan and Goldstein estimated the total amount of phophorus in a number of iron meteorites from measurements of the percentage of screibersite, and obtained a range of $0.50-1.3$ percent $P$.

Besides schreibersite, the common phosphorus minerals of meteorites are chlorapatite, $\mathrm{Ca}_{5}\left(\mathrm{PO}_{4}\right)_{3} \mathrm{Cl}$, and merrillite, $\mathrm{Ca}_{9} \mathrm{MgNa}\left(\mathrm{PO}_{4}\right)_{7}$. Merrillite has been generally identified with the terrestrial mineral whitlockite, but Prewitt and Rothbard (1975) produced evidence indicating that the two minerals are distinct but closely related species, being compositional and structural variants of $\beta-\mathrm{Ca}_{3}\left(\mathrm{PO}_{4}\right)_{2}$. Merrillite and chlorapatite commonly occur together in stony meteorites, and their relative amounts are probably controlled by the available chlorine. The state of combination of phophorus in carbonaceous chondrites is not well known. In the common chondrites, phosphorus is present as merrillite and chlorapatite; schreibersite is absent or present only in traces, and the metal is essentially phosphorus free $(<45 \mathrm{ppm}$ in five chondrites, according to Reed (1969)). The enstatite chondrites contain no phosphates, the phosphorus being present as schreibersite and in solid solution in the nickel-iron (Keil, 1968). Some iron meteorites contain assemblages of schreibersite and phosphate minerals, and Olsen and Fuchs (1967) deduced that these metallic meteorites represent approximately the same degree of oxidation as the ordinary chondrites; the enstatite chondrites clearly are much more highly reduced.

Ahrens (1970) pointed out that phosphorus shows a slight but consistent enrichment in $\mathrm{H}$ chondrites relative to $\mathrm{L}$ chondrites, and noted that this indicated a positive Fe-P correlation, which also applied to the $E$ chondrites. He commented, "Perhaps $P$ was associated with $\mathrm{Fe}$ in the early stages of the formation of the common chondrites and later events,

TABLE 26.-Phosphorus in iron meteorites

[In weight percent. From Moore, Lewis, and Nava, 1969]

\begin{tabular}{lccc}
\hline $\begin{array}{c}\text { Meteorite } \\
\text { group }\end{array}$ & $\begin{array}{c}\text { Number } \\
\text { analyzed }\end{array}$ & Range & Mean \\
\hline IIA & 7 & $0.39-0.46$ & 0.44 \\
IIB & 2 & $.18-.24$ & .21 \\
I & 6 & $.15-.34$ & .20 \\
IIIA & 13 & $.09-.36$ & .15 \\
IIIB & 2 & $.20-.63$ & .41 \\
IIIAB & 2 & $.51-.52$ & .52 \\
IVA & 10 & $.02-.16$ & .05 \\
IVB & 2 & $.04-.10$ & .05 \\
IIC & 1 & $-0-$ & .30 \\
IID & 2 & $.61-.65$ & .63 \\
\hline
\end{tabular}


whatever they may be, produced minerals in which $P$ was associated with oxygen" (p. 346). The fact that achondrites, which are almost or entirely metal free, are relatively depleted in phosphorus, and mesosiderites, which contain large amounts of metal, are relatively enriched in this element, further supports Ahrens' concept. Fuchs (1969) noted that the phosphate minerals in the mesosiderites are closely associated with the metal phase, and suggested that they originated by reaction of phosphorus in solid solution in the metal with the silicate minerals. These observations suggest that phosphorus was taken up originally in solid solution in nickel-iron, and was redistributed during later reequilibration.

\section{SULFUR}

Sulfur is ubiquitous in meteorites, most of it occurring as troilite $(\mathrm{FeS})$, although a considerable variety of sulfide minerals is known from them. In $\mathrm{C} 1$ and $\mathrm{C} 2$ carbonaceous chondrites this element is mainly present as free sulfur and inorganic sulfates, with small amounts of organic sulfur compounds; in C3 carbonaceous chondrites pentlandite, $(\mathrm{Ni}, \mathrm{Fe})_{9} \mathrm{~S}_{8}$, is an important sulfide phase. Troilite is the principal sulfide in the enstatite chondrites and enstatite achondrites, but these meteorites may contain a variety of unusual sulfides, such as oldhamite, $\mathrm{CaS}$; niningerite, $(\mathrm{Mg}, \mathrm{Fe}) \mathrm{S}$; alabandite, $(\mathrm{Mn}, \mathrm{Fe}) \mathrm{S}$; daubreelite, $\mathrm{FeCr}_{2} \mathrm{~S}_{4}$; sphalerite, $(\mathrm{Zn}, \mathrm{Fe}) \mathrm{S}$; djerfisherite, $\mathrm{K}_{3} \mathrm{CuFe}_{12} \mathrm{~S}_{14}$, and heideite, $(\mathrm{Fe}, \mathrm{Cr})_{1+x}$ $(\mathrm{Ti}, \mathrm{Fe})_{2} \mathrm{~S}_{4}$.

The data in table 27 show marked depletion of sulfur in the sequence C1-C2-C3-ordinary chondrites; a similar depletion is evident in the sequence E4-E5-E6 chondrites. For the ordinary chondrites the range in values for individual analyses

TABLE 27.-Sulfur in stony meteorites

[From C. B. Moore in Mason, 1971; and additional data]

$\begin{array}{ccc}\text { Number } & \text { Range } \\ \text { analyzed }\end{array} \quad \begin{gathered}\text { Mean } \\ \text { (weight percent) }\end{gathered}$ Atoms/10 ${ }^{6} \mathrm{Si}$

Chondrites

\begin{tabular}{lrrrr}
\hline C1 & 5 & $5.01-6.70$ & 5.90 & 502,000 \\
C2 & 9 & $2.80-5.44$ & 3.42 & 229,000 \\
C3 & 9 & $1.31-2.66$ & 2.19 & 124,000 \\
H & 87 & $1.30-2.64$ & 2.00 & 102,000 \\
L & 110 & $1.73-2.74$ & 2.22 & 104,000 \\
LL & 32 & $1.08-5.47$ & 2.34 & 109,000 \\
E4 & 3 & $5.65-6.12$ & 5.85 & 301,000 \\
E5 & 2 & $5.50-5.82$ & 5.66 & 283,000 \\
E6 & 6 & $2.62-4.44$ & 3.32 & 149,000 \\
\hline
\end{tabular}

Calcium-poor achondrites

\begin{tabular}{rlrrr}
\hline Ae & 3 & $.14-.70$ & .45 & 14,000 \\
$\mathrm{Ah}$ & 5 & $.13-.63$ & .38 & 13,000 \\
$\mathrm{Au}$ & 4 & $.19-.63$ & .50 & 23,000 \\
\hline & \multicolumn{1}{c}{ Calcium-rich } & & \\
\hline $\mathrm{Aa}$ & 1 & .46 & -.34 & 20,000 \\
$\mathrm{Aho}$ & 6 & $.25-.40$ & .34 & 13,000 \\
$\mathrm{Aeu}$ & 5 & $.02-.26$ & .13 & 4,900 \\
\hline
\end{tabular}


may be largely due to analytical error and inadequate sampling; however, the mean values are probably good approximations, although inadequate to tell whether the small difference between $\mathrm{H}$ and $\mathrm{L}, \mathrm{LL}$ means is significant.

Achondrites contain considerably less sulfur than the chondrites. The figures for sulfur in pallasites and mesosiderites range widely, because of both heterogeneous distribution of sulfide minerals and sampling problems; no attempt has been made to derive means for these meteorites.

Moore, Lewis, and Nava (1969) determined sulfur in 93 different iron meteorites (the samples selected to avoid visible inclusions of troilite) and found a range of 0.001-0.50 percent. Most figures are between 0.001 and 0.01 percent, and the median is 0.004 percent. This is a measure of the solubility of sulfur in the metal phase. The sulfur content in iron meteorites is best determined by planimetric analysis of large slices; determinations by Buchwald (1975) on 64 irons gave sulfur contents ranging from 0.02 to 5.0 percent, with two exceptionally S-rich meteorites, Mundrabilla (8 percent) and Soroti (12 percent).

The isotopic composition of sulfur in meteoritic troilite is remarkably uniform, the $\mathrm{S}^{32} / \mathrm{S}^{34}$ ratio being 22.22. Kaplan and Hulston (1966) studied the isotopic composition of sulfur in compounds from carbonaceous chondrites and found a variation from +2.5 to -5.5 parts per thousand for the $\delta \mathrm{S}^{34}$ content with respect to troilite.

\section{CHLORINE (17)}

The chlorine content of stony meteorites (table 28) has been studied by a number of investigators, and the results have been collated and discussed by G. W.

TABLE 28.-Chlorine in stony meteorites

[From G. W. Reed, in Mason, 1971]

\begin{tabular}{|c|c|c|c|c|}
\hline Class & $\begin{array}{c}\text { Number } \\
\text { analyzed }\end{array}$ & $\begin{array}{c}\text { Range } \\
\text { (ppm) }\end{array}$ & $\begin{array}{l}\text { Mean } \\
(\mathrm{ppm})\end{array}$ & Atoms $/ 10^{6} \mathrm{Si}$ \\
\hline \multicolumn{5}{|c|}{ Chondrites } \\
\hline $\mathrm{Cl}$ & 2 & $720-840$ & 773 & 5,700 \\
\hline $\mathrm{C} 2$ & 2 & $190-510$ & 335 & 2,050 \\
\hline C3 & 2 & $260-288$ & 273 & 1,350 \\
\hline $\mathrm{H}$ & 24 & $7-210$ & 80 & 370 \\
\hline $\mathrm{L}$ & 8 & $27-212$ & 76 & 320 \\
\hline LL & 2 & $121-131$ & 126 & 530 \\
\hline E4 & 2 & $570-750$ & 660 & 3,150 \\
\hline E5 & 1 & 210 & -- & 960 \\
\hline E6 & 3 & $160-250$ & 210 & 860 \\
\hline \multicolumn{5}{|c|}{ Calcium-poor achondrites } \\
\hline $\mathrm{Ae}$ & 1 & 3.8 & -- & 12 \\
\hline Ah & 1 & 13 & -- & 41 \\
\hline $\mathrm{Au}$ & 1 & 35 & $-\infty$ & 150 \\
\hline \multicolumn{5}{|c|}{ Calcium-rich achondrites } \\
\hline Aho & 1 & 14.9 & - & 51 \\
\hline Aeu & 3 & $8-34 \cdot 5$ & 20 & 69 \\
\hline
\end{tabular}


Reed, in Mason (1971). The results are rather sparse, sometimes conflicting, and difficult to interpret. Great variations are found in different samples of the same meteorite; for example, six samples of the Bruderheim chondrite measured by Goles, Greenland, and Jérome (1967) gave figures from $66 \mathrm{ppm}$ to $130 \mathrm{ppm}$, and six samples of the same meteorite measured by Reed and Allen (1966) gave figures from $2.5 \mathrm{ppm}$ to $50.0 \mathrm{ppm}$. The widely varying results suggest an inhomogeneous distribution of chlorine within the meteorites. Reed and Allen found that considerable amounts of the chlorine in enstatite and carbonaceous chondrites were leachable in hot water, whereas little was leachable from the ordinary chondrites. Clorapatite is an accessory min- eral in the ordinary chondrites, and the amount of $\mathrm{P}_{2} \mathrm{O}_{5}$ shown by analyses is more than sufficient to bind all chlorine as this mineral. Lawrencite, (Fe,Ni) $\mathrm{Cl}_{2}$, may account for some of the chlorine; although its validity as a meteorite mineral has been questioned, most recently by Buchwald (1975), its presence is suggested by the rapid rusting of grains of nickel-iron in some freshly fallen chondrites. Keil (1968) has presented evidence, including microprobe data, for the occurrence of lawrencite as a primary mineral in enstatite chondrites. Lawrencite would account for the small amounts of water-soluble chloride found by Reed and Allen in the ordinary chondrites, and possibly for the larger amounts in carbonaceous and enstatite chondrites. Fuchs (1966)

TABLE 29.-Potassium in stony meteorites

[From Edwards, 1955 ; Kirsten and others, 1963 ; and additional data]

\begin{tabular}{|c|c|c|c|c|}
\hline Class & $\begin{array}{c}\text { Number } \\
\text { analyzed }\end{array}$ & $\begin{array}{l}\text { Range } \\
\text { (ppm) }\end{array}$ & $\begin{array}{l}\text { Mean } \\
\text { (ppm) }\end{array}$ & Atoms $/ 10^{6} \mathrm{Si}$ \\
\hline \multicolumn{5}{|c|}{ Chondrites } \\
\hline $\mathrm{Cl}$ & 3 & $380-570$ & 500 & 3,500 \\
\hline $\mathrm{C} 2$ & 10 & $270-490$ & 370 & 2,000 \\
\hline C3 & 5 & $250-420$ & 370 & 1,700 \\
\hline $\mathrm{H}$ & 17 & $710-920$ & 800 & 3,400 \\
\hline $\mathrm{L}$ & 28 & $720-998$ & 870 & 3,300 \\
\hline LL & 5 & $855-950$ & 910 & 3,500 \\
\hline E4 & 2 & $822-905$ & 860 & 3,700 \\
\hline E5 & 1 & 757 & --- & 3,200 \\
\hline E6 & 5 & $670-874$ & 730 & 2,700 \\
\hline \multicolumn{5}{|c|}{ Calcium-poor achondrites } \\
\hline $\mathrm{Ae}$ & 5 & $70-550$ & 330 & 860 \\
\hline Ah & 5 & $3-80$ & 29 & 85 \\
\hline Ac & 1 & 270 & -- & 1,100 \\
\hline $\mathrm{Au}$ & 2 & $60-97$ & 80 & 300 \\
\hline \multicolumn{5}{|c|}{ Calcium-rich achondrites } \\
\hline$\overline{\mathrm{Aa}}$ & 1 & 12.9 & -- & 45 \\
\hline An & 1 & 810 & -- & 2,600 \\
\hline Aho & 7 & $165-470$ & 290 & 910 \\
\hline Aeu & 9 & $236-600$ & 400 & 1,250 \\
\hline
\end{tabular}


described djerfisherite, a potassium copper iron sulfide, as an accessory mineral in some enstatite chondrites; the microprobe analyses show 1 percent $\mathrm{Cl}$, which Fuchs believed may be in the structure. Sodalite, $\mathrm{Na}_{4} \mathrm{Al}_{3} \mathrm{Si}_{3} \mathrm{O}_{12} \mathrm{Cl}$, has been recorded as an accessory mineral in the Allende (C3) chondrite. Some of the chlorine in carbonaceous chondrites may be present in organic compounds; Mueller (1953) recorded 4.8 percent $\mathrm{Cl}$ in the organic material extracted by solvents from Cold Bokkeveld.

Berkey and Fisher (1967) studied the abundance and distribution of chlorine in irons. Chlorine content of finds is usually profoundly influenced by terrestrial weathering. In falls, they obtained figures from $<0.1$ to $20 \mathrm{ppm}$; the chlorine is inhomogeneously distributed in the metal phase, being strongly depleted in kamacite and being concentrated at grain boundaries and around inclusions. Mason and Graham (1970) measured chlorine in the metal phases of the Modoc and St. Severin chondrites, obtaining $74 \mathrm{ppm}$ and $52 \mathrm{ppm}$ respectively; they suggested that this was due to occluded lawrencite.

\section{POTASSIUM}

Potassium is present in trace to minor amounts in meteorites, the concentration seldom exceeding 0.1 percent. On this account many of the older gravimetric analyses for this element are unreliable. The data in table 29 are mostly taken from the analyses of Edwards (1955), who used flame-spectrophotometry, and Kirsten, Krankowsky, and Zähringer (1963), who used isotope dilution. The common chondrites show slightly increasing $K$ contents in the sequence $\mathrm{H}-\mathrm{L}-\mathrm{LL}$, but in terms of atoms $/ 10^{6} \mathrm{Si}$ the abundances are not significantly different, and are equal to that in $\mathrm{C} 1$ chondrites. Carbonaceous chondrites show a marked diminution in $\mathrm{K}$ content in the sequence $\mathrm{C} 1-\mathrm{C} 2-\mathrm{C} 3$, as do the enstatite chondrites to a lesser degree in the sequence E4-E5-E6. The achondrites are depleted in potassium relative to the chondrites, especially the feldspar-free diogenites and angrite. The data in table 29 omit some anomalous figures for LL meteorites ; Kirsten, Krankowsky, and Zähringer (1963) recorded 199 ppm in Ensisheim, and Zähringer (1968) found a dark inclusion in Krähenberg with 1.2 percent $K$.

In most chondrites (and other stony meteorites), the potassium is contained in plagioclase feldspar. The potassium-iron silicate merrihueite was discovered in the Mezö-Madaras (L3) chondrite, and the potassium-magnesium silicate roedderite and the complex potassium-bearing sulfide djerfisherite are rare accessories in some enstatite chondrites.
Small amounts of potassium feldspar have been recorded in silicate inclusions in iron meteorites.

\section{CALCIUM}

Calcium is a minor element in most classes of stony and stony-iron meteorites, being present at about the 1 percent level; exceptions are the calciumrich achondrites and mesosiderites, which contain considerably greater amounts, and the pallasites, in which this element is present in trace amounts only. Calcium is determined in all complete analyses of these meteorites, so the data on this element in the literature are very extensive; however, the quality is not good, as has been demonstrated by Von Michaelis, Ahrens, and Willis (1969). Classical wetchemical analysis for calcium at the 1 percent level, especially in the presence of much magnesium (as in meteorites), may produce poor results unless great care is taken. An extensive series of X-ray fluoresence analyses by Nichiporuk and others (1967) and Von Michaelis, Ahrens, and Willis has shown very uniform calcium concentrations within the specific chondrite classes; their results are extremely consistent, and those of Von Michaelis, Ahrens, and Willis are used in table 30, except for the carbonaceous chondrites and the amphoterites (LL), for which a broader cover of reliable analyses is obtainable from the literature.

The $\mathrm{Ca} / \mathrm{Si}$ ratios are remarkably uniform and distinctive for the three major groups of chondrites, as follows: carbonaceous, 0.073 ; ordinary (hypersthene, bronzite, amphoterite), 0.048; enstatite, 0.036 . For the classes within these major groups the differences in this ratio are small and probably not significant. In the C3 chondrites the enrichment in calcium is manifested by the presence of calcium. rich minerals such as anorthite and melilite, not found in other classes of chondrites.

The calcium-poor achondrites, as their name implies, are notably depleted in calcium in relation to the chondrites, whereas the calcium-rich achondrites show a notable enrichment; the individual calcium values for many meteorites in these groups are illustrated in figure 3. The two meteorites richest in calcium are the angrite Angra dos Reis and the nakhlite Nakhla; in both of these the calcium is present as a calcium-rich pyroxene. In the other meteorites of these groups most of the calcium is present as calcic plagioclase. In the stony-irons, the pallasites contain only traces of calcium, in solid solution in olivine; the mesosiderite silicates resemble those of the howardites, and have comparable calcium contents. 
Calcium is usually considered to be entirely lithophilic in character; however, in the extremely reduced and sulfide-rich enstatite chondrites and enstatite achondrites, some of the calcium is present as the sulfide oldhamite. In the common chrondites the calcium is distributed over a number of minerals-as the calcium phosphates chlorapatite and (or) merrillite, as the pyroxene diopside, and in solid solution in orthopyroxene and sodic plagioclase. As mentioned above, the C3 chondrites are characterized by the presence of some calcium-rich minerals; the distribution of calcium in the $\mathrm{C} 1$ and C2 chondrites is not well known, but gypsum, calcite, and dolomite have been recorded from some meteorites in these classes.

\section{SCANDIUM}

Scandium is a dispersed trace element in stony meteorites. A very extensive set of data has been provided by Schmitt and others (1972), who analyzed 180 stony meteorites by instrumental neutronactivation analysis; their results are summarized in table 31. The total range of variability over all chondrite classes is small, and the atomic abundances (effectively, Sc/Si ratios) are indistinguishable from one another on a rigorous statistical basis. Abundances in the calcium-poor achondrites are comparable with those in the chondrites; the calciumrich achondrites are notably enriched in this element relative to the chondrites.

TABLE 30.-Calcium in stony meteorites

[From Von Michaelis and others, 1969 ; and additional data]

\begin{tabular}{|c|c|c|c|c|}
\hline Class & $\begin{array}{l}\text { Number } \\
\text { ana1yzed }\end{array}$ & $\begin{array}{c}\text { Range } \\
\text { (weight percent) }\end{array}$ & $\begin{array}{l}\text { Mean } \\
\text { (weight percent) }\end{array}$ & Atoms $/ 10^{6} \mathrm{Si}$ \\
\hline \multicolumn{5}{|c|}{ Chondrites } \\
\hline $\begin{array}{l}\mathrm{C} 1 \\
\mathrm{C} 2 \\
\mathrm{C} 3 \\
\mathrm{H} \\
\mathrm{L} \\
\mathrm{LL} \\
\mathrm{E} 4 \\
\mathrm{E} 6\end{array}$ & $\begin{array}{r}3 \\
9 \\
6 \\
12 \\
19 \\
9 \\
2 \\
5\end{array}$ & $\begin{array}{c}0.87-1.34 \\
1.11-1.63 \\
1.40-1.87 \\
1.15-1.22 \\
1.22-1.35 \\
1.07-1.43 \\
.81-.87 \\
.94-1.24\end{array}$ & $\begin{array}{l}1.06 \\
1.34 \\
1.70 \\
1.19 \\
1.28 \\
1.25 \\
.84 \\
1.07\end{array}$ & $\begin{array}{l}72,100 \\
71,900 \\
74,300 \\
49,800 \\
48,400 \\
46,400 \\
35,700 \\
38,600\end{array}$ \\
\hline \multicolumn{5}{|c|}{ Calcium-poor achondrites } \\
\hline $\begin{array}{l}\mathrm{Ae} \\
\mathrm{Ah} \\
\mathrm{Ac} \\
\mathrm{Au}\end{array}$ & $\begin{array}{l}4 \\
5 \\
1 \\
3\end{array}$ & $\begin{array}{c}.47-1.16 \\
.52-1.27 \\
.54 \\
.31-0.97\end{array}$ & $\begin{array}{l}.80 \\
.79 \\
-.62\end{array}$ & $\begin{array}{l}21,000 \\
22,000 \\
22,000 \\
23,000\end{array}$ \\
\hline \multicolumn{5}{|c|}{ Calcium-rich achondrites } \\
\hline $\begin{array}{l}\text { Aa } \\
\text { An } \\
\text { Aho } \\
\text { Aeu }\end{array}$ & $\begin{array}{r}1 \\
1 \\
5 \\
11\end{array}$ & $\begin{array}{c}17.52 \\
10.78 \\
2.94-5.76 \\
6.49-7.63\end{array}$ & $\begin{array}{l}--- \\
--- \\
4.16 \\
7.23\end{array}$ & $\begin{array}{l}598,000 \\
336,000 \\
124,000 \\
222,000\end{array}$ \\
\hline
\end{tabular}


In terrestrial rocks, scandium is enriched in pyroxene, and this appears to be true of meteorites also. The calcic pyroxenes of the calcium-rich achondrites evidently contain more scandium than the orthopyroxenes of the calcium-poor achondrites. The highest content in any meteorites is in Angra dos Reis, which consists almost entirely of a titanian fassaite. Most of the scandium in chondrites is evidently present in the pyroxenes; Allen and Mason (1973) recorded $96 \mathrm{ppm} \mathrm{Sc}$ in diopside and 12.1 $\mathrm{ppm}$ in orthopyroxene from the Modoc chondrite, and relatively little in the other minerals.

\section{TITANIUM}

Titanium is a minor element in stony and stonyiron meteorites, usually in the range of $500-5,000$ ppm by weight. It is normally determined by standard colorimetric methods in complete analyses of these meteorites, but was frequently omitted in older analyses. Moore and Brown (1962), by spectrographical analysis of a large number of chondrites, found a rather constant titanium content. For 19 bronzite chondrite falls, the mean was 620 ppm $\mathrm{Ti}$, equivalent to 0.103 percent $\mathrm{TiO}_{2}$; for 23 hypersthene chondrite falls, the mean was $660 \mathrm{ppm}$ $\mathrm{Ti}$, equivalent to 0.110 percent $\mathrm{TiO}_{2}$. These figures are in agreement with recent wet-chemical analyses of ordinary chondrites.

The data on titanium classes of stony meteorites are summarized in table 32 . These determinations have been made by standard wet-chemical procedures (usually colorimetric), except for the figures

TABLE 31.-Scandium in stony meteorites

[From Schmitt and others, 1972]

\begin{tabular}{|c|c|c|c|c|}
\hline Class & $\begin{array}{c}\text { Number } \\
\text { analyzed }\end{array}$ & $\begin{array}{l}\text { Range } \\
\text { (ppm) }\end{array}$ & $\begin{array}{l}\text { Mean } \\
(\mathrm{ppm})\end{array}$ & Atoms $/ 10^{6} \mathrm{Si}$ \\
\hline \multicolumn{5}{|c|}{ Chondrites } \\
\hline $\begin{array}{l}\text { C1 } \\
\text { C2 } \\
\text { C3 } \\
\text { H } \\
\text { L } \\
\text { LL } \\
\text { E4 } \\
\text { E5, } 6\end{array}$ & $\begin{array}{r}3 \\
7 \\
9 \\
46 \\
50 \\
21 \\
2 \\
4\end{array}$ & $\begin{array}{l}4.8-8 \cdot 1 \\
6.0-10.6 \\
5.8-14 \cdot 0 \\
5.0-11.6 \\
5.4-12 \cdot 1 \\
5 \cdot 9-11.6 \\
6.2-7.5 \\
5 \cdot 5-10.8\end{array}$ & $\begin{array}{l}5.1 \\
7.4 \\
9.1 \\
7.6 \\
8.2 \\
7.8 \\
6.7 \\
7.6\end{array}$ & $\begin{array}{l}31 \\
35 \\
36 \\
28 \\
28 \\
26 \\
25 \\
24\end{array}$ \\
\hline \multicolumn{5}{|c|}{ Calcium-poor achondrites } \\
\hline $\begin{array}{l}\mathrm{Ae} \\
\mathrm{Ah} \\
\mathrm{Ac} \\
\mathrm{Au}\end{array}$ & $\begin{array}{l}5 \\
2 \\
1 \\
2\end{array}$ & $\begin{array}{c}5.0-8.5 \\
9.8-14 \\
5.6 \\
6.8-8.8\end{array}$ & $\begin{array}{r}6.4 \\
11.9 \\
--- \\
7.9\end{array}$ & $\begin{array}{l}16 \\
30 \\
20 \\
26\end{array}$ \\
\hline \multicolumn{5}{|c|}{ Calcium-rich achondrites } \\
\hline $\begin{array}{l}\mathrm{Aa} \\
\mathrm{An} \\
\mathrm{Aho} \\
\mathrm{Aeu}\end{array}$ & $\begin{array}{r}1 \\
2 \\
8 \\
20\end{array}$ & $\begin{array}{c}57 \\
47-53 \\
15-26 \\
14-41\end{array}$ & $\begin{array}{r}-- \\
49 \\
20 \\
29\end{array}$ & $\begin{array}{r}170 \\
140 \\
53 \\
79\end{array}$ \\
\hline
\end{tabular}


for the bronzite and hypersthene chondrites, which are spectrographic. This table shows a fairly uniform level of titanium in the chondrites at 2,0003,000 atoms $/ 10^{6} \mathrm{Si}$, although the data suggest a moderate degree of enrichment in the C3 chondrites. Titanium contents are somewhat lower in the calcium-poor achondrites than in the chondrites, except for the enstatite achondrites, which show a marked depletion; in the latter meteorites, the titanium resides almost entirely in the troilite, which is small in amount and irregularly distributed. The calcium-rich achondrites show a marked enrichment in titanium, both absolutely and relative to silicon. The unique meteorite Angra dos Reis shows extreme enrichment; this meteorite consists almost entirely of a calcium-rich aluminous pyroxene, in which ti- tanium is present in atomic substitution, probably as the component $\mathrm{CaTiAl}_{2} \mathrm{O}_{6}$. Among the stonyirons, the pallasites are notably deficient in titanium, because this element does not readily enter olivine, the silicate mineral; the mesosiderites contain silicates similar to the howardites, and the titanum content is comparable in these two classes.

In most meteorites, titanium is mainly lithophile, but it also has moderate chalcophile affinity; in enstatite chrondites and enstatite achondrites, however, it is almost completely chalcophile. Titanium is considered to have little or no siderophile tendency, and is seldom looked for in analyses of meteoritic iron; A.A. Moss (oral commun., 1965) reported it to be below the limit of detection $(<5 \mathrm{ppm})$ in several irons.

TABLE 32.-Titanium in stony meteorites

[From Mason, 1971; and additional data]

\begin{tabular}{|c|c|c|c|c|}
\hline Class & $\begin{array}{c}\text { Number } \\
\text { analyzed }\end{array}$ & $\begin{array}{c}\text { Range } \\
\text { (ppm) }\end{array}$ & $\begin{array}{l}\text { Mean } \\
(\mathrm{ppm})\end{array}$ & Atoms $/ 10^{6} \mathrm{Si}$ \\
\hline \multicolumn{5}{|c|}{ Chondrites } \\
\hline $\mathrm{Cl}$ & 3 & $400-450$ & 430 & 2,400 \\
\hline $\mathrm{C} 2$ & 9 & $480-700$ & 540 & 2,900 \\
\hline C3 & 6 & $600-1,400$ & 870 & 3,600 \\
\hline $\mathrm{H}$ & 19 & $510-780$ & 620 & 2,100 \\
\hline $\mathrm{L}$ & 23 & $460-810$ & 660 & 2,100 \\
\hline LL & 11 & $540-1,300$ & 840 & 2,600 \\
\hline E4 & 3 & $400-800$ & 570 & 2,000 \\
\hline $\mathrm{E} 5,6$ & 7 & $300-900$ & 620 & 1,900 \\
\hline \multicolumn{5}{|c|}{ Calcium-poor achondrites } \\
\hline $\mathrm{Ae}$ & 4 & $160-480$ & 340 & 750 \\
\hline $\mathrm{Ah}$ & 5 & $340-720$ & 460 & 1,100 \\
\hline $\mathrm{Ac}$ & 1 & 400 & -- & 1,350 \\
\hline $\mathrm{Au}$ & 3 & $720-1,100$ & 880 & 2,700 \\
\hline \multicolumn{5}{|c|}{ Calcium-rich achondrites } \\
\hline $\mathrm{Aa}$ & $\overline{1}$ & 14,300 & -- & 41,000 \\
\hline An & 1 & 1,700 & -- & 4,400 \\
\hline Aho & 5 & $1,400-2,930$ & 1,990 & 4,900 \\
\hline Aeu & 11 & $1,000-5,880$ & 3,820 & 9,800 \\
\hline
\end{tabular}


Titanium may be present in several phases in a single meteorite. The only meteoritic minerals in which this element is an essential constituent are ilmenite $\left(\mathrm{FeTiO}_{3}\right)$, rutile $\left(\mathrm{TiO}_{2}\right)$, perovskite $\left(\mathrm{CaTiO}_{3}\right)$, rhönite $\left(\mathrm{CaMg}_{2} \mathrm{TiAl}_{2} \mathrm{SiO}_{10}\right)$, osbornite $(\mathrm{TiN})$, and heideite $\left.\left.\left[(\mathrm{Fe}, \mathrm{Cr})_{1+x}\right) \mathrm{Ti}, \mathrm{Fe}\right)_{2} \mathrm{~S}_{4}\right]$ Ilmenite is not uncommon as an accessory mineral; Ramdohr (1963, p. 2028) reported, "It was observed in more than 50 percent of all the stony meteorites examined. It appears to be absent in some of the strongly reduced chondrites and in carbonaceous chondrites. Usually it occurs in very small quantities, only a few grains being found in sections of normal size." Th ecomposition of meteoritic ilmenite is reported by Snetsinger and Keil (1969). Rutile is a rare accessory mineral (in some meteorites as exsolution lamellae in ilmenite and chromite), in a few chondrites and some mesosiderites (Buseck and Keil, 1966). Osbornite was described many years ago from the Bustee enstatite achondrite, and may occur in other enstatite achondrites and enstatite chondrites in trace amounts. Perovskite and rhönite occur as accessory minerals in calcium-rich inclusions in C3 chondrites, along with pyroxene containing up to 17.7 percent $\mathrm{TiO}_{2}$ (Mason, 1974). However, most of the titanium in meteorites is dispersed in the more abundant minerals in substitution for the major elements. Olivine contains little titanium, probably in the $10-100 \mathrm{ppm}$ range. Orthopyroxene contains about $1,000 \mathrm{ppm}$ (except for enstatite from

TABLE 33.-Vanadium in stony meteorites

[From Walter Nichiporuk in Mason, 1971; and additional data from Baedecker and Wasson, 1975, and Jérome, 1970]

\begin{tabular}{|c|c|c|c|c|}
\hline Class & $\begin{array}{c}\text { Number } \\
\text { analyzed }\end{array}$ & $\begin{array}{l}\text { Range } \\
\text { (ppm) }\end{array}$ & $\begin{array}{l}\text { Mean } \\
(\mathrm{ppm})\end{array}$ & Atoms $/ 10^{6} \mathrm{Si}$ \\
\hline \multicolumn{5}{|c|}{ Chondrites } \\
\hline $\mathrm{Cl}$ & 1 & $41-57$ & 49 & 254 \\
\hline $\mathrm{C} 2$ & 2 & $56-71$ & 64 & 270 \\
\hline C3 & 6 & $50-117$ & 88 & 312 \\
\hline $\mathrm{H}$ & 32 & 44-88 & 61 & 196 \\
\hline $\mathrm{L}$ & 49 & $45-94$ & 65 & 193 \\
\hline LL & 7 & $53-93$ & 74 & 217 \\
\hline E4 & 3 & $56-58$ & 57 & 189 \\
\hline E5 & 1 & 55 & -- & 176 \\
\hline E6 & 4 & $64-80$ & 68 & 193 \\
\hline \multicolumn{5}{|c|}{ Calcium-poor achondrites } \\
\hline $\mathrm{Ae}$ & 4 & $14-21$ & 17 & 34 \\
\hline Ah & 3 & $133-260$ & 180 & 393 \\
\hline Ac & 1 & 50 & - & 159 \\
\hline $\mathrm{Au}$ & 3 & $78-147$ & 110 & 318 \\
\hline \multicolumn{5}{|c|}{ Calcium-rich achondrites } \\
\hline $\mathrm{Aa}$ & 1 & 150 & - & 393 \\
\hline An & 2 & $169-210$ & 190 & 466 \\
\hline Aho & 7 & $105-178$ & 140 & 327 \\
\hline Aeu & 9 & $84-115$ & 95 & 230 \\
\hline
\end{tabular}


enstatite chondrites and enstatite achondrites, which contains less than $100 \mathrm{ppm}$ ), whereas the clinopyroxenes diopside and pigeonite can take up considerably larger amounts, usually up to about 5,000 ppm; the clinopyroxene from the Angra dos Reis meteorite is exceptional with $15,000 \mathrm{ppm}$. Plagioclase may contain a little titanium, but no measurements in meteoritic plagioclase have been reported; in terrestrial plagioclase, the maximum appears to be about $400 \mathrm{ppm}$. Chromite $\left(\mathrm{FeCr}_{2} \mathrm{O}_{4}\right)$ is an accessory mineral in stony meteorites, usually in the 0.1-0.5 percent range, and it contains significant amounts of titanium; in the common chondrites it contains 2-4 percent $\mathrm{TiO}_{2}$ (Snetsinger and others, 1967). In the enstatite chondrites and enstatite achondrites, almost all the titanium is present in solid solution in troilite; usually about 0.5 percent is present in enstatite chondrites (Keil, 1968), but as much as 4.1 percent was recorded in troilite from the Norton County enstatite achondrite (Keil and Fredriksson, 1963), and up to about 10 percent in this mineral from the Khor Temiki enstatite achondrite (Keil, 1969). In the common chrondites Moss and others (1967) found 192, 100, and $132 \mathrm{ppm} \mathrm{Ti}$ in troilite from three hypersthene chondrites, and $398 \mathrm{ppm}$ in troilite from a bronzite chondrite. Titanium has not been recorded from other sulfide minerals except daubreelite $\left(\mathrm{FeCr}_{2} \mathrm{~S}_{4}\right)$, in which Keil (1968) found up to $1,500 \mathrm{ppm}$.

Titanium is clearly a dispersed element in stony meteorites, but the major amount is probably contained in the pyroxenes, except in the enstatite chondrites and enstatite achondrites.

\section{VANADIUM}

Vanadium is a trace element in stony meteorites. Its distribution has been discussed by Walter Nichiporuk (in Mason, 1971), and his summary of the data is presented in table 33, supplemented by additional determinations on enstatite chondrites by Baedecker and Wasson (1975) and on achondrites by Jérome (1970). Vanadium is unusual in showing little fractionation between the different classes of chondrites, and even between chondrites and achondrites, except for the enstatite achondrites, which are considerably depleted in this element. Bunch, Keil, and Snetsinger (1967) showed that in the ordinary chondrites much of the vanadium is concentrated in the chromite, which contains an average of 4,800 ppm V; most of the remainder is probably in the pyroxenes (Mason and Graham, 1970). Meteoritic ilmenite contains little $\mathrm{V}(<100 \mathrm{ppm}$, according to Snetsinger and Keil, 1969). In the enstatite chon- drites, which contain no chromite, vanadium is probably in a sulfide phase, most likely daubreelite $\left(\mathrm{FeCr}_{2} \mathrm{~S}_{4}\right)$; Allen and Mason (1973) recorded $>0.1$ percent $V$ in sulfide in the Khairpur enstatite chondrite. The depleted nature of the enstatite achondrites may be ascribed to the small amount of sulfide in these meteorites.

Vanadium has essentially no siderophile affinity; Linn, Moore, and Schmitt (1968) analyzed five iron meteorites and found less than $0.2 \mathrm{ppm}$ in the metal phase; coexisting troilite contained vanadium in concentrations ranging from 0.62 to $44.5 \mathrm{ppm}$.

\section{CHROMIUM}

Chromium is a minor constituent in most stony meteorites and a trace constituent in irons. The analytical data are very extensive. Schmitt, Linn, and Wakita (1972) determined chromium in 120 stony meteorites by instrumental neutron-activation analysis, and their results are summarized in table 34. Bunch and Olsen (1975) provided a comprehensive discussion of the geochemistry of chromium in meteorites.

In most stony meteorites, chromium is present partly as chromite and partly in atomic substitution in pyroxenes. The conditions governing this partition are not well known. In ordinary chrondrites, Mason and Graham (1970) recorded $\sim 800$ ppm in orthopyroxene and $\sim 4,000 \mathrm{ppm}$ in clinopyroxene; however, in the Shaw chondrite Fredriksson and Mason (1967) recorded 6,000 ppm in orthopyroxene and $8,000 \mathrm{ppm}$ in clinopyroxene, and orthopyroxene in the Johnstown achondrite contains $5,600 \mathrm{ppm}$. The high $\mathrm{Cr}$ contents in the pyroxenes in Shaw and Johnstown may reflect unusually high temperatures of equilibration. Olivine in meteorites usually contains $300-500 \mathrm{ppm} \mathrm{Cr}$, and troilite about the same amount. The metal phase in chondrites contains less than $100 \mathrm{ppm}$, except in the C2 and C3 chondrites, in which as much as 1.0 percent has been recorded (Bunch and Olsen, 1975). Chromium is thus lithophile in most stony meteorites, and has little chalcophile or siderophile affinity. However, in the highly reduced enstatite chondrites and enstatite achrondites, chromium is present not as chromite but as the sulfospinel daubreelite, $\mathrm{FeCr}_{2} \mathrm{~S}_{4}$, and as heideite, $(\mathrm{Fe}, \mathrm{Cr})_{1+\alpha}(\mathrm{Ti}, \mathrm{Fe})_{2} \mathrm{~S}_{4}$.

Chromium is generally in trace concentration in the metal phase of iron meteorites. Lovering and others (1957) measured this element in 88 irons and found a range of $<1-2,360 \mathrm{ppm}$ and an average of 37 ppm; Smales, Mapper, and Fouché (1967) measured 66 irons and found a range of $<5-2,441 \mathrm{ppm}$, 
with an average of $115 \mathrm{ppm}$. The averages tend to be weighted by a few very high values: Tucson, 2,360; Nedagolla, 2,441; and Clark County, 1,565 ppm. Some of this chromium may be present as minute inclusions of daubreelite or carlsbergite (CrN). Scott (1972) plotted $\mathrm{Cr}$ versus $\mathrm{Ni}$ content for many irons, and found a negative correlation for groups IIAB, IIIAB, and IVA; groups IIC, IIC, and IVB cluster well on the $\mathrm{Cr}-\mathrm{Ni}$ plot.

\section{MANGANESE}

Manganese is a minor element in stony meteorites, and is always determined in a complete analysis. Extensive series of measurements have been made by spectrographic (Moore and Brown, 1962) and neutron-activation analysis (Schmitt and others, 1972) ; the latter data have been used in the compila- tion of table 35. Manganese shows a remarkably small degree of variation between the different classes of stony meteorites. Although of comparable abundance to chromium, it differs from this element in not occurring as specific manganese minerals, except as alabandite, $(\mathrm{Mn}, \mathrm{Fe}) \mathrm{S}$, in enstatite chondrites and enstatite achondrites; in other chondrites most of it is present in solid solution in olivine and pyroxenes, Mason and Graham (1970) recording $\sim 3,000$ ppm in olivine, $\sim 3,000 \mathrm{ppm}$ in orthopyroxene, and $\sim 2,000 \mathrm{ppm}$ in diopside. A small amount $(\sim 5,000$ $\mathrm{ppm})$ is contained in accessory chromite, and trace amounts $(\sim 200 \mathrm{ppm})$ in troilite. The chief feature of the meteorite geochemistry of manganese is the very close coherence with ferrous iron, a consequence of the similarity in ionic radius between $\mathrm{Fe}^{+2}$ and $\mathrm{Mn}^{+2}$; this coherence extends to both lunar and ter.

TABLE 34.-Chromium in stony meteorites

[From Schmitt and others, 1972]

\begin{tabular}{lcccc}
\hline Class & $\begin{array}{c}\text { Number } \\
\text { analyzed }\end{array}$ & $\begin{array}{c}\text { Range } \\
(\mathrm{ppm})\end{array}$ & $\begin{array}{c}\text { Mean } \\
(\mathrm{ppm})\end{array}$ & Atoms/106 Si
\end{tabular}

\begin{tabular}{lrrrr}
\hline \multicolumn{5}{c}{ Chondrites } \\
\hline C 1 & \multicolumn{5}{c}{} \\
C 2 & 3 & $2,010-2,720$ & 2,430 & 12,700 \\
C 3 & 7 & $2,830-3,770$ & 3,070 & 12,400 \\
H & 9 & $2,160-3,900$ & 3,530 & 12,300 \\
L & 40 & $2,240-4,410$ & 3,430 & $10,9,00$ \\
L L & 47 & $3,000-4,900$ & 3,780 & 10,900 \\
E 4 & 17 & $3,230-4,980$ & 3,690 & 10,600 \\
E5,6 & 2 & $3,050-3,240$ & 3,210 & 10,100 \\
& 5 & $2,800-4,160$ & 3,290 & 9,600
\end{tabular}

Calcium-poor achondrites

\begin{tabular}{llccc}
\hline Ae & 5 & $180-730$ & 460 & 1,000 \\
$\mathrm{Ah}$ & 4 & $5,000-16,500$ & 10,100 & 22,000 \\
$\mathrm{Ac}$ & 1 & 5,700 & -- & 17,800 \\
$\mathrm{Au}$ & 2 & $4,430-5,060$ & 4,890 & 13,800 \\
\hline
\end{tabular}

Calcium-rich achondrites

\begin{tabular}{lrrrr}
\hline Aa & 1 & 1,700 & $-\overline{-}$ & 4,500 \\
An & 2 & $1,580-1,820$ & 1,680 & 4,000 \\
Aho & 7 & $2,720-5,380$ & 4,470 & 10,200 \\
Aeu & 19 & $1,350-3,920$ & 2,280 & 5,400 \\
\hline
\end{tabular}


restrial rocks, as illustrated by Laul and Schmitt (1973).

Few data are available on manganese in the metal phases of meteorites. Bauer and Schaudy (1970) determined the contents of carefully selected metal phases in 21 iron meteorites and found a range of 9.8-22 ppm.

\section{IRON}

Iron is a major element in all classes of meteorites except the enstatite achondrites, and as a consequence the abundance data are very extensive. The standard procedures of analytical chemistry, when carefully applied, give reliable results for total iron. Von Michaelis, Ahrens, and Willis (1969) have shown that the older data on chondrites summarized by Urey and Craig (1953) show a greater spread of values than more recent analyses, indicating an improvement in overall quality in recent years. The figures in table 36 are derived as far as possible from recent analyses of observed falls.

As discussed in the introduction to this report, the individual classes of chondrites can be distinguished by their total iron content, and by the relative proportion of iron in oxidic compounds (mainly ferromagnesian silicates) and in nickel-iron and troilite (fig. 2). Urey and Craig (1953) utilized the total iron content to divide the chondrites into $\mathrm{H}$ (high-iron) and L (low-iron) groups. Bronzite chondrites are all $\mathrm{H}$, averaging 27.6 percent, whereas hypersthene chondrites are all $\mathrm{L}$, averaging 21 percent; the amphoterites are sometimes considered a

TABLE 35.-Manganese in stony meteorites

[From Schmitt and others, 1972]

\begin{tabular}{|c|c|c|c|c|}
\hline Class & $\begin{array}{c}\text { Number } \\
\text { analyzed }\end{array}$ & $\begin{array}{l}\text { Range } \\
(p p m)\end{array}$ & $\begin{array}{l}\text { Mean } \\
(\text { ppm) }\end{array}$ & Atoms $/ 10^{6} \mathrm{Si}$ \\
\hline \multicolumn{5}{|c|}{ Chondrites } \\
\hline $\mathrm{Cl}$ & 3 & $1,740-2,300$ & 1,880 & 9,300 \\
\hline $\mathrm{C} 2$ & 7 & $1,540-1,740$ & 1,630 & 6,200 \\
\hline C3 & 9 & $1,280-1,650$ & 1,490 & 4,900 \\
\hline $\mathrm{H}$ & 40 & $1,860-2,800$ & 2,260 & 6,700 \\
\hline $\mathrm{L}$ & 47 & $2,210-2,780$ & 2,460 & 6,700 \\
\hline LL & 17 & $2,330-2,830$ & 2,560 & 7,000 \\
\hline E4 & 3 & $1,800-2,500$ & 2,200 & 6,800 \\
\hline $\mathrm{E} 5,6$ & 5 & $1,480-2,540$ & 1,790 & 5,000 \\
\hline \multicolumn{5}{|c|}{ Calcium-rich achondrites } \\
\hline $\mathrm{Ae}$ & 5 & $830-2,550$ & 1,400 & 2,800 \\
\hline $\mathrm{Ah}$ & 5 & $3,570-4,390$ & 3,990 & 8,300 \\
\hline $\mathrm{Ac}$ & 1 & 4,100 & -- & 12,000 \\
\hline $\mathrm{Au}$ & 2 & $2,860-2,910$ & 2,890 & 7,700 \\
\hline \multicolumn{5}{|c|}{ Calcium-rich achondrites } \\
\hline$\overline{\mathrm{Aa}}$ & 1 & 700 & -- & 1,700 \\
\hline An & 2 & $3,520-3,860$ & 3,700 & 8,200 \\
\hline Aho & 8 & $3,460-4,000$ & 3,800 & 8,200 \\
\hline Aeu & 20 & $2,440-5,810$ & 4,000 & 9,000 \\
\hline
\end{tabular}


subclass of hypersthene chondrites, denoted LL, and averaging 20.0 percent. Carbonaceous chondrites seem to be all $\mathrm{H}$, since on a volatile-free basis they contain 25-27 percent, and their $\mathrm{Fe} / \mathrm{Si}$ ratio is similar to or somewhat greater than that for the bronzite chondrites. Enstatite chondrites show a wide range of total iron contents, and designation as $\mathrm{H}$ or $\mathrm{L}$ types is of doubtful utility.

Urey (1961) pointed out the significance of the $\mathrm{Fe} / \mathrm{Si}$ ratio in chondrites, both for the recognition of different classes and subclasses, and as an indication of chemical fractionations between different classes. The data in table 36 show small but consistent differences between the three types of carbonaceous chondrites, the $\mathrm{Fe} / \mathrm{Si}$ ratio being 0.901 for $\mathrm{C} 1,0.841$ for C2, and 0.816 for C3. The latter figure is essentially identical with that for the bronzite chondrites $(0.812)$. The lower iron content of the hypersthene chondrites and the amphoterites is reflected in the $\mathrm{Fe} / \mathrm{Si}$ ratios of 0.577 and 0.536 respectively. Enstatite chondrites show a wide range of $\mathrm{Fe} / \mathrm{Si}$ ratios, and those that are most iron-rich have ratios slightly exceeding one.

The interpretation of this range of $\mathrm{Fe} / \mathrm{Si}$ ratios in terms of iron-silicate fractionation in the chondrites has been cogently discussed by Anders (1964). He came to the following conclusions: (1) The metal-silicate fractionation in chondrites involved loss of metal from primordial matter with $\mathrm{Fe} / \mathrm{Si} \approx$ 0.8-1.0. (2) At the time of fractionation, the material had gone through a high-temperature stage and contained individual metal and silicate grains.

TABLE 36.-Iron in stony meteorites

[From Mason, 1971 ; and additional data]

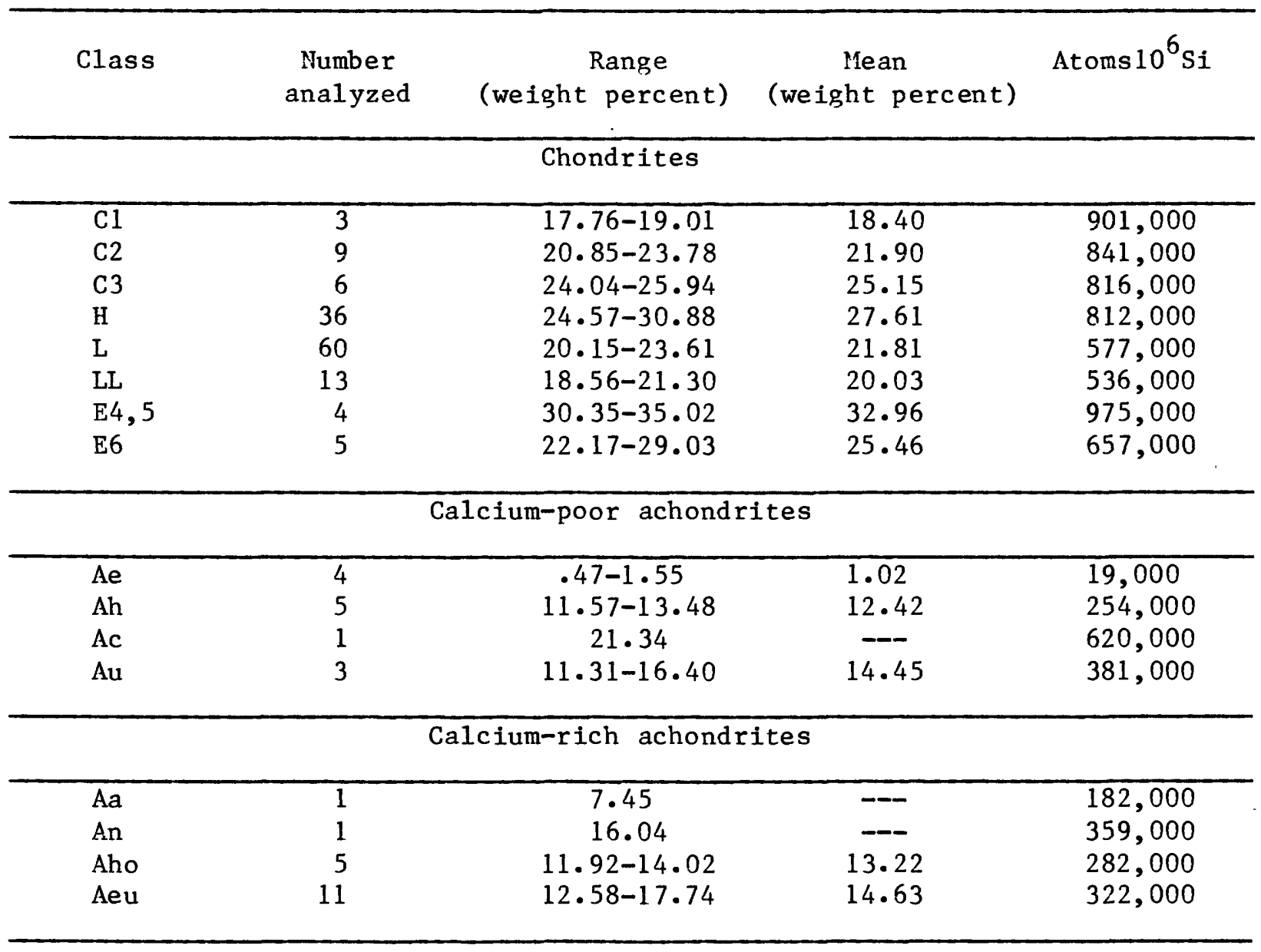


(3) The fractionation probably occurred while the material was in a dispersed state.

At the time Anders wrote, a serious objection to his postulate of primordial matter with $\mathrm{Fe} / \mathrm{Si} \approx$ 0.8-1.0 was the apparent low abundance of iron in the $\mathrm{Sun}-\mathrm{Fe} / \mathrm{Si}=0.12$, according to Goldberg, Müller, and Aller (1960). This seemed to require that primordial matter was low in iron, and that highiron chondrites must have been enriched in this element. However, this apparent impasse has been resolved by a reevaluation of the spectrographic data for the solar abundance of iron (Garz and Kock, 1969). This reevaluation has led to an increase in the figure for the solar abundance of iron by a factor of $\sim 10$ compared to that given by Goldberg, Müller, and Aller, the $\mathrm{Fe} / \mathrm{Si}$ ratio now being given as 1.0. Thus, it now appears that the highiron chondrites, specifically the $\mathrm{C} 1$ carbonaceous chondrites, are closely akin to original solar matter.

Relative to the chondrites, all the achondrites (except the unique chassignite) show marked depletion in iron and correspondingly lower $\mathrm{Fe} / \mathrm{Si}$ ratios. To a considerable extent, this is due to marked impoverishment of these meteorites in nickel-iron and troilite, which are present in very small amounts (except in the ureilites). The enstatite achondrites are extremely depleted; they consist essentially of almost iron-free enstatite $\left(\mathrm{MgSiO}_{3}\right)$.
The iron meteorites consist essentially of nickeliron, and minor to trace amounts of accessory minerals such as troilite, schreibersite, and graphite. Samples for analysis are generally selected to avoid the accessory minerals as far as possible, and the resulting data thus correspond more closely to the metal phase than to the overall composition of the meteorite. The metal phase is essentially a threecomponent system $\mathrm{Fe}-\mathrm{Ni}$-Co; the cobalt content is uniformly low, ranging from $0.3-1.0$ percent, so the iron and nickel contents are inversely related. The range of iron content in iron meteorites can thus be derived directly from a plot of nickel contents (fig. 9).

Buddhue (1946) compiled the analytical data for the different classes of iron meteorites, and calculated average compositions, after eliminating those analyses that appeared unreliable. His results are given in table 37 .

In stony and stony-iron meteorites the principal iron-bearing minerals are nickel-iron, troilite, and the ferromagnesian silicates olivine and pyroxene. Small amounts of the accessory minerals chromite $\left(\mathrm{FeCr}_{2} \mathrm{O}_{4}\right)$ and ilmenite $\left(\mathrm{FeTiO}_{3}\right)$ are usually present. The $\mathrm{C} 1$ and $\mathrm{C} 2$ carbonaceous chondrites are unique in having much of their iron present as the hydrated magnesium-iron silicate serpentine (or chlorite), and in having magnetite $\left(\mathrm{Fe}_{3} \mathrm{O}_{4}\right)$ and pentlandite $\left((\mathrm{Fe}, \mathrm{Ni}){ }_{9} \mathrm{~S}_{8}\right)$ as accessory minerals.

TABLE 37.-Mean iron content of individual classes of iron meteorites

[From Buddhue, 1946]

\begin{tabular}{ccc}
\hline Class & Number of meteorites & Weight percent \\
\hline Hx & 34 & 93.59 \\
Ogg & 18 & 92.33 \\
Og & 34 & 91.22 \\
Om & 92 & 90.67 \\
Of & 37 & 90.53 \\
Off & 10 & 86.75 \\
D & 38 & 79.63 \\
A11 irons & & 89.70 \\
\hline
\end{tabular}

1 Including metal in pallasites, mesosiderites, and chondrites; the average for the metal from these groups is very close to the overall average. 


\section{COBALT}

Cobalt is a ubiquitous element in meteorites, being present in amounts up to 1 percent in irons. Schmitt and others (1972) made extensive measurements by instrumental neutron-activation analysis in most classes of stony meteorites, and their results, along with some additional data, are reported in table 38. The concentration of cobalt shows a close correlation with the amount of metallic nickeliron in a meteorite; the distinction between $\mathrm{H}$ and $\mathrm{L}$ $(+\mathrm{LL})$ classes of chondrites is clearly seen, and the low Co contents of the achondrites is related to their low metal contents.
Lovering and others (1957) found cobalt in 88 iron meteorites to range from 0.38 to 0.92 percent with an average of 0.51 percent. Moore, Lewis, and Nava (1969) analyzed 100 irons and found a range of $0.32-1.02$ percent. The relationship between cobalt and nickel content of iron meteorites is illustrated in figure 8. In the two metal phases of meteorites, cobalt is concentrated in kamacite, which usually contains two to five times as much Co as the associated taenite.

Cobalt is a strongly siderophile element in meteorites, generally with little or no chalcophile or lithophile affinity. For example, in the Sikhote-Alin iron

TABLE 38.-Cobalt in stony meteorites

[From Schmitt and others, 1972 ; and additional data from Laul and others, 1972; Case and others, 1973; Binz, Kurimoto, and Lipschutz, 1974; Binz and others, 1975, 1976; and Baedecker and Wasson, 1975]

\begin{tabular}{|c|c|c|c|c|}
\hline C1as s & $\begin{array}{c}\text { Number } \\
\text { analyzed }\end{array}$ & $\begin{array}{l}\text { Range } \\
(\mathrm{ppm})\end{array}$ & $\begin{array}{l}\text { Mean } \\
(p p m)\end{array}$ & Atoms $/ 10^{6} \mathrm{si}$ \\
\hline \multicolumn{5}{|c|}{ Chondrites } \\
\hline $\begin{array}{l}\text { C } 1 \\
\text { C } 2 \\
\text { C } 3 \\
\text { H } \\
\text { L } \\
\text { L L } \\
\text { E } 4 \\
\text { E } 5,6\end{array}$ & $\begin{array}{r}3 \\
7 \\
9 \\
46 \\
50 \\
21 \\
2 \\
4\end{array}$ & $\begin{array}{r}460-550 \\
460-700 \\
480-740 \\
440-1,260 \\
290-870 \\
250-870 \\
810-870 \\
680-1,000\end{array}$ & $\begin{array}{l}480 \\
530 \\
620 \\
820 \\
570 \\
460 \\
860 \\
820\end{array}$ & $\begin{array}{l}2,2000 \\
1,900 \\
1,900 \\
2,300 \\
1,450 \\
1,2000 \\
2,400 \\
2,100\end{array}$ \\
\hline \multicolumn{5}{|c|}{ Calcium-poor achondrites } \\
\hline $\begin{array}{l}\mathrm{Ae} \\
\mathrm{Ah} \\
\mathrm{Ac} \\
\mathrm{Au}\end{array}$ & $\begin{array}{l}5 \\
2 \\
1 \\
6\end{array}$ & $\begin{array}{c}2.1-57 \\
18-19 \\
141 \\
65-172\end{array}$ & $\begin{array}{r}14 \\
19 \\
-112\end{array}$ & $\begin{array}{r}26 \\
37 \\
390 \\
280\end{array}$ \\
\hline \multicolumn{5}{|c|}{ Calcium-rich achondrites } \\
\hline $\begin{array}{l}\text { Aa } \\
\text { An } \\
\text { Aho } \\
\text { Aeu }\end{array}$ & $\begin{array}{r}1 \\
2 \\
8 \\
20\end{array}$ & $\begin{array}{r}20.4 \\
43-47 \\
10-34 \\
2-22\end{array}$ & $\begin{array}{r}--\overline{45} \\
20 \\
7\end{array}$ & $\begin{array}{l}47 \\
90 \\
43 \\
14\end{array}$ \\
\hline
\end{tabular}


Yavnel (1950) found 0.47 percent in the kamacite, 0.03 percent in the schreibersite, 0.01 percent in the troilite, and 0.01 percent in the chromite. Mason and Graham (1970) have shown that in stony meteorites the metal phase contains up to 1 percent $\mathrm{Co}$, whereas the silicates (olivine, pyroxene, plagioclase) contain 1-50 ppm and the troilite 40-60 ppm. The C1 and C2 carbonaceous chondrites contain little or no free metal, and the state of combination of the cobalt is not known; in the C3 chondrites, Fuchs and Olsen (1973) have found up to 6.9 percent in kamacite, up to 2.0 percent in taenite, 0.8 percent in pentlandite, brt less than 0.05 percent in troilite.

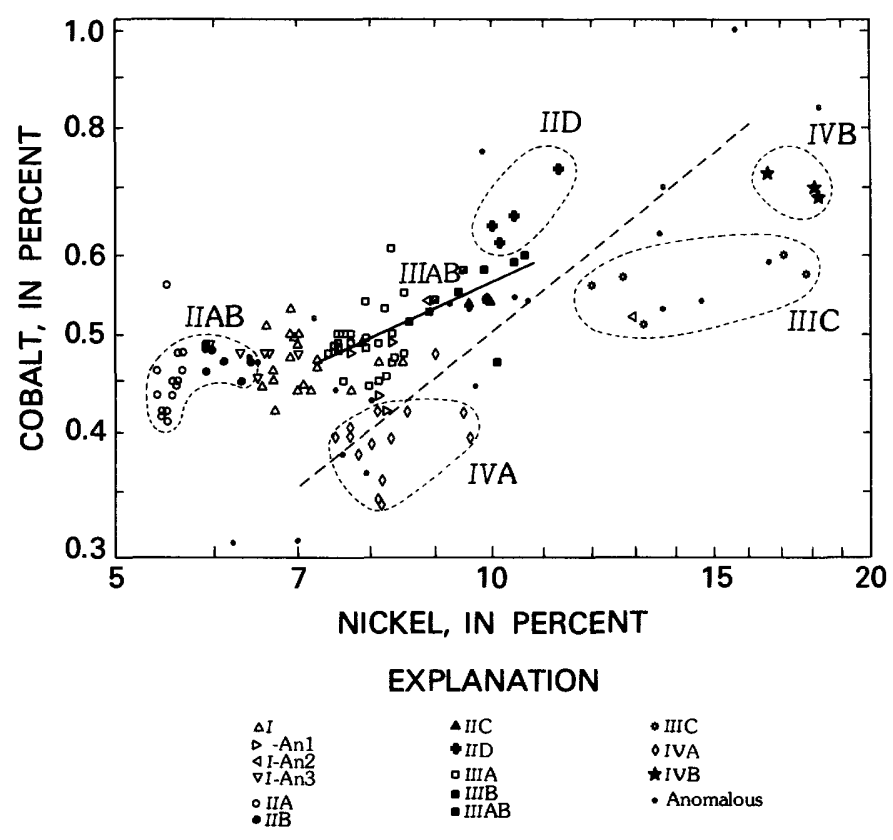

FIgURE 8.-Co-Ni distribution in iron meteorites. Most chemical groups are well resolved (as indicated by shortdashed outlines), but they are scattered on either side of the $\mathrm{Co} / \mathrm{Ni}$ ratio for $\mathrm{C} 1$ chondrites (dashed line). In group IIIAB, Co content correlates positively with $\mathrm{Ni}$ content. Reprinted from Scott (1972) and published with permission.

\section{NICKEL}

The extensive data on nickel in meteorites were comprehensively reviewed by C.B. Moore, in Mason (1971); the data for stony meteorites are summarized in table 39. Nickel in chondrites shows a fairly constant relationship to total iron, the ratio $\mathrm{Fe} / \mathrm{Ni}$ (atomic) ranging from 18 to 20 . In the ordinary $(H, L, L L)$ chondrites, essentially all the nickel is contained in the metal phase; the mean content of metal in each of these classes, in weight percent, is :
$\mathrm{H}, 18.5$; L, 7.4 ; LL, 2.6, and the nickel concentrations reflect these metal contents. However, the nickel concentration does not diminish proportionally with the metal content. This was noted many years ago by Prior (1916), who established certain chemical and mineralogical regularities within the chondrites, which have been codified as Prior s rules, as follows: 1. The smaller the amount of nickel-iron in a chondrite, the higher the $\mathrm{Ni} / \mathrm{Fe}$ ratio in the nickeliron.

2. The smaller the amount of nickel-iron in a chondrite, the higher the $\mathrm{FeO} / \mathrm{MgO}$ ratio in the ferromagnesian silicate minerals.

The carbonaceous chondrites contain little or no nickel-iron. In the $\mathrm{C} 1$ and $\mathrm{C} 2$ chondrites most of the nickel is probably contained in the layer-lattice silicates that form the matrix of these meteorites; the C3 chondrites contain a little metal, with up to 66 percent $\mathrm{Ni}$, and pentlandite, with up to 19 percent $\mathrm{Ni}$ (Fuchs and Olsen, 1973) - coexisting troilite contains less than 0.05 percent $\mathrm{Ni}$.

Most achondrites are practically metal free, and nickel is then present only in trace amounts. Even in the ureilites, which contain 3-6 percent nickeliron, the nickel content is only about 0.1 percent, a notable depletion relative to chondritic abundances.

In the pallasites, which consist of approximately equal amounts of nickel-iron and olivine, the nickel content of the metal ranges from 7.9-16.4 percent, with a mean of 10.5 percent, and the coexisting olivine contains 40-70 ppm (Buseck and Goldstein, 1969).

The nickel content of iron meteorites is illustrated in figure 9 . The vast majority contain between 5 percent and 11 percent nickel. Those with the very lowest nickel contents are hexahedrites made up primarily of kamacite that has lost nickel to adjacent schreibersite $\left[(\mathrm{Fe}, \mathrm{Ni})_{3} \mathrm{P}\right]$ inclusions.

\section{COPPER}

Copper is a trace element in meteorites, being present in irons usually at the $100-200 \mathrm{ppm}$ level, in chondrites at about $100 \mathrm{ppm}$, and being significantly depleted in achondrites at about 1-20 ppm. The data for the stony meteorites are summarized in table 40. Some fractionation is evident between the chondrite classes, the copper concentration decreasing in the order C1-C2-C3- $(\mathrm{H}, \mathrm{L}, \mathrm{LL})$.

Smales, Mapper, and Fouché (1967) reported on copper in 67 irons and found a range of $74-360 \mathrm{ppm}$ (mean $172 \mathrm{ppm}$ ), with four exceptions (Hoba 1.3, Nedagolla 1.5, Santa Catharina 850, San Cristobal 
1,016 ppm). Moore, Lewis, and Nava (1969) obtained similar results in analyses of 70 irons : range 60-360 ppm, mean $170 \mathrm{ppm}$, with exceptions Dayton $(510 \mathrm{ppm})$, Tlacotepec (10 ppm), and Weaver Mountains $(10 \mathrm{ppm})$.

It is remarkable that, in spite of its low concentration, copper generally occurs in meteorites as minute grains of native copper. Ramdohr (1973) recorded native copper in more than half of the 350 meteorites he examined, and noted that many of his polished sections were so small that one of the rare copper grains would not likely be exposed. He commented: "The occurrence of copper is very surprising, because copper is rather soluble in the structure of $\gamma-(\mathrm{Fe}, \mathrm{Ni})$, and because taenite is always so plenti- ful that all the copper present ought to be dissolved in it" (p. 26). Ramdohr noted that the native copper is commonly found in taenite-rich plessite, which suggests formation by exsolution at relatively low temperatures during the very slow cooling that most meteorites have undergone.

Hey and Easton (1968) studied the distribution of copper in the different minerals of four chondrites, with the following results in parts per million: kamacite 22-65, taenite 1,610-2,610, troilite $<1-114$, olivine 17.8-41.5, pyroxene 6.0-22.3; these data show that most of the copper in these meteorites must reside in the taenite.

TABLE 39.-Nickel in stony meteorites

[From C. B. Moore in Mason, 1971 ; and additional data]

$\begin{array}{llll}\text { C1ass } & \begin{array}{c}\text { Number } \\ \text { analyzed }\end{array} & \text { Range Aan }\end{array}$

\begin{tabular}{|c|c|c|c|c|}
\hline \multicolumn{5}{|c|}{ Chondrites (weight percent) } \\
\hline $\begin{array}{r}\text { C } 1 \\
\text { C } 2 \\
\text { C } 3 \\
\text { H } \\
\text { L } \\
\text { L L } \\
\text { E } 4 \\
\text { E } 5 \\
\text { E } 6\end{array}$ & $\begin{array}{l}3 \\
10 \\
7 \\
27 \\
29 \\
12 \\
3 \\
2 \\
6\end{array}$ & $\begin{array}{l}0.97-1.09 \\
1.17-1.34 \\
1.24-1.50 \\
1.38-1.99 \\
.98-1.57 \\
.68-1.28 \\
1.66-1.95 \\
1.62-1.81 \\
1.11-1.96\end{array}$ & $\begin{array}{r}1.03 \\
1.23 \\
1.33 \\
1.70 \\
1.27 \\
.91 \\
1.81 \\
1.71 \\
1.53\end{array}$ & $\begin{array}{l}47,800 \\
44,900 \\
41,100 \\
47,600 \\
32,500 \\
23,200 \\
52,200 \\
47,000 \\
37,700\end{array}$ \\
\hline \multicolumn{5}{|c|}{ Calcium-poor achondrites (ppm) } \\
\hline \multicolumn{5}{|c|}{ Calcium-rich achondrites (ppm) } \\
\hline $\begin{array}{l}\text { Aa } \\
\text { An } \\
\text { Aho } \\
\text { Aeu }\end{array}$ & $\begin{array}{l}1 \\
1 \\
6 \\
6\end{array}$ & $\begin{array}{c}40 \\
990 \\
8-88 \\
5-12\end{array}$ & $\begin{array}{c}--- \\
--- \\
48 \\
7\end{array}$ & $\begin{aligned} 93 \\
2,100 \\
97 \\
15\end{aligned}$ \\
\hline
\end{tabular}




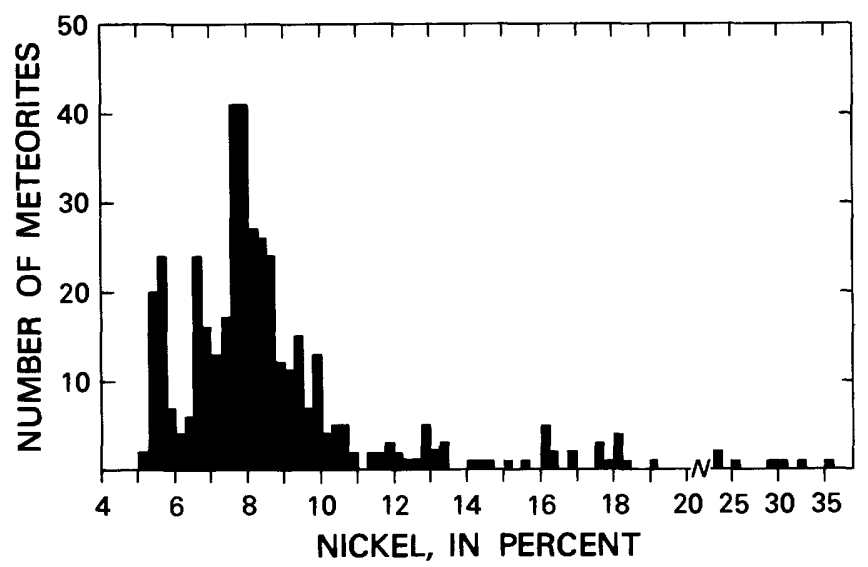

FIGURE 9.-Histogram of the nickel content of analyzed iron meteorites, plotted at 0.25 -percent $\mathrm{Ni}$ intervals. No analyzed iron meteorite contains less than 5 percent $\mathrm{Ni}$, and only seven contain more than 20 percent; Dermbach (42 percent) and Oktibbeha County (61 percent) lie outside the histogram. Copyright (C) 1975 by the Regents of the University of California; reprinted from Buchwald (1975) by permission of the University of California Press.

\section{ZINC}

The data on zinc in meteorites have been comprehensively reviewed by C.B. Moore, in Mason (1971). Zinc abundances in stony meteorites are summarized in table 41. Zinc in chondrites is a strongly depleted element in terms of the criteria of Anders (1971b) ; the atomic ratio $\mathrm{C} 1: \mathrm{C} 2: \mathrm{C} 3$ is $1.00: 0.48: 0.26$, and the ordinary $(\mathrm{H}, \mathrm{L}, \mathrm{LL})$ chondrites are more depleted than the C3 class. Within the ordinary chondrites, the different types $(3,4,5,6)$ show no significaint fractionation of zinc (Binz and others, 1976). Enstatite chondrites show strong fractionation, with E3, 4 meteorites having zinc abundances comparable to $\mathrm{C} 1$ chondrites, whereas E5, 6 meteorites average even lower than the ordinary chondrites, although the range is large. The achondrites, except for the ureilites and nakhlites, are notably depleted in zinc relative to the chondrites.

Zinc abundances in stony meteorites are comparable to those of copper. However, in contrast to copper, which is siderophile, zinc is lithophile in most meteorites. Nishimura and Sandell (1964) showed that in the ordinary chondrites very little zinc is contained in the metal or troilite phases; it is distributed in subequal amounts in the acid-soluble (olivine and phosphate) and acid-insoluble (pyroxene, plagioclase, and chromite) fractions. In the enstatite chondrites, on the contrary, most of the zinc is in the sulfide phases. This is consistent with mineralogical observations; enstatite chondrites contain sphalerite and zincian daubreelite, (up to 5.5 percent $\mathrm{Zn}$ (Keil, 1968), but these phases have not been recorded from ordinary chondrites. Meteoritic chromite may show considerable concentration of zinc, up to 2.31 percent $\mathrm{ZnO}$ (Bunch and others, 1970).

Zinc is present at very low concentration in the metal phase of iron meteorites, except for group I (table 42). The data confirm that zinc has little or no siderophile affinity in meteorites; chromite, sphalerite, and zincian daubreelite have been recorded from irons, and inclusions of these minerals may contribute to the higher zinc values of some iron meteorites.

\section{GALLIUM}

Gallium is a trace element in meteorites, seldom exceeding $10 \mathrm{ppm}$ in stony meteorites and $100 \mathrm{ppm}$ in irons. The data were assembled and evaluated by P.A. Baedecker and J.T. Wasson, in Mason (1971), and additional determinations since that time have confirmed the earlier work. The information on stony meteorites is summarized in table 43. Gallium shows moderate depletion in the sequence C1-C2C3-ordinary chondrites, the relative atomic ratio being $1.00: 0.66: 0.45: 0.29$. Enstatite chrondrites have gallium abundances comparable to those in the carbonaceous chondrites, and show moderate depletion in the sequence E4-E5-E6. Ordinary chondrites show no significant variation of gallium content between the different types (Case and others, 1973). Achondrites are notably depleted in gallium relative to the chrondrites.

Fouche and Smales (1967a) studied the distribution of gallium in 27 chondrites belonging to the $\mathrm{H}$, $\mathrm{L}$, and $\mathrm{E}$ classes, by separating each into magnetic (that is, metal-phase) and nonmagnetic fractions and analyzing each fraction separately. The average values in parts per million for the $\mathrm{H}$ chondrites are: metal 11.3, nonmagnetic 3.8 , bulk 5.3 ; for the $L$ chondrites: metal 11.4, nonmagnetic 5.3, bulk 5.6. They found that in the enstatite chondrites practically all the gallium is in the metal phase. Moss and others (1967) found 2.4-2.8 ppm in the silicate fraction of four ordinary chondrites, and $2-9 \mathrm{ppm}$ in the sulfide fraction. These results were confirmed by Allen and Mason (1973), who also measured this element in separated minerals; in the nonmetallic phases gallium is notably concentrated in plagioclase (up to $18 \mathrm{ppm}$ ) and chromite (up to $90 \mathrm{ppm}$ ). Gallium is mainly siderophile in the ordinary chondrites, but does show chalcophile and lithophile affinities. Chou, Baedecker, and Wasson (1973) found that metal/silicate concentration ratios for $\mathrm{Ga}$ and 
Ge were lower in type 3 ordinary chondrites than in types 4-6; they commented: "Apparently appreciable fractions of these elements condensed from the nebula in oxidized form and entered the metal during later thermal events" (p. 2159).

The abundance of gallium in iron meteorites has been extensively studied since Lovering and others (1957) demonstrated a wide range in gallium contents $(<2-93 \mathrm{ppm})$ and a quantization into four groups. This work has been greatly extended by Wasson and his coworkers, and was comprehensively discussed by Scott and Wasson (1975); their results are summarized in table 7 and figure 10. They concluded that each of these discrete groups probably formed in a separate parent body.

\section{GERMANIUM}

Germanium is almost exclusively siderophile in meteorites, being present in the metal phases kamacite and taenite. The extensive data have been assembled and discussed by P.A. Baedecker and J.T. Wasson, in Mason (1971). On the whole, the data from different investigators are remarkably consistent. The information on stony meteorites is summarized in table 44, largely from the results of Fouché and Smales (1967a), with some additional data. This table shows that Ge is strongly fractionbetween the different chondrite classes, being relatively depleted in the sequence $\mathrm{C} 1-\mathrm{C} 2-\mathrm{C} 3-\mathrm{H}-(\mathrm{L}$, $\mathrm{LL}$ ) in the ratio (atomic) 1.00: 0.57:0.39:0.25:0.15. Enstatite chondrites have Ge concentrations com-

TABLE 40.-Copper in stony meteorites

[From Schmitt and others, 1972; and additional data from Laul and others, 1972; and Binz and others, 1974]

\begin{tabular}{|c|c|c|c|c|}
\hline Class & $\begin{array}{c}\text { Number } \\
\text { analyzed }\end{array}$ & $\begin{array}{l}\text { Range } \\
\text { (ppm) }\end{array}$ & $\begin{array}{l}\text { Mean } \\
(\text { ppm })\end{array}$ & Atoms $/ 10^{6} \mathrm{si}$ \\
\hline \multicolumn{5}{|c|}{ Chondrites } \\
\hline $\mathrm{Cl}$ & 3 & $106-137$ & 127 & 540 \\
\hline $\mathrm{C} 2$ & 7 & $90-129$ & 116 & 390 \\
\hline C3 & 10 & $85-138$ & 108 & 300 \\
\hline $\mathrm{H}$ & 24 & $48-137$ & 90 & 230 \\
\hline $\mathrm{L}$ & 32 & $52-132$ & 94 & 220 \\
\hline LL & 15 & $60-107$ & 80 & 190 \\
\hline E4 & 2 & $172-193$ & 185 & 430 \\
\hline E5, 6 & 4 & $87-202$ & 110 & 260 \\
\hline \multicolumn{5}{|c|}{ Calcium-poor achondrites } \\
\hline$\overline{\mathrm{Ae}}$ & 5 & $1-24$ & 13 & 22 \\
\hline Ah & 1 & 7 & -- & 13 \\
\hline $\mathrm{Au}$ & 2 & $11-22$ & 11 & 25 \\
\hline \multicolumn{5}{|c|}{ Calcium-rich achondrites } \\
\hline$\overline{A a}$ & 1 & 10 & -- & 22 \\
\hline An & 2 & $3.7-5.0$ & 4.4 & 8.6 \\
\hline Aho & 5 & $.8-18 \cdot 2$ & 6.7 & 13 \\
\hline Aeu & 7 & $.9-8 \cdot 5$ & 3.0 & 5.8 \\
\hline
\end{tabular}


parable to those in $\mathrm{C} 1$ and $\mathrm{C} 2$ chondrites (Baedecker and Wasson 1975). Data are very sparse for Ge in achondrites, but the figures show extreme depletion, as would be expected from the absence or near absence of nickel-iron in most of these meteorites. (The ureilites analyzed contain as much as $\sim 6$ percent nickel-iron, and the mean Ge content is similar to that of the ordinary chondrites.)

Chou and Cohen (1973) and Chou, Baedecker, and Wasson (1973) have studied the distribution of $\mathrm{Ge}$ between metal and silicates in the different petrologic types $(3,4,5,6)$ of the ordinary chondrites. They find that, as for $\mathrm{Ga}$, the metal/silicate concen- tration ratio of $\mathrm{Ge}$ is lower in type 3 chondrites than in types 4-6; they ascribe this to a redistribution of the element from oxidized to reduced form during postcondensation thermal events.

Lovering and others (1957) discovered that germanium shows a remarkable variation in iron meteorites, and, like gallium, the values are quantized into discrete groups. This work has been greatly extended by Wasson and his coworkers, and was comprehensively reviewed by Scott and Wasson (1975) ; their results are summarized in table 7 and figure 11. Table 7 shows a range of Ge content over the different groups of iron meteorites from 0.03 to

TABLE 41.-Zinc in stony meteorites

[From C. 13. Moore, in Mason, 1971; and additional data from Keays and others, 1971; Laul and others, 1972; Laul and Schmitt, 1973; Case and others, 1973; Krahenbuhl and others, 1973; Binz and others, 1974, 1975; and Rosman and de Laeter, 1974]

\begin{tabular}{|c|c|c|c|c|}
\hline Class & $\begin{array}{l}\text { Number } \\
\text { analyzed }\end{array}$ & $\begin{array}{l}\text { Range } \\
\text { (ppm) }\end{array}$ & $\begin{array}{l}\text { Mean } \\
(\mathrm{ppm})\end{array}$ & Atoms $/ 10^{6} \mathrm{Si}$ \\
\hline \multicolumn{5}{|c|}{ Chondrites } \\
\hline $\mathrm{Cl}$ & 3 & $295-310$ & 303 & 1,260 \\
\hline $\mathrm{C} 2$ & 3 & $175-187$ & 183 & 600 \\
\hline $\mathrm{C} 3$ & 6 & $105-130$ & 120 & 330 \\
\hline $\mathrm{H}$ & 8 & $28-89$ & 51 & 130 \\
\hline $\mathrm{L}$ & 15 & $8-102$ & 58 & 130 \\
\hline LL & 11 & $44-82$ & 68 & 150 \\
\hline E3, 4 & 4 & $90-519$ & 400 & 1,040 \\
\hline $\mathrm{E} 5,6$ & 6 & $7 \cdot 5-86$ & 29 & 64 \\
\hline \multicolumn{5}{|c|}{ Calcium-poor achondrites } \\
\hline$\overline{\mathrm{Ae}}$ & 2 & $5-25$ & 15 & 24 \\
\hline $\mathrm{Ah}$ & 2 & $3-63$ & 34 & 60 \\
\hline $\mathrm{Au}$ & 6 & $35-280$ & 186 & 420 \\
\hline \multicolumn{5}{|c|}{ Calcium-rich achondrites } \\
\hline $\mathrm{Aa}$ & 1 & 2.1 & -- & 4.4 \\
\hline An & 2 & $42-71$ & 57 & 110 \\
\hline Aho & 5 & $.35-30$ & 5.8 & 11 \\
\hline Aeu & 7 & $.78-20$ & 4.8 & 9.0 \\
\hline
\end{tabular}


TABLE 42.-Zinc in iron meteorites

[Data from Kelly and Moore, 1973, except for group I, which are from Smales, Mapper, and Fouche, 1967]

\begin{tabular}{lccc}
\hline Group & $\begin{array}{c}\text { Number } \\
\text { Analyzed }\end{array}$ & Range & Median \\
\hline I & 10 & $12-42$ & 27 \\
IIA & 5 & $\cdot 34-1.5$ & .5 \\
IIB & 3 & $\cdot 25-.39$ & .3 \\
IIC & 4 & $.23-2.2$ & .4 \\
IID & 5 & $2 \cdot 1-3.7$ & 2.9 \\
IIIA & 8 & $.40-2.8$ & .6 \\
IIIB & 4 & $1.2-2.1$ & 1.5 \\
IVA & 5 & $.1-12$ & .5 \\
IVB & 4 & $.45-16$ & 2.5 \\
\hline
\end{tabular}

$520 \mathrm{ppm}$, but some anomalous irons contain even higher concentrations ; one exceptional iron, Butler, a finest octahedrite with 16 percent $\mathrm{Ni}$, contains 2,000 ppm.

\section{ARSENIC}

Arsenic is a trace element in meteorites, in amounts ranging up to about $30 \mathrm{ppm}$. The data have been assembled and discussed by M.E. Lipschutz, in Mason (1971), and are summarized in table 45. Arsenic concentrations show relatively small variations between the different chondrite classes. The H, L, LL classes show a consistent relationship between As and metal content, the As content diminishing as the metal content decreases in the sequence H-L-LL. Enstatite chondrites, which usually have higher metal content than ordinary chondrites, also show higher As concentrations; the high content for the E5 chondrite, St. Marks, may be due to an unusually high metal content in the sample analyzed. Data for achondrites are too sparse to be worth tabulating; Wänke and others (1972) recorded 0.092 $\mathrm{ppm}$ in the Kapoeta howardite and $0.18 \mathrm{ppm}$ in the Juvinas eucrite, thus showing strong depletion for these meteorites relative to the chondrites.

Onishi and Sandell (1955) claimed As to be both siderophile and chalcophile in chondrites on the basis of their analyses of As contents in separated metal, sulfide, and silicate portions of two composites, each consisting of $7 \mathrm{H}$ and $\mathrm{L}$ group meteorites; their results in parts per million were $11,8,0.4$ and 13 ,
11, 0.2 espectively. However, Fouché and Smales (1967) found As in chondrites to be contained almost entirely in the metal phase, and this was confirmed by Mason and Graham (1970). The explanation of this discrepancy perhaps lies in incomplete separation of metal from sulfide in the material analyzed by Onishi and Sandell.

Smales, Mapper, and Fouché (1967) determined As in 67 irons and found a range from 0.43 to 30.7 ppm, with a mean of $8.8 \mathrm{ppm}$. Cobb (1967) analyzed 33 irons and found a range of $<1-30 \mathrm{ppm}$, with a mean of $9 \mathrm{ppm}$. Scott (1972) correlated these and other data with $\mathrm{Ni}$ content (fig. 12).

\section{SELENIUM}

The data for selenium in meteorites have been assembled and critically evaluated by I. Pelly and M.E. Lipschutz, in Mason (1971). The information in table 46 has been extracted from their compilation, and additional data taken from other sources. Selenium shows relative depletion in the sequence $\mathrm{C} 1-\mathrm{C} 2-$ $\mathrm{C3}-\mathrm{H}, \mathrm{L}, \mathrm{LL})$, the atomic ratio being $1.00: 0.48: 0.27$ : 0.24 ; the concentrations in enstatite chondrites are comparable to those in $\mathrm{C} 1$ and $\mathrm{C} 2$ chondrites. Pelly and Lipschutz pointed out that selenium concentrations in chondrites are independent of petrologic type, and that the $\mathrm{Se} / \mathrm{S}$ ratio is relatively uniform throughout. (For the different classes of chondrites the atomic ratio $\mathrm{Se} / \mathrm{S}$ ranges from $14 \times 10^{-5}$ to $19 \times$ $10^{-5}$.) Mason and Graham (1970) found that selenium is concentrated in meteoritic troilite, and was not detectable in other phases. Thus, selenium is entirely 
TABLE 43.-Gallium in stony meteorites

[From Baedecker and Wasson, in Mason, 1971; and additional data from Keays and others, 1971 ; Laul and others, 1972 ; Baedecker and Wasson, 1975; Case and others, 1973; Binz and others, 1974, 1975, and 1976; Chou, Batedeker, and Wasson, 1973 and 1976a, b; Ikramuddin and Lipschutz, 1975; and Ikramuddin and others, 1976]

\begin{tabular}{|c|c|c|c|c|}
\hline Class & $\begin{array}{c}\text { Number } \\
\text { analyzed }\end{array}$ & $\begin{array}{c}\text { Range } \\
(\mathrm{ppm})\end{array}$ & $\begin{array}{l}\text { Mean } \\
\text { (ppm) }\end{array}$ & Atoms $/ 10^{6} \mathrm{Si}$ \\
\hline \multicolumn{5}{|c|}{ Chondrites } \\
\hline $\mathrm{Cl}$ & 2 & $9.2-10.0$ & 9.6 & 38 \\
\hline $\mathrm{C} 2$ & 2 & $8.1-8.2$ & 8.2 & 25 \\
\hline $\mathrm{C} 3$ & 6 & $4 \cdot 9-8 \cdot 1$ & 6.4 & 17 \\
\hline $\mathrm{H}$ & 7 & $4 \cdot 9-5.8$ & 5.3 & 12 \\
\hline $\mathrm{L}$ & 26 & $3 \cdot 6-6 \cdot 2$ & 5.2 & 11 \\
\hline LL & 5 & $2.9-6.0$ & 4.6 & 10 \\
\hline E4 & 3 & $13 \cdot 5-17 \cdot 5$ & 16.0 & 39 \\
\hline E5 & 1 & 14.9 & -- & 35 \\
\hline $\mathrm{E} 6$ & 5 & $8.5-12.0$ & $10 \cdot 5$ & 22 \\
\hline \multicolumn{5}{|c|}{ Calcium-poor achondrites } \\
\hline $\mathrm{Ae}$ & 1 & 0.056 & -- & 0.08 \\
\hline $\mathrm{Au}$ & 6 & $.95-5.0$ & 2.5 & 5.3 \\
\hline \multicolumn{5}{|c|}{ Calcium-rich achondrites } \\
\hline $\mathrm{Aa}$ & 1 & 0.36 & --- & 0.71 \\
\hline An & 1 & 2.70 & -- & 4.4 \\
\hline Aho & 5 & $.72-1.34$ & 1.08 & 1.8 \\
\hline Aeu & 8 & $1.26-1.51$ & 1.42 & 2.5 \\
\hline
\end{tabular}




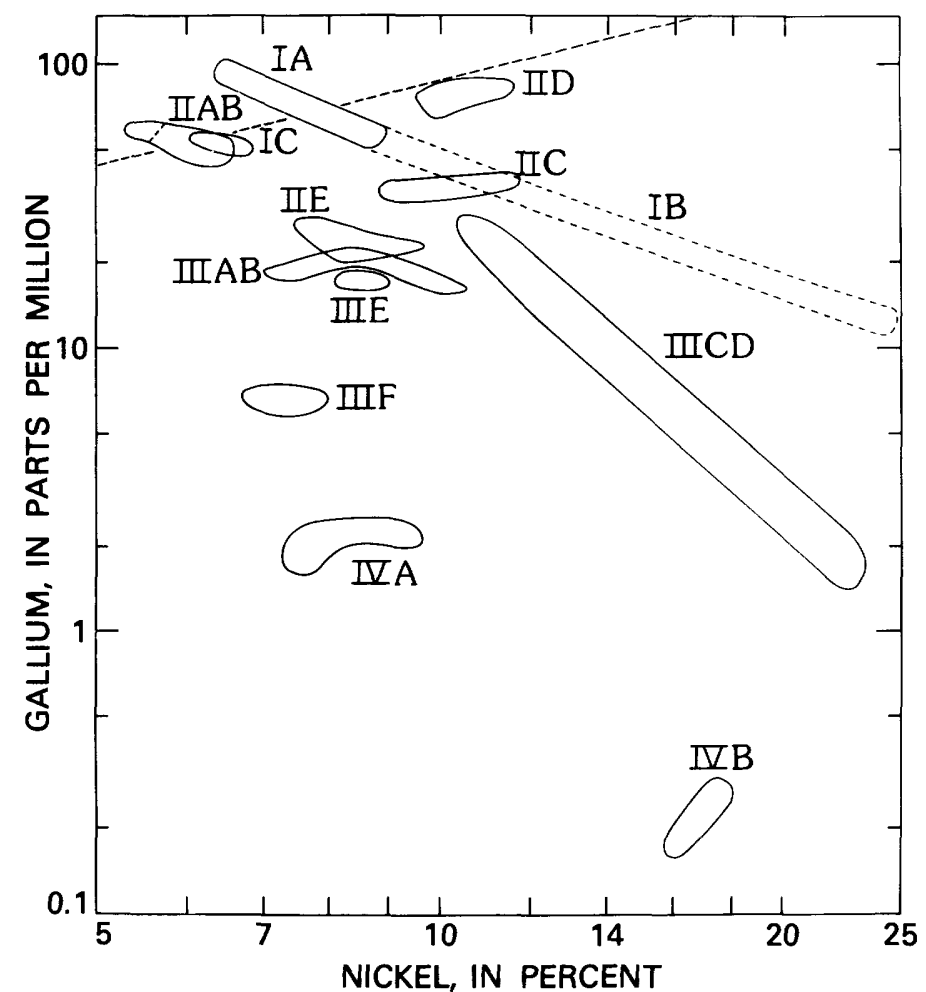

FIGURE 10.-Logarithmic plot of $\mathrm{Ga}$ against $\mathrm{Ni}$ for iron meteorites, showing quantization into the different groups. Apart from IA and IIICD, the groups show very limited ranges of $\mathrm{Ga}$ contents, less than \pm 20 percent about the mean. IB is very sparsely populated with only eight meteorites and is shown in short-dashed outline. About 14 percent of known iron meteorites are anomalous and are not shown. The straight dashed line through groups IA, $\mathrm{IC}$, and IIAB shows the $\mathrm{Ga} / \mathrm{Ni}$ ratio for $\mathrm{C} 1$ chondrites. Reprinted from Scott and Wasson (1975); copyrighted by American Geophysical Union.

chalcophile in stony meteorites and is camouflaged in troilite and other sulfur-bearing minerals. The extreme depletion of Se in achondrites is due to the paucity of troilite in these meteorites.

Relatively few data exist for Se in iron meteorites. Seitner and others (1971) analyzed 10 irons, and found an upper limit of $0.01 \mathrm{ppm}$ in 6 of them. Kiesl and Hecht (1969) analyzed troilite from three irons, and found Se contents ranging from 128 to $300 \mathrm{ppm}$. These data confirm the highly chalcophile character of this element.

\section{BROMIME}

The abundance of this element has been the subject of several investigations, but the results are confusing and difficult to interpret. For example, the following figures in parts per million have been

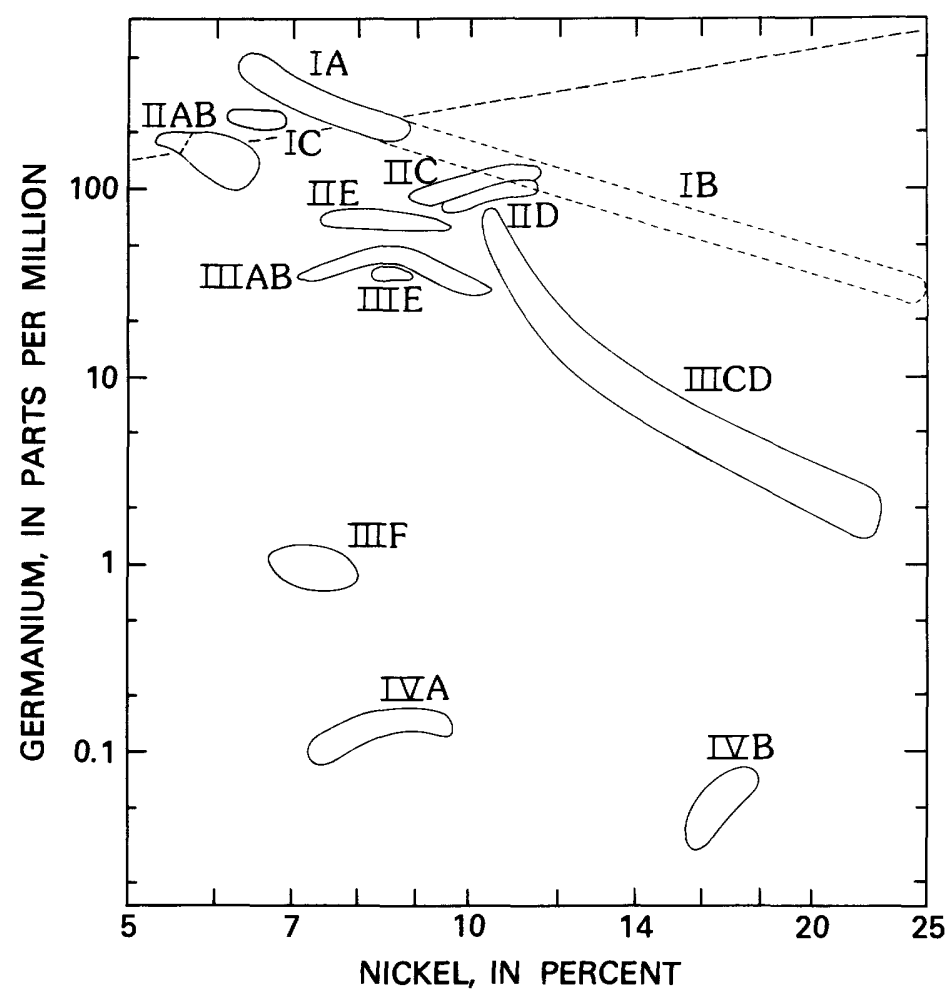

FIGURE 11.-Logarithmic plot of $\mathrm{Ge}$ against $\mathrm{Ni}$ for iron meteorites; note the similarity to figure 10. Most groups except IAB and IICD show very small Ge variations in comparison with the total range of more than four orders of magnitude. Group IB is very sparsely populated with only eight meteorites and is shown in short-dashed outline. The straight dashed line through groups IIAB and IA is the $\mathrm{Ge} / \mathrm{Ni}$ ratio for $\mathrm{C} 1$ chondrites. Reprinted from Scott and Wasson (1975) ; copyrighted by American Geophysical Union.

published for Bruderheim, a hypersthene (L6) chondrite: 0.97, 1.56 (Wyttenbach and others, 1965); $0.05,0.13,0.20,0.23,0.24$ (Reed and Allen, 1966); $0.18,0.18,0.15,0.16,0.11,0.12$ (Goles and others, 1967 ) ; 0.030, 0.026 (Lieberman and Ehmann, 1967). If this spread in figures is not the result of experimental error or of contamination, it indicates that bromine is distributed very inhomogeneously within this meteorite, and that sampling is a major problem. Reed and Allen found that much of the bromine in Bruderheim and other meteorites was leachable in hot water.

The data in table 47 have been selected from the compilation by G.W. Reed, in Mason (1971), and additional information on C3 chondrites from Anders and others (1976), and on the achondrites from Laul and others (1972). Bromine shows strong relative depletion in the sequence $\mathrm{C} 1-\mathrm{C} 2-\mathrm{C} 3-(\mathrm{H}, \mathrm{L})$, the atomic abunrdance ratios being $1.00: 0.48: 0.24$ :- 
TABLE 44.-Germanium in stony meteorites

[From Fouché and Smales, 1967; and additional data from Krahenbuh] and others, 1979; Chou and others, 1973 and 1976a, b; Baedecker and Wasson, 1975 ; and Anders and others, 1976]

\begin{tabular}{|c|c|c|c|c|}
\hline C1ass & $\begin{array}{c}\text { Number } \\
\text { analyzed }\end{array}$ & $\begin{array}{l}\text { Range } \\
(\mathrm{ppm})\end{array}$ & $\begin{array}{l}\text { Mean } \\
(\mathrm{ppm})\end{array}$ & Atoms $/ 10^{6} \mathrm{Si}$ \\
\hline \multicolumn{5}{|c|}{ Chondrites } \\
\hline $\begin{array}{l}\text { C } 1 \\
\text { C } 2 \\
\text { C } 3 \\
\text { H } \\
\text { L } \\
\text { LL } \\
\text { E } 4 \\
\text { E } 5 \\
\text { E } 6\end{array}$ & $\begin{array}{l}3 \\
3 \\
7 \\
7 \\
9 \\
4 \\
3 \\
1 \\
4\end{array}$ & $\begin{array}{c}27.8-34 \cdot 9 \\
19.6-24.9 \\
18.2-24.0 \\
11.3-13.4 \\
4.6-12.4 \\
6.9-11.6 \\
42-51 \\
45 \\
21-36\end{array}$ & $\begin{array}{l}31.2 \\
22.8 \\
21.1 \\
12.7 \\
8.7 \\
8.4 \\
47 \\
-- \\
30\end{array}$ & $\begin{array}{r}117 \\
67 \\
52 \\
29 \\
18 \\
17 \\
110 \\
100 \\
60\end{array}$ \\
\hline \multicolumn{5}{|c|}{ Calcium-poor achondrites } \\
\hline $\begin{array}{l}\mathrm{Ae} \\
\mathrm{Au}\end{array}$ & $\begin{array}{l}1 \\
5\end{array}$ & $\begin{array}{c}0.21 \\
2.0-29.5\end{array}$ & $-\overline{11}$ & $\begin{array}{l}0.29 \\
22\end{array}$ \\
\hline \multicolumn{5}{|c|}{ Calcium-rich achondrites } \\
\hline $\begin{array}{l}\text { An } \\
\text { Aho } \\
\text { Aeu }\end{array}$ & $\begin{array}{l}1 \\
1 \\
1\end{array}$ & $\begin{array}{r}2.6 \\
.31 \\
.06\end{array}$ & $\begin{array}{l}-- \\
--- \\
---\end{array}$ & $\begin{array}{r}4.5 \\
.51 \\
.10\end{array}$ \\
\hline
\end{tabular}

TABLE 45.-Arsenic in chondritic meteorites

[From M. E. Lipschutz, in Mason, 1971; and additional data from Case and others, 1973; and Binz and others, 1974 and 1976]

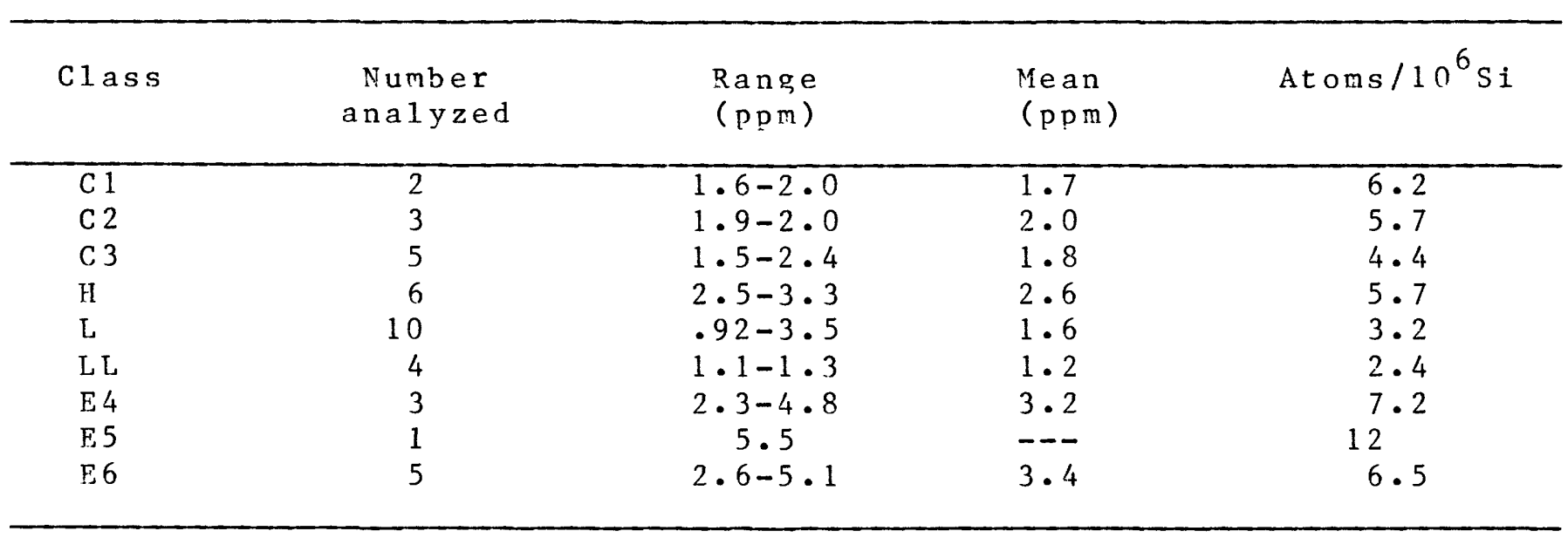


TABLE 46.-Selenium in stony meteorites

[From I. Z. Pelly and M. E. Lipschutz, in Mason, 1971; and additiona] data on carbonaceous chondrites from Krähenbühl and others, 1973, and Anders and others, 1976 ; on enstatite chondrites from Binz and others, 1974; on ureilites from Binz and others, 1975 ; and on other achondrites from Laul and others, 1972]

\begin{tabular}{|c|c|c|c|c|}
\hline CIas s & $\begin{array}{c}\text { Number } \\
\text { analyzed }\end{array}$ & $\begin{array}{c}\text { Range } \\
(\mathrm{ppm})\end{array}$ & $\begin{array}{l}\text { Mean } \\
(\mathrm{ppm})\end{array}$ & Atoms $/ 10^{6} \mathrm{si}$ \\
\hline
\end{tabular}

\begin{tabular}{|c|c|c|c|c|}
\hline \multicolumn{5}{|c|}{ Chondrites } \\
\hline C 1 & 3 & $19 \cdot 1-21 \cdot 1$ & 19.5 & 67 \\
\hline $\mathrm{C} 2$ & 3 & $11 \cdot 3-12 \cdot 3$ & 11.8 & 32 \\
\hline C 3 & 7 & $5.7-10.8$ & 8.0 & 18 \\
\hline $\mathrm{H}$ & 6 & $7 \cdot 0-9 \cdot 5$ & 7.9 & 16 \\
\hline $\mathrm{L}$ & 6 & $5 \cdot 9-12$ & 8.4 & 16 \\
\hline LL & 8 & $5 \cdot 6-14$ & 10 & 19 \\
\hline E4 & 3 & $28-41$ & 34 & 73 \\
\hline E 5 & 1 & 30 & --- & 62 \\
\hline E 6 & 5 & $14-24$ & 19 & 35 \\
\hline \multicolumn{5}{|c|}{ Calcium-poor achondrites } \\
\hline $\mathrm{Ae}$ & 1 & $1.78-2.09$ & $1 \cdot 9$ & 2.4 \\
\hline $\mathrm{Au}$ & 4 & $.68-1.24$ & .92 & 1.7 \\
\hline \multicolumn{5}{|c|}{ Calcium-rich achondrites } \\
\hline An & 1 & 0.088 & -- & 0.14 \\
\hline Aho & 3 & $.118-.603$ & .42 & .63 \\
\hline Aeu & 5 & $.078-.396$ & .25 & .39 \\
\hline
\end{tabular}




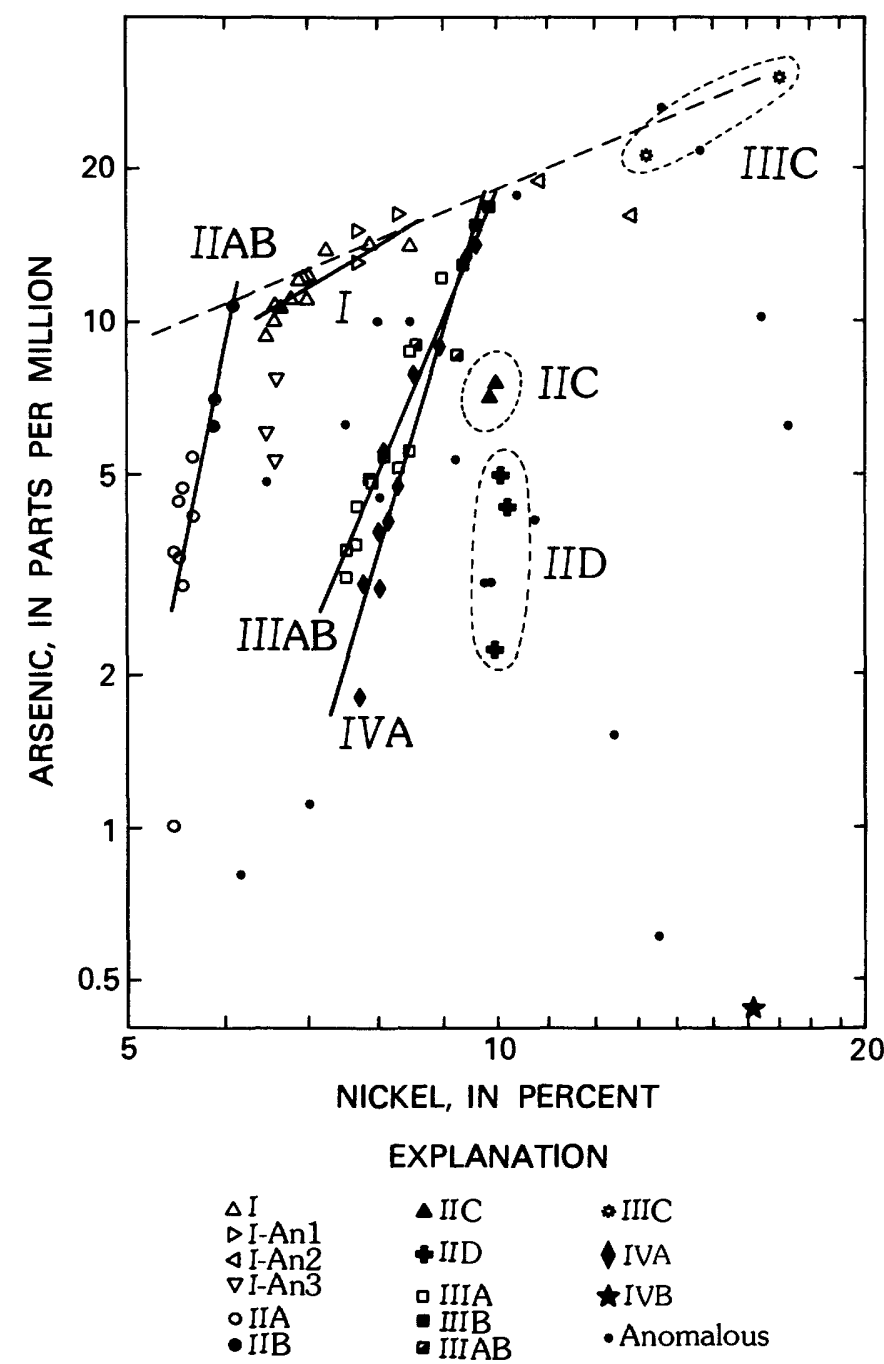

FIGURE 12.-As-Ni distribution in iron meteorites. The dashed line is the $\mathrm{As} / \mathrm{Ni}$ ratio for $\mathrm{C} 1$ chondrites; group $\mathrm{I}$ and IIIC meteorites contain these elements in this ratio. In groups I, IIAB, IIIAB, and IVA, As content correlates positively with $\mathrm{Ni}$ content. Short-dashed lines enclose well-resolved groups. Reprinted from Scott (1972) and published with permission.

0.24:0.04. Bromine also shows relative depletion with petrologic type in ordinary chondrites; Keays, Ganapathy, and Anders (1971) demonstrated a decrease of average $\mathrm{Br}$ concentrations of $3.1,2.7,0.50$, and $0.40 \mathrm{ppm}$ in the sequence L3-L4-L5-L6. Enstatite chondrites have comparable abundances to the carbonaceous chondrites.

No obvious correlation exists between bromine and any of the major elements in meteorites. However, as shown in table 47, the chondrites show a fairly consistent $\mathrm{Cl} / \mathrm{Br}$ relationship. Reed and Allen (1966) found $40 \mathrm{ppm} \mathrm{Br}$ in chlorapatite from the Mt. Sterling iron meteorite; this suggests that chlorapatite may be the principal host of bromine in meteorites.

\section{RUBIDIUM}

A considerable number of rubidium determinations have been made on stony meteorites, many with a view to ${ }^{87} \mathrm{Rb}-{ }^{87} \mathrm{Sr}$ dating. The data have been assembled and discussed by G.G. Goles, in Mason (1971), and are summarized in table 48, along with additional determinations. Rubidium shows a rather narrow abundance range in chondrites, with some exceptions, notably among the LL and E classes. Three different samples of Soko-Banja (LL) gave $0.580,4.880$, and $0.515 \mathrm{ppm} \mathrm{Rb}$ (Gopalan and Wetherill, 1969) ; Krähenberg (LL) has light and dark areas, and a light area contained $1.94 \mathrm{ppm}$ and a dark area $50.8 \mathrm{ppm} \mathrm{Rb}$ (Kempe and Müller, 1969). The low value of $0.8 \mathrm{ppm} \mathrm{Rb}$ in the E5 chondrite St. Marks has been established by two independent analyses (Gopalan and Wetherill, 1970; Laul and others, 1973). For most chondrites, the $K / R b$ weight ratio is in the range $200-400$.

Selective solution experiments on Abee (E4) and Bruderheim (L6) chondrites by Shima and Honda (1967) showed that $\mathrm{Rb}$ is contained almost entirely in the HF-soluble fraction, hence probably in plagioclase. This was confirmed by Mason and Graham (1970), who found up to $28 \mathrm{ppm} \mathrm{Rb}$ in chondrite plagioclase. El Goresy (1967) identified some grains of potassium feldspar in troilite nodules in the Odessa iron, and found that they have remarkably high $\mathrm{Rb}$ contents, $0.2-0.6$ percent; the $\mathrm{K} / \mathrm{Rb}$ ratio is of the order of 30 , implying a high degree of fractionation.

Rubidium, unlike lithium, sodium, and potassium, appears to show little or no chalcophile affinity in the enstatite chondrites.

\section{STRONTIUM}

The data on strontium in stony meteorites are quite extensive, and have been assembled and discussed by K. Gopalan and G.W. Wetherill, in Mason (1971); a selection of the data is provided in table 49. Strontium abundances show relatively small variations between different chondrite classes; the somewhat higher concentration in C3 chondrites is linked with the higher calcium content of these meteorites, frequently in the form of chondrules and inclusions consisting largely of melilite and calic pyroxene. Strontium in chondrites and many achondrites shows a close coherence with calcium, as can 
TABLE 47.-Bromine in stony meteorites

[From G. W. Reed, in Mason, 1971; and additional data from Anders and others, 1976; and Laul and others, 1972]

\begin{tabular}{|c|c|c|c|c|c|}
\hline C1ass & $\begin{array}{c}\text { Number } \\
\text { analyzed }\end{array}$ & $\begin{array}{l}\text { Range } \\
\text { (ppm) }\end{array}$ & $\begin{array}{l}\text { Mean } \\
(p p m)\end{array}$ & Atoms $/ 10^{6} \mathrm{Si}$ & $\begin{array}{c}\mathrm{Cl} / \mathrm{Br} \\
(\mathrm{atoms})\end{array}$ \\
\hline \multicolumn{6}{|c|}{ Chondrites } \\
\hline $\mathrm{CI}$ & 2 & $3 \cdot 3-5 \cdot 1$ & 4.0 & 14 & 410 \\
\hline $\mathrm{C} 2$ & 3 & $.8-4.8$ & 2.5 & 6.7 & 310 \\
\hline C 3 & 7 & $.81-2.24$ & 1.5 & $3 \cdot 4$ & 400 \\
\hline $\mathrm{H}$ & 8 & $.14-.78$ & .26 & .53 & 700 \\
\hline $\mathrm{L}$ & 10 & $.12-.39$ & .23 & .43 & 740 \\
\hline LL & 3 & $.18-.87$ & .57 & 1.1 & 480 \\
\hline E 4 & 2 & $1 \cdot 8-6 \cdot 5$ & 3.9 & $8 \cdot 3$ & 380 \\
\hline E 6 & 2 & $1 \cdot 0-1 \cdot 5$ & 1.3 & 2.4 & 360 \\
\hline \multicolumn{6}{|c|}{ Calcium-poor achondrites } \\
\hline$\overline{A e}$ & 2 & $0.01-.28$ & 0.14 & 0.18 & 67 \\
\hline $\mathrm{Ah}$ & 1 & .11 & --- & .16 & 260 \\
\hline $\mathrm{Au}$ & 1 & .55 & --- & 1.0 & 150 \\
\hline \multicolumn{6}{|c|}{ Calcium-rich achondrites } \\
\hline $\mathrm{Aa}$ & 1 & 0.41 & --- & 0.70 & --- \\
\hline An & 1 & .44 & --- & .69 & --- \\
\hline Aho & 5 & $.04-.37$ & .13 & .19 & 270 \\
\hline Aeu & 6 & $.03-.29$ & .11 & .17 & 410 \\
\hline
\end{tabular}


TABLE 48.-Rubidium in stony meteorites

[From G. G. Goles in Mason, 1971; and additional data from Keays and others, 1971; Laul and others, 1972 and 1973; Krähenbüh] and others, 1973 ; Anders and others, 1976 ; and Higuchi and others, 1976]

\begin{tabular}{|c|c|c|c|c|}
\hline C1 ass & $\begin{array}{c}\text { Number } \\
\text { analyzed }\end{array}$ & $\begin{array}{l}\text { Range } \\
(\mathrm{ppm})\end{array}$ & $\begin{array}{l}\text { Mean } \\
(\mathrm{ppm})\end{array}$ & Atoms $/ 10^{6} \mathrm{Si}$ \\
\hline
\end{tabular}

Chondrites

\begin{tabular}{lrlll}
\hline C 1 & 3 & $1.42-2.33$ & 1.88 & 6.0 \\
C 2 & 3 & $1.20-1.85$ & 1.25 & 3.1 \\
C 3 & 7 & $1.04-1.36$ & 1.21 & 2.6 \\
H & 11 & $2.0-3.5$ & 2.9 & 5.6 \\
L & 20 & $1.9-4.0$ & 3.1 & 5.4 \\
L & 11 & $.5-5.5$ & 2.3 & 4.0 \\
E 5 & 4 & $1.4-2.5$ & 2.2 & 4.4 \\
E 5 & 1 & .8 & --5 & 1.5 \\
E6 & 5 & $.8-1.9$ & 1.4 & 2.5 \\
\hline
\end{tabular}

Calcium-poor achondrites

\begin{tabular}{|c|c|c|c|c|}
\hline $\begin{array}{l}\mathrm{Ae} \\
\mathrm{Ah} \\
\mathrm{Ac} \\
\mathrm{Au}\end{array}$ & $\begin{array}{l}2 \\
1 \\
1 \\
4\end{array}$ & $\begin{array}{c}1.65-2.00 \\
.14 \\
.4 \\
.016-.076\end{array}$ & $\begin{array}{l}1.81 \\
--- \\
--- \\
.035\end{array}$ & $\begin{array}{r}2.1 \\
.19 \\
.76 \\
.06\end{array}$ \\
\hline \multicolumn{5}{|c|}{ Calcium-rich achondrites } \\
\hline $\begin{array}{l}\text { Aa } \\
\text { An } \\
\text { Aeu }\end{array}$ & $\begin{array}{l}1 \\
2 \\
9\end{array}$ & $\begin{array}{l}0.031 \\
2.4-2.8 \\
.05-.70\end{array}$ & $\begin{array}{l}--- \\
2.6 \\
.28\end{array}$ & $\begin{array}{l}0.05 \\
3.4 \\
.40\end{array}$ \\
\hline
\end{tabular}




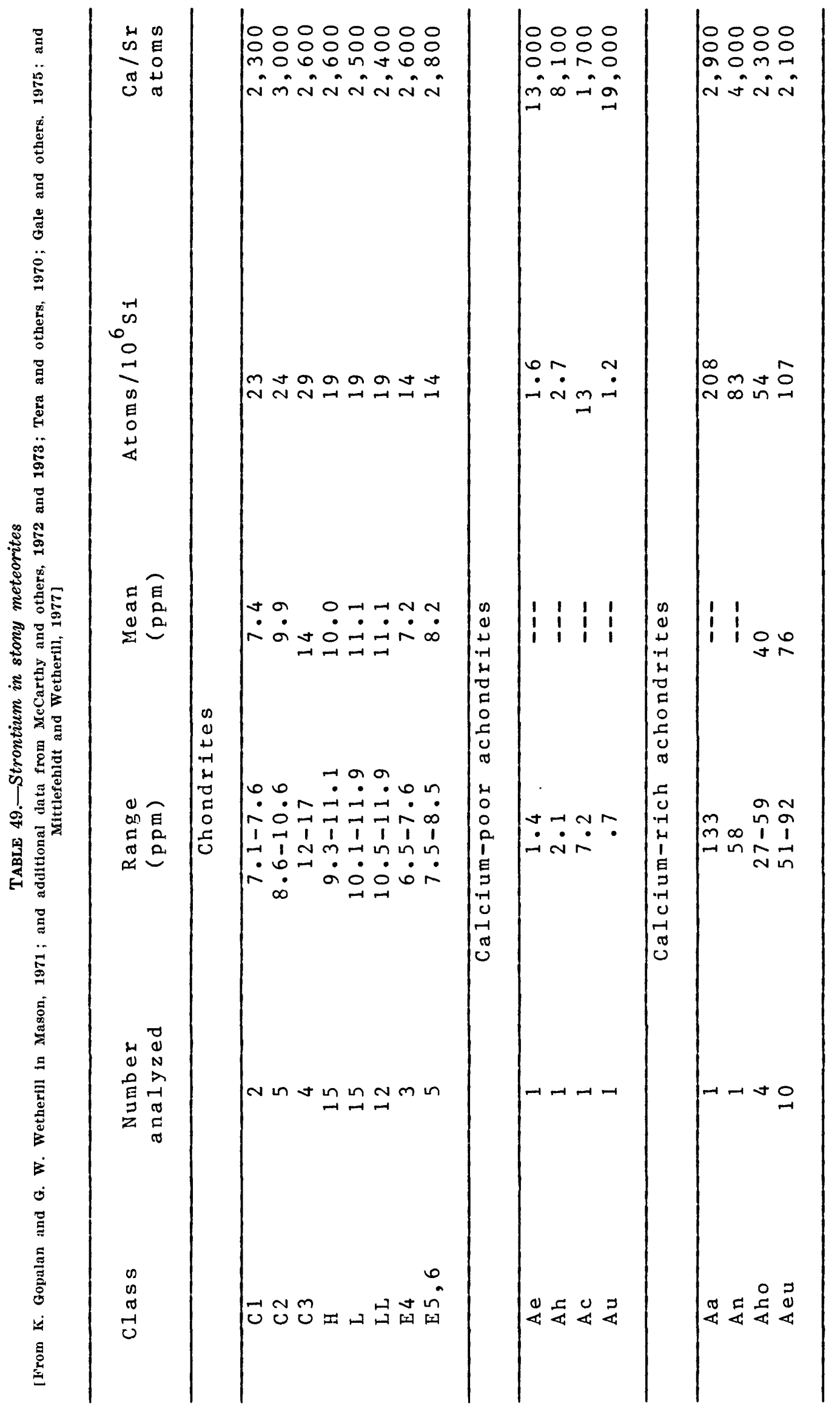


be seen from the relative constancy of the $\mathrm{Ca} / \mathrm{Sr}$ ratios in table 49 ; a few achondrites, notably the aubrites, diogenites, and ureilites are strongly depleted in strontium relative to calcium.

As might be expected, most of the strontium in meteorites resides in the calcium minerals-plagioclase, clinopyroxene, and phosphates (chlorapatite and merrillite). The data of Mason and Graham (1970) and Allen and Mason (1973) on separated minerals demonstrated that $\mathrm{Sr}$ shows a marked preference for plagioclase over clinopyroxene. Gray, Papanastassiou, and Wasserburg (1973) recorded the following $\mathrm{Sr}$ contents in parts per million in the Peace River (L6) chondrite: total meteorite 11.18, plagioclase 92.86, phosphate 75.49. Shima and Honda (1967) in in selective solution experiments showed that in Bruderheim, in L6 chondrite, practically all the $\mathrm{Sr}$ was contained in the HF-soluble fraction (plagioclase and pyroxene), whereas in Abee, an E4 chondrite, about half was in the sulfide fraction, which dissolved in bromine water. Thus, strontium resembles calcium and magnesium in showing chalcophile affinity in enstatite chondrites.

The calcium-rich achondrite Angra dos Reis is notable for having the highest $\mathrm{Sr}$ content and the most primitive ${ }^{87} \mathrm{Sr} /{ }^{\mathrm{si}} \mathrm{Sr}$ ratio $(0.69884)$; this primitive ratio is due to this meteorite's extremely low $\mathrm{Rb}$ content, which has thus contributed essentially no radiogenic Sr. Slightly lower ${ }^{87} \mathrm{Sr} /{ }^{86} \mathrm{Sr}$ ratios, down to 0.69877 , have been recorded in meliliteclinopyroxene chondrules from the Allende (C3) meteorite (Gray, Papanastassiou, and Wasserburg, 1973). In chondrites this ratio ranges up to 1.001 (Gopalan and Wetherill, 1970).

\section{YTTRIUM}

The data on the abundance of yttrium in meteorites are comparatively sparse. However, Haskin and others (1966) have provided figures for meteorites representing all the chondrite classes, and for the principal classes of achondrites; their data are summarized in table 50, along with additional data on the howardites and the eucrites.

The figures show that yttrium is relatively unfractionated between the different classes of chondrites. In terms of the $\mathrm{Y} / \mathrm{Si}$ atomic ratio, there is a small but systematic decrease from the carbonaceous chondrites through the ordinary (H, L, LL) chondrites to the enstatite chondrites. The $\mathrm{Ca} / \mathrm{Y}$ atomic ratio is relatively uniform at $13,000-17,000$.

Among the calcium-poor achondrites, the single enstatite achondrite analyzed (Norton County) is comparable in $\mathrm{Y} / \mathrm{Si}$ ratio to the enstatite chondrites, and the two hypersthene achondrites give rather divergent figures, but appear significantly lower in yttrium than the chondrites. The calcium-rich achondrites are enriched in this element, moderately for the nakhlites, and quite markedly for the howardites and eucrites. Angra dos Reis, a unique calcium-rich achondrite, has the highest $\mathrm{Y} / \mathrm{Si}$ ratio so far found for meteorites, and also has the highest calcium content of any meteorite.

Yttrium is essentially lithophilic in meteorites. Mason and Graham (1970) analyzed mineral separates of two chondrites (Modoc and St. Severin) and found yttrium to be highly enriched in the calcium phosphate minerals, being present in them at concentrations about $200 \mathrm{ppm}$; it was not detected in metal or olivine, and was present at about 1 ppm in plagioclase, pyroxene, and troilite. The only mineral besides the phosphates enriched in yttrium was calcic clinopyroxene (diopside and pigeonite), which contained about $20 \mathrm{ppm}$. Yttrium is very similar to calcium in ionic radius, and this evidently conditions its tendency to concentrate in calciumrich minerals.

\section{ZIRCONIUM}

Zirconium (and hafnium) were determined by neutron-activation analysis in 28 chondrites and 7 achondrites by Ehmann and Rebagay (1970), who also reviewed earlier meteorite analysis for these elements; the data for achondrites were revised and extended by Ehmann and others (1976). Their results are summarized in table 51, together with additional data on the calcium-rich achondrites and on chondrites by Palme (1974) Ehmann and Chyi (1974), and Ganapathy, Papia, and Grossman, (1976). Zirconium shows a rather uniform concentration in all classes of chondrites. The calcium-poor achondrites are depleted in $\mathrm{Zr}$ relative to the chondrites, whereas the calcium-rich achondrites are notably enriched.

The location of the zirconium within the meteorite phases is not revealed by the chemical analyses. However, Marvin and Klein (1964) discovered zircon as an accessory mineral in the Vaca Muerta mesosiderite and in troilite nodules of the Toluca iron (the latter confirming a report by Laspeyres and Kaiser as long ago as 1895). They recovered about $2 \mathrm{mg}$ of zircon from $125 \mathrm{~g}$ of the mesosiderite. P. Ramdohr (written commun., 1965) has identified a crystal of zircon in a section of the Muizenberg chondrite. In stony meteorites, zirconium (and hafnium) are probably contained largely in small, 
sporadically distributed crystals of zircon; $10 \mathrm{ppm}$ zirconium corresponds to $20 \mathrm{ppm}(0.002$ percent zircon. In Angra dos Reis, the achondrite with the highest $\mathrm{Zr}$ content, Keil and others (1976) identified baddeleyite, $\mathrm{ZrO}_{2}$.

\section{NIOBIUM}

Information on the abundance and distribution of niobium in meteorites is extremely sparse. Graham and Mason (1972) analyzed 6 chondrites and 6 achondrites for this element by spark-source mass spectrometry, and Erlank and others (1972) analyzed 10 achondrites by X-ray fluorescence. These data are summarized in table 52 ; they show niobium at a fairly uniform concentration in all the chondrites analyzed, and a relative enrichment in the calciumrich achondrites.

Niobium is remarkably concentrated in meteoritic rutile; El Goresy (1971) determined $\mathrm{Nb}$ in rutile from three irons and one mesosiderite, and reported $\mathrm{NoO}_{2}$ 1.63-2.93 percent in rutile from the irons and 0.04-0.38 percent in rutile from the mesosiderite. Graham and Mason (1972) noted a remarkably linear covariance of $\mathrm{Nb}$ and $\mathrm{Zr}$ both in the meteorites and in lunar rocks, and this was also established by Erlank and others (1972). Marvin (1975) noted that the marked coherence of $\mathrm{Nb}$ and $\mathrm{Zr}$ in lunar rocks does not extend to the constituent minerals ; niobium is concentrated in titanium minerals, especially rutile, not in zirconium minerals. It is, therefore,

TABLE 50.-Yttrium in stony meteorites

[From Haskin and others, 1966; and additional data on howardites from McCarthy and others, 1972; and on eucrites from MeCarthy and others, 1973]

\begin{tabular}{|c|c|c|c|c|}
\hline C1ass & $\begin{array}{c}\text { Number } \\
\text { analyzed }\end{array}$ & $\begin{array}{l}\text { Range } \\
(p p m)\end{array}$ & $\begin{array}{l}\text { Mean } \\
(p p m)\end{array}$ & Atoms $/ 10^{6}$ \\
\hline \multicolumn{5}{|c|}{ Chondrites } \\
\hline $\begin{array}{l}\text { C } 1 \\
\text { C } 2 \\
\text { C } 3 \\
\text { H } \\
\text { L } \\
\text { LL } \\
\text { E } 4 \\
\text { E } 5\end{array}$ & $\begin{array}{l}2 \\
2 \\
3 \\
2 \\
2 \\
2 \\
2 \\
1\end{array}$ & $\begin{array}{r}1 \cdot 4-1 \cdot 7 \\
1 \cdot 8-2 \cdot 1 \\
2 \cdot 4 \\
2 \cdot 1-2 \cdot 2 \\
2 \cdot 0-2 \cdot 1 \\
1 \cdot 9-2 \cdot 0 \\
1 \cdot 0-1 \cdot 5 \\
1 \cdot 74\end{array}$ & $\begin{array}{l}1.6 \\
2.0 \\
2.4 \\
2.2 \\
2.1 \\
2.0 \\
1.3 \\
---\end{array}$ & $\begin{array}{l}4.8 \\
4.6 \\
4.9 \\
3.9 \\
3.4 \\
3.2 \\
2.1 \\
3.2\end{array}$ \\
\hline \multicolumn{5}{|c|}{ Calcium-poor achondrites } \\
\hline $\begin{array}{l}\mathrm{Ae} \\
\mathrm{Ah} \\
\mathrm{AC}\end{array}$ & $\begin{array}{l}1 \\
2 \\
1\end{array}$ & $\begin{array}{c}2.09 \\
.22-1.22 \\
.64\end{array}$ & $\begin{array}{r}--- \\
.7 \\
---\end{array}$ & $\begin{array}{r}2.6 \\
.9 \\
1.2\end{array}$ \\
\hline \multicolumn{5}{|c|}{ Calcium-rich achondrites } \\
\hline $\begin{array}{l}\text { Aa } \\
\text { An } \\
\text { Aho } \\
\text { Aeu }\end{array}$ & $\begin{array}{l}1 \\
2 \\
4 \\
8\end{array}$ & $\begin{array}{c}35 \\
3 \cdot 2-4 \cdot 4 \\
4 \cdot 4-12 \\
14-26\end{array}$ & $\begin{array}{l}---\overline{-} \\
3.8 \\
7.6 \\
17\end{array}$ & $\begin{array}{l}54 \\
5 \cdot 2 \\
10 \\
24\end{array}$ \\
\hline
\end{tabular}


somewhat paradoxical that the $\mathrm{Ti} / \mathrm{Nb}$ ratio in the rocks is much more variable than the $\mathrm{Zr} / \mathrm{Nb}$ ratio.

\section{MOLYBDENUM}

Information on the abundance and distribution of molybdenum in meteorites is rather limited. For stony meteorites, no data are available for achondrites; Case and others (1973) analyzed 26 chondrites for this element, and their data are summarized in table 53. They are in agreement with the earlier work of Kuroda and Sadwell (1954). Molybdenum shows a somewhat higher concentration (in terms of atoms $/ 10^{6} \mathrm{Si}$ ) in the carbonaceous chondrites than in the ordinary chondrites; among the latter, the concentration decreases in the sequence H-L-LL, which is also the sequence of decreasing metal content. This is to be expected in view of the siderophile nature of molybdenum. In composites of the chondrites they analyzed, Kuroda and Sanwell (1954) found the metal to contain an average of $8.0 \mathrm{ppm}$, the troilite $5.7 \mathrm{ppm}$, and the silicate 0.6 ppm. Mason and Graham (1970) analyzed metal and troilite separates from two chondrites, and found that the metal contained $7-10 \mathrm{ppm}$, the troilite 3 ppm Mo. The siderophile nature of molybdenum in chondrites has been strikingly confirmed by the discovery by Wark and Lovering (1976) of minute grains of Mo-rich alloy (Mo as high as 26 percent) in the Allende (C3) chondrite.

TABLE 51.-Zirconium in stony meteorites

LFrom Lnmann and Rebagay, 1970, and Lhmann and others, 1976; and additional data on calcium-rich achondrites from IfeCarthy and others, 1972 and 1973 ; on chondrites by Palme, 1974, Ehmann and Chyi, 1974, and Ganapthy and others, 1976]

\begin{tabular}{|c|c|c|c|c|}
\hline Class & $\begin{array}{c}\text { Number } \\
\text { analyzed }\end{array}$ & $\begin{array}{l}\text { Range } \\
(p p m)\end{array}$ & $\begin{array}{l}\text { Mean } \\
(p p m)\end{array}$ & Atoms $/ 10^{6} \mathrm{Si}$ \\
\hline \multicolumn{5}{|c|}{ Chondrites } \\
\hline $\mathrm{Cl}$ & 1 & 4.1 & --- & 12 \\
\hline C 2 & 3 & $4 \cdot 6-5 \cdot 8$ & 5.2 & 11 \\
\hline C 3 & 1 & 5.9 & --- & 12 \\
\hline $\mathrm{H}$ & 5 & $4 \cdot 8-7 \cdot 5$ & $6 \cdot 3$ & 11 \\
\hline $\mathrm{L}$ & 9 & $3 \cdot 9-8 \cdot 9$ & 5.9 & 9.7 \\
\hline LL & 2 & $5 \cdot 2-6 \cdot 5$ & 5.9 & 9.7 \\
\hline E 4 & 2 & $3 \cdot 8-6$ & 4.9 & 9.1 \\
\hline E 5 & 1 & 7 & -- & 13 \\
\hline E 6 & 2 & $3 \cdot 6-7 \cdot 7$ & 5.2 & 8.4 \\
\hline \multicolumn{5}{|c|}{ Calcium-poor achondrites } \\
\hline $\mathrm{Ae}$ & 2 & $0.64-1.2$ & 0.9 & 1.0 \\
\hline Ah & 2 & $1 \cdot 0-2 \cdot 2$ & 1.5 & 1.9 \\
\hline $\mathrm{Ac}$ & 1 & 1.5 & -- & 2.7 \\
\hline $\mathrm{Au}$ & 1 & $3 \cdot 9$ & --- & 6.4 \\
\hline \multicolumn{5}{|c|}{ Calcium-rich achondrites } \\
\hline $\mathrm{Aa}$ & 1 & 100 & -- & 150 \\
\hline An & 1 & $8 \cdot 1$ & --- & 11 \\
\hline Aho & 4 & $15-36$ & 24 & 31 \\
\hline Aeu & 8 & $36-87$ & 52 & 70 \\
\hline
\end{tabular}


Smales, Mapper and Fouché (1967) determined molybdenum in 67 irons, and found a narrow range, 2.2-24.5 ppm, with a mean of $7.2 \mathrm{ppm}$. Fifty-eight of these meteorites were in the restricted range 4.1$8.6 \mathrm{ppm}$, and there appear to be no systematic differences between the different classes. These results are in agreement with the more limited data of Murthy (1963) and Wetherill (1964); however, Wetherill found one iron, Weaver Mountains (an ataxite with 18 percent $\mathrm{Ni}$ ), with $30.1 \mathrm{ppm}$.

\section{RUTHENIUM}

The data on the abundance of ruthenium in chondrites have been assembled and discussed by W. Nichiporuk, in Mason (1971), and are summarized in table 54. They show a relatively small range over the different chondrite classes, and a notable correlation between diminishing metal content and diminishing $\mathrm{Ru}$ concentration in the sequence H-L-LL. Hara and Sandell (1960) prepared two composite samples of six and nine chondrites
( $\mathrm{H}$ and $\mathrm{L}$ ), and separated and analyzed the metal and the troilite phases; the metal contained 4.3 and $5.3 \mathrm{ppm}$, the troilite 6.3 and $5.2 \mathrm{ppm} \mathrm{Ru}$. This indicates that $\mathrm{Ru}$ is about equally siderophile and chalcophile in ordinary chondrites. However, Mason and Graham (1970) found $\mathrm{Ru}$ to be concentrated in the metal phase of chondrites, and did not detect this element in troilite, which suggests that Ru may be completely siderophile in these meteorites.

The only analysis for $\mathrm{Ru}$ in an achondrite is for the diogenite Johnstown, for which a concentration of $0.0029 \mathrm{ppm}$ has been recorded (Bate and Huizenga, 1963).

The most extensive data in $\mathrm{Ru}$ in iron meteorites are those of Crocket (1972), who analyzed for this element in 46 irons. He found a range of 0.16-36 $\mathrm{ppm}$, and an average of $7.32 \mathrm{ppm}$. Scott and Wasson (1975) have plotted the data on a $\mathrm{Ru}-\mathrm{Ni}$ diagram (fig. 13) ; negative correlations are present within the major groups, excluding IA. They noted many similarities to the Ir-Ni plot, although the total

TABLE 52.-Niobium in meteorites

[From Graham and Mason, 1972 ; Erlank and others, 1972]

\begin{tabular}{|c|c|c|c|c|}
\hline C1ass & $\begin{array}{c}\text { Number } \\
\text { ana1yzed }\end{array}$ & $\begin{array}{l}\text { Range } \\
(\mathrm{ppm})\end{array}$ & $\begin{array}{l}\text { Mean } \\
(p p m)\end{array}$ & Atoms $/ 10^{6} \mathrm{Si}$ \\
\hline \multicolumn{5}{|c|}{ Chondrites } \\
\hline C 1 & 1 & 0.3 & --- & 0.9 \\
\hline $\mathrm{C} 2$ & 2 & $.5-.6$ & 0.6 & 1.2 \\
\hline C 3 & 1 & .7 & --- & $1 \cdot 3$ \\
\hline $\mathrm{H}$ & 1 & .4 & --- & .7 \\
\hline L & 1 & .4 & -- & .7 \\
\hline \multicolumn{5}{|c|}{ Calcium-poor achondrites } \\
\hline Ac & 1 & 0.3 & -- & 0.6 \\
\hline \multicolumn{5}{|c|}{ Calcium-rich achondrites } \\
\hline$\overline{A a}$ & 1 & 5 & $\overline{--\infty}$ & 6.5 \\
\hline Aho & 5 & $1 \cdot 0-2 \cdot 9$ & $1 \cdot 9$ & $2 \cdot 4$ \\
\hline Aeu & 8 & $2 \cdot 1-6 \cdot 3$ & $3 \cdot 5$ & 4.6 \\
\hline
\end{tabular}


TABLE 53.-Molybdenum in stony meteorites [From Case and others, 1973]

\begin{tabular}{lcccc}
\hline Class & $\begin{array}{c}\text { Number } \\
\text { Rnalyzed } \\
(\mathrm{ppm})\end{array}$ & $\begin{array}{c}\text { Mean } \\
(\mathrm{ppm})\end{array}$ & Atoms/10 ${ }^{6} \mathrm{Si}$ \\
\hline C 1 & Chondrites & & 4.0 \\
C 2 & 2 & $1.2-1.5$ & 1.4 & 3.4 \\
C 3 & 3 & $1.2-1.8$ & 1.5 & 3.8 \\
H & 6 & $1.7-2.4$ & 2.0 & 2.9 \\
L & 7 & $1.3-2.0$ & 1.7 & 2.0 \\
LL & 3 & $1.1-1.6$ & 1.3 & 1.7 \\
\hline
\end{tabular}

TABLE 54.-Ruthenium in stony meteorites [From Walter Nichlporuk, in Mason, 1971]

\begin{tabular}{lcccc}
\hline Class & $\begin{array}{c}\text { Number } \\
\text { Rnalyzed }\end{array}$ & $\begin{array}{c}\text { Meange } \\
\text { (ppm) } \\
\text { (ppm) }\end{array}$ & Atoms/10 ${ }^{6}$ Si \\
\hline C 1 & Chondrites & & 1.9 \\
C 2 & 3 & $0.58-0.78$ & 0.69 & 1.8 \\
C 3 & 3 & $.69-.88$ & .83 & 1.8 \\
H & 1 & $1.0-1.1$ & 1.0 & 1.8 \\
L & 14 & $.82-1.4$ & 1.1 & .74 \\
LL & 11 & $.60-.82$ & .75 & 1.6 \\
E4 & 1 & .50 & 1.0 & 1.0 \\
\hline
\end{tabular}

variation of Ru is only $10^{2}$, in contrast to $10^{4}$ for $\mathrm{Ir}$.

Wark and Lovering (1976) have identified micronsized metallic grains containing as much as 49 percent $\mathrm{Ru}$ in $\mathrm{Ca}, \mathrm{Al}$-rich inclusions in the Allende (C3) chondrite.

\section{RHODIUM}

The data on rhodium in meteorites have been assembled and discussed by W. Nichiporuk, in Mason (1971). They indicate that this element is the least abundant of the platinum group. The sparse data for the stony meteorites are presented in table $\mathbf{5 5}$. No analyses are available for the carbonaceous chondrites. For the other classes of chondrites $\mathrm{Rh}$ concencentrations do not range widely; however, it may be significant that the single LL meteorite (Benton) has the largest $\mathrm{Rh}$ concentration and the smallest content of metallic nickel-iron of any of the analyzed chondrites. Nichiporuk and Brown (1965) separated the metal phase from five chondrites and found this metal to contain $0.9-1.1 \mathrm{ppm} \mathrm{Rh}$ and to account for the total rhodium content of these meteorites. This 


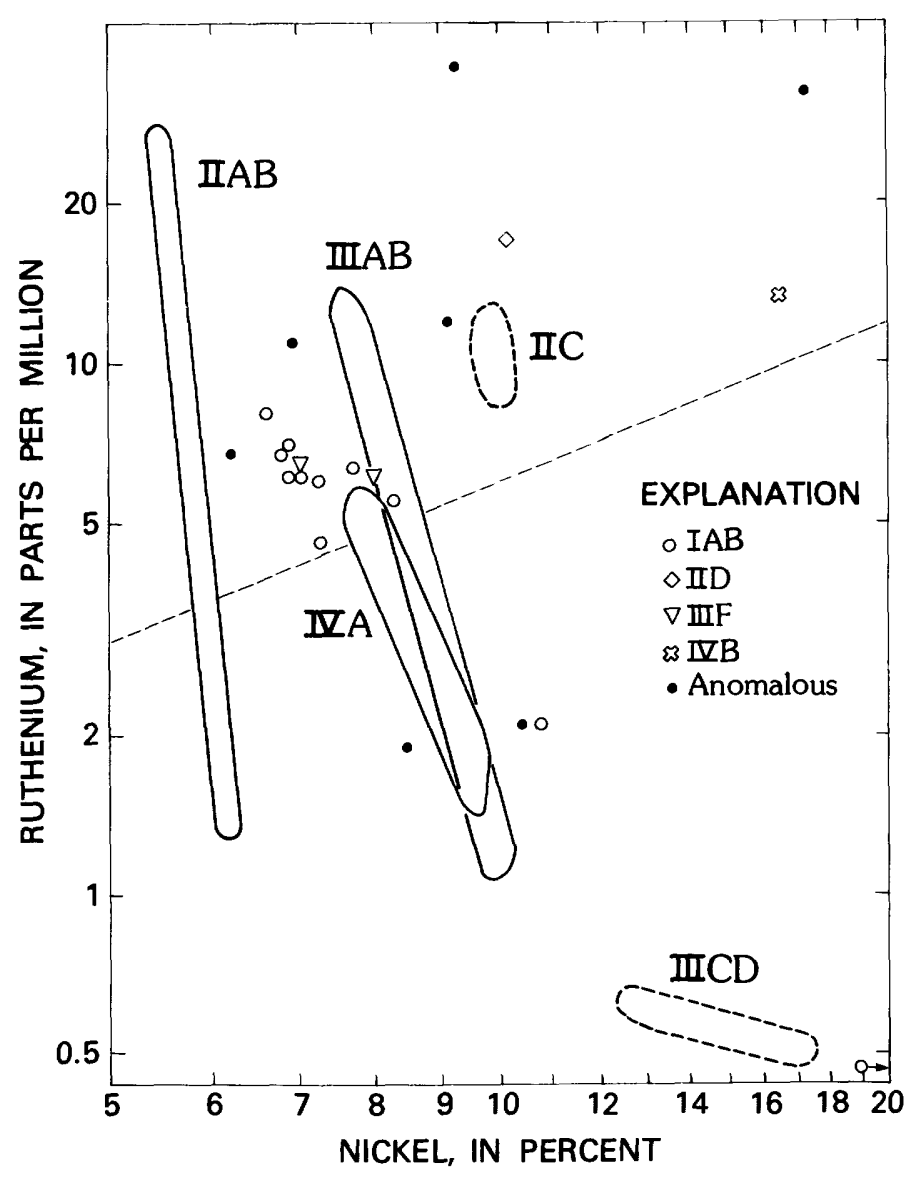

FIGURE 13.-Logarithmic plot of $\mathrm{Ru}$ against $\mathrm{Ni}$ for iron meteorites. Most groups are shown only in outline; this is short dashed when only a few data points define a group. The straight dashed line shows the $\mathrm{Ru} / \mathrm{Ni}$ ratio for $\mathrm{C1}$ chondrites. Reprinted from Scott and Wasson (1975), copyrighted by American Geophysical Union. indicates that the rhodium is probably entirely siderophile in chondrites.

The data on $\mathrm{Rh}$ in iron meteorites indicate a range of 0.14-5.5 ppm. Rhodium concentration shows a generally inverse relationship to nickel concentration, although there are some exceptions.

\section{PALLADIUM}

The date on palladium in meteorites have been assembled and discussed by W. Nichiporuk, in Mason (1971). The information on stony meteorites is given in table 56; this table includes data from Keays, Ganapathy, and Anders (1971) on L and LL chondrites, and omits the data of Greenland (1967), which are inconsistently high for this element. Palladium concentrations are comparable with and a little lower than those for ruthenium. Fouché and Smales (1967b) analyzed separated magnetic (nickel-iron) and nonmagnetic fractions of 20 chondrites and found $\mathrm{Pd}$ to be concentrated in the magnetic fraction at 28 to 360 times that in the nonmagnetic fraction; thus palladium is siderophile with little or no chalcophile or lithophile affinity.

Nichiporuk and Brown (1965) measured palladium in 24 irons, Smales, Mapper, and Fouché (1967) in 67 , and their results are in good agreement. Smales and his coworkers found a range from 1.6 to 19.7 ppm with a mean of $4.3 \mathrm{ppm}$; only two irons contained more than $10 \mathrm{ppm}$, San Cristobal (13.8) and Santa Catharina (19.7), both of these being ataxites having more than 20 percent Ni. Scott (1972) correlated the $\mathrm{Pd}-\mathrm{Ni}$ relationship in iron meteorites with

TABLE 55.-Rhodium in stony meteorites

[From Walter Nichiporuk, in Mason, 1971]

$\begin{array}{ccccc}\text { Class } & \text { Number } & \text { Range } & \text { Mean } & \text { Atoms } / 10^{6} \mathrm{Si} \\ \text { analyzed } & (\mathrm{ppm}) & (\mathrm{ppm}) & \end{array}$

Chondrites

\begin{tabular}{lcccc}
\hline $\mathrm{H}$ & 4 & $0.20-0.40$ & 0.25 & 0.40 \\
$\mathrm{~L}$ & 4 & $.15-.31$ & .22 & .31 \\
$\mathrm{LL}$ & 1 & .48 &.-- & .70 \\
$\mathrm{E}$ & 1 & .25 &.-- & .36 \\
\hline
\end{tabular}


the chemical groupings (fig. 14); he pointed out that $\mathrm{Pd}$, unlike the other platinum metals, shows positive correlations with $\mathrm{Ni}$ in several groups, specifically I, IIAB, IIIAB, and IVA.

\section{SILVER}

Silver is an element of notably low abundance in meteorites, seldom as high as $1 \mathrm{ppm}$ and usually much less. P. R. Buseck, in Mason (1971), assembled and reviewed the data available at that time, but since then several papers have been published on the abundance of silver in different classes of stony meteorites, and these data are summarized in table 57. Individual values within the different classes are notably variable, and this variation is sometimes seen in different samples of the same meteorite. However, the mean values show some significant trends, notably a depletion in the sequence C1-C2-C3-(H, L, LL) and in the sequence E4E5-E6. The achondrites are depleted in silver relative to the chondrites. Silver shows a fairly good correlation with sulfur in the chondrites, the S/Ag ratio (atomic, $\times 10^{-6}$ ) showing a relatively small range, from 0.45 to 1.24 , suggesting that this element is chalcophile in behavior. Greenland (1967) found fairly uniform $\mathrm{Se} / \mathrm{Ag}$ ratios in the chondrites he analyzed, which supports this hypothesis. Little direct information is available on the distribution of

TABLE 56.-Palladium in stony meteorites

[From Walter Nichiporuk, in Mason, 1971; and additional data from Keays and others, 1971]

\begin{tabular}{|c|c|c|c|c|}
\hline C1ass & $\begin{array}{c}\text { Number } \\
\text { analyzed }\end{array}$ & $\begin{array}{l}\text { Range } \\
(\text { ppm })\end{array}$ & $\begin{array}{l}\text { Mean } \\
(\mathrm{ppm})\end{array}$ & Atoms $/ 10^{6} \mathrm{Si}$ \\
\hline \multicolumn{5}{|c|}{ Chondrites } \\
\hline C 1 & 3 & $0.33-0.62$ & 0.49 & 1.3 \\
\hline C 2 & 4 & $.59-.79$ & .68 & 1.3 \\
\hline C 3 & 3 & $.66-1.0$ & .77 & $1 \cdot 3$ \\
\hline $\mathrm{H}$ & 6 & $.52-1.4$ & .91 & 1.4 \\
\hline $\mathrm{L}$ & 11 & $.38-.78$ & .56 & .78 \\
\hline LL & 3 & $.48-.60$ & .54 & .76 \\
\hline E4 & 2 & $.44-1.08$ & .80 & $1 \cdot 3$ \\
\hline E 6 & 2 & $.67-.69$ & .68 & .93 \\
\hline
\end{tabular}




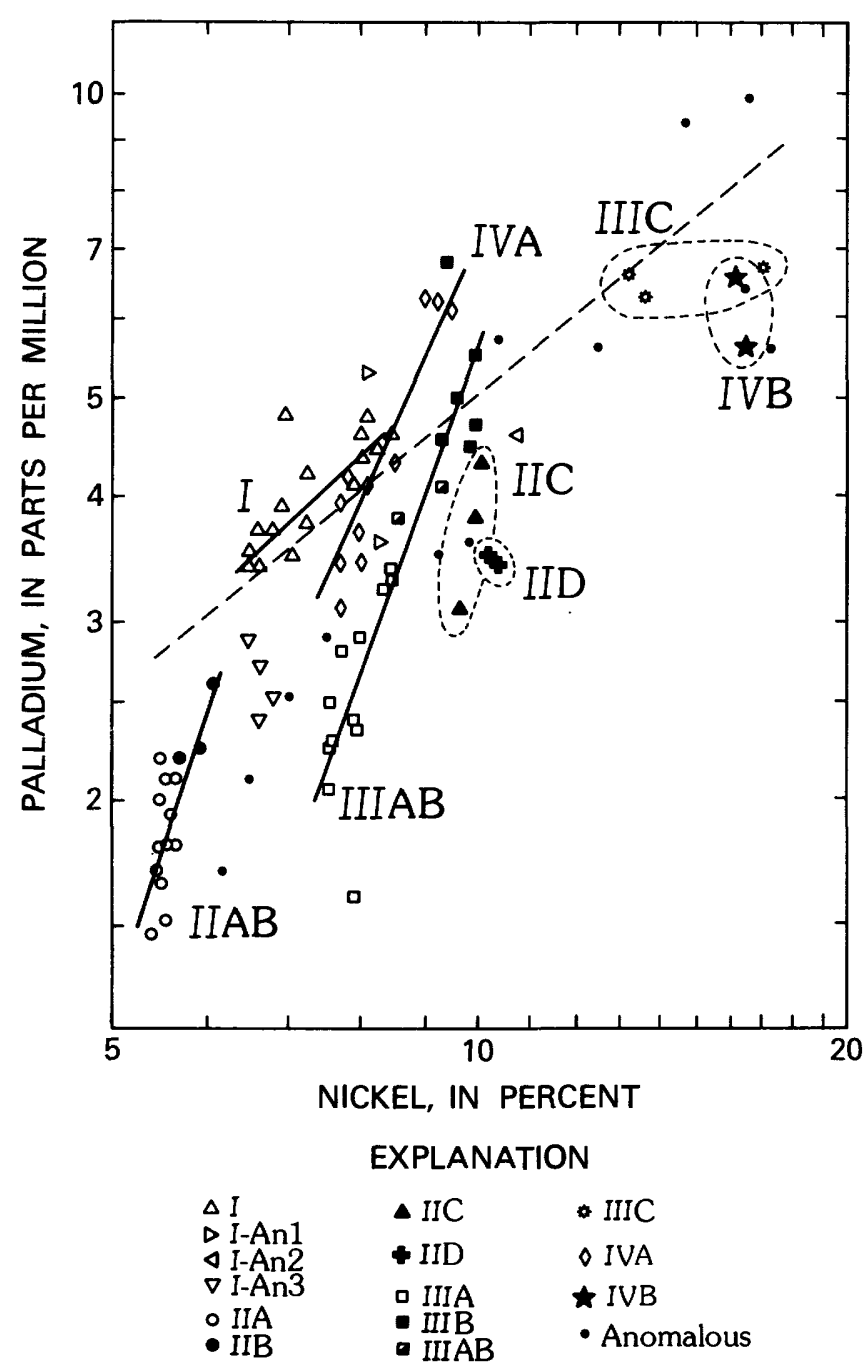

FIGURE 14.-Pd-Ni distribution in iron meteorites; the dashed line is the $\mathrm{Pd} / \mathrm{Ni}$ ratio for $\mathrm{C} 1$ chondrites. Solid lines indicate positive $\mathrm{Pd}-\mathrm{Ni}$ correlation within groups; short-dashed lines enclose well-resolved groups. Reprinted from Scott (1972) and published with permission.

silver in meteorites. Mason and Graham (1970) noted that this element was detected in troilite separated from chondrites, but not in other minerals. Anders and others (1975) found 1.48 and $1.66 \mathrm{ppm}$ $\mathrm{Ag}$ in $\mathrm{HCl}, \mathrm{HF}$-insoluble fractions (largely chromite and spinel) of the Allende meteorite, and 0.090 ppm in the buk meteorite; however, treatment of these fractions with nitric acid reduced the silver content to 0.08 and $0.03 \mathrm{ppm}$, which suggests that the silver was probably contained in pentlandite rather than the chromite and spinel.

Several investigations have been made of silver in iron meteorites, the most extensive being that of Smales, Mapper, and Fouché (1967). In 67 irons they found 28 having less than $0.01 \mathrm{ppm}$, and the concentration in the remainder ranged up to 0.1 $\mathrm{ppm}$. Thus, the concentrations in the irons is notably lower than in the chondrites, indicating that silver has relatively little siderophile affinity.

\section{CADMIUM}

The data on cadmium abundances in meteorites were assembled and discussed by P. R. Buseck, in Mason (1971). However, since then a considerable number of papers with data on cadmium in stony meteorites have been published and table 58 is compiled from these sources. The data are extensive, but where the same meteorite has been analyzed by different investigators the agreement is frequently poor. Different samples of the same meteorite may give markedly different results (Keays and others, 1971), suggesting that $\mathrm{Cd}$ is inhomogeneously distributed, and sampling may be a problem. The data in table 58 show that $\mathrm{Cd}$ concentrations may be extremely variable within a single class. However, significant trends can be distinguished in the means. Carbonaceous and E4 chondrites have much higher Cd concentrations than other classes of stony meteorites. Cadmium is clearly a strongly depleted element as defined by Anders (1971b), the relative depletion in the sequence C1-C2-C3- $(\mathrm{H}, \mathrm{L}, \mathrm{LL})$ being 1.00: 0.58:0.16:0.03. The $\mathrm{Zn} / \mathrm{Cd}$ ratio (atomic) is fairly constant for the carbonaceous and enstatite chondrites at $700-1,100$, whereas in the ordinary $(\mathrm{H}, \mathrm{L}, \mathrm{LL})$ chondrites this ratio is $2,600-3,300$, indicating a considerable depletion in Cd relative to $\mathrm{Zn}$ in the $(\mathrm{H}, \mathrm{L}, \mathrm{LL})$ classes. In general, the achondrites are depleted in $\mathrm{Cd}$ relative to the chondrites.

Iron meteorites have even lower $\mathrm{Cd}$ abundances than stones. Rossman and de Laeter (1974) analyzed 19 irons, and found Cd contents ranging from 0.1 to $22.3 \mathrm{ppb}$, the mean being $5.2 \mathrm{ppb}$. They note a strikingly different abundance pattern of $\mathrm{Cd}$ and $\mathrm{Zn}$ in irons; for example, $\mathrm{Zn}$ abundances in group I irons are tightly clustered, whereas $\mathrm{Cd}$ abundances range widely.

Cadmium is chalcophile in terrestrial rocks and presumably also in meteorites, although no analyses for cadmium on separated minerals have been found in the literature.

\section{INDIUM}

The abundance data for indium in meteorites were assembled and discussed by P. A. Baedecker, in Mason (1971), but since then a large number of publications dealing with this element has appeared 
and table 59 has been compiled from these sources. The data for chondrites show that indium is a strongly depleted element, the relative depletion in the sequence C1-C2-C3-(H, L) being 1.00:0.48:0.25:0.04; a similar depletion is evident in the sequence E4E5-E6. Table 59 shows the extreme variability in indium concentrations within the $\mathrm{H}, \mathrm{L}$, and $\mathrm{LL}$ groups. This was first established by Tandon and Wasson (1968) in a suite of L chondrites, and they found a significant correlation with petrological type, indium concentrations diminishing in the sequence L3-L4-L5-L6; they also establshed a strong correlation between indium concentrations, total $\mathrm{C}$, and concentrations of primordial ${ }^{36} \mathrm{Ar}$ and ${ }^{132} \mathrm{Xe}$. These findings stimulated a great interest in the abundance and distribution of indium in meteorites, hence the large number of recent publications. Other investigators have confirmed Tandon and Wasson's findings, and extended them to the other chondrite classes. The geochemical behavior of indium is evidently linked with its volatility; along with $\mathrm{Bi}$ and $\mathrm{Tl}$, it has the lowest condensation temperature of any of the metallic elements $\left(\sim 460^{\circ} \mathrm{K}\right.$ from a solar gas at $10^{-5}$ atmosphere, according to Laul and others, 1973). Accordingly, it is also an element likely to be volatilized and lost from a meteorite undergoing mild thermal metamorphism; Ikramuddin and Lipschutz (1975) and Ikramuddin, Binz, and Lipschutz (1976) demonstrated this experimentally in the Allende (C3) and Abee (E4) meteorites.

TABLE 57.-Silver in stony meteorites

[From P. R. Buseck, in Mason, 1971; and additional data from Keays and others, 1971; Laul and others, 1972 and 1973; Krähenbühl and others, 1973; Binz and others, 1975; Anders and others, 1976; and Higueh! and others, 1976]

\begin{tabular}{|c|c|c|c|c|}
\hline Class & $\begin{array}{c}\text { Number } \\
\text { analyzed }\end{array}$ & $\begin{array}{l}\text { Range } \\
(p p b)\end{array}$ & $\begin{array}{l}\text { Mean } \\
(p p b)\end{array}$ & Atoms $/ 10^{6} \mathrm{si}$ \\
\hline \multicolumn{5}{|c|}{ Chondrites } \\
\hline C1 & 3 & $118-238$ & 182 & 0.46 \\
\hline $\mathrm{C} 2$ & 3 & $33-172$ & 115 & .23 \\
\hline C 3 & 7 & $81-158$ & 111 & .19 \\
\hline $\mathrm{H}$ & 22 & $22-240$ & 91 & .14 \\
\hline $\mathrm{L}$ & 11 & $36-1,350$ & 163 & .23 \\
\hline LL & 11 & $29-554$ & 137 & .19 \\
\hline E 4 & 4 & $220-377$ & 304 & .48 \\
\hline E 5 & 1 & 189 & --- & .29 \\
\hline E 6 & 5 & $14-167$ & 91 & .12 \\
\hline
\end{tabular}

Calcium-poor achondrites

\begin{tabular}{llrrr}
\hline $\mathrm{Ae}$ & 1 & $13-74$ & 44 & 0.04 \\
$\mathrm{Au}$ & 6 & $4.4-89$ & 32 & .04
\end{tabular}

Calcium-rich achondrites

\begin{tabular}{llccc}
\hline Aa & 1 & 18 & --- & 0.02 \\
An & 2 & $40-58$ & 49 & .06 \\
Aho & 5 & $3.1-214$ & 44 & .05 \\
Aeu & 7 & $13.3-98$ & 34 & 0.04 \\
\hline
\end{tabular}

1 omitting one value of $2,100 \mathrm{ppb}$. 
TABLE 58.-Cadmium in stony meteorites

[From P. R. Buseck, in Mason, 1971; and alditional data from Laul and others, 1972 and 1973; Krähenbühl and others, 1973; Binz and others, 1974, 1975 and 1976; Rosman and de Laeter, 1974; Chou and others, 1976a; and Anders and others, 1976]

\begin{tabular}{|c|c|c|c|c|}
\hline C1ass & $\begin{array}{c}\text { Number } \\
\text { analyzed }\end{array}$ & $\begin{array}{l}\text { Range } \\
(\mathrm{ppb})\end{array}$ & $\begin{array}{l}\text { Mean } \\
(p p b)\end{array}$ & Atoms $/ 10^{6} \mathrm{Si}$ \\
\hline
\end{tabular}

\begin{tabular}{|c|c|c|c|c|}
\hline \multicolumn{5}{|c|}{ Chondrites } \\
\hline $\mathrm{C} 1$ & 3 & $434-686$ & 639 & 1.55 \\
\hline $\mathrm{C} 2$ & 3 & $379-610$ & 470 & .90 \\
\hline C 3 & 7 & $4-485$ & 155 & .25 \\
\hline $\mathrm{H}$ & 11 & $1-152$ & 30 & .04 \\
\hline $\mathrm{L}$ & 12 & $7-129$ & 41 & .05 \\
\hline LL & 11 & $3-96$ & 37 & .05 \\
\hline E 4 & 4 & $85-918$ & 640 & .96 \\
\hline E 5 & 1 & 42 & --- & .06 \\
\hline E 6 & 5 & $4-220$ & 72 & .09 \\
\hline \multicolumn{5}{|c|}{ Calcium-poor achondrites } \\
\hline$\overline{\mathrm{Ae}}$ & 2 & $2-14$ & 8 & 0.007 \\
\hline $\mathrm{Ah}$ & 1 & 14 & --- & .014 \\
\hline $\mathrm{Au}$ & 4 & $12-85$ & 38 & .050 \\
\hline \multicolumn{5}{|c|}{ Calcium-rich achondrites } \\
\hline$\overline{\mathrm{An}}$ & 2 & $71-92$ & 82 & 0.091 \\
\hline Aho & 5 & $1 \cdot 6-88$ & 23 & .024 \\
\hline Aeu & 5 & $1 \cdot 7-8 \cdot 7$ & $4 \cdot 4$ & .005 \\
\hline
\end{tabular}


Indium is evidently strongly chalcophile in chondrites. Fouché and Smales (1967a) separated six $\mathrm{H}$ and $\mathrm{L}$ chondrites into magnetic (metal phase) and nonmagnetic fractions and analyzed each fraction separately; an upper limit of $0.0005 \mathrm{ppm}$ was found in the metal phase, whereas in the nonmagnetic fractions the In concentration ranged up to 0.10 $\mathrm{ppm}$. They also found that 90 percent of the indium in the nonmagnetic fractions of the Abee (E4), Daniel's Kuil (E6), and Bruderheim (L6) meteorites could be leached out with bromine water, which dissolves troilite and other sulfides.

Smales, Mapper, and Fouché (1967) measured indium in 67 iron meteorites; for 38 they recorded $<0.01 \mathrm{ppm}$, and for the remainder the range is 0.0003-0.041 ppm.

\section{TIN}

The rather sparse data on tin in meteorites were assembled and discussed by P. R. Buseck, in Mason (1971). He noted the variability of the results obtained on the same meteorite by different analysts, and sometimes in replicates of the same meteorite by a single analyst, and remarked, "It is unclear whether the spread is a reflection of the difficulties of the analyses or whether it indicates a lack of tin homogeneity in these meteorites" (p. 377). De Laeter, McCulloch, and Rosman (1974) analyzed 18 chondrites and 2 achondrites; their results are summarized in table 60 . They pointed out that $\mathrm{Sn}$ is a strongly depleted element in chondrites, the ratio (atomic) in the sequence $\mathrm{C} 1-\mathrm{C} 2-\mathrm{C} 3-(\mathrm{H}, \mathrm{L})$ being

TABLE 59.-Indium in stony meteorites

[From P. A. Baedecker, in Mason, 1971; and additional data from Keays and others, 1971; Laul and others, 1972 and 1973 ; Krähenbühl and others, 1973; Binz and others, 1974, 1975, and 1976; Baedecker and Wasson, 1975; Ikramuddin and Lipschutz, 1975; Ikramud. din and others, 1976; Chow and others, 1976a, b; Wasson and others, 1976; and Anders and others, 1976]

\begin{tabular}{|c|c|c|c|c|}
\hline Class & $\begin{array}{c}\text { Number } \\
\text { analyzed }\end{array}$ & $\begin{array}{l}\text { Range } \\
(\mathrm{ppb})\end{array}$ & $\begin{array}{l}\text { Mean } \\
(p p b)\end{array}$ & Atoms $/ 10^{6} \mathrm{si}$ \\
\hline
\end{tabular}

Chondrites

\begin{tabular}{|c|c|c|c|c|}
\hline C 1 & 3 & $72-88$ & 80 & 0.19 \\
\hline $\mathrm{C} 2$ & 3 & $46-51$ & 49 & .091 \\
\hline C 3 & 7 & $23-45$ & 30 & .047 \\
\hline $\mathrm{H}$ & 22 & $.054-103$ & $5 \cdot 5$ & .008 \\
\hline $\mathrm{L}$ & 10 & $.06-25.5$ & 5.7 & .007 \\
\hline $\mathrm{LL}$ & 11 & $.59-81$ & 11 & .014 \\
\hline E 4 & 4 & $13-87$ & 68 & .10 \\
\hline E 5 & 1 & 22 & --- & .031 \\
\hline E 6 & 5 & $.39-5.7$ & 3.2 & .004 \\
\hline
\end{tabular}

\begin{tabular}{|c|c|c|c|c|}
\hline \multicolumn{5}{|c|}{ Calcium-poor achondrites } \\
\hline $\begin{array}{l}\mathrm{Ae} \\
\mathrm{Ah} \\
\mathrm{Au}\end{array}$ & $\begin{array}{l}2 \\
1 \\
5\end{array}$ & $\begin{aligned} 0.22-0.29 \\
.50 \\
1.2-2.5\end{aligned}$ & $\begin{array}{r}0.26 \\
--- \\
1.7\end{array}$ & $\begin{array}{r}0.0002 \\
.0005 \\
.002\end{array}$ \\
\hline \multicolumn{5}{|c|}{ Calcium-rich achondrites } \\
\hline $\begin{array}{l}\text { An } \\
\text { Aho } \\
\text { Aeu }\end{array}$ & $\begin{array}{l}2 \\
5 \\
7\end{array}$ & $\begin{array}{r}20.3-24.4 \\
1.67-13.8 \\
.52-4.04\end{array}$ & $\begin{array}{r}22 \cdot 4 \\
5 \cdot 2 \\
1 \cdot 5\end{array}$ & $\begin{array}{r}0.024 \\
.005 \\
.002\end{array}$ \\
\hline
\end{tabular}


$1.00: 0.46: 0.24: 0.12$; the limited data for the enstatite chondrites shows a comparable depletion from E4 to E6.

Tin appears to be siderophile in chondrites. Onishi and Sandell (1957) and Shima (1964) found this element to be essentially confined to the magnetic (nickel-iron) fraction of these meteorites. Its concentration in the metal phase may account for the variable analytical results, owing to sampling problems.

De Laeter and Jeffery (1967) analyzed 14 irons for $\mathrm{Sn}$, and compared their results with those of previous investigators. They found a range from 0.1 to $7.6 \mathrm{ppm}$, in good agreement with prior results; however, Winchester and Aten (1957) recorded two irons with higher values, Tocopilla $(20.2 \mathrm{ppm})$ and Muonionalusta $(10.7 \mathrm{ppm})$. De Laeter and Jeffery's mean is $1.9 \mathrm{ppm}$; they observed that this mean is raised by a high mean $(5.8 \mathrm{ppm})$ for the coarse octahedrites, and that the other classes of iron meteorites appear to be relatively impoverished in tin. Scott (1972) correlated Sn contents with the
Ga-Ge groups; he noted that the highest abundances (4-8 ppm) are found in group I.

\section{ANTIMONY}

The data on antimony in meteorites were assembled and discussed by W. D. Ehmann, in Mason (1971). Since then, however, a considerable amount of new data has been published, and this has been used in the preparation of table 61 ; in general these new data are in good agreement with earlier work. Antimony shows moderate depletion in the sequence $\mathrm{C} 1-\mathrm{C} 2-(\mathrm{H}, \mathrm{L}, \mathrm{LL})$, the ratio (atomic) being 1.00 : $0.61: 0.32$ (the mean figure for C3 chondrites seems anomalously high). Among the enstatite chondrites the E6 class is significantly depleted with respect to E4 and E5. The limited data on achondrites show that most of them are depleted relative to the chondrites.

Antimony appears to be siderophile in stony meteorites. Fouché and Smales (1967b) analyzed separately the metallic phase and the nonmagnetic

TABLE 60.-Tin in.stony meteorites

[From de Laeter and others, 1974]

\begin{tabular}{|c|c|c|c|c|}
\hline Class & $\begin{array}{c}\text { Number } \\
\text { analyzed }\end{array}$ & $\begin{array}{l}\text { Range } \\
(\mathrm{ppm})\end{array}$ & $\begin{array}{l}\text { Mean } \\
(p p m)\end{array}$ & Atoms $/ 10^{6} \mathrm{Si}$ \\
\hline \multicolumn{5}{|c|}{ Chondrites } \\
\hline C 1 & 1 & 1.64 & --- & 3.7 \\
\hline $\mathrm{C} 2$ & 2 & $.88-1.02$ & 0.95 & 1.7 \\
\hline C 3 & 2 & $.42-.78$ & .58 & .89 \\
\hline $\mathrm{H}$ & 8 & $.08-.57$ & .31 & .43 \\
\hline $\mathrm{L}$ & 3 & $.27-.37$ & .34 & .43 \\
\hline E 4 & 1 & 1.65 & --- & 2.2 \\
\hline E 6 & 1 & .67 & --- & .82 \\
\hline
\end{tabular}

Calcium-poor achondrites

\begin{tabular}{|c|c|c|}
\hline & & $0.04-0.12 \quad 0.08$ \\
\hline
\end{tabular}

Calcium-rich achondrites

$\begin{array}{lllll}\text { Aeu } & 1 & 0.37-0.42 & 0.39 & 0.41\end{array}$


material in 20 chondrites, and found that most of the antimony was in the metal phase. For the $\mathrm{H}$ chondrites, the metal contained an average of $0.39 \mathrm{ppm}$ and nonmagnetic fraction $0.034 \mathrm{ppm}$; for the $\mathrm{L}$ chondrites, $0.81 \mathrm{ppm}$ and $0.031 \mathrm{ppm}$; for the $\mathrm{E}$ chondrites, $0.67 \mathrm{ppm}$ and $0.055 \mathrm{ppm}$. The antimony not in the metal phase is probably in troilite rather than silicates, since this element is strongly chalcophile in terrestrial environments.

Smales, Mapper, and Fouché (1967) measured antimony in 67 irons, finding a range from 0.003 to $2.2 \mathrm{ppm}$, with a mean of $0.21 \mathrm{ppm}$. Except for San Cristobal (2.2) and Santa Catharina (1.56), all figures were less than $0.7 \mathrm{ppm}$, and they suggested that the two high values may be due to the presence of troilite inclusions in the samples of these meteorites. Scott (1972) correlated these data with $\mathrm{Ni}$ content and Ga-Ge grouping (fig. 15) ; groups I, IIIAB, and IVA are clearly resolved, with a positive correlation plainly visible in IIIAB.

\section{TELLURIUM}

Fairly extensive data exist for the abundance of tellurium in stony meteorites, but very little for tellurium in iron meteorites. The data available to 1970 were assembled and discussed by I. Pelly and M. E. Lipschutz, in Mason (1971). However, since then, extensive new data have been published on

TABLE 61.-Antimony in stony meteorites

[Data for chondrites from Krähenbühl and others, 1973; Binz and others, 1974 and 1976; Anders and others, 1976; for achondrites from Tanner and Ehmann, 1967, and Higuchi and others, 1976]

\begin{tabular}{|c|c|c|c|c|}
\hline Class & $\begin{array}{c}\text { Number } \\
\text { analyzed }\end{array}$ & $\begin{array}{l}\text { Range } \\
(\mathrm{ppb})\end{array}$ & $\begin{array}{l}\text { Mean } \\
(p p b)\end{array}$ & Atoms $/ 10^{6} \mathrm{Si}$ \\
\hline \multicolumn{5}{|c|}{ Chondrites } \\
\hline $\mathrm{C} 1$ & 3 & $124-184$ & 138 & 0.31 \\
\hline $\mathrm{C} 2$ & 2 & $103-107$ & 105 & .19 \\
\hline C3 & 7 & $41-203$ & 126 & .19 \\
\hline $\mathrm{H}$ & 7 & $59-130$ & 79 & .11 \\
\hline $\mathrm{L}$ & 5 & $58-110$ & 82 & .10 \\
\hline LL & 3 & $64-88$ & 74 & .091 \\
\hline E4 & 3 & $138-241$ & 215 & .30 \\
\hline E5 & 2 & $232-345$ & 289 & .38 \\
\hline E6 & 4 & $87-301$ & 156 & .19 \\
\hline \multicolumn{5}{|c|}{ Calcium-poor achondrites } \\
\hline $\mathrm{Ae}$ & 2 & $15-38$ & 27 & 0.022 \\
\hline $\mathrm{Ah}$ & 2 & $6-36$ & 21 & .020 \\
\hline $\mathrm{Au}$ & 4 & $8-28$ & 14 & .017 \\
\hline \multicolumn{5}{|c|}{ Calcium-rich achondrites } \\
\hline Aho & 2 & $62-230$ & 146 & 0.14 \\
\hline Aeu & 1 & 24 & -- & .024 \\
\hline
\end{tabular}




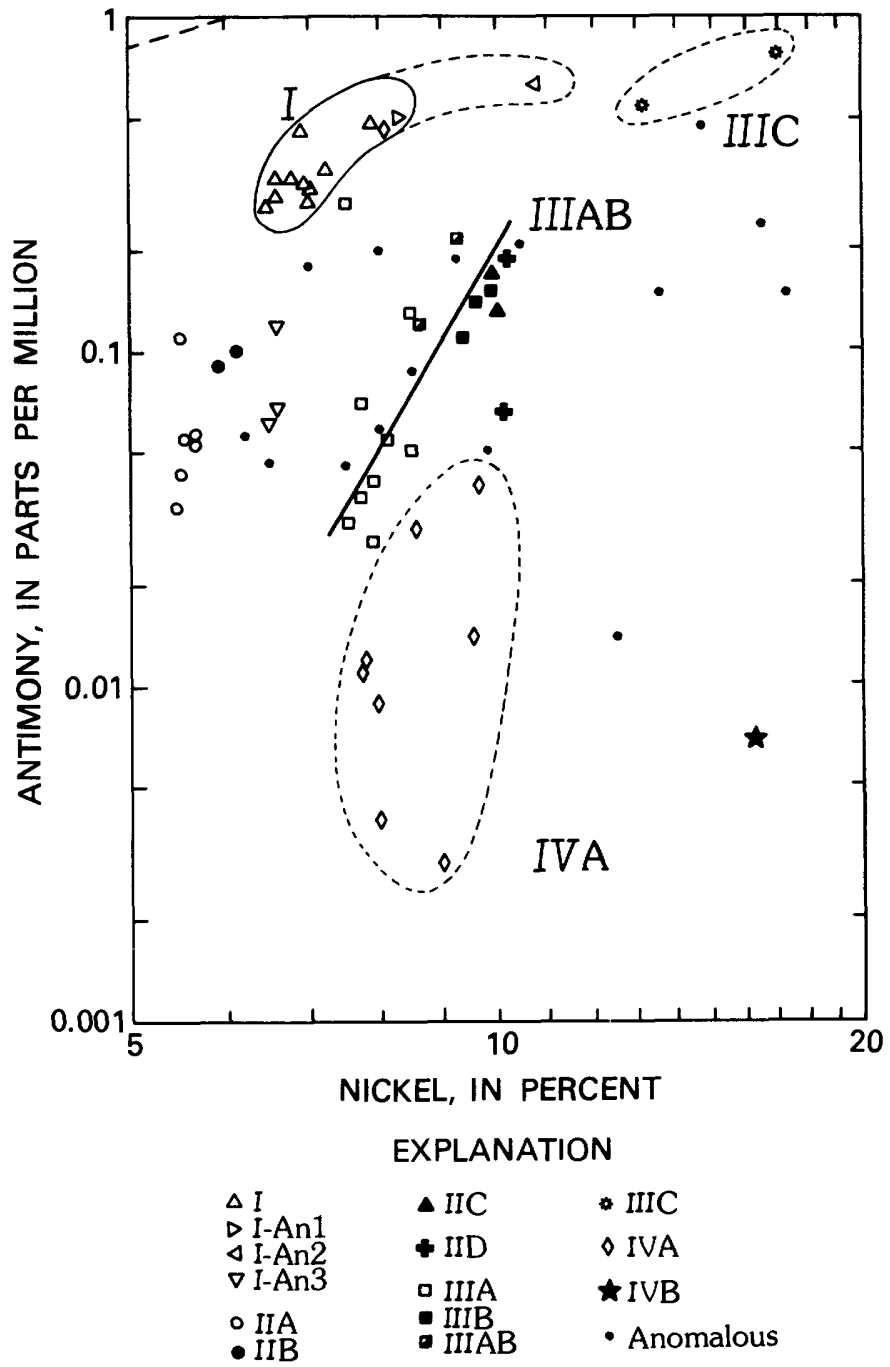

Figure 15.-Sb-Ni distribution in iron meteorites; all iron meteorites fall below the $\mathrm{Sb} / \mathrm{Ni}$ ratio for $\mathrm{C} 1$ chondrites, dashed in upper left corner. Solid line indicates positive Sb-Ni correlation within group IIIAB; short-dashed lines enclose well-resolved groups. Reprinted from Scott (1972) and published with permission.

chondrites, and these have been used in the preparation of table 62. Tellurium is a normally depleted element in chondrites, according to Case and others (1973) and Krähenbühl and others (1973); in the sequence $\mathrm{C} 1-\mathrm{C} 2-\mathrm{C} 3-\mathrm{H}$ the relative concentration (atomic) of tellurium decreases in the proportion 1.00:048:0.20:0.06, and a similar depletion is evident in the sequence E4-E5-E6.

Little is known about the distribution of tellurium among different phases of meteorites. Mason and Graham (1970) recorded that this element shows approximately equal concentration in metal and troilite of chondrites and is absent from the other phases; this indicates that tellurium is both siderophile and chalcophile in these meteorities. In iron meteorites, however, tellurium appears to be almost exclusively chalcophile, according to Goles and Anders (1962); they recorded $5 \mathrm{ppm}$ in Canyon Diablo troilite, $0.09 \mathrm{ppm}$ in the metal, and $1.7 \mathrm{ppm}$ in Toluca troilite, $0.05 \mathrm{ppm}$ in the metal. The equilibrium conditions in iron meteorites, however, may have been considerably different from those in the chondrites.

\section{IODINE}

The data on iodine in meteorites were assembled and discussed by G. W. Reed, in Mason (1971). Since then, no additional data have been published. The information for chondrites are summarized in table 63. The data are rather sparse, and are frequently variable for the same meteorite analyzed by different investigators, and for different samples of the same meteorite analyzed by the same investigator. Thus, for Bruderheim (L6) the following values (ppb) have been recorded: 16, 27, 5 (Goles and Anders, 1962) ; 450, $\leq 74$ (Reed and Allen, 1966) ; 6, 7 (Goles and others, 1967) ; 18, 27 (Clark and others, 1967). The figures for $\mathrm{C} 1$ carbonaceous chondrites are somewhat more consistent: Orgueil 400 (Goles and others), 230 (Reed and Allen); Ivuna 500, 1040, 1210 (Reed and Allen). Goles and Anders (1962) and Reed and Allen (1966) have shown that a significant amount of the iodine in chondrites is water leachable, which may account for much of the variability shown by different samples of the same meteorite. Iodine behaves as a strongly depleted element in the sequence $\mathrm{C1}-\mathrm{C} 2-\mathrm{C} 3-(\mathrm{H}$, $\mathrm{L}$ ), the ratio (atomic) being 1.00:0.57:0.26:0.08; a similar depletion is evident in the sequence E4E5-E6.

Clark and others (1967) determined iodine in a considerable number of achondrites, the results ranging from 14 to $1,000 \mathrm{ppb}$, and most were less than $100 \mathrm{ppb}$. Goles and Anders (1962) and Goles and others (1967) measured iodine in troilite and metal from several iron meteorites, with the following results (in ppb, the first figure for metal, the second for troilite) : Grant 11, 24; Toluca 250, 1,030; Canyon Diablo 28, 62; Sardis 99, 3,590. The higher figure for iodine in some of the troilites suggests that this element is chalcophile; however, both Toluca and Sardis are finds, and the latter is strongly weathered, so the high iodine contents may be a terrestrial effect. Reed and Allen (1966) found 1,700 ppb I in chlorapatite from the Mt. Stirling iron. 


\section{CESIUM}

Cesium is an element of low abundance in meteorites. The only record greater than $1 \mathrm{ppm}$ is 2.8 ppm in the dark part of the Krähenberg (LL5) chondrite; the light part contained $0.08 \mathrm{ppm}$. The data available to 1970 were assembled and discussed by G. G. Goles, in Mason (1971). However, since then, many additional determinations have been made, and these have been used in the compilation of table 64. Cesium is a depleted element in chondrites; in the sequence $\mathrm{C} 1-\mathrm{C} 2-\mathrm{C} 3-(\mathrm{HL} 5,6)$ the atomic ratio is $1.00: 0.54: 0.28: 0.12$, and a similar depletion is seen in the sequence E4-E5, 6. However, the figures for the ordinary $(\mathrm{H}, \mathrm{L}, \mathrm{LL})$ chondrites show a high degree of variability. The H3,4 and L3,4 chondrites are notably enriched in Cs relative to the $(5,6)$ types of these classes. This trend is not evident in the data for the LL class (Laul and others, 1973), in which Jelica (LL6) has the highest Cs content, except for the light part of Krähenberg mentioned above. Since $\mathrm{Cs}$ is the most volatile of the alkali metals, the erratic behavior of this element in chondrites can be ascribed, at least in part, to this factor (Goles, 1971).

The only information on the distribution of $\mathrm{Cs}$ over the different minerals of meteorites has been provided by Mason and Graham (1970), who found 0..3-0.4 ppm Cs in plagioclase from the Modoc (L6),

TABLE 62.-Tellurium in stony meteorites

I Data on chondrites from Keays and others, 1971; Krähenbühl and others, 1973; and Binz and others, 1974, 1976; on achondrites, from Clark and others, 1967, and Binz and others, 1975]

\begin{tabular}{|c|c|c|c|c|}
\hline Clas s & $\begin{array}{c}\text { Number } \\
\text { analyzed }\end{array}$ & $\begin{array}{l}\text { Range } \\
(p p m)\end{array}$ & $\begin{array}{l}\text { Mean } \\
(\mathrm{ppm})\end{array}$ & Atoms $/ 10^{6} \mathrm{Si}$ \\
\hline \multicolumn{5}{|c|}{ Chondrites } \\
\hline $\begin{array}{l}\text { C } 1 \\
\text { C } 2 \\
\text { C } 3 \\
\text { H } \\
\text { L } \\
\text { LL } \\
\text { E } 4 \\
\text { E } 5 \\
\text { E } 6\end{array}$ & $\begin{array}{l}3 \\
3 \\
6 \\
3 \\
10 \\
2 \\
3 \\
2 \\
4\end{array}$ & $\begin{array}{c}2.89-3.14 \\
1.75-2.02 \\
.15-1.4 \\
.22-.43 \\
.14-.97 \\
.41-.61 \\
1.5-3.0 \\
.25-1.3 \\
.25-.52\end{array}$ & $\begin{array}{r}3.04 \\
1.86 \\
.90 \\
.30 \\
.48 \\
.55 \\
2.4 \\
.78 \\
.41\end{array}$ & $\begin{array}{l}6.5 \\
3.1 \\
1.3 \\
.39 \\
.57 \\
.64 \\
3.2 \\
.99 \\
.46\end{array}$ \\
\hline \multicolumn{5}{|c|}{ Calcium-poor achondrites } \\
\hline $\begin{array}{l}\mathrm{Ae} \\
\mathrm{Ah} \\
\mathrm{Au}\end{array}$ & $\begin{array}{l}3 \\
1 \\
5\end{array}$ & $\begin{array}{c}0.22-2.3 \\
.12 \\
.023-.093\end{array}$ & $\begin{array}{c}0.93 \\
--- \\
.050\end{array}$ & $\begin{array}{l}0.74 \\
.11 \\
.059\end{array}$ \\
\hline \multicolumn{5}{|c|}{ Calcium-rich achondrites } \\
\hline $\begin{array}{l}\text { An } \\
\text { Aho } \\
\text { Ae u }\end{array}$ & $\begin{array}{l}1 \\
1 \\
6\end{array}$ & $\begin{array}{c}0.15 \\
.16 \\
.16-.36\end{array}$ & $\begin{array}{l}--- \\
--- \\
.25\end{array}$ & $\begin{array}{r}0.15 \\
.15 \\
.24\end{array}$ \\
\hline
\end{tabular}


St. Severin (LL6), and Winona (E?) meteorites. This would account for the major part of the Cs in these meteorites.

The achondrites are generally depleted in Cs relative to the chondrites, with the notable exception of the nakhlites; it should be noted that the nakhlites are also notably rich in $\mathrm{Rb}$ relative to the other achondrites.

\section{BARIUM}

The data on barium in meteorites were assembled and discussed by C. C. Schnetzler, in Mason (1971). Since then, additional information has been published and has been incorporated in table 65. Although the data on stony meteorites are quite extensive, for many of them, especially finds, values tend to be high and erratic, probably the result of terrestrial contamination; for example, Moore and Brown (1963) found a range from 3 to $290 \mathrm{ppm}$ in 45 chondrite finds. On this account, considerable selectivity has been used in assembling the data for table 65, finds being omitted; where different figures are available for the same meteorite, the lowest value has generally been taken. The table shows that the abundance of barium is fairly uniform over the different chondrite classes, and ranges from 2 to $6 \mathrm{ppm}$, with no significant fractionation between the different classes. Hubbard and Gast (1971) analyzed a chondrite composite and found $3.8 \mathrm{ppm}$. The calcium-poor achondrites have $\mathrm{Ba}$ abundances comparable with those in the chondrites, whereas the calcium-rich achondrites are relatively enriched in this element. Mason and Graham (1970) found that most of the $\mathrm{Ba}$ in stony meteorites is contained in plagioclase (40-72 ppm), and minor amounts in calcium phosphate minerals (11-16 $\mathrm{ppm}$ ). In a melilite-clinopyroxene chondrule from the Allende meteorite, Mason and Martin (1974) found $66 \mathrm{ppm}$ in the melilite and $18 \mathrm{ppm}$ in the pyroxene. In the angrite Angra dos Reis, the 21.5 ppm $\mathrm{Ba}$ probably resides in the accessory mineral celsian, $\mathrm{BaAl}_{2} \mathrm{Si}_{2} \mathrm{O}_{8}$.

\section{THE LANTHANIDES}

Prior to 1960, our knowledge of the abundance of the lanthanides in meteorites was limited to a single determination by Noddack (1935), using X-ray spectroscopy, of these elements in a composite mixture (12 parts chondrite, 1 part achondrite). Beginning in 1960, however (Schmitt and others, 1960), a large amount of data has been accumulated, mainly by the techniques of neutron activation, isotope dilution, and spark-source mass spectrographic analysis. An extensive account was provided by Haskin and others (1966), and their data are summarized in table 66 , together with additional information from table 84 on a chassignite, a ureilite, an angrite, and two howardites.

The lanthanides are a unique group of elements, strongly coherent geochemically because of the filling of the 4-f electron shell. The ionic radius decreases gradually from $1.14 \mathrm{~A}\left(\mathrm{La}^{+3}\right)$ to $0.85 \mathrm{~A}$ $\left(\mathrm{Lu}^{+3}\right)$ - the lanthanide contraction-and chemical fractionation of the individual elements is thereby inhibited (as was demonstrated by the century-long struggle to separate and characterize the individual

TABLE 63.-Iodine in chondrites

[From G. W. Reed, in Mason, 1971]

\begin{tabular}{lcccc}
\hline C1 ass & $\begin{array}{c}\text { Number } \\
\text { analyzed }\end{array}$ & $\begin{array}{c}\text { Range } \\
(\mathrm{ppb})\end{array}$ & $\begin{array}{c}\text { Mean } \\
(\mathrm{ppb})\end{array}$ & Atoms $/ 10^{6} \mathrm{Si}$ \\
\hline C1 & 2 & $230-1,210$ & 580 & 1.16 \\
C2 & 2 & $300-480$ & 390 & .66 \\
C3 & 2 & $170-260$ & 215 & .30 \\
H & 2 & $67-120$ & 68 & .09 \\
L & 3 & $30-76$ & 53 & .07 \\
E4 & 2 & $140-300$ & 220 & .29 \\
E5 & 1 & $64-100$ & 82 & .10 \\
E6 & 1 & $17-89$ & 53 & .06 \\
\hline
\end{tabular}


elements). This geochemical coherence may be somewhat modified for Ce by its having a stable $\mathrm{Ce}^{+4}$ ion, and for Eu by its existence as Eu $\mathbf{u}^{+2}$ under reducing conditions.

Table 66 shows that the abundances of the individual elements vary little over the different classes of chondrites, especially when the figures for atoms/ ${ }^{10} 0^{6} \mathrm{Si}$ are compared (which eliminates the effect of the combined water content of $\mathrm{C} 1$ and $\mathrm{C} 2$ chondrites). Cerium shows greater variability than the other lanthanides; Masuda, Nakamura, and Tanaka
(1973) noted anomalous Ce abundances in some chondrites. Among the chondrite classes, lanthanide abundances are consistently highest in the C3 chondrites. This has been investigated intensively in the Allende meteorite, and shown to be due to the presence therein of $\mathrm{Ca}, \mathrm{Al}-$ rich chondrules and aggregates containing concentrations of lanthanides up to 20 and more times the chondritic average (for example, Gast and others, 1970; Tanaka and Masuda, 1973; Martin and Mason, 1974). Enstatite chondrites show consistently lower lanthanide abun-

TABLE 64.-Cesium in stony meteorites

[From Keays and others, 1971; Laul and others, 1972 and 1973; Krähenbühl and others, 1973; Binz and others, 1975; Anders and others, 1976; and Higuchi and others, 1976]

\begin{tabular}{|c|c|c|c|c|}
\hline Class & $\begin{array}{c}\text { Number } \\
\text { analyzed }\end{array}$ & $\begin{array}{l}\text { Range } \\
(p p b)\end{array}$ & $\begin{array}{l}\text { Mean } \\
(p p b)\end{array}$ & Atoms $/ 10^{6} \mathrm{Si}$ \\
\hline \multicolumn{5}{|c|}{ Chondrites } \\
\hline $\mathrm{C}_{1}$ & 3 & $178-211$ & 192 & 0.39 \\
\hline C 2 & 3 & $121-137$ & 131 & .21 \\
\hline C 3 & 7 & $59-98$ & 81 & .11 \\
\hline H 3,4 & 7 & $22-188$ & 101 & .12 \\
\hline H 5,6 & 15 & $53-110$ & 38 & .046 \\
\hline L 3,4 & 8 & $110-619$ & 307 & .35 \\
\hline L 5,6 & 4 & $4 \cdot 0-72$ & 40 & .045 \\
\hline LL & 11 & $36-590$ & 202 & .23 \\
\hline E4 & 4 & $110-241$ & 202 & .26 \\
\hline E 5 & 1 & 35 & --- & .043 \\
\hline E 6 & 5 & $36-147$ & 90 & .098 \\
\hline \multicolumn{5}{|c|}{ Calcium-poor achondrites } \\
\hline $\mathrm{Ae}$ & 1 & 60 & -- & 0.046 \\
\hline $\mathrm{Ah}$ & 1 & 7.6 & --- & .0064 \\
\hline $\mathrm{Au}$ & 4 & $1 \cdot 9-6 \cdot 3$ & 3.5 & .0039 \\
\hline \multicolumn{5}{|c|}{ Calcium-rich achondrites } \\
\hline Aa & 1 & 1.9 & --- & 0.0020 \\
\hline An & 2 & $287-288$ & 288 & .27 \\
\hline Aho & 5 & $2 \cdot 3-28$ & 9.6 & .0086 \\
\hline Ae u & 7 & $2 \cdot 1-43 \cdot 5$ & 14 & .013 \\
\hline
\end{tabular}


dances than the other chondrite classes. The calciumpoor achondrites have abundances similar to those in chondrites, except for the ureilite, which is strongly depleted in these elements. The calcium-rich achondrites show strong enrichment in the lanthanides, the highest concentrations being in Angra dos Reis (Aa), a unique meteorite which also has the highest $\mathrm{Ca}$ concentration of any meteorite. It can be predicted that calcium would be the only major element for which the lanthanides could be expected to proxy, since its ionic radius falls within the lanthanide series, being close to that of $\mathrm{Nd}$.

Although the lanthanides proxy for calcium, they are quite selective in the phases that they enter. Mason and Graham (1970) have shown that in the Modoc (L6) and St. Severin (LL6) chondrites prac- tically all the lanthanides are contained in the accessory phosphate minerals, and very little in other calcium minerals (except Eu, which is enriched in plagioclase as $\mathbf{E u}^{+2}$ ). In the calcium-rich achondrites, which contain little or no phosphate, the lanthanides are distributed between the calcium-rich pyroxene and the calcium-rich plagioclase in a complementary fashion, the pyroxene being relatively enriched in the heavier elements and strongly depleted in Eu, whereas the plagioclase is enriched in the lighter elements and shows a strong positive Eu anomaly (Schnetzler and Philpotts, 1969). A similar distribution pattern between calcium-rich pyroxene and melilite in a chondrule from the Allende (C3) meteorite has been established by Mason and Martin (1974).

TABLE 65.-Barium in stony meteorites

[From C. C. Schnetzler, in Mason, 1971; and additional data from McCarthy and others, 1972 and 1973; Nakamura and Masuda, 1973; and Nakamura, 1974]

\begin{tabular}{|c|c|c|c|c|}
\hline Class & $\begin{array}{c}\text { Number } \\
\text { analyzed }\end{array}$ & $\begin{array}{l}\text { Range } \\
(\mathrm{ppm})\end{array}$ & $\begin{array}{l}\text { Mean } \\
(p p m)\end{array}$ & Atoms $/ 10^{6} \mathrm{Si}$ \\
\hline \multicolumn{5}{|c|}{ Chondrites } \\
\hline $\begin{array}{l}\text { C } 1 \\
\text { C } 2 \\
\text { C } 3 \\
\text { H } \\
\text { L } \\
\text { L L } \\
\text { E } 4 \\
\text { E } 6\end{array}$ & $\begin{array}{l}1 \\
2 \\
1 \\
4 \\
4 \\
2 \\
2 \\
1\end{array}$ & $\begin{array}{c}2 \cdot 4 \\
2 \cdot 5-3 \cdot 1 \\
4 \cdot 4 \\
3 \cdot 2-5 \cdot 3 \\
3 \cdot 3-3 \cdot 9 \\
3 \cdot 5-6 \\
2 \cdot 3-2 \cdot 8 \\
2 \cdot 8\end{array}$ & $\begin{array}{l}--- \\
2.8 \\
--- \\
4.1 \\
3.7 \\
4.8 \\
2.6 \\
---\end{array}$ & $\begin{array}{l}4 \cdot 8 \\
4.4 \\
5.8 \\
4.9 \\
4.0 \\
5.2 \\
3.2 \\
3.0\end{array}$ \\
\hline \multicolumn{5}{|c|}{ Calcium-poor achondrites } \\
\hline $\begin{array}{l}\mathrm{Ae} \\
\mathrm{Ah} \\
\mathrm{Ac}\end{array}$ & $\begin{array}{l}1 \\
2 \\
1\end{array}$ & $\begin{array}{c}2 \\
2 \cdot 5-4 \\
7 \cdot 1\end{array}$ & $\begin{array}{l}-\overline{-} \\
3 \cdot 3 \\
---\end{array}$ & $\begin{array}{l}1.5 \\
2.7 \\
8.4\end{array}$ \\
\hline \multicolumn{5}{|c|}{ Calcium-rich achondrites } \\
\hline $\begin{array}{l}\text { Aa } \\
\text { An } \\
\text { Aho } \\
\text { Aeu }\end{array}$ & $\begin{array}{l}1 \\
1 \\
4 \\
8\end{array}$ & $\begin{array}{c}21.5 \\
32 \cdot 5 \\
10-22 \\
18.6-53.0\end{array}$ & $\begin{array}{l}--- \\
--\overline{1} \\
15 \\
30.7\end{array}$ & $\begin{array}{l}21 \\
30 \\
13 \\
28\end{array}$ \\
\hline
\end{tabular}




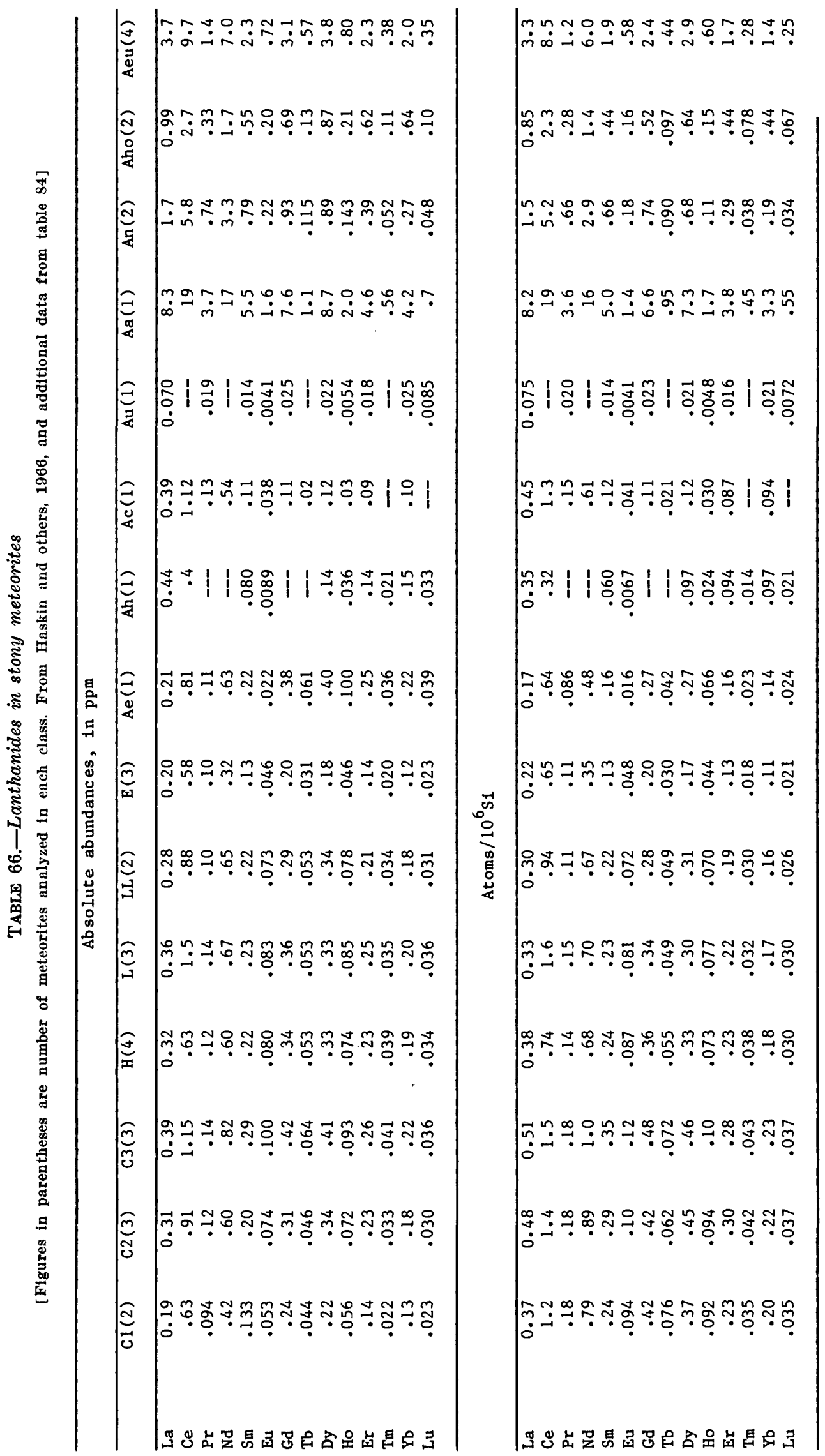


COSMOCHEMISTRY PART 1. METEORITES

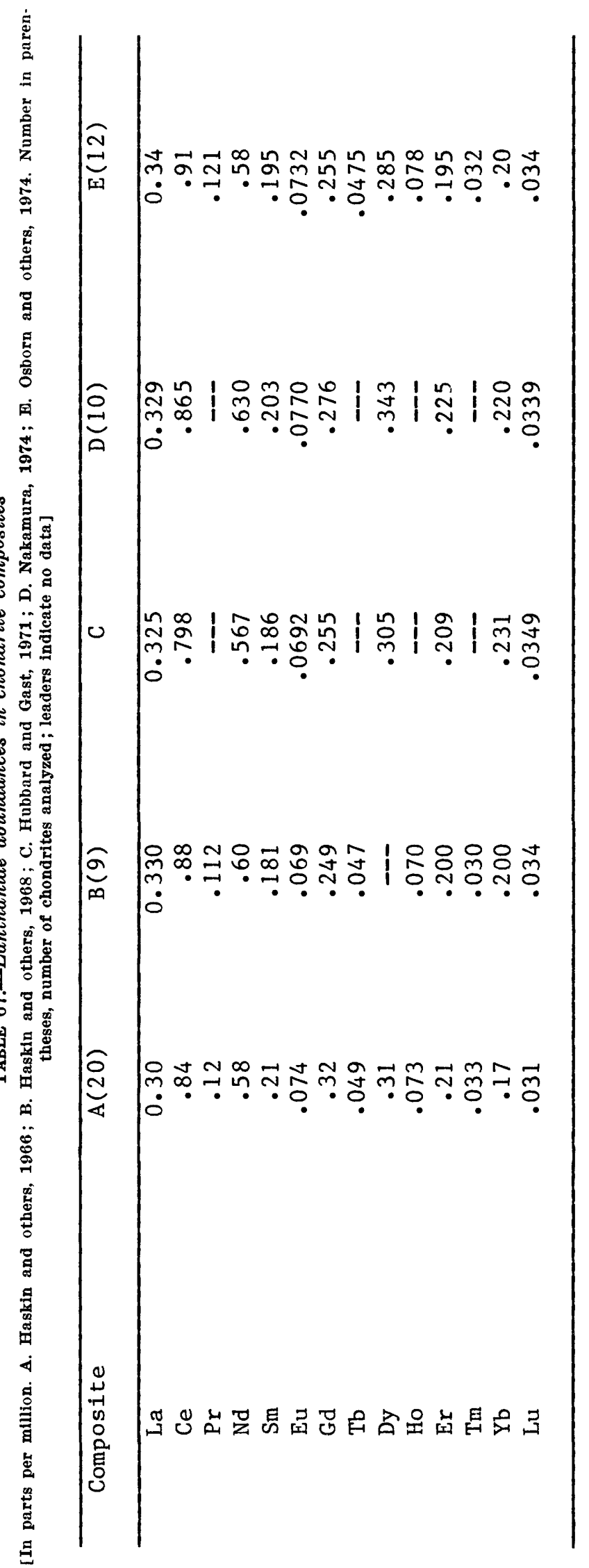




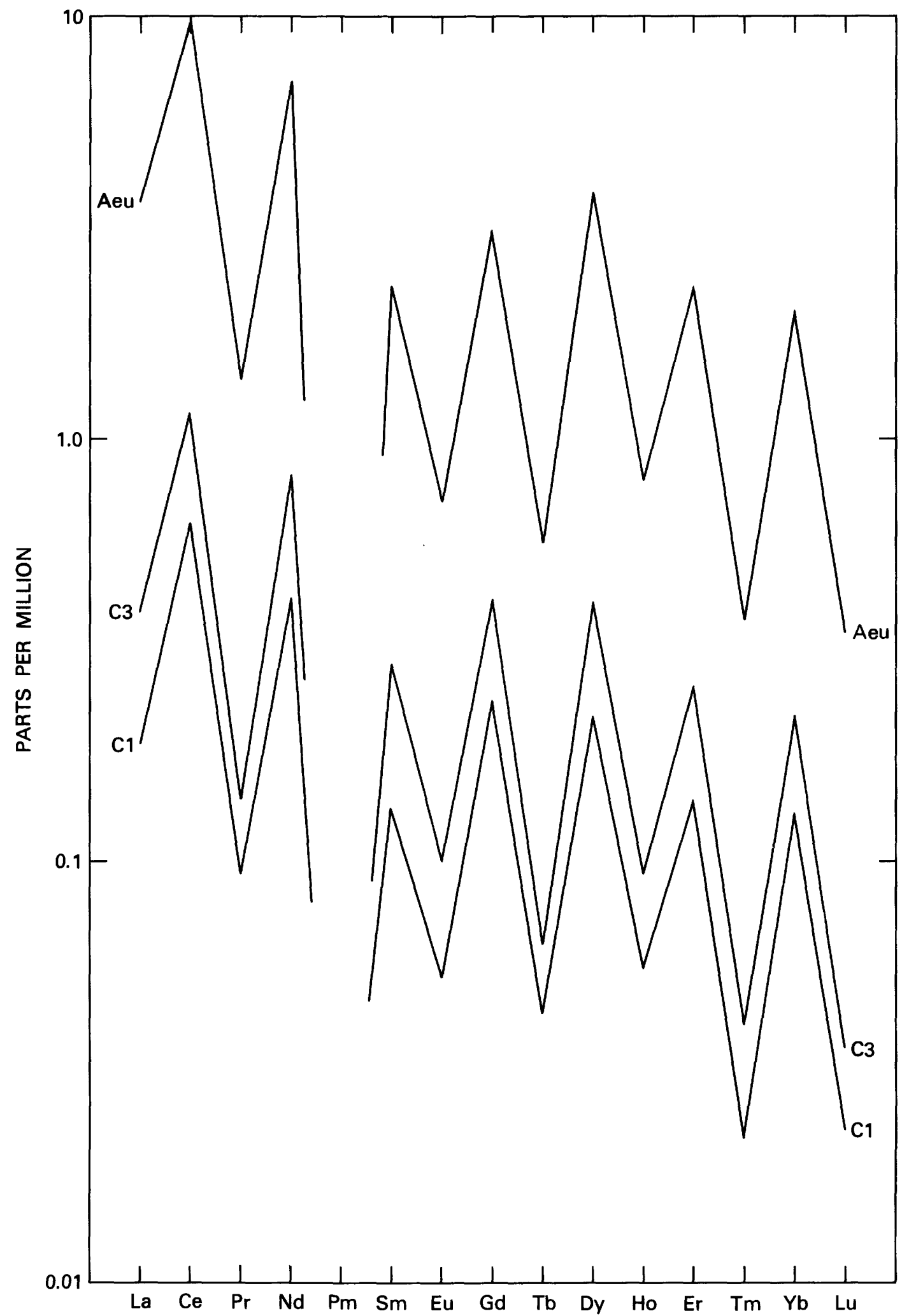

Figure 16.-Lanthanide abundances in C1 chondrites, C3 chondrites, and the eucrites (calciumrich achondrites); note the regularity of the even-odd elemental pattern and the gradual decrease in abundance with increasing atomic number. 


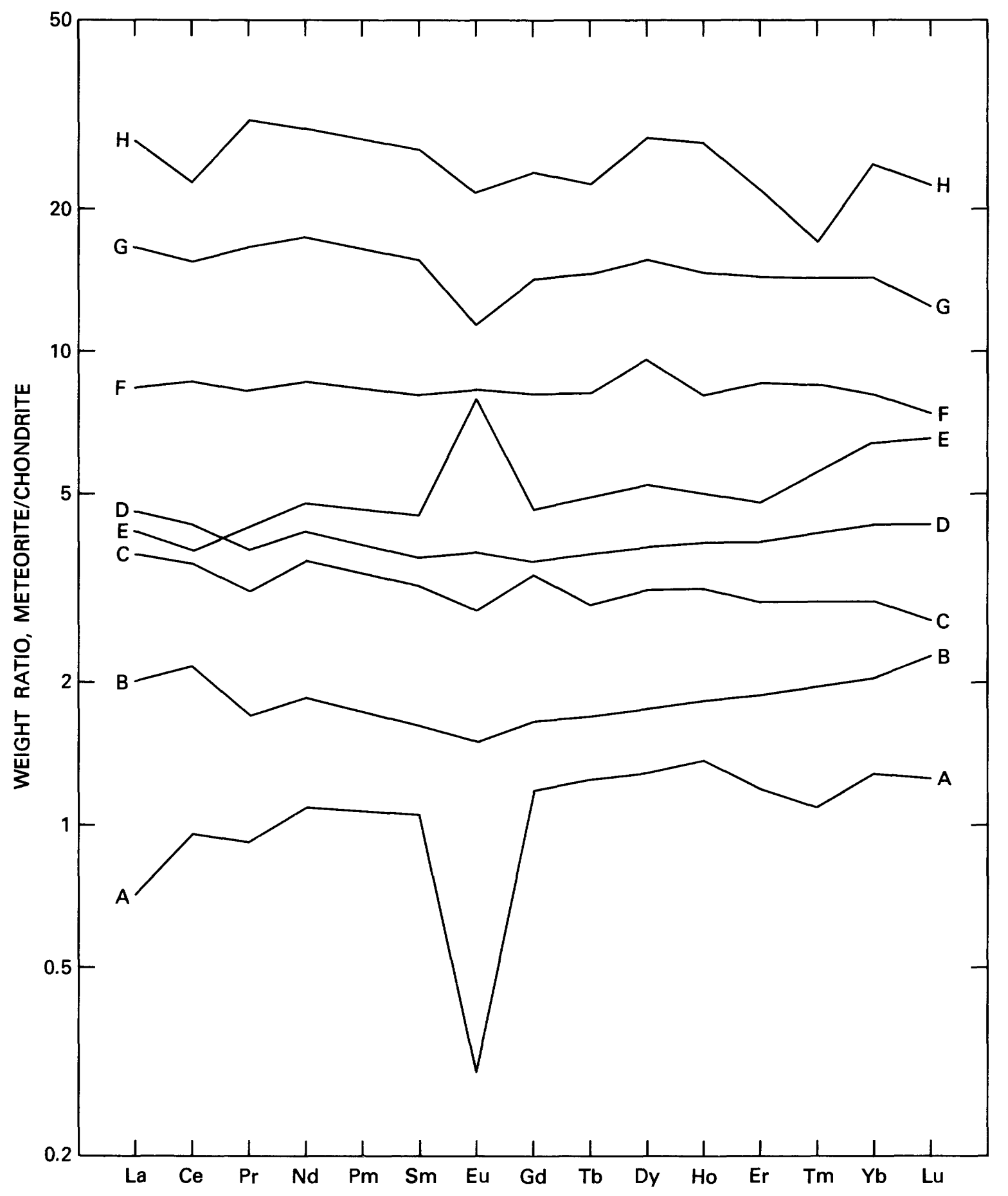

FIGURE 17.-Chondrite-normalized lanthanide abundances in achondrites. $A$, Norton County (Ae); $B$, Zmenj (Aho); $C$, Estherville silicates (M); $D$, Bununu (Aho); $E$, Moore County (Aeu); $F$, Juvinas (Aeu); G, Stannern (Aeu); $H$, Angra dos Reis (Aa).

The lanthanide distribution in meteorites provides the clearest example of the validity of the Oddo-Harkins rule, which states that elements of even atomic number are more abundant than those of odd atomic number on either side. This is il- lustrated in figure 16, which compares the lanthanide abundances in the $\mathrm{C} 1, \mathrm{C} 3$, and Aeu meteorites (from table 66). The close parallelism of these patterns, covering practically the full range of anthanide abundances in stony meteorites, is quite remarkable. 
The figure also illustrates the gradual decrease in abundance with increasing atomic number, although Sm shows a somewhat lower abundance than would be predicted from a smooth curve.

To aid in the comparison of lanthanide distribution paterns not only in meteorites, but also in lunar and terrestrial rocks, the convention of normalization to mean chondritic abundances has been widely adopted. This procedure, in which the abundance of each element is divided by the mean chondritic abundance of that element and the quotient then plotted (usually on a logarithmic scale, as in fig. 17), eliminates the sawtooth pattern of figure 16 and facilitates the interpretation of lanthanide distributions. A number of chondrite composites have been analyzed by different researchers to provide the normalizing abundances; these are given in table 67. As can be seen, good agreement exists between the different sets of figures, especially when the figures for $\mathrm{Gd}$ and $\mathrm{Yb}$ in set $\mathrm{A}$ are eliminated.

Figure 17 presents normalized lanthanide distributions for a variety of achondrites. (The numerical data for these meteorites are given in table 84.) A notable feature is the relative flatness and parallelism of most of the curves, indicating a lack of fractionation between individual elements. The lanthanide abundances increase in the sequence Norton County (Ae), Zmenj (Aho), Estherville (silicates from a mesosiderite), Bununu (Aho), Moore County, Juvinas, Stannern (Aeu), Angra dos Reis (Aa). The anomalous behavior of $\mathrm{Eu}$ is clearly seen in Moore County and Norton County, and to a lesser extent in Stannern. The positive Eu anomaly in Moore County has been plausibly ascribed to the presence of cumulus plagioclase enriched in this element (Schnetzler and Philpotts, 1969). The negative Eu anomalies in Norton County and Stannern can correspondingly be considered evidence for the possible removal of plagioclase from the parent material of these meteorites.

The Eu anomalies in meteorites were for a long time considered unique to this element among the lanthanides. However, Tanaka and Masuda (1973) discovered $\mathrm{Yb}$ anomalies (both positive and negative) in components of the Allende meteorite, and these have been confirmed by Martin and Mason (1974) and others. Conrad, Schmitt, and Boynton (1975) and Mason and Martin (1977) found strong positive $\mathrm{Tm}$ anomalies in $\mathrm{Ca}, \mathrm{Al}$-rich aggregates from the Allende meteorite. Therefore, although in general the lanthanides behave as a very coherent group in meteorites, individual components in these meteorites may show marked fractionations between adjacent elements.
Haskin and others (1966) reported that partial analyses of two irons for lanthanides show these elements to be present in very low concentrations of the order of $10^{-4}-10^{-5} \mathrm{ppm}$, confirming their lithophile character.

\section{HAFNIUM}

Hafnium (and zirconium) were determined by neutron activation analysis in 28 chondrites and 7 achondrites by Ehmann and Rebagay (1970); the data for achondrites were revised and extended by Ehmann and others (1976). Additional data have been provided by Jérome (1970), Ehmann and Chyi (1974), and Ganapathy, Papia, and Grossman (1976). The more recent data have tended to revise earlier determinations for both elements downwards, and to lower the $\mathrm{Zr} / \mathrm{Hf}$ weight ratio; Ehmann and Rebagay (1970) gave an average value of approximately 38 for this ratio in 28 chondrites, and

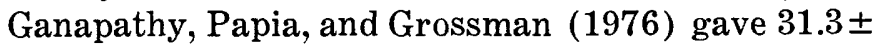
2.2 (on the basis of analyses of 4 chondrites). The information summarized in table 68 indicates that a weight ratio in the $30-35$ range is reasonable; it is probably significant that this ratio is shown by the calcium-rich achondrites, in which both $\mathrm{Zr}$ and Hf are strongly enriched relative to the chondrites. Values deviating from the 30-35 range are based on few data points and very low values for $\mathrm{Hf}$ in the calcium-poor achondrites. The evidence favors close geochemical coherence of $\mathrm{Zr}$ and $\mathrm{Hf}$ in stony meteorites, and no fractionation between these elements in different classes.

\section{TANTALUM}

The data on tantalum abundance in meteorites are rather sparse, being essentially those of Atkins and Smales (1960) and Ehmann (1965), with two determinations by Wänke, Baddenhausen, Balacescu, and others (1972)-Kapoeta (Aho), 0.10 ppm; Juvinas (Aeu), $0.12 \mathrm{ppm}$. The data are summarized in table 69 . They indicate a rather uniform abundance in the different chondrite classes, and relative depletion in the calcium-poor achondrites and enrichment in the calcium-rich achondrites-a pattern characteristic of many nonvolatile lithophile elements. Graham and Mason (1972) noted that the $\mathrm{Nb} / \mathrm{Ta}$ weight ratio in stony meteorites ranged from 14 to 30 , but in view of the paucity of data for both these elements, no significance can be deduced from the range of this ratio; for the calcium-rich achondrites, in which both $\mathrm{Nb}$ and $\mathrm{Ta}$ have been determined in the same meteorites, this ratio is 29 (Kapoeta), 23 (Juvinas), and 30 (Pasamonte).

The few determinations of Ta in iron meteorites 
give concentrations of the order of $1 \mathrm{ppb}$, confirming the lack of siderophile affinity of this element.

\section{TUNGSTEN}

The most extensive data on tungsten in meteorites have been provided by Atkins and Smales (1960) and Amiruddin and Ehmann (1962), and their results are in excellent agreement. Rieder and Wänke (1969) measured this element in 10 chondrites, but their results are approximately 50 percent higher than those reported by the other two groups, and have not been used in compiling table 70. Wänke, Baddenhausen, Balacescu, and others (1972) provided data on two calcium-rich achondrites: Kapoeta (Aho), $36 \mathrm{ppb;} \mathrm{Juvinas} \mathrm{(Aeu),} 41$ ppb. Hintenberger, Jochum, and Seufert (1973) analyzed 11 stony meteorites; their results for comparable meteorites are somewhat higher than those of Amiruddin and Ehmann, but have been used in table $\mathbf{7 0}$ for the $\mathrm{C} 1$ and $\mathrm{E}$ chondrites.

Amiruddin and Ehmann noted a correlation between tungsten abundances and metal-phase content in stony meteorites. This is reflected in the high abundance in the $\mathrm{E}$ chondrites, which are relatively enriched in metal phase, and in the low abundances in the LL chondrite and the achondrites, which contain little or no metal (except the ureilite). Tungsten is evidently a strongly siderophile element; Mason and Graham (1970) noted the presence of this element in metal separates from chondrites, and were unable to detect it in other phases. Iron meteorites are notably enriched in this element relative to

TABLE 68.-Hafnium in meteorites

[From Ehmann and Rebagay, 1970; and additional data from Ehmann and others, 1976; Jérome, 1970; Ehmann and Chyl, 1974 ; and Ganapathy and others, 1976]

\begin{tabular}{|c|c|c|c|c|c|}
\hline Class & $\begin{array}{c}\text { Number } \\
\text { analyzed }\end{array}$ & $\begin{array}{l}\text { Range } \\
\text { (ppm) }\end{array}$ & $\begin{array}{l}\text { Mean } \\
\text { (ppm) }\end{array}$ & Atoms $/ 10^{6} \mathrm{Si}$ & $\begin{array}{c}\mathrm{Zr} / \mathrm{Hf} \\
\text { (weight) }\end{array}$ \\
\hline \multicolumn{6}{|c|}{ Chondrites } \\
\hline $\mathrm{Cl}$ & 1 & 0.11 & -- & 0.17 & 28 \\
\hline $\mathrm{C} 2$ & 1 & .14 & - - & .17 & 33 \\
\hline C3 & 1 & .19 & -- & .19 & 31 \\
\hline $\mathrm{H}$ & 5 & $.09-.38$ & 0.18 & .17 & 35 \\
\hline $\mathrm{L}$ & 8 & $.07-.32$ & .17 & .14 & 35 \\
\hline LL & 2 & $.14-.15$ & .15 & .13 & 48 \\
\hline$E$ & 3 & $.07-.21$ & .14 & .12 & 36 \\
\hline \multicolumn{6}{|c|}{ Calcium-poor achondrites } \\
\hline $\mathrm{Ae}$ & 2 & $0.01-0.03$ & 0.02 & 0.01 & 45 \\
\hline Ah & 2 & $.01-.05$ & .03 & .02 & 50 \\
\hline $\mathrm{Au}$ & 1 & .055 & -- & .05 & 71 \\
\hline \multicolumn{6}{|c|}{ Calcium-rich achondrites } \\
\hline $\mathrm{Aa}$ & 1 & 3 & -- & 2.30 & 33 \\
\hline An & 1 & .25 & $-\infty$ & .17 & 32 \\
\hline Aho & 5 & $.50-.92$ & .70 & .47 & 34 \\
\hline Aeu & 9 & $.61-2.88$ & 1.50 & 1.04 & 35 \\
\hline
\end{tabular}


chondrites. In five irons, Amiruddin and Ehmann (1962) recorded $0.78-1.45 \mathrm{ppm}$; in a sample of troilite from the Canyon Diablo iron they recorded $0.020,0.013 \mathrm{ppm}$, and remarked that these figures were upper limits because of the possibility of inclusions of metal.

Wänke and others (1974) noted the remarkably high concentration of $1.84 \mathrm{ppm} \mathrm{W}$ in a $\mathrm{Ca}, \mathrm{Al}$-rich chondrule from the Allende (C3) meteorite, approximately 20 times the concentration in the bulk meteorite. Similar enrichment was noted for many other refractory elements, and this is consistent with the interpretation of these chondrules as high-temperature condensates. Wark and Lovering (1976) have found up to 2 percent tungsten in metal grains included in these Allende chondrules. Scott (1972) pointed out that tungsten has the highest condensation temperature of the elements, $1,960 \mathrm{~K}$ at $10^{-4}$ atm.

\section{RHENIUM}

The data on rhenium in meteorites have been assembled and discussed by J.W. Morgan, in Mason (1971). Additional information has been provided by Case and others (1973), Krähenbühl and others (1973), Hintenberger, Jochum, and Seufert (1973), Herman and Wichtl (1974), Anders and others (1976), and Higuchi and others (1976). These additional figures are in good agreement with earlier determinations, except for the data of Hintenberger, Jochum, and Seufert (1973), which tend to be considerably higher than other measurements on the same meteorites; the discrepancy may lie in the technique used, since Hintenberger and coworkers utilized spark-source mass spectrometry, whereas all other determinations were made by neutron-activation analysis. The results are summarized in table 71. Rhenium is a strongly siderophile element, and the data in table 71 reflect this. Atomic abundances

TABLE 69.-Tantalum in stony meteorites

[Data from Atkins and Smales, 1960; Ehmann, 1965; Wänke, Baddenhausen, Balacescu, and others, 1972; and Ma and others, 1977]

\begin{tabular}{|c|c|c|c|c|}
\hline Class & $\begin{array}{c}\text { Number } \\
\text { analyzed }\end{array}$ & $\begin{array}{l}\text { Range } \\
\text { (ppb) }\end{array}$ & $\begin{array}{l}\text { Mean } \\
(p p b)\end{array}$ & Atoms $/ 10^{6} \mathrm{Si}$ \\
\hline \multicolumn{5}{|c|}{ Chondrites } \\
\hline $\mathrm{C} 2$ & 1 & 17 & -- & 0.020 \\
\hline $\mathrm{H}$ & 4 & $18-29$ & 23 & .021 \\
\hline $\mathrm{L}$ & 8 & $17-31$ & 23 & .019 \\
\hline \multicolumn{5}{|c|}{ Calcium-poor achondrites } \\
\hline $\mathrm{Ae}$ & 2 & $<10, \sim 4$ & $-\infty$ & -- \\
\hline $\mathrm{Ah}$ & 1 & 8 & -- & .005 \\
\hline \multicolumn{5}{|c|}{ Calcium-rich achondrites } \\
\hline $\mathrm{Aa}$ & 1 & 370 & -- & 0.28 \\
\hline Aho & 1 & 100 & -- & .066 \\
\hline Aeu & 2 & 120 & -- & .082 \\
\hline
\end{tabular}


in the $\mathrm{C} 1, \mathrm{C} 2, \mathrm{C} 3, \mathrm{H}$, and $\mathrm{E}$ chondrites are essentially the same, but the $\mathrm{L}$ and LL classes are depleted relative to the $\mathrm{H}$ chondrites, which correlates with their lower metal contents. The achondrites (essentially metal free except the ureilites) are strongly depleted relative to the chondrites. Fouche and Smales (1967b) analyzed magnetic (metal) and nonmagnetic fractions of a number of chondrites, and found the metal phase to contain 36-360 times the Re concentration of the nonmagnetic fraction. Wänke and others (1974) have recorded a notable enrichment (0.73 ppm) of $\mathrm{Re}$ in a Ca,Al-rich chondrule from the Allende (C3) meteorite, about 20 times the concentration in the bulk meteorite.

Most iron meteorites are notably enriched in $\mathrm{Re}$ relative to the chondrites, although the concentration range is large, $0.002-4.8 \mathrm{ppm}$. Scott (1972) plotted $\mathrm{Re}$ against $\mathrm{Ni}$ and demonstrated a correlation with the chemical groups (fig. 18). Group IIAB spans the total range of $\mathrm{Re}$ concentrations, and groups IIIAB and IVA are fractionated by factors of at least 100 and 50. Group I forms a tight cluster lying on the cosmic $\mathrm{Re} / \mathrm{Ni}$ ratio line. The limited data show a clustering for groups IIC, IID, and IVB.

\section{OSMIUM}

The data on osmium in meteorites were assembled and discussed by J. W. Morgan, in Mason (1971), and table 72 provides a summary. Additional information has been provided by Vinogradov and others $(1972,1973)$, Hintenberger, Jochum, and Seufert (1973), and Herman and Wichtl (1974). The results of these more recent investigations are generally in good agreement with previous determinations, although the figures given by Hintenberger and coworkers for chondrites are consistently higher

TABLE 70.-Tungsten in stony meteorites

[From Atkins and Smales, 1960 ; Amiruddin and Ehmann, 1962 ; and additional data]

\begin{tabular}{|c|c|c|c|c|}
\hline Class & $\begin{array}{c}\text { Number } \\
\text { analyzed }\end{array}$ & $\begin{array}{l}\text { Range } \\
\text { (ppb) }\end{array}$ & $\begin{array}{l}\text { Mean } \\
(\mathrm{ppb})\end{array}$ & Atoms $/ 10^{6} \mathrm{Si}$ \\
\hline \multicolumn{5}{|c|}{ Chondrites } \\
\hline $\mathrm{Cl}$ & 1 & 200 & - & 0.30 \\
\hline $\mathrm{C} 2$ & 2 & $130-150$ & 140 & .16 \\
\hline C3 & 1 & 150 & -- & .15 \\
\hline $\mathrm{H}$ & 7 & $100-170$ & 140 & .13 \\
\hline L & 13 & $70-190$ & 120 & .10 \\
\hline LL & 1 & 80 & -- & .065 \\
\hline $\mathrm{E}$ & 2 & $320-370$ & 350 & .32 \\
\hline \multicolumn{5}{|c|}{ Calcium-poor achondrites } \\
\hline $\mathrm{Ae}$ & 3 & $20-120$ & 80 & 0.044 \\
\hline $\mathrm{Ah}$ & 1 & $50-80$ & 65 & .040 \\
\hline $\mathrm{Au}$ & 1 & 180 & -- & .14 \\
\hline \multicolumn{5}{|c|}{ Calcium-rich achondrites } \\
\hline Aho & 1 & 36 & -- & 0.023 \\
\hline Aeu & 1 & 41 & -- & .028 \\
\hline
\end{tabular}


than those for the same meteorites analyzed by other investigators. The pattern of Os abundances in chondrites shows marked depletion in the sequence $\mathrm{H}-\mathrm{L}-\mathrm{LL}$, paralleling a decrease in the metal content; achondrites are strongly depleted in Os relative to the chondrites. This pattern is typical of a siderophile element. Wark and Lovering (1976) found microscopic metallic grains in the Allende (C3) chondrite that contain 38 percent Os, although the meteorite contains the normal concentration of Os $(\sim 0.9 \mathrm{ppm})$ for a C3 meteorite. In the ordinary chondrites one would expect to find most of the osmium in the metal phase; however, the data of Vinogradov and others $(1972,1973)$ on separated phases of chondrites indicate that appreciable amounts may be present in the troilite.

Osmium is present in iron meteorites in concen- trations ranging from 0.009 to $58 \mathrm{ppm}$, with an average of $5.36 \mathrm{ppm}$ (Crocket, 1972). Figure 19 shows the relationship between $\mathrm{Os}, \mathrm{Ni}$, and the chemical groupings of iron meteorites; the distribution pattern is similar to that for Re and Ir. Crocket (1972) discussed the high degree of correlation between $\mathrm{Os}, \mathrm{Ir}$, and $\mathrm{Ru}$ in iron meteorites.

\section{IRIDIUM}

The data on iridium abundances in meteorites were assembled and discussed by P. A. Baedecker, in Mason (1971). Since then, however, a large number of new analyses have been made on stony meteorites, and these have been used in the compilation of table 73. Iridium abundances in specific classes are closely similar to those for osmium (table

TABLE 71.-Rhenium in stony meteorites

[From J. W. Morgan, in Mason, 1971; and additional data from Case and others, 1973; Krähenbühl and others, 1973; Hintenberger and others, 1973; Herman and Wichtl, 1974; Anders and others, 1976; and Higuchi and others, 1976]

\begin{tabular}{|c|c|c|c|c|}
\hline Class & $\begin{array}{c}\text { Number } \\
\text { analyzed }\end{array}$ & $\begin{array}{l}\text { Range } \\
\text { (ppb) }\end{array}$ & $\begin{array}{l}\text { Mean } \\
(\mathrm{ppb})\end{array}$ & Atoms $/ 10^{6} \mathrm{si}$ \\
\hline \multicolumn{5}{|c|}{ Chondrites } \\
\hline$\overline{\mathrm{Cl}}$ & 3 & $25-43$ & 35 & 0.051 \\
\hline $\mathrm{C} 2$ & 3 & $43-49$ & 46 & .053 \\
\hline $\mathrm{C} 3$ & 7 & $50-59$ & 55 & .052 \\
\hline $\mathrm{H}$ & 12 & $60-100$ & 67 & .059 \\
\hline $\mathrm{L}$ & 16 & $23-67$ & 37 & .030 \\
\hline LL & 4 & $16-25$ & 22 & .018 \\
\hline $\mathrm{E}$ & 7 & $51-68$ & 60 & .050 \\
\hline \multicolumn{5}{|c|}{ Calcium-poor achondrites } \\
\hline $\mathrm{Ae}$ & 1 & 0.25 & -- & 0.00014 \\
\hline Ah & 2 & $.06-1.3$ & .4 & .00024 \\
\hline $\mathrm{Au}$ & 4 & $6.8-38.6$ & 20 & .016 \\
\hline \multicolumn{5}{|c|}{ Calcium-rich achondrites } \\
\hline $\mathrm{Aa}$ & 1 & 0.07 & -- & 0.000051 \\
\hline An & 1 & .08 & -- & .000054 \\
\hline Aho & 1 & .07 & -- & .000045 \\
\hline Aeu & 1 & .06 & -- & .000039 \\
\hline
\end{tabular}




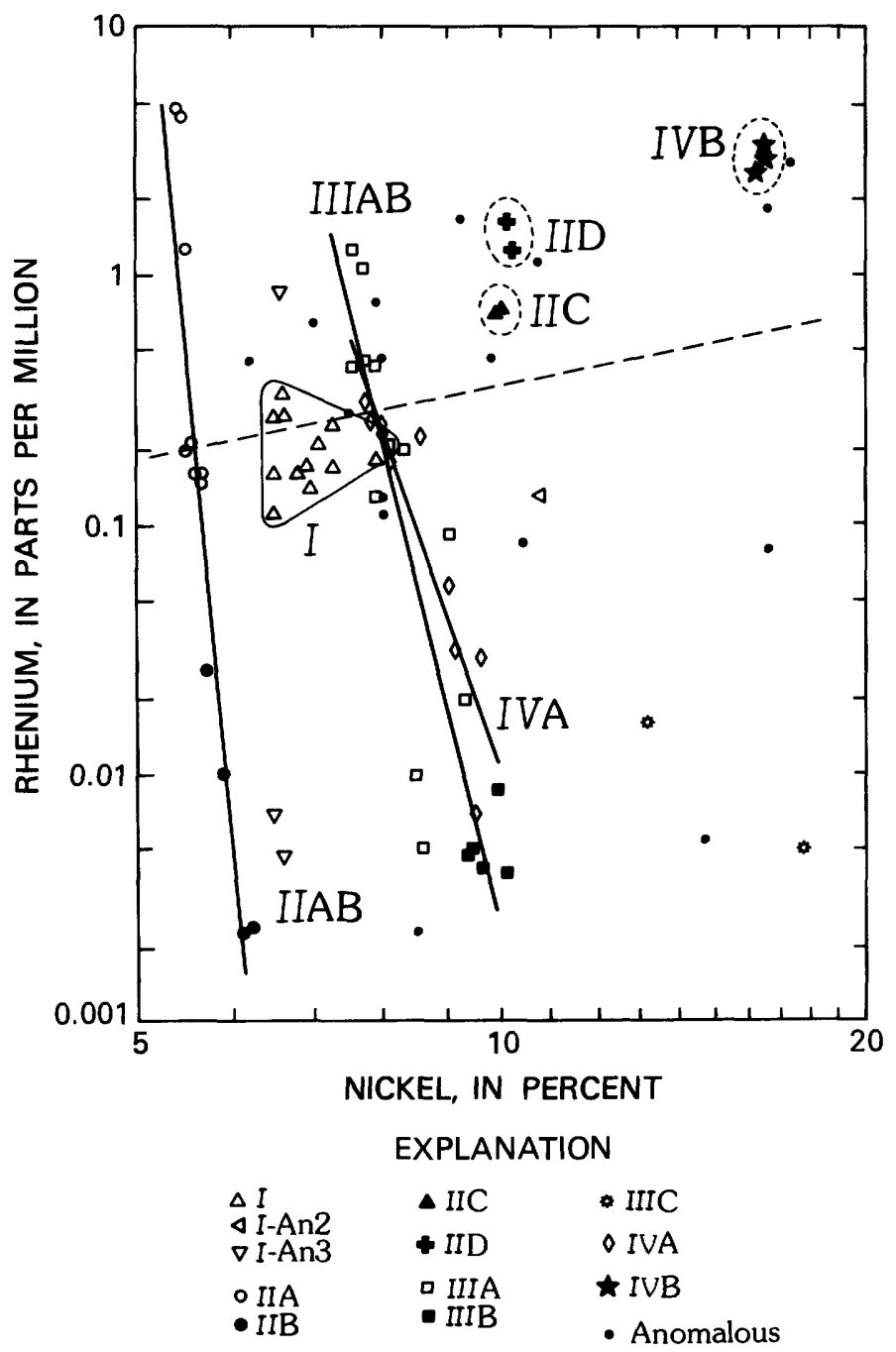

FIgURE 18.-Re-Ni distribution in iron meteorites; the dashed line represents the $\mathrm{Re} / \mathrm{Ni}$ ratio in $\mathrm{C} 1$ chondrites. Solid lines indicate correlations within groups; short-dashed lines enclose well-resolved groups. Reprinted from Scott (1972) and published with permission.

72), which is perhaps surprising, in view of the usually lower abundance of an odd-numbered element than its even-numbered neighbors (the OddoHarkins rule). Like Os, Ir abundances in chondrites show a marked depletion in the sequence H-L-LL, paralleling a decrease in metal content; achondrites are strongly depleted in Ir relative to the chondrites. This pattern is typical of a siderophile element. Wark and Lovering (1976) found microscopic metallic grains in the Allende (C3) chondrite containing up to 21 percent Ir.

Chou, Baedecker, and Wasson (1973) magnetically separated metal from 15 chondrites $(\mathrm{H})$ and analyzed the metal and silicate fraction (leached with

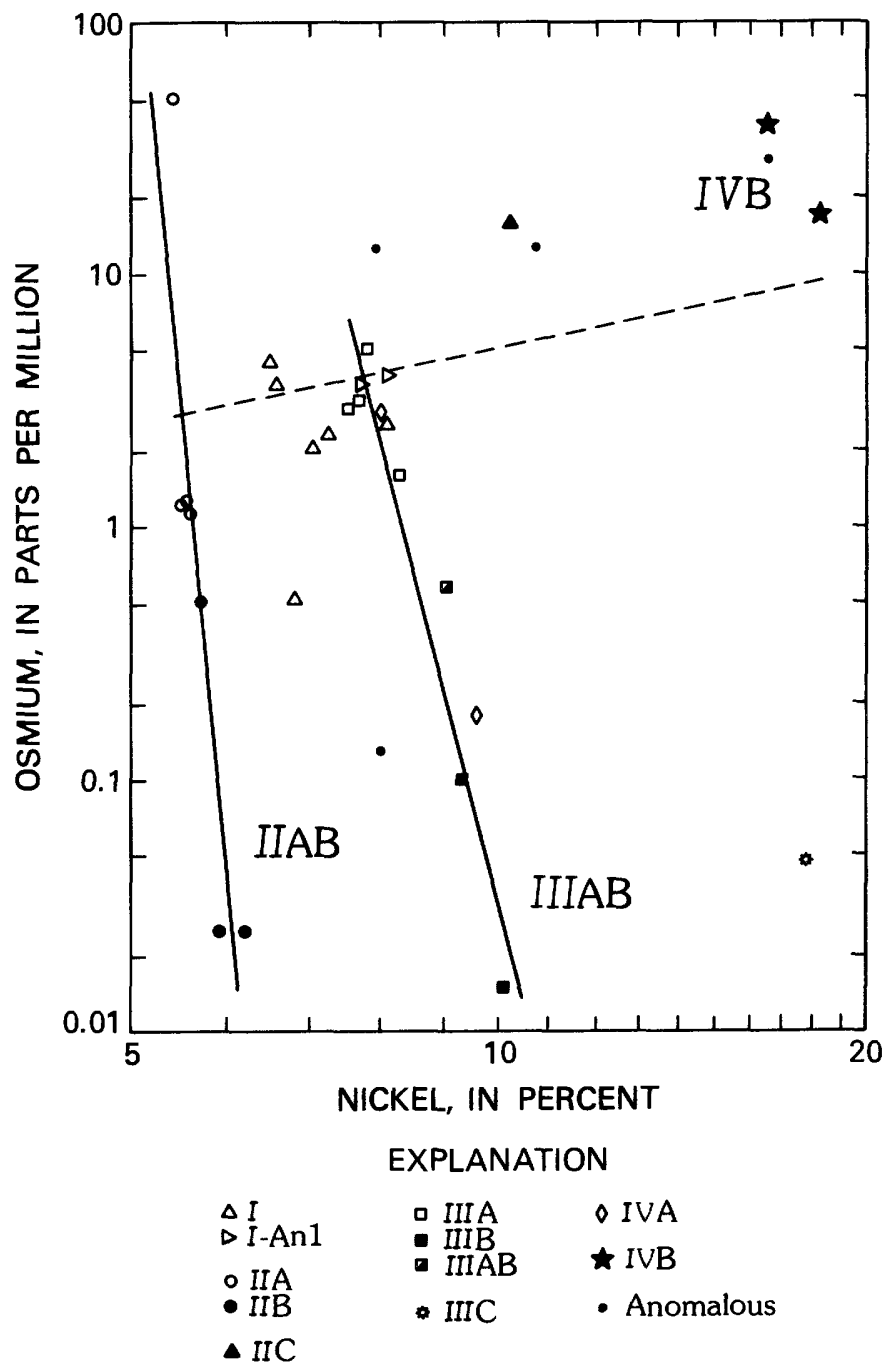

Figure 19.-Os-Ni distribution in iron meteorites; the dashed line represents the $\mathrm{Os} / \mathrm{Ni}$ ratio in $\mathrm{C} 1$ chondrites. Solid lines indicate correlations within groups. Reprinted from Scott (1972) and published with permission.

bromine water to remove troilite) separately. They found 1.4-4.6 ppm Ir in the metal, $0.03-0.12 \mathrm{ppm}$ Ir in the silicates. This confirms the siderophile nature of Ir; the small amount of Ir in the silicate fraction could be present as minute metal inclusions. Vinogradov and others $(1972,1973)$ analyzed metal, troilite, and silicate fractions from several chondrites, and found Ir concentrated in the metal and greatly depleted in the silicates, but the troilite showed Ir values up to those in the associated metal. However, Ehmann, Baedecker, and McKown (1970) found 10 to 30 times more Ir in meteoritic nickeliron than in coexisting troilite.

A large number of $\mathrm{Ir}$ determinations in iron 
meteorites have been made, most of them by J. T. Wasson and his coworkers. The data are summarized in figure 20, from Scott and Wasson (1975). Iridium concentrations range over 4 orders of magnitude, from 0.01 to nearly $100 \mathrm{ppm}$, with an average of $\therefore 3.96$ ppm (Crocket, 1972), and show a marked quantization within the individual chemical groups.

The geochemical behavior of Ir in meteorites is evidently conditioned largely by its high condensation temperature. Scott (1972) listed the following elements having the highest condensation temperatures (in $\mathrm{K}$ at $10^{-4} \mathrm{~atm}$ ) : W, 1,960 ; Os, 1,840 ; Re, 1,775 ; Mo, 1,$620 ;$ Ir, 1,550; Ru, 1,540. This group of elements shows a remarkable degree of geochemical coherence in meteorites, typified by similar distribution patterns in iron meteorites (Scott, 1972), and their concentration in the Ca,Al-rich inclusions in the Allende meteorite as microscopic alloy grains (Wark and Lovering, 1976).

\section{PLATINUM}

The rather sparse data on platinum abundances in meteorites were assembled and discussed by $\mathrm{W}$. D. Ehmann, in Mason (1971). For stony meteorites these data have been superseded by the work of Ehmann and Gillum (1972) and Hintenberger, Jochum, and Seufert (1973). Their results are generally in good agreement, and since Ehmann and Gillum analyzed a larger number of meteorites, their data have been used in compiling table $\mathbf{7 4}$. Platinum shows a distribution pattern similar to those of Os and Ir, at about twice the absolute abundance level, and the discussion of the geochemical behavior of these elements applies equally to $\mathrm{Pt}$. Wark and Lovering (1976) recorded up to 35 percent $\mathrm{Pt}$ in microscopic metallic grains in the $\mathrm{Al}$ lende (C3) meteorite. Vinogradov and others (1972, 1973) analyzed separated metal, troilite, and silicate fractions for several chondrites and found $\mathrm{Pt}$ concentrated in the metal, although in some meteorites

TABLE 72.-Osmium in stony meteorites

[From J. W. Morgan, in Mason, 1971]

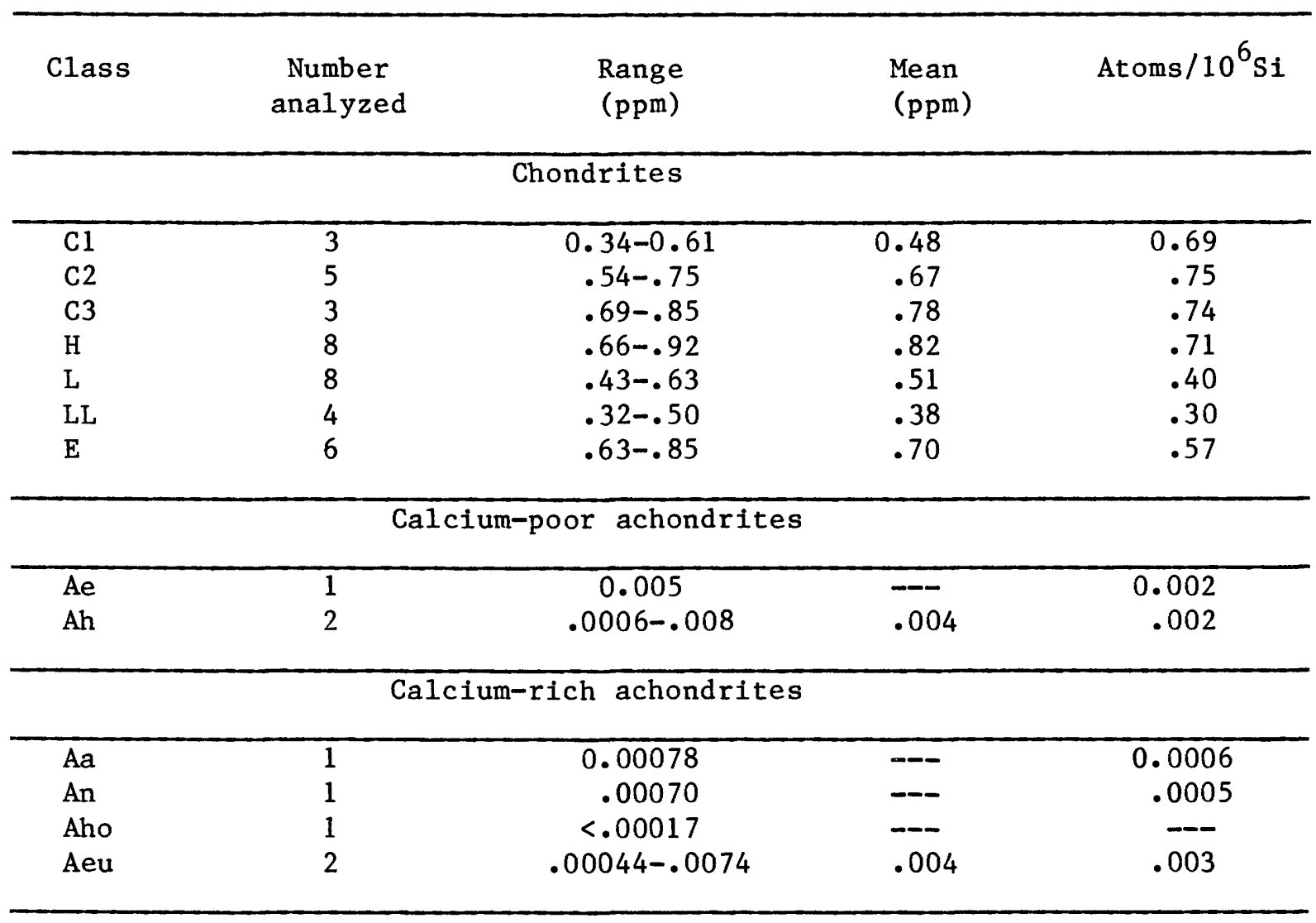


TABLE 73.-Iridium in stony meteorites

[Data as follows: C1, C2, Krähenbühl and others, 1973; C3, Anders and others, 1976; H, L, LL, Müller, Baedecker, and Waswon, 1971 ; E, Baedecker and Wasson, 1975; Ae, Ah, tho, Aeu, Chou, Baedecker, and Wasson, 1976; Au, Wasson and others, 1976; Aa, An, Laul and others, 1972; Ac, Boynton, Starzyk, and Sehmitt, 1976]

\begin{tabular}{|c|c|c|c|c|}
\hline Class & $\begin{array}{c}\text { Number } \\
\text { analyzed }\end{array}$ & $\begin{array}{c}\text { Range } \\
\text { (ppm) }\end{array}$ & $\begin{array}{l}\text { Mean } \\
(p p m)\end{array}$ & Atoms $/ 10^{6} \mathrm{Si}$ \\
\hline
\end{tabular}

\begin{tabular}{lrcrr}
\hline \multicolumn{5}{c}{ Chondrites } \\
\hline C1 & 3 & $0.49-0.56$ & 0.51 & 0.72 \\
C2 & 3 & $.61-.66$ & .63 & .70 \\
C3 & 7 & $.65-.74$ & .69 & .65 \\
H & 18 & $.51-.83$ & .73 & .62 \\
L & 17 & $.31-.59$ & .46 & .36 \\
LL & 10 & $.18-.44$ & .33 & .26 \\
E & 8 & $.40-.70$ & .56 & .45 \\
\hline
\end{tabular}

Calcium-poor achondrites

\begin{tabular}{llccc}
\hline Ae & 2 & $0.00034-0.00059$ & 0.00047 & 0.00025 \\
$\mathrm{Ah}$ & 1 & .0065 &.-- & .0038 \\
$\mathrm{Ac}$ & 1 & .006 & -005 \\
$\mathrm{Au}$ & 5 & $.055-.76$ & .33 & .25 \\
\hline & & Calcium-rich achondrites & \\
\hline $\mathrm{Aa}$ & 1 & 0.0026 &.-- & 0.0019 \\
$\mathrm{An}$ & 2 & $.00013-.017$ & .009 & .0054 \\
Aho & 6 & $.0005-.018$ & .015 & .0094 \\
Aeu & 3 & $.00013-.00065$ & .00032 & .00020 \\
\hline
\end{tabular}




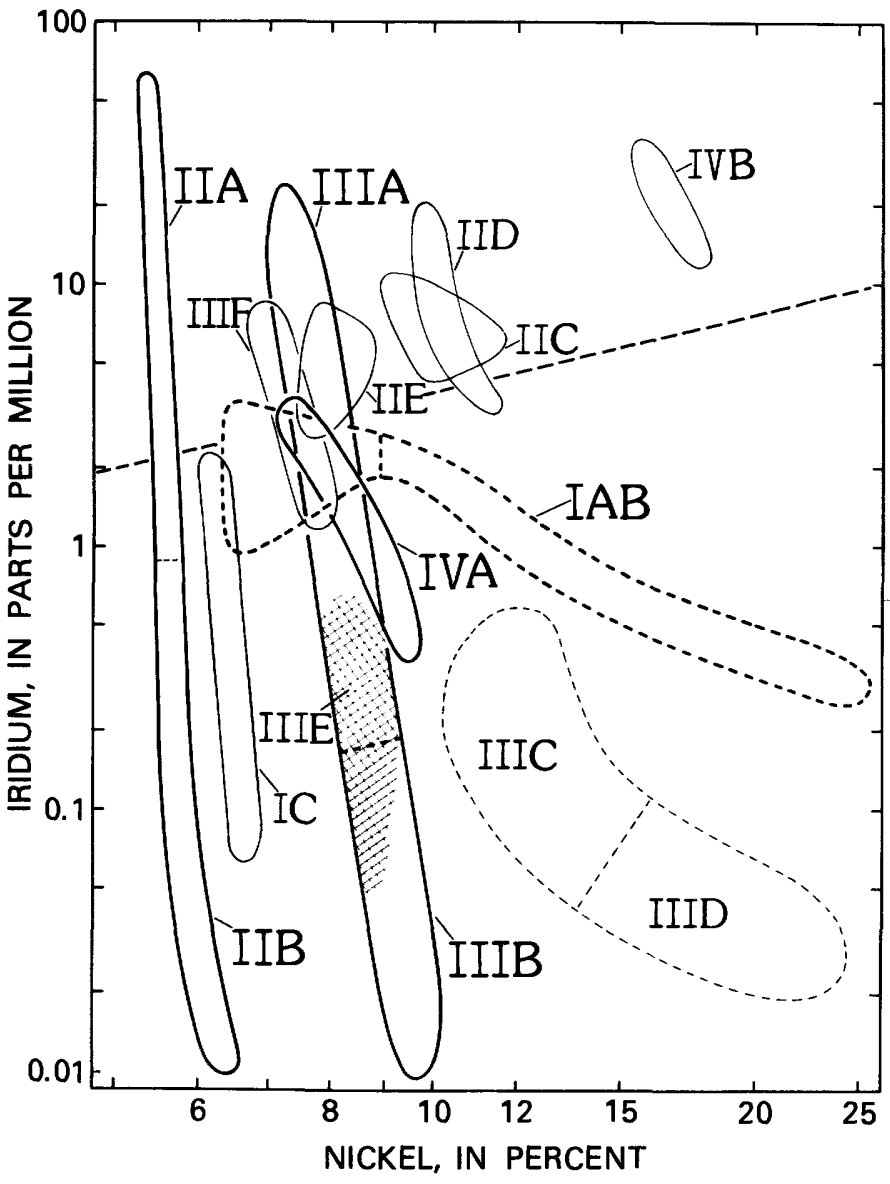

FiguRe 20.-Ir-Ni distribution in iron meteorites; the dashed line represents the $\mathrm{Ir} / \mathrm{Ni}$ ratio in $\mathrm{C} 1$ chondrites. The major groups, IIAB, IIIAB, and IVA are shown in heavier outline; groups IAB and IIICD are drawn with short-dashed lines to contrast them with the other groups. Reprinted from Scott and Wasson (1975), copyrighted by American Geophysical Union.

the troilite fraction contained approximately he same amounts as the metal.

The only determinations of $\mathrm{Pt}$ in achondrites are: Haverö $(\mathrm{Au}), 0.41 \mathrm{ppm}$ (Wänke, Baddenhausen, Spettel, and others, 1972) ; Yamato (b) (Ah), 0.005 ppm; Johnstown (Ah), 0.019 ppm (Hintenberger, Jochum, and Seufert, 1973).

The data on $\mathrm{Pt}$ abundances in iron meteorites are summarized in figure 21. This shows a range of $\mathrm{Pt}$ values about 0.5 to $29 \mathrm{ppm}$, with an average of $9.42 \mathrm{ppm}$ (Crocket, 1972). Crocket pointed out that $\mathrm{Pt}$ is more strongly correlated with $\mathrm{Ru}$ than with the other platinum-group elements.

\section{GOLD}

The data on gold in meteorites available to 1969 were assembled and discussed by W. D. Ehmann, in Mason (1971). Since then, however, a large amount of additional data has been published, by Keays, Ganapathy, and Anders (1971); Crocket (1972); Ehmann and Gillum (1972); Laul and others (1972) ; Case and others (1973); Krähenbühl and others (1973) ; Hintenberger, Jochum, and Seufert (1973) ; Hermann and Wichtl (1974) ; Binz, Kurimoto, and Lipschutz (1974) ; Binz, Ikramudden, and Lipschutz (1975) ; Binz and others (1976); Baedecker and Wasson (1975), Chou, Baedecker, and Wasson (1976b), Wasson and others (1976), Anders and others (1976), and Higuchi and others (1976). The results of different analysts on the same meteorites are usually in good agreement. Table 75 is compiled from a selection of these data. Gold is

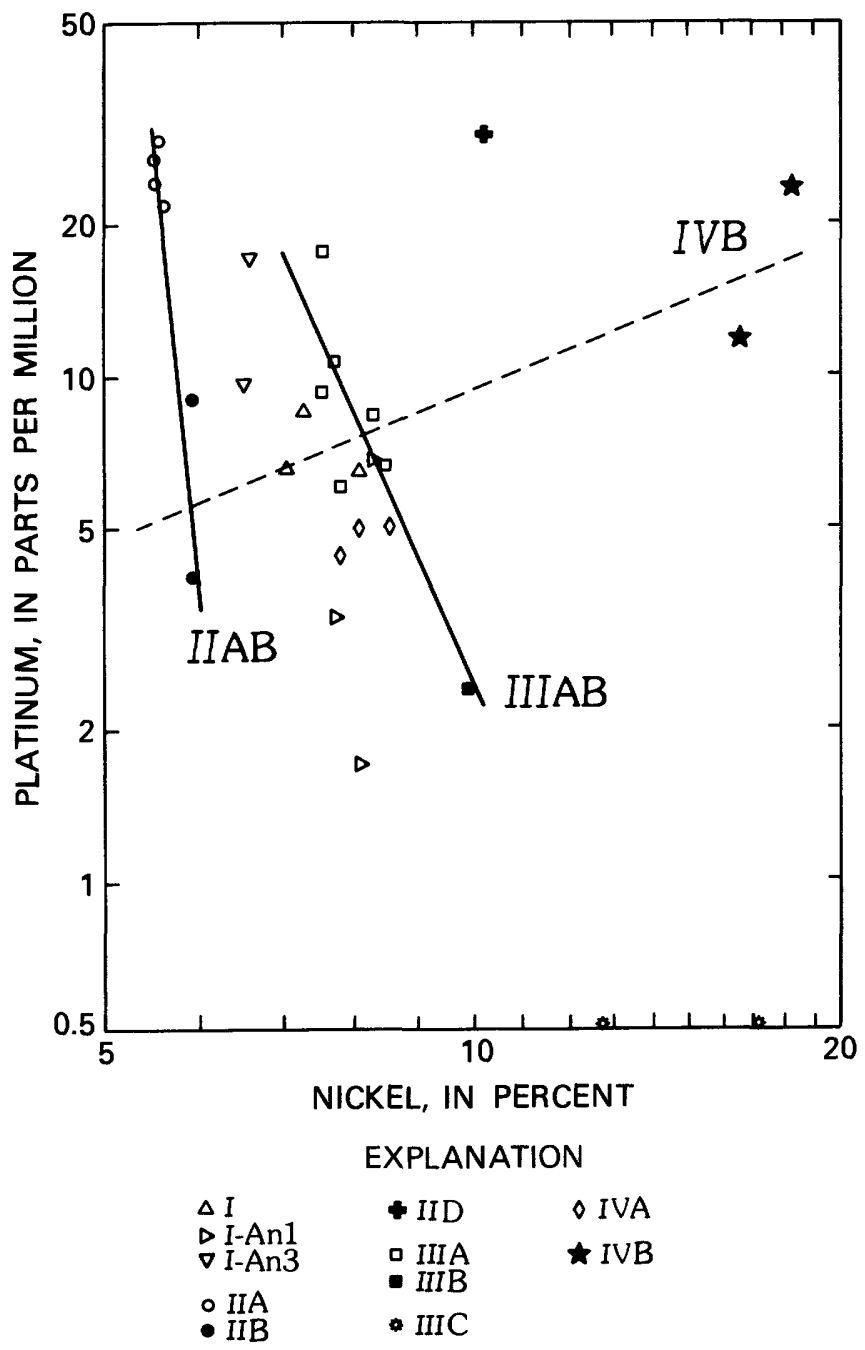

FIgURe 21.-Pt-Ni distribution in iron meteorites; the dashed line represents the cosmic $\mathrm{Pt} / \mathrm{Ni}$ ratio in $\mathrm{C1}$ chondrites. Solid lines indicate correlations within groups. Reprinted from Scott (1972) and published with permission. 
TABLE 74.-Platinum in chondrites

[From Ehmann and Gillum, 1972]

\begin{tabular}{lcccc}
\hline Class & $\begin{array}{c}\text { Number } \\
\text { analyzed }\end{array}$ & $\begin{array}{c}\text { Range } \\
(\mathrm{ppm})\end{array}$ & $\begin{array}{c}\text { Mean } \\
(\mathrm{ppm})\end{array}$ & Atoms $/ 10^{6} \mathrm{Si}$ \\
\hline C1 & 2 & Chondrites & \\
C2 & 4 & $0.94-1.06$ & 1.01 & 1.41 \\
C3 & 2 & $1.05-1.66$ & 1.28 & 1.41 \\
H & 10 & $1.22-2.03$ & 1.55 & 1.44 \\
L & 14 & $.91-2.36$ & 1.49 & 1.25 \\
LL & 3 & $0.70-1.61$ & 1.05 & .81 \\
E & 6 & $.63-1.09$ & .85 & .65 \\
\hline
\end{tabular}

considerably less abundant than any of the neighboring platinum metals, but shows the same distribution pattern, evidently because of a similar siderophile character. Fouché and Smales (1967b) separated a number of chondrites into magnetic (metal) and nonmagnetic (silicate+sulfide) fractions, and found that $\mathrm{Au}$ was present in metal fractions at 27-290 times the concentration in the nonmagnetic fractions, demonstrating the strong partition of this element into the metal phase. Vinogradov and others $(1972,1973)$ reported $\mathrm{Au}$ determinations on separated metal, troilite, and silicate fractions of several chondrites, and some of their analyses show more $\mathrm{Au}$ (up to $1.5 \mathrm{ppm}$ ) in troilite than in coexisting metal. This is inconsistent with the results of other investigators, who have found much lower values for $\mathrm{Au}$ in troilite; Herman and others (1971) found an average of $0.0046 \mathrm{ppm}$ $\mathrm{Au}$ for six troilite samples. Ehmann, Baedecker, and McKown (1970) recorded 30-620 times as much $\mathrm{Au}$ in magnetic (metal) fractions of chondrites as in nonmagnetic (troilite plus silicate) fractions.

The numerous determinations of $\mathrm{Au}$ in iron meteorites have been assembled and discussed by Scott and Wasson (1975), and are presented in figure 22. The total range of $\mathrm{Au}$ values is about $0.05-5 \mathrm{ppm}$, or approximately 2 orders of magnitude; Crocket (1972) gave an average of $1.32 \mathrm{ppm}$ for iron meteorites. Strong positive correlations between $\mathrm{Au}$ and $\mathrm{Ni}$ are visible within all chemical groups for which there are sufficient data, with the exception of IAB and IICD. Scott (1972) noted that the distribution of $\mathrm{Au}$ is almost identical with that of As.

\section{MERCURY}

The data on mercury in meteorites were assembled and discussed by G. W. Reed, in Mason (1971), who commented: "The extremely large range observed within a given class of meteorites makes averaging meaningless. Even for a given meteorite large variations are obtained in the same laboratory. . . . These variations have nothing to do with the laboratory or the method used for analysis" (p. 488). Although many additional analyses for mercury in meteorites have since been reported, this situation has not changed. For example, the following values (in $\mathrm{ppm}$ ) have been reported for the Orgueil (C1) meteorite: $0.48,40$ (Case and others, 1973) ; 2.40, 14.0, 213 (Reed and Jovanovic, 1967) ; 7.80 (Hintenberger, Jochum, and Seufert, 1973) ; 12.8 (Hermann and Wichtl, 1974) ; 17.3, 20.1, 20.8. 22.2, 114 (Ehmann and Lovering, 1967) ; 500 (Ozerova and others, 1973). This is an extreme example, and may be unique to the Orgueil meteorite. However, other meteorites show similar, but less extreme variations; for example, the data for the Holbrook (L6) meteorite: 0.022 (Case and others, 1973) ; 0.17 (Ehmann and Lovering, 1967); 0.44 (Reed and Jovanovic, $1967) ; 1.80$ (Kiesl and others, 1967). On this account no attempt has been made to average the data in table 76 , nor to calculate the mean atoms $/ 10^{6} \mathrm{Si}$ for the different classes. If one were to assume 
TABLE 75.-Gold in stony meteorites

I Data as follows: C1, C2, C3, H, L, LL, Ehmann and Gillum, 1972; E4, E5, E6, Baedecker and Wasson, $1975 ;$ Ae, Ah, Chop, Baedecker, and Watsson, 1976b; Au, Wasson and others, 1976; Aa, An, Laul and others. 1972; Aho, Aeu, Laul and others, 1972, and Chou, Baedecker, and Wasson, 1976b; Ac, Boynton and others, 1976]

\begin{tabular}{|c|c|c|c|c|}
\hline Class & $\begin{array}{c}\text { Number } \\
\text { analyzed }\end{array}$ & $\begin{array}{c}\text { Range } \\
\text { (ppm) }\end{array}$ & $\begin{array}{l}\text { Mean } \\
(\mathrm{ppm})\end{array}$ & Atoms $/ 10^{6} \mathrm{Si}$ \\
\hline \multicolumn{5}{|c|}{ Chondrites } \\
\hline $\mathrm{Cl}$ & 2 & $0.12-0.17$ & 0.15 & 0.21 \\
\hline $\mathrm{C} 2$ & 5 & $.15-.28$ & .19 & .21 \\
\hline C3 & 2 & $.18-.22$ & .21 & .19 \\
\hline $\mathrm{H}$ & 10 & $.13-.38$ & .21 & .18 \\
\hline $\mathrm{L}$ & 13 & $.10-.24$ & .16 & .12 \\
\hline LL & 3 & $.12-.19$ & .15 & .11 \\
\hline E4 & 3 & $.32-.44$ & .36 & $\cdot 31$ \\
\hline E5 & 1 & .34 & -- & .28 \\
\hline E6 & 4 & $.18-.29$ & .23 & .17 \\
\hline \multicolumn{5}{|c|}{ Calcium-poor achondrites } \\
\hline $\mathrm{Ae}$ & 2 & $0.0005-0.0017$ & 0.0011 & 0.00057 \\
\hline Ah & 1 & .0019 & -- & .0011 \\
\hline $\mathrm{Ac}$ & 1 & .006 & --- & .005 \\
\hline $\mathrm{Au}$ & 5 & $.014-.045$ & .029 & .021 \\
\hline \multicolumn{5}{|c|}{ Calcium-rich achondrites } \\
\hline $\mathrm{Aa}$ & 1 & 0.0072 & $-\infty$ & 0.0050 \\
\hline An & 1 & .00055 & -- & .00034 \\
\hline Aho & 10 & $.0029-.019$ & .0065 & .0040 \\
\hline Aeu & 7 & $.0003-.0067$ & .0025 & .0016 \\
\hline
\end{tabular}




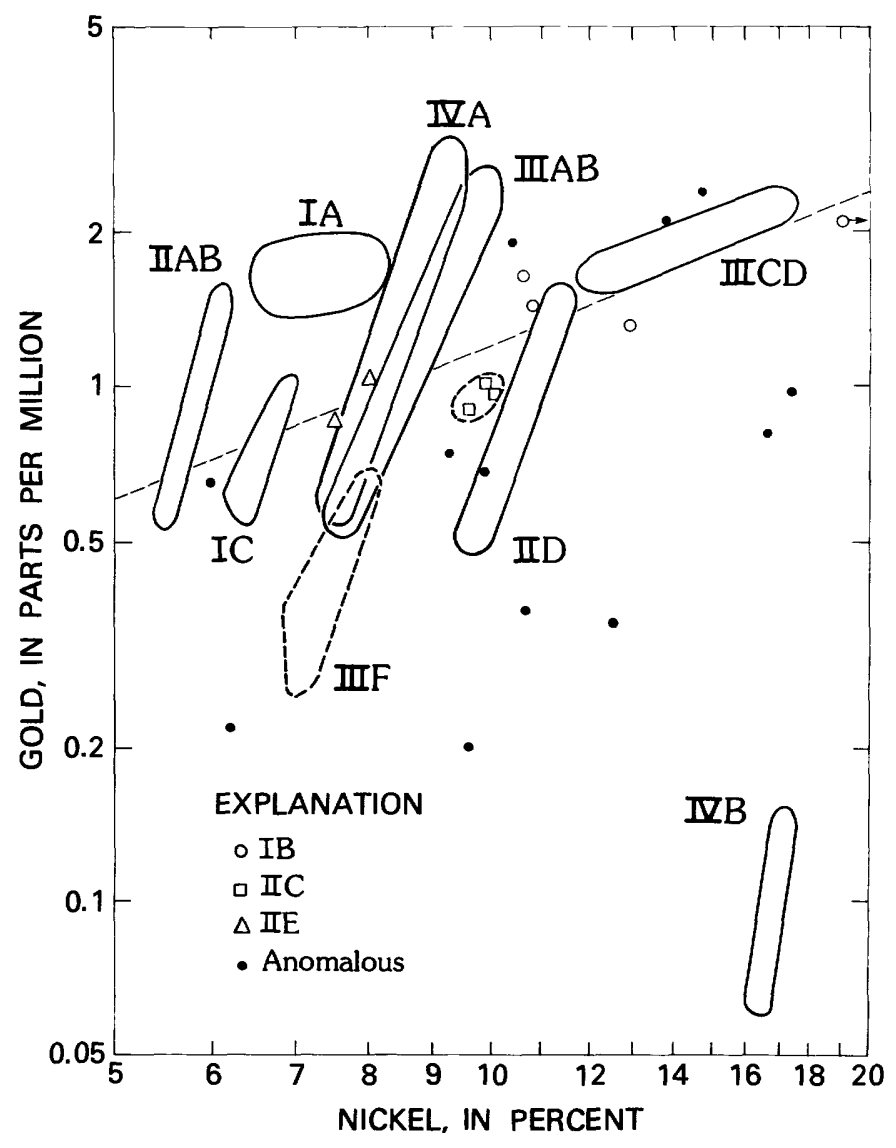

Figure 22.-Au-Ni distribution in iron meteorites; the dashed line represents the $\mathrm{Au} / \mathrm{Ni}$ ratio in $\mathrm{C} 1$ chondrites. Most groups are shown only in outline; this is short dashed when only a few data points define a group. Reprinted from Scott and Wasson (1975), copyrighted by American Geophysical Union.

similar abundance for $\mathrm{Hg}$ as for the neighboring even-numbered elements $\mathrm{Pt}$ and $\mathrm{Pb}$, a mean abundance in $\mathrm{C} 1$ chondrites of $\sim 1 \mathrm{ppm}$ (equivalent to $\sim 1.4$ atoms $/ 10^{6} \mathrm{Si}$ ) would be reasonable.

Reed and Jovanovic (1967) investigated the progressive release of $\mathrm{Hg}$ from chondrites on heating, and found in many of them that a large part of the $\mathrm{Hg}$ was given off below $450^{\circ} \mathrm{C}$. They interpreted the $\mathrm{Hg}$ released above $450^{\circ} \mathrm{C}$ as trapped in crystal lattices or present in solid solution, and released after diffusion to surfaces in a manner analogous to the escape of trapped gases. The most likely phase to contain $\mathrm{Hg}$ in solid solution is troilite, and Ozerova and others (1973) noted that troilite appears to be a good mercury concentrator in several meteorite classes, having a consistently higher mercury content than the meteorite as a whole. Thus, mercury in combination in meteorites is a chalcophile element, but much of it is in a labile form which is readily released and transported by gentle heating. This ready release and transportation is probably responsible, at least in part, for the extreme variability in the $\mathrm{Hg}$ content of stony meteorites.

The limited data on $\mathrm{Hg}$ in iron meteorites show low concentrations and hence a lack of siderophile character. Ozerova and others (1973) reported analyses of 10 iron meteorites, the range of $\mathrm{Hg}$ concentration being 0.01-0.12 ppm, with a mean of 0.04 ppm. Tanner (1968) analyzed 19 irons, and found a range from 0.03 to $1.25 \mathrm{ppm}$ (all but three less than $0.4 \mathrm{ppm}$ ) ; he found troilite to be considerably enriched in $\mathrm{Hg}$ relative to the metal phase.

\section{THALLIUM}

The abundance data for thallium in meteorites were assembled and discussed by M. E. Lipschutz, in Mason (1971), but since then a considerable number of publications dealing with this element have appeared, and table 77 has been compiled from these sources. The data for chondrites show that $\mathrm{Tl}$ is a strongly depleted element, the relative depletion in the sequence $\mathrm{C} 1-\mathrm{C} 2-\mathrm{C} 3-(\mathrm{H}, \mathrm{L}, \mathrm{LL})$ being 1.00:0.51:0.24: 0.02; a similar depletion is evident in the sequence E4-E5, 6. In some chondrite classes Tl abundances are extremely variable, particularly noteworthy in the $\mathrm{H}$ chondrites: if, out of the 22 meteorites analyzed, Sharps (220 ppb), Tieschitz $(53 \mathrm{ppb})$, and Supuhee (361 ppb) are omitted, the range is much less, 0.11-5.64 ppb. (Sharps and Tieschitz are type 3 chondrites, Supuhee a type 6 .) The geochemical behavior of thallium in meteorites is very similar to that of indium, and a comparison of table 77 with table 59 shows that the atomic abundances of these two elements are remarkably similar in most meteorite classes. The geochemistry of $\mathrm{Tl}$ in meteorites is evidently related to its volatility; along with In and $\mathrm{Bi}$, it has the lowest condensation temperature of any of the metallic elements $\left(\sim 430 \mathrm{~K}\right.$ from a solar gas at $10^{-6}$ atm, according to Laul and others, 1973). Accordingly, it is also an element likely to be volatilized and lost from a meteorite undergoing mild thermal metamorphism; Ikramuddin and Lipschutz (1975) and Ikramuddin, Binz, and Lipschutz (1976) demonstrated this experimentally in the Allende (C3) and Abee (E4) meteorites.

Tandon (1967) has shown that in iron meteorites the metal phase contains $0.1-10 \mathrm{ppb} \mathrm{Tl}$, the troilite 2-200 ppb, demonstrating that $\mathrm{Tl}$ is distinctly chalcophile in these meteorites. The same is probably true for the stony meteorites; indeed, the $\mathrm{C} 1$ and E4 meteorites, which show the highest mean $\mathrm{Tl}$ con- 
tents, are also those with the highest sulfur contents.

\section{LEAD}

Many studies have been made on lead in meteorites, but most of these have been concerned with its isotopic composition, and the abundance data are rather sparse. These data are summarized in table 78; they are taken from Virginia Oversby, in Mason (1971) and additional later sources. Lead is a relatively volatile element, and it condenses in the same temperature range as $\mathrm{Bi}, \mathrm{In}$, and $\mathrm{Tl}$, as shown by Larimer and Anders (1967). Like these elements, it is a strongly depleted element in chondrites, the relative depletion in the sequence $\mathrm{C} 1-\mathrm{C} 2-\mathrm{C} 3-(\mathrm{H}, \mathrm{L})$ being $1.00: 0.62: 0.34: 0.09$. Abundance of $\mathrm{Pb}$ in ac- hondrites are similar to those in ordinary chondrites; the one determination on the diogenite Johnstown $(\mathrm{Ah})$ is anomalously high, and suggests terrestrial contamination, always a possible complication with $\mathrm{Pb}$ at the low levels in stony meteorites.

Most lead concentrations in the metal phase of iron meteorites range from 0.01 to $0.1 \mathrm{ppm}$; the coexisting troilite contains $2-10 \mathrm{ppm}$. Lead is thus a strongly chalcophile element. Because the troilite of iron meteorites contains a substantial amount of $\mathrm{Pb}$ but essentially no $\mathrm{U}$ and $\mathrm{Th}$ (which would add radiogenic $\mathrm{Pb}$ ), the $\mathrm{Pb}$ in the troilite is considered to be the "primordial" $\mathrm{Pb}$ existing when the parent bodies of meteorites (and the Earth) accreted. The troilite from the Canyon Diablo iron has been in-

TABLE 76.-Mercury in stony meteorites

[From G. W. Reed, in Mason, 1971; and additional data from Case and others, 1973; Reed and Jovanovic, 1967; Hintenberger and others, 1973; Hermann and Wichtl, 1974; Ehmann and Lovering, 1967; Ozerova and others, 1973; and Kiesl and others, 1976]

\begin{tabular}{lcc}
\hline Class & $\begin{array}{c}\text { Number } \\
\text { analyzed }\end{array}$ & $\begin{array}{c}\text { Range } \\
\text { (ppm) }\end{array}$ \\
\hline C1 & Chondrites \\
C2 & 2 & $0.18-500$ \\
C3 & 4 & $.01-20$ \\
H & 5 & $.06-7.3$ \\
L & 13 & $.26-13.90$ \\
LL & 16 & $.015-5.99$ \\
E & 2 & $.24-.84$ \\
& 3 & $.16-1.4$ \\
\hline Ae & & \\
Ah & Calcium-poor & achondrites \\
Au & & $0.014-0.14$ \\
\hline Alu & 1 & 0.12 \\
An & 1 & 0.09 \\
\hline
\end{tabular}


TABLE 77.-Thallium in stony meteorites

[Data as follows: C1, C2, Krähenbühl and others, 1973; C3, Anders and others, 1976; H, LL, L, Laul and others, 1973; L, Ganapathy and Anders, 1971; Ah, Hintenberger and others, 1973; Au, Binz and others, 1975, Aa, An, Aho, Aeu, Laul and others, 1972]

\begin{tabular}{|c|c|c|c|c|}
\hline Class & $\begin{array}{c}\text { Number } \\
\text { analyzed }\end{array}$ & $\begin{array}{l}\text { Range } \\
\text { (ppb) }\end{array}$ & $\begin{array}{l}\text { Mean } \\
(\mathrm{ppb})\end{array}$ & Atoms $/ 10^{6} \mathrm{Si}$ \\
\hline \multicolumn{5}{|c|}{ Chondrites } \\
\hline $\mathrm{Cl}$ & 3 & $124-188$ & 145 & 0.19 \\
\hline $\mathrm{C} 2$ & 3 & $84-97$ & 92 & .096 \\
\hline C3 & 7 & $15-84$ & 52 & .046 \\
\hline $\mathrm{H}$ & 22 & $.11-361$ & $1_{3.7}$ & .0030 \\
\hline $\mathrm{L}$ & 10 & $.05-6.6$ & 1.9 & .0014 \\
\hline LL & 11 & $.75-31$ & 7.2 & .0053 \\
\hline E4 & 4 & $85-115$ & 103 & .085 \\
\hline E5 & 1 & 3.7 & -- & .0029 \\
\hline E6 & 5 & $1 \cdot 2-8 \cdot 6$ & 5.0 & .0035 \\
\hline \multicolumn{5}{|c|}{ Calcium-poor achondrites } \\
\hline Ah & 1 & 5.8 & -- & 0.0032 \\
\hline $\mathrm{Au}$ & 4 & $\cdot 31-5 \cdot 31$ & $1 \cdot 6$ & .0011 \\
\hline \multicolumn{5}{|c|}{ Calcium-rich achondrites } \\
\hline $\mathrm{Aa}$ & 1 & .86 & -- & 0.00058 \\
\hline An & 2 & $3 \cdot 1-7 \cdot 2$ & $5 \cdot 2$ & .0030 \\
\hline Aho & 4 & $.51-4.3$ & 1.8 & .0010 \\
\hline Aeu & 7 & $.12-1 \cdot 97$ & .73 & .00044 \\
\hline
\end{tabular}

1 omitting high value of 221 and 361 . 
tensively investigated by several research teams, and its $\mathrm{Pb}$ is the least radiogenic yet discovered. Tatsumoto, Knight, and Allegre (1973) gave the following isotope ratios for this $\mathrm{Pb}: 206 / 204$, $9.307 ; 207 / 204,10.294 ; 208 / 204,29.476$. These ratios have been modified in stony meteorites by the addition of radiogenic isotopes $(206,207,208)$; the most radiogenic lead is that from the Nuevo Laredo achondrite (Aeu), which has the following isotopic ratios: $206 / 204,222.38 ; 207 / 204,140.05 ; 208 / 204$, 233.64 (Tatsumoto and others, 1973).

\section{BISMUTH}

Since 1970, a large amount of data on the abundance of $\mathrm{Bi}$ in stony meteorites has been published, and is summarized in table 79. Bismuth abundances are closely comparable with those of thallium for the same meteorite classes, and this geochemical co- herence has been noted and discussed by several investigators (for example, Laul and others, 1973) ; it is evidently related to similar condensation histories. Bismuth is a strongly depleted element, the relative depletion in the sequence $\mathrm{C} 1-\mathrm{C} 2-\mathrm{C} 3-\mathrm{H}$, L, LL) being 1.00:0.55:0.31: 0.08; similar depletion is seen in the sequence E4-E6, with the two E5 meteorites showing anomalously low abundances. Within the H, L, and LL classes, the abundance range is very great; high abundances are characteristic of, but not exclusive to, the type 3 meteorites. Achondrites are strongly depleted in $\mathrm{Bi}$ relative to the chondrites.

Because of its low condensation temperature ( $\sim 460 \mathrm{~K}$ from a solar gas at $10^{-5} \mathrm{~atm}$, according to Laul and others, 1973), $\mathrm{Bi}$ is an element likely to be volatilized and lost from a meteorite undergoing mild thermal metamorphism. Ikramuddin and Lip-

TABLE 78.-Lead in stony meteorites

[From Virginia Oversby, in Mason, 1971; and additional data from Gale and others, 1972; Tatsumoto and others, 1973; Tilton, 1973; Hintenberger and others, 1973; Huey and Kohman, 1973; and Hutchison and others, 1975]

\begin{tabular}{cccc} 
C1ass & $\begin{array}{c}\text { Number } \\
\text { analyzed }\end{array}$ & $\begin{array}{c}\text { Range } \\
(p p m)\end{array}$ & $\begin{array}{c}\text { Mean } \\
(p p m)\end{array} \quad$ Atoms/lo Si \\
\hline
\end{tabular}

\section{Chondrites}

\begin{tabular}{llrrr}
\hline C 1 & 1 & 1.94 & --- & 2.6 \\
C 2 & 3 & $1.51-1.60$ & 1.54 & 1.6 \\
C 3 & 2 & $.93-1.10$ & 1.02 & .89 \\
H & 6 & $.08-.46$ & .24 & .19 \\
L & 7 & $.06-.51$ & .37 & .27 \\
E 4 & 2 & $1.98-2.17$ & 1.08 & .88 \\
\hline
\end{tabular}

Calcium-poor achondrites

$\begin{array}{lcccc}\text { Ae } & 2 & 0.36-0.57 & 0.47 & 0.23 \\ \mathrm{Ah} & 1 & 4.37 & --- & 2.4\end{array}$

Calcium-rich achondrites

\begin{tabular}{llccc}
\hline Aa & 1 & 0.55 & --- & 0.36 \\
An & 1 & $.352-.553$ & .48 & .29 \\
Aeu & 2 & $.193-.324$ & .26 & .15 \\
\hline
\end{tabular}


schutz (1975) and Ikramuddin, Binz, and Lipschutz (1976) demonstrated this experimentally for the Allende (C3) and Abee (E4) meteorites.

Few data exist on $\mathrm{Bi}$ in iron meteorites. Tanner (1968) analyzed 19 irons and found a range from 0.5 to $7.9 \mathrm{ppb} ; 3$ samples of troilite from these irons contained 61-68 ppb. Santoliquido and Ehmann (1972) found $1.6 \mathrm{ppb} \mathrm{Bi}$ in Canyon Diablo metal and $125 \mathrm{ppb}$ in troilite from this meteorite. Bismuth is thus a strongly chalcophile element in these meteorites.

\section{THORIUM}

Most of the information on thorium abundances in meteorites has resulted from the analyses of $\mathrm{J}$. W. Morgan and J. F. Lovering. Morgan, in Mason (1971), assembled and discussed the data available at that time. Additional information has since been published and the data are summarized in table 80. Thorium shows a distribution pattern characteristic of refractory lithophile elements: relatively uniform abundances in the different chondrite classes, marked depletion in calcium-poor achondrites

TABLE 79.-Bismuth in stony meteorites

[Data as follows: C1, C2, Krähenbühl and others, 1973; C3, Anders and others, 1976; H, LL, Laul and others, 1973; L, Keays and others, 1971 ; E, Binz and others, 1974; Ee, Santoliquido and Ehmann, 1972; Ah, Ehmann and Huisenga, 1959; Au, Binz and others, 1975; Aa, An, Aho, Aeu, Laul and others, 1972]

\begin{tabular}{|c|c|c|c|c|}
\hline C1ass & $\begin{array}{c}\text { Number } \\
\text { analyzed }\end{array}$ & $\begin{array}{c}\text { Range } \\
(p p b)\end{array}$ & $\begin{array}{l}\text { Mean } \\
(p p b)\end{array}$ & Atoms $/ 10^{6} \mathrm{si}$ \\
\hline
\end{tabular}

\begin{tabular}{lrrrr}
\hline \multicolumn{5}{c}{ Chondrites } \\
\hline C 1 & \multicolumn{5}{c}{} & \\
C 2 & 3 & $103-188$ & 110 & 0.14 \\
C 3 & 3 & $64-96$ & 75 & .077 \\
H & 7 & $43-59$ & 49 & .043 \\
L & 22 & $.17-100$ & 17 & .013 \\
L L & 10 & $.14-80$ & 14 & .010 \\
E 4 & 11 & $1.30-67$ & 16 & .011 \\
E5 & 2 & $86-177$ & 133 & .11 \\
E6 & 2 & $2.5-2.6$ & 2.6 & .0020 \\
& 4 & $15.0-28.9$ & 18 & .012 \\
\hline
\end{tabular}

Calcium-poor achondrites

\begin{tabular}{llccc}
$\mathrm{Ae}$ & 3 & $0.74-5.5$ & 2.8 & 0.0013 \\
$\mathrm{Ah}$ & 1 & $1.2-5.6$ & 2.8 & .0015 \\
$\mathrm{Au}$ & 6 & $.96-10$ & 3.3 & .0023 \\
\hline
\end{tabular}

Calcium-rich achondrites

\begin{tabular}{llccc}
\hline Aa & 1 & 2.4 & --- & 0.0016 \\
An & 2 & $.50-5.64$ & 3.1 & .0019 \\
Aho & 4 & $.59-4.56$ & 2.6 & .0015 \\
Aeu & 7 & $.37-7.0$ & 3.9 & .0023 \\
\hline
\end{tabular}


(except for the chassignite), and marked enrichment in the calcium-rich achondrites; Angra dos Reis (Aa) has the highest concentration of any meteorite. This distribution pattern parallels those of the lanthanides.

Crozaz (1974) separated the phosphate mineral merrillite from the St. Severin (LL6) chondrite and analyzed it for $T h$ and $U$. The Th value, $3.21 \mathrm{ppm}$, indicates strong concentration of the element in this mineral; the meteorite contains approximately 0.5 percent merrillite, which accounts for $16 \mathrm{ppb} \mathrm{Th}$, about one-third of the total Th in the meteorite.

Bate, Potratz, and Huizenga (1958) analyzed two iron meteorites for $\mathrm{Th}$, and found extremely low values, of the order of $10^{-11} \mathrm{~g} / \mathrm{g}$.

\section{URANIUM}

The data on uranium abundances in meteorites were assembled and discussed by J. W. Morgan, in Mason (1971), and additional information has since been published, and a summary is presented in table 81. The distribution pattern is similar to that for thorium. The $\mathrm{Th} / \mathrm{U}$ ratio for chondrites is usual. ly between 3 and 4, although Morgan and Lovering (1968) recorded $\mathrm{Th} / \mathrm{U}$ ratios ranging from 2.2 to 7.1. Morgan and Lovering (1973) recorded $\mathrm{Th} / \mathrm{U}$ ratios ranging from 1.0 to 10.0 for achondrites. In the chondrites, uranium is concentrated in the phosphate minerals merrillite and apatite. Pellas and Storzer (1975) found a range from 0.05 to 0.77 ppm U in merrillite from 16 chondrites, with a mean of about $0.3 \mathrm{ppm}$, and a range from 1 to $5 \mathrm{ppm}$ in

TABLE 80.-Thorium in stony meteorites

[From J. W. Morgan, in Mason, 1971; and additional data from Morgan and Lovering, 1973; Hintenberger and others, 1973; and Tatsumoto, 1973]

\begin{tabular}{|c|c|c|c|c|}
\hline C1 ass & $\begin{array}{c}\text { Number } \\
\text { analyzed }\end{array}$ & $\begin{array}{l}\text { Range } \\
(\mathrm{ppb})\end{array}$ & $\begin{array}{l}\text { Mean } \\
(p p b)\end{array}$ & At oms $/ 10^{6} \mathrm{Si}$ \\
\hline \multicolumn{5}{|c|}{ Chondrites } \\
\hline $\begin{array}{l}\text { C } 1 \\
\text { C } 2 \\
\text { C } 3 \\
\text { H } \\
\text { L } \\
\text { LL } \\
\text { E }\end{array}$ & $\begin{array}{l}4 \\
6 \\
3 \\
8 \\
8 \\
5 \\
6\end{array}$ & $\begin{array}{l}26-38 \\
38-46 \\
61-79 \\
34-42 \\
38-49 \\
43-50 \\
29-42\end{array}$ & $\begin{array}{l}32 \\
42 \\
67 \\
40 \\
42 \\
46 \\
34\end{array}$ & $\begin{array}{r}0.038 \\
.039 \\
.052 \\
.028 \\
.027 \\
.029 \\
.023\end{array}$ \\
\hline \multicolumn{5}{|c|}{ Calcium-poor achondrites } \\
\hline $\begin{array}{l}\mathrm{Ae} \\
\mathrm{Ah} \\
\mathrm{Ac} \\
\mathrm{Au}\end{array}$ & $\begin{array}{l}2 \\
3 \\
1 \\
1\end{array}$ & $\begin{array}{c}4-47 \\
4-30 \\
57 \\
3\end{array}$ & $\begin{array}{r}28 \\
15 \\
--- \\
---\end{array}$ & $\begin{array}{c}0.012 \\
.0074 \\
.040 \\
.0019\end{array}$ \\
\hline \multicolumn{5}{|c|}{ Calcium-rich achondrites } \\
\hline $\begin{array}{l}\text { Aa } \\
\text { An } \\
\text { Aho } \\
\text { Aeu }\end{array}$ & $\begin{array}{l}1 \\
1 \\
3 \\
7\end{array}$ & $\begin{array}{c}885 \\
191 \\
63-312 \\
340-680\end{array}$ & $\begin{array}{l}---- \\
--- \\
167 \\
450\end{array}$ & $\begin{array}{c}0.52 \\
.10 \\
.086 \\
.24\end{array}$ \\
\hline
\end{tabular}


apatite; compared to merrillite, uranium in apatite is always enriched by a factor between 6 and 13 . Zircon, an extremely rare mineral in meteorites, acts as a sink for uranium; Fleischer and others (1965) found up to $4,000 \mathrm{ppm}$ in this mineral from the Vaca Muerta mesosiderite, and the only coexisting mineral having more than $1 \mathrm{ppm} U$ was merrillite ( $\leqslant 90 \mathrm{ppm}$ ).

Tatsumoto, Unruh, and Desborough (1976) found the Ca,Al-rich inclusions in the Allende (C3) meteorite to be strongly enriched in $\mathrm{U}$ and $\mathrm{Th}$, with up to $0.112 \mathrm{ppm} \mathrm{U}$ and $0.546 \mathrm{ppm} \mathrm{Th}$; the $\mathrm{Th} / \mathrm{U}$ ratio in these inclusions ranges from 3.5 to 10.6 .

The metal phase of iron meteorites contains uranium at levels of $10^{-10} \mathrm{~g} / \mathrm{g}$ or less (Reed and others, 1958). Goles and Anders (1962) found a range from 3.5 to $17 \mathrm{ppb} \mathrm{U}$ in troilites from five iron meteorites, indicating that $U$ has distinct chalcophile affinity in these meteorites.

\section{CONCLUSIONS}

As discussed in the introduction, agreement is now widespread that elemental abundances in chondrites, specifically the $\mathrm{C} 1$ carbonaceous chondrites, approximate those of the unfractionated nonvolatile matter of the solar system. In order to provide a compact summary, the data for the C1 chondrites are assembled in table 82 , in ppm and as atoms/ $10^{6} \mathrm{Si}$.

TABLE 81.-Uranium in stony meteorites

[From J. W. Morgan, in Mason, 1971; and additional data from Gale and others, 1972; Fisher, 1972 and 1973; Hintenberger and others, 1973; Morgan and Lovering, 1973; Tatsumoto and others, 1973; Tilton, 1973; Kräbenbühl and others, 1973; Anders and others, 1976; and Higuchi and others, 1976]

\begin{tabular}{|c|c|c|c|c|c|}
\hline Class & $\begin{array}{c}\text { Number } \\
\text { analyzed }\end{array}$ & $\begin{array}{l}\text { Range } \\
\text { (ppb) }\end{array}$ & $\begin{array}{l}\text { Mean } \\
(p p b)\end{array}$ & Atoms $/ 10^{6} \mathrm{Si}$ & $\operatorname{Th} / \mathrm{U}$ \\
\hline \multicolumn{6}{|c|}{ Chondrites } \\
\hline $\begin{array}{l}\text { C1 } \\
\text { C2 } \\
\text { C3 } \\
\text { H } \\
\text { L } \\
\text { LL } \\
\text { E }\end{array}$ & $\begin{array}{r}4 \\
5 \\
7 \\
11 \\
13 \\
5 \\
6\end{array}$ & $\begin{array}{c}7.4-11.5 \\
10.2-11.9 \\
12.9-18.8 \\
11-25 \\
8-24 \\
11-14 \\
6-16\end{array}$ & $\begin{array}{l}9.1 \\
11.7 \\
16.1 \\
13 \\
15 \\
13 \\
10\end{array}$ & $\begin{array}{r}0.011 \\
.010 \\
.012 \\
.0090 \\
.0095 \\
.0082 \\
.0066\end{array}$ & $\begin{array}{l}3.5 \\
3.6 \\
4.2 \\
3.1 \\
2.8 \\
3.5 \\
3.4\end{array}$ \\
\hline \multicolumn{6}{|c|}{ Calcium-poor achondrites } \\
\hline $\begin{array}{l}\mathrm{Ae} \\
\mathrm{Ah} \\
\mathrm{Ac} \\
\mathrm{Au}\end{array}$ & $\begin{array}{l}2 \\
3 \\
1 \\
4\end{array}$ & $\begin{array}{c}3.7-5.2 \\
1.5-11.6 \\
21 \\
\leq .9-6.9\end{array}$ & $\begin{array}{l}4.5 \\
8.2 \\
--- \\
\sim 4\end{array}$ & $\begin{array}{c}0.0019 \\
.0039 \\
.014 \\
\sim .003\end{array}$ & $\begin{array}{l}6.2 \\
1.8 \\
2.7 \\
\sim 1\end{array}$ \\
\hline \multicolumn{6}{|c|}{ Calcium-rich achondrites } \\
\hline $\begin{array}{l}\text { Aa } \\
\text { An } \\
\text { Aho } \\
\text { Aeu }\end{array}$ & $\begin{array}{l}1 \\
1 \\
3 \\
7\end{array}$ & $\begin{array}{c}207 \\
49 \\
23-89 \\
16-214\end{array}$ & $\begin{array}{r}--- \\
--- \\
53 \\
101\end{array}$ & $\begin{array}{l}0.12 \\
.026 \\
.026 \\
.052\end{array}$ & $\begin{array}{l}4.3 \\
3.9 \\
3.2 \\
4.5\end{array}$ \\
\hline
\end{tabular}


This table brings out some well-established features of the elemental abundances. All the abundant elements $\left(>10,000\right.$ atoms $\left./ 10^{6} \mathrm{Si}\right)$ have low atomic numbers, $28(\mathrm{Ni})$ or less. The abundances of elements of higher atomic number are uniformly low (only $\mathrm{Cu}, \mathrm{Zn}, \mathrm{Ga}, \mathrm{Ge}, \mathrm{Se}, \mathrm{Br}$, and Se have abundances greater than 10 atoms $/ 10^{6} \mathrm{Si}$ ) and relatively constant; the odd-even relationship is well marked, elements of odd atomic number being generally about 10 times less abundant than those of even atomic number on either side. Elements of low atomic number $(<28)$ show much greater variability in relative abundances than those of higher atomic number. The very low abundances of the lightest elements, $\mathrm{Li}, \mathrm{Be}$, and $\mathrm{B}$, can be ascribed to the relative instability of their nuclei; $\mathrm{Sc}$ is also an element of unusually low abundance. The most abundant nonvolatile elements, $\mathrm{Mg}$, $\mathrm{Si}$, and $\mathrm{Fe}$, have almost identical atomic abundances, and hence when completely oxidized will form olivine, $(\mathrm{Mg}, \mathrm{Fe})_{2} \mathrm{SiO}_{4}$, whereas if the iron is partly reduced to metal and/or sulfide, olivine will be partly replaced by pyroxene, $(\mathrm{Mg}, \mathrm{Fe}) \mathrm{SiO}_{3}$, and if all the iron is reduced the silicate will be pure $\mathrm{MgSiO}_{3}$. This is the sequence we observe in the chondrites, from C3-L-H-E chondrites, although the sequence is not a continuous one and does not imply direct production of one class from another.

Also included in table 82 are the current solar abundances (Ross and Aller, 1976). Ross and Aller commented (p. 1228): "Except for lithium, beryllium, and boron, the non-volatile component of the solar atmosphere fits well with data from carbonaceous chondrites. There are a few exceptions, such as indium, but one can be skeptical of the abundance of an otherwise unremarkable metal whose solar abundance is alleged to differ markedly from the meteoritic value. The difference is almost certainly to be attributed to bad $f$-values or to blending or confusion with other lines, or both. Lithium, beryllium, and boron can be destroyed at the bottom of the solar convection zone." 
TABLE 82.-Chondritic and solar abundances

[For C1 chondrites, except as noted. Solar abundances from Ross and Aller, 1976]

\begin{tabular}{|c|c|c|c|}
\hline Element & $\mathrm{Cl}$ & $\mathrm{Cl}$ & Sun \\
\hline & $\mathrm{ppm}$ & atoms $/ 10^{6} \mathrm{Si}$ & atoms $/ 10^{6} \mathrm{Si}$ \\
\hline $\mathrm{Li}$ & 1.6 & 60 & 0.22 \\
\hline $\mathrm{Be}^{1}$ & .035 & .81 & .32 \\
\hline B & 5.7 & 144 & $<4$ \\
\hline F & 72 & 1,000 & 810 \\
\hline $\mathrm{Na}$ & 5,100 & 60,000 & 43,000 \\
\hline $\mathrm{Mg}$ & 95,600 & $1,060,000$ & 890,000 \\
\hline Al & 8,500 & 85,000 & 74,000 \\
\hline $\mathrm{Si}$ & 103,000 & $10^{6}$ & $10^{6}$ \\
\hline $\mathrm{P}$ & 800 & 7,000 & 7,100 \\
\hline$S$ & 59,000 & 502,000 & 320,000 \\
\hline $\mathrm{C} 1$ & 773 & 5,700 & 6,300 \\
\hline $\mathrm{K}$ & 500 & 3,500 & 3,200 \\
\hline $\mathrm{Ca}$ & 10,600 & 72,000 & 50,000 \\
\hline $\mathrm{Sc}$ & 5.1 & 31 & 25 \\
\hline $\mathrm{Ti}$ & 430 & 2,400 & 2,500 \\
\hline V & 49 & 254 & 230 \\
\hline $\mathrm{Cr}$ & 2,430 & 12,700 & 11,000 \\
\hline Mn & 1,880 & 9,300 & 5,900 \\
\hline $\mathrm{Fe}$ & 184,000 & 901,000 & 710,000 \\
\hline Co & 480 & 2,200 & 1,800 \\
\hline $\mathrm{Ni}$ & 10,300 & 47,000 & 43,000 \\
\hline $\mathrm{Cu}$ & 127 & 540 & 260 \\
\hline $\mathrm{Zn}$ & 303 & 1,260 & 630 \\
\hline $\mathrm{Ga}$ & 9.6 & 14 & 38 \\
\hline $\mathrm{Ge}$ & 31.2 & 117 & 71 \\
\hline As & 1.7 & 6.2 & -- \\
\hline $\mathrm{Se}$ & 19.5 & 67 & - \\
\hline $\mathrm{Br}$ & 4.0 & 14 & - \\
\hline $\mathrm{Rb}$ & 1.88 & 6.0 & 8.9 \\
\hline $\mathrm{Sr}$ & 8.6 & 27 & 18 \\
\hline Y & 1.6 & 4.8 & 2.8 \\
\hline $\mathrm{Zr}$ & 3.1 & 9.1 & 13 \\
\hline $\mathrm{Nb}$ & .3 & .9 & 1.6 \\
\hline Mo & 1.4 & 4.0 & 3.2 \\
\hline $\mathrm{Ru}$ & .69 & 1.9 & 1.5 \\
\hline $\mathrm{Rh}^{2}$ & .25 & .40 & .56 \\
\hline $\mathrm{Pd}$ & .49 & 1.3 & .6 \\
\hline $\mathrm{Ag}$ & .18 & .46 & .16 \\
\hline $\mathrm{Cd}$ & .64 & 1.55 & 1.6 \\
\hline In & .080 & .19 & 1.0 \\
\hline Sn & 1.64 & 3.7 & 2.0 \\
\hline $\mathrm{Sb}$ & .14 & .31 & .22 \\
\hline
\end{tabular}


TABLE 82.-Chondritic and solar abundances-Continued

\begin{tabular}{|c|c|c|c|}
\hline Element & $\begin{array}{r}\mathrm{Cl} \\
\mathrm{ppm}\end{array}$ & $\begin{array}{c}\mathrm{Cl} \\
\text { atoms } / 10^{6} \mathrm{Si}\end{array}$ & $\begin{array}{c}\text { Sun } \\
\text { atoms } / 10^{6} \mathrm{~S}\end{array}$ \\
\hline $\mathrm{Te}$ & 3.04 & 6.5 & -- \\
\hline I & .58 & 1.16 & -- \\
\hline Cs & .19 & .39 & $<.6$ \\
\hline $\mathrm{Ba}$ & 2.4 & $4 \cdot 8$ & 2.8 \\
\hline La & .19 & .37 & .30 \\
\hline $\mathrm{Ce}$ & .63 & 1.2 & .79 \\
\hline $\operatorname{Pr}$ & .094 & .18 & .10 \\
\hline $\mathrm{Nd}$ & .42 & .79 & .38 \\
\hline $\mathrm{Sm}$ & .133 & .24 & .12 \\
\hline $\mathrm{Eu}$ & .053 & .094 & .1 \\
\hline $\mathrm{Gd}$ & .24 & .42 & .30 \\
\hline $\mathrm{Tb}$ & .044 & .076 & -- \\
\hline Dy & .22 & .37 & -- \\
\hline Ho & .056 & .092 & -- \\
\hline Er & .14 & .23 & .13 \\
\hline $\mathrm{Tm}$ & .022 & .035 & .041 \\
\hline $\mathrm{Yb}$ & .13 & .20 & .16 \\
\hline $\mathrm{Lu}$ & .023 & .035 & .13 \\
\hline Hf & .11 & .17 & .1 \\
\hline $\mathrm{Ta}^{1}$ & .017 & .020 & -- \\
\hline $\mathrm{W}$ & .20 & .30 & 1.0 \\
\hline $\operatorname{Re}$ & .035 & .051 & $\sim .01$ \\
\hline Os & .48 & .69 & .1 \\
\hline Ir & .51 & .72 & .16 \\
\hline Pt & 1.01 & 1.4 & 1.3 \\
\hline $\mathrm{Au}$ & .15 & .21 & .13 \\
\hline $\mathrm{Hg}$ & $\sim 1 ?$ & $\sim 1.4 ?$ & .3 \\
\hline $\mathrm{T} 1$ & .145 & .19 & .18 \\
\hline $\mathrm{Pb}$ & 1.94 & 2.6 & 1.9 \\
\hline $\mathrm{Bi}$ & .11 & .14 & $<1.6$ \\
\hline Th & .038 & .045 & .03 \\
\hline $\mathrm{U}$ & .0086 & .010 & $<.1$ \\
\hline
\end{tabular}

1 Abundances for $\mathrm{C} 2$ chondrites.

2

Abundances for $\mathrm{H}$ chondrites. 


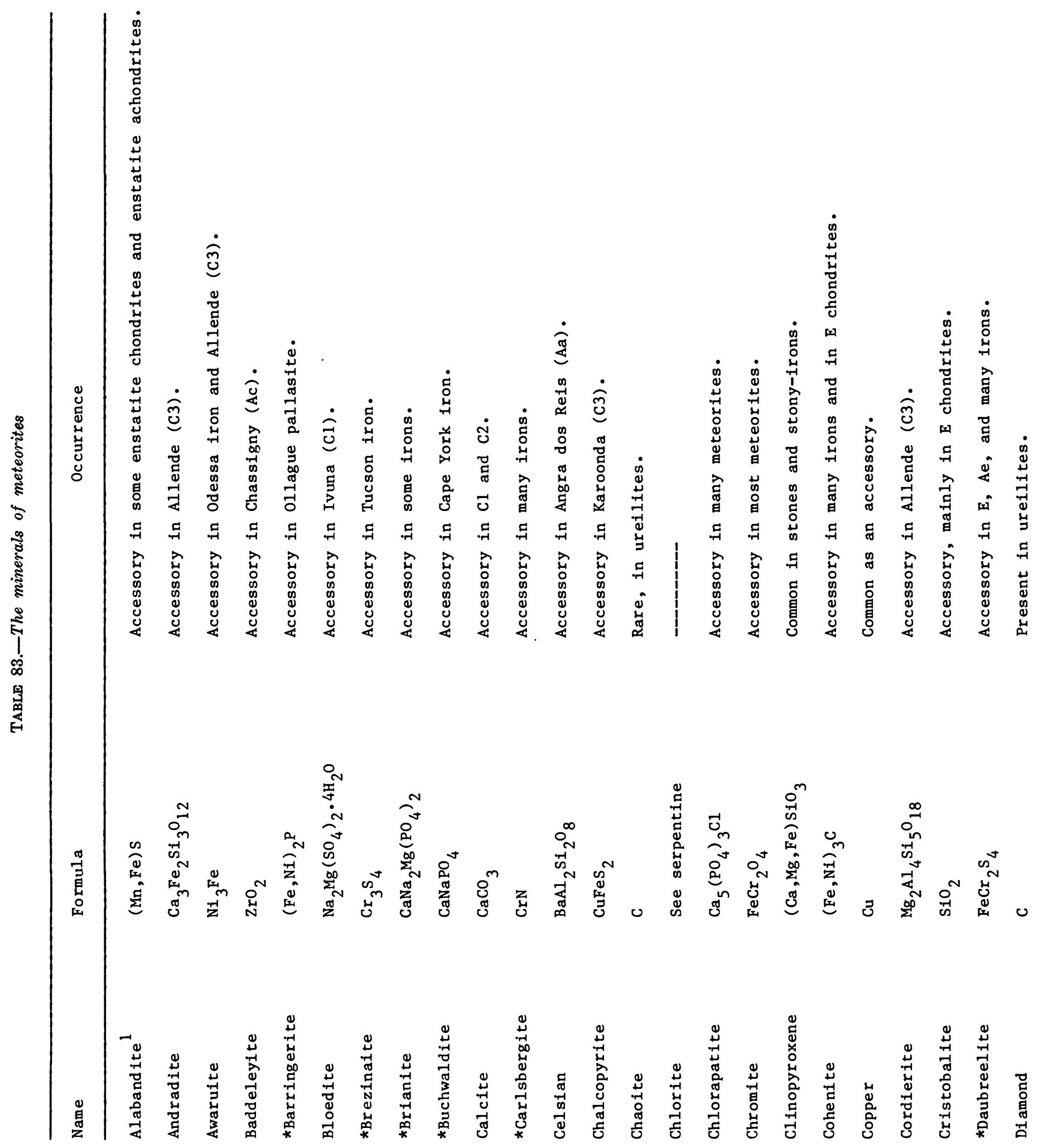




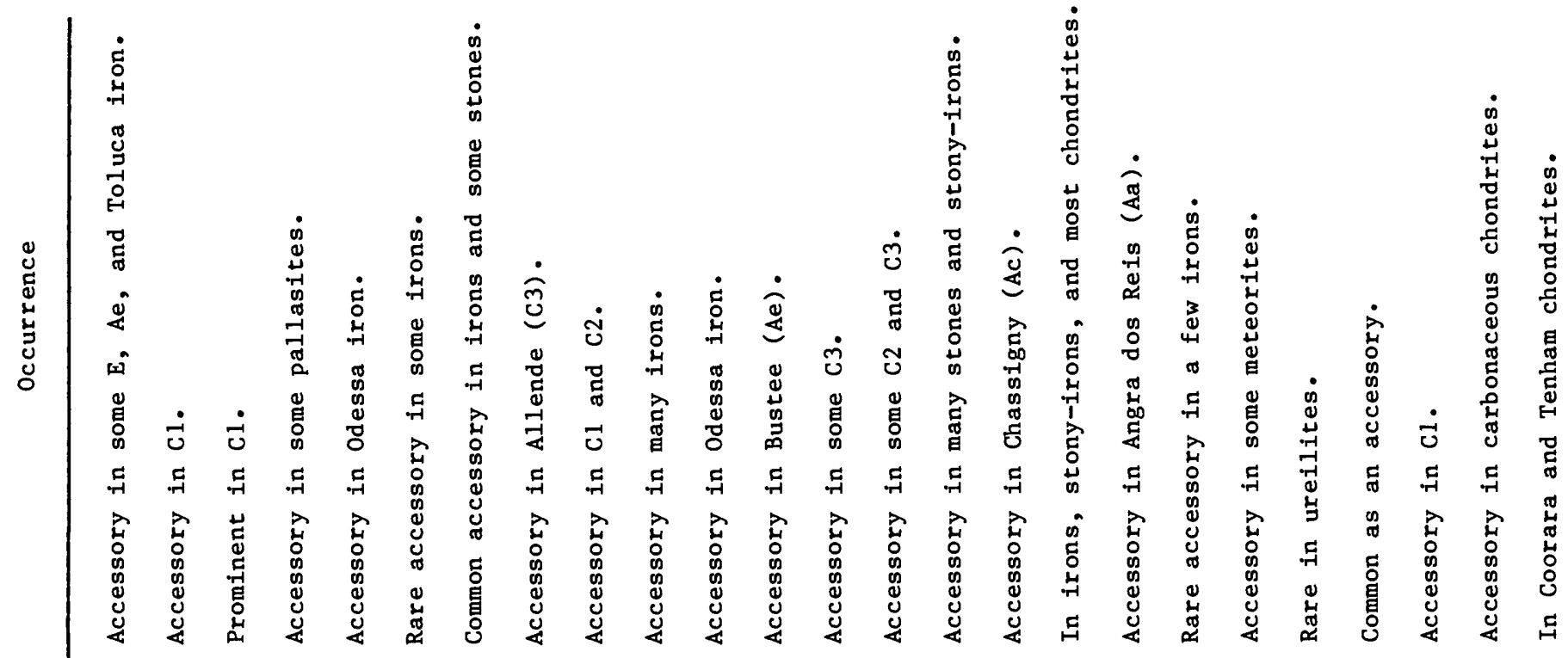

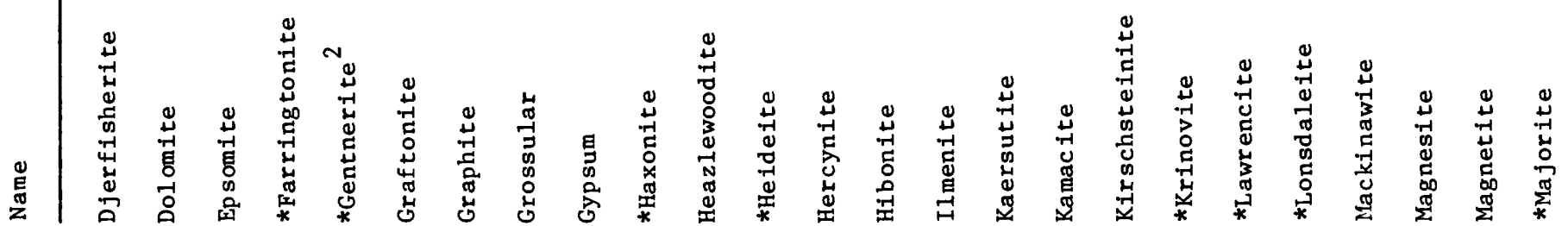




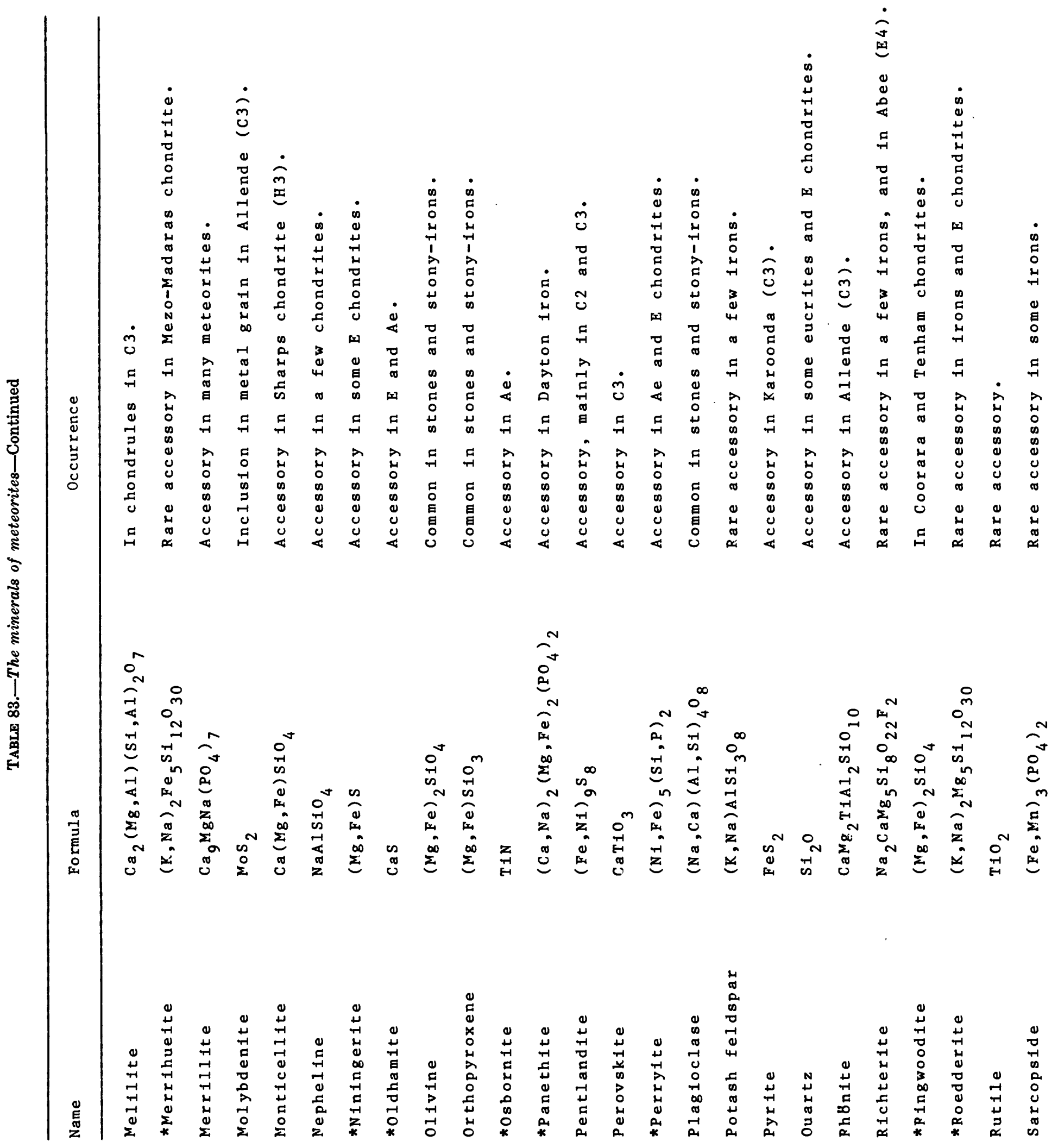




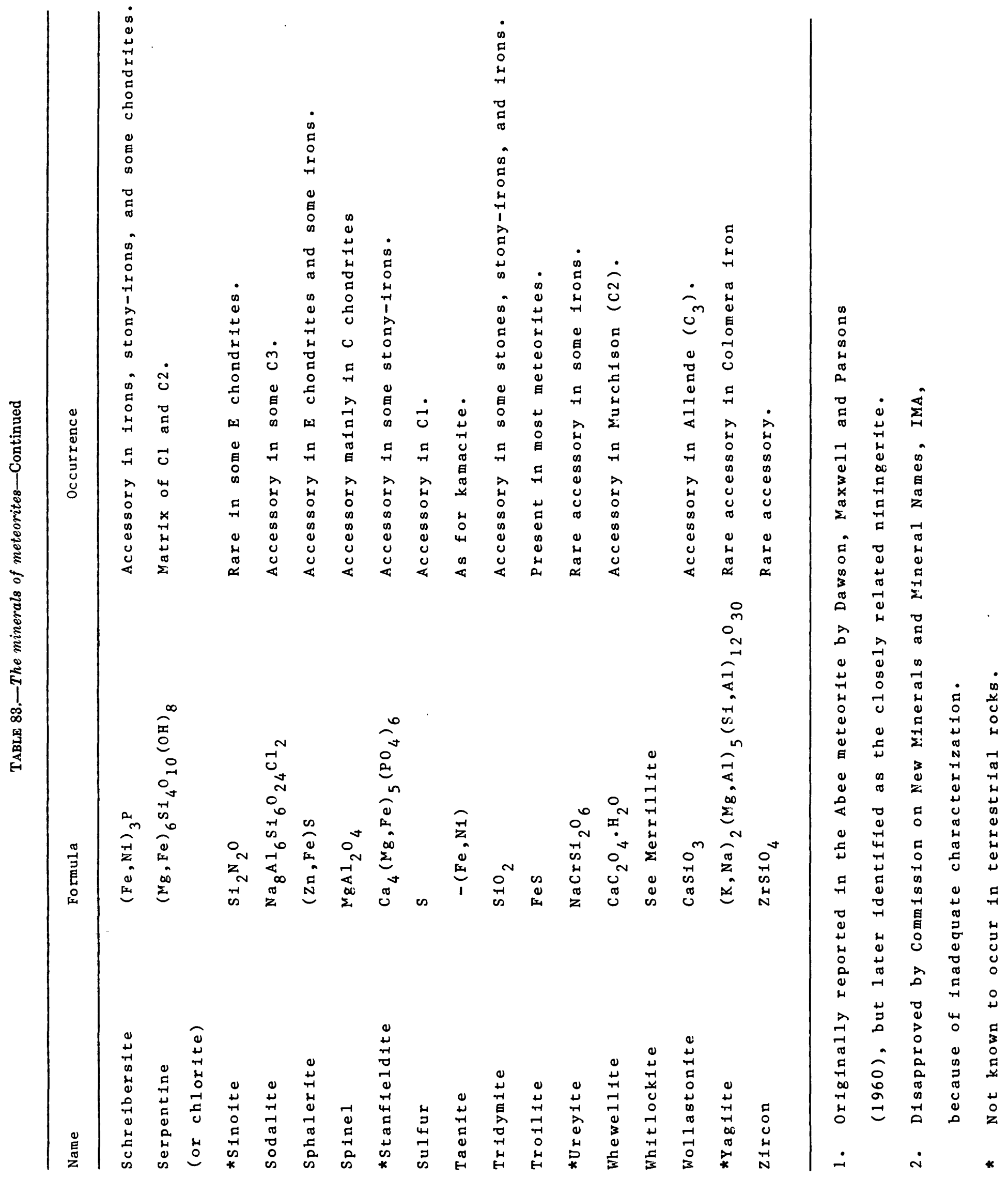




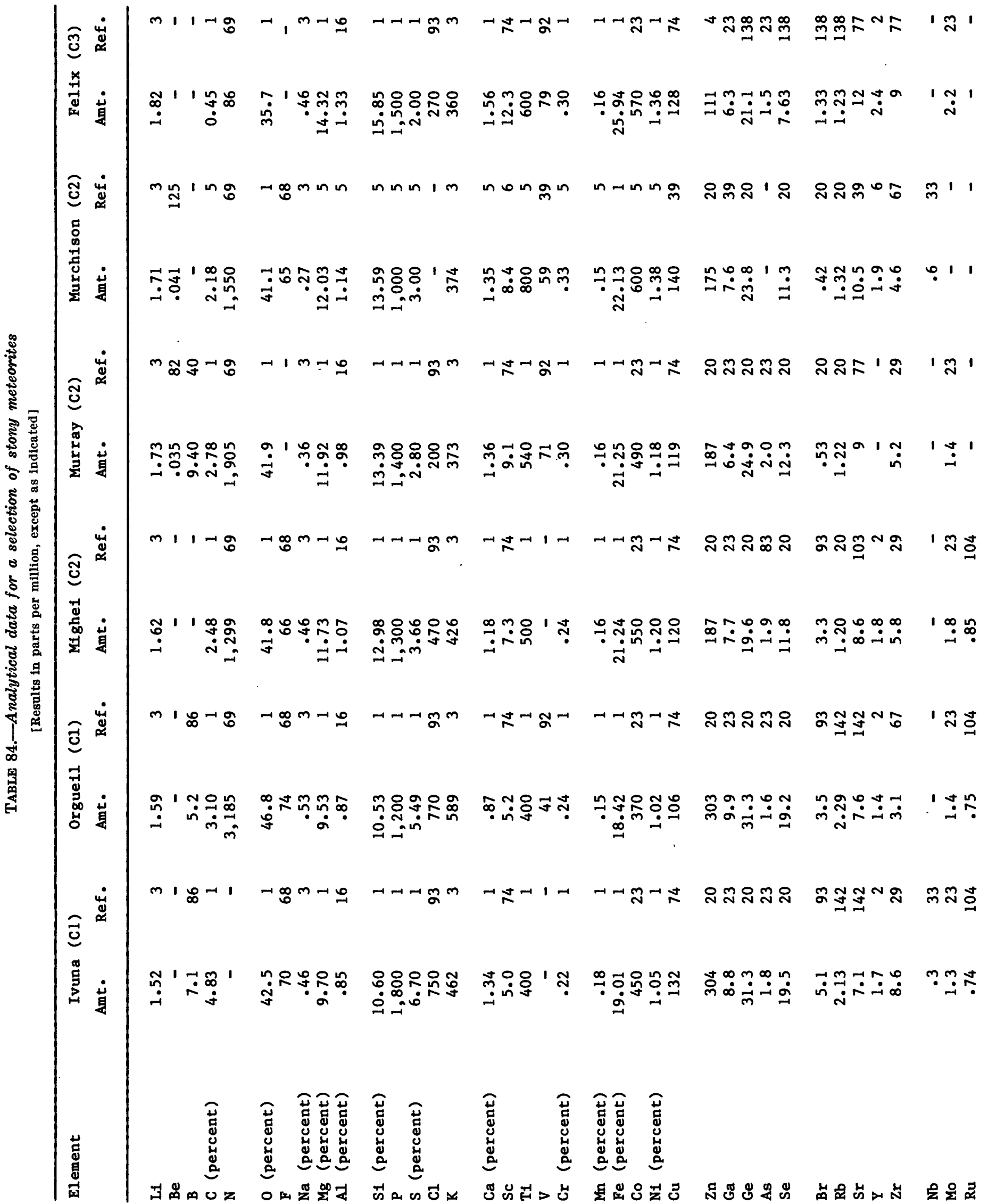




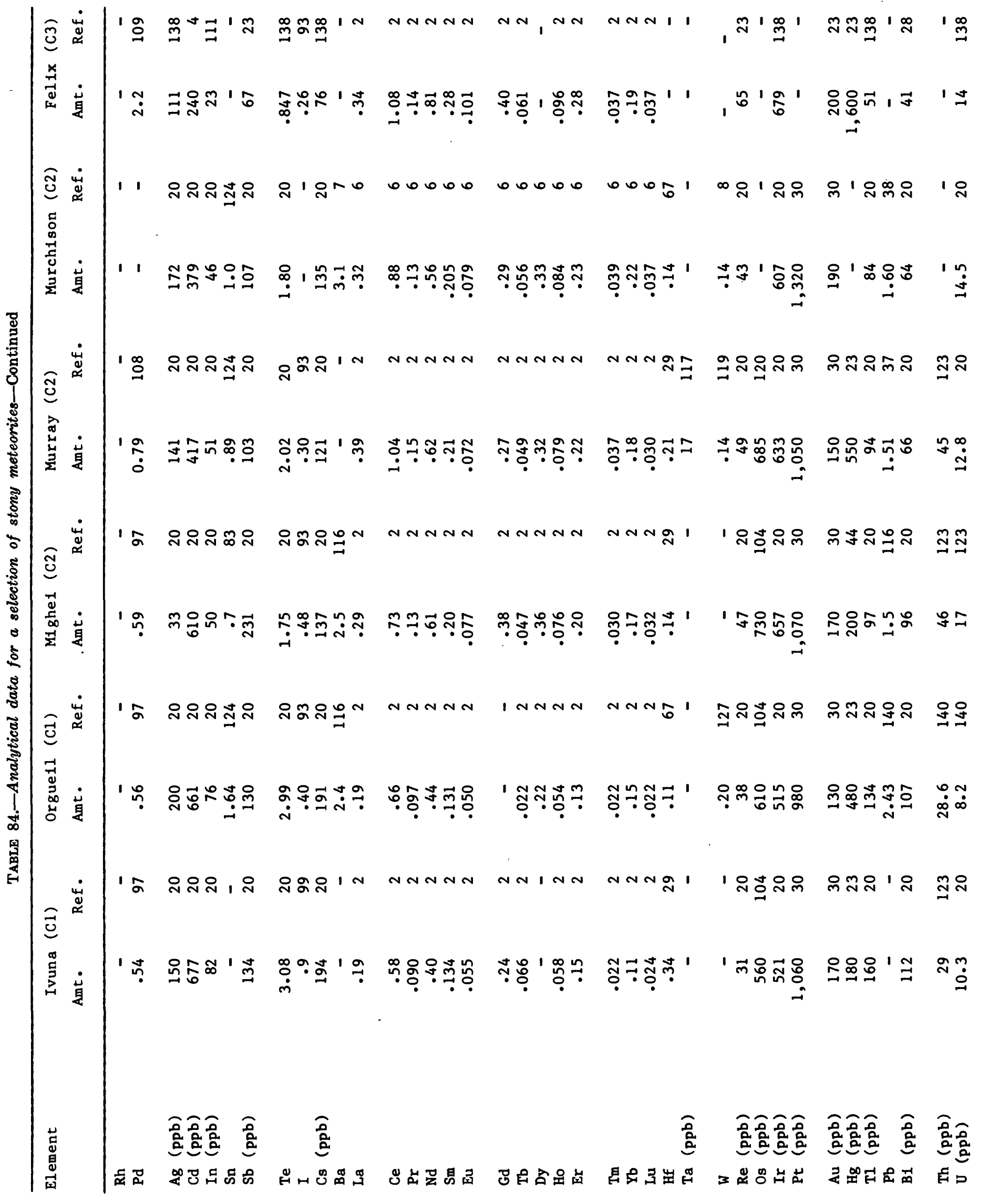




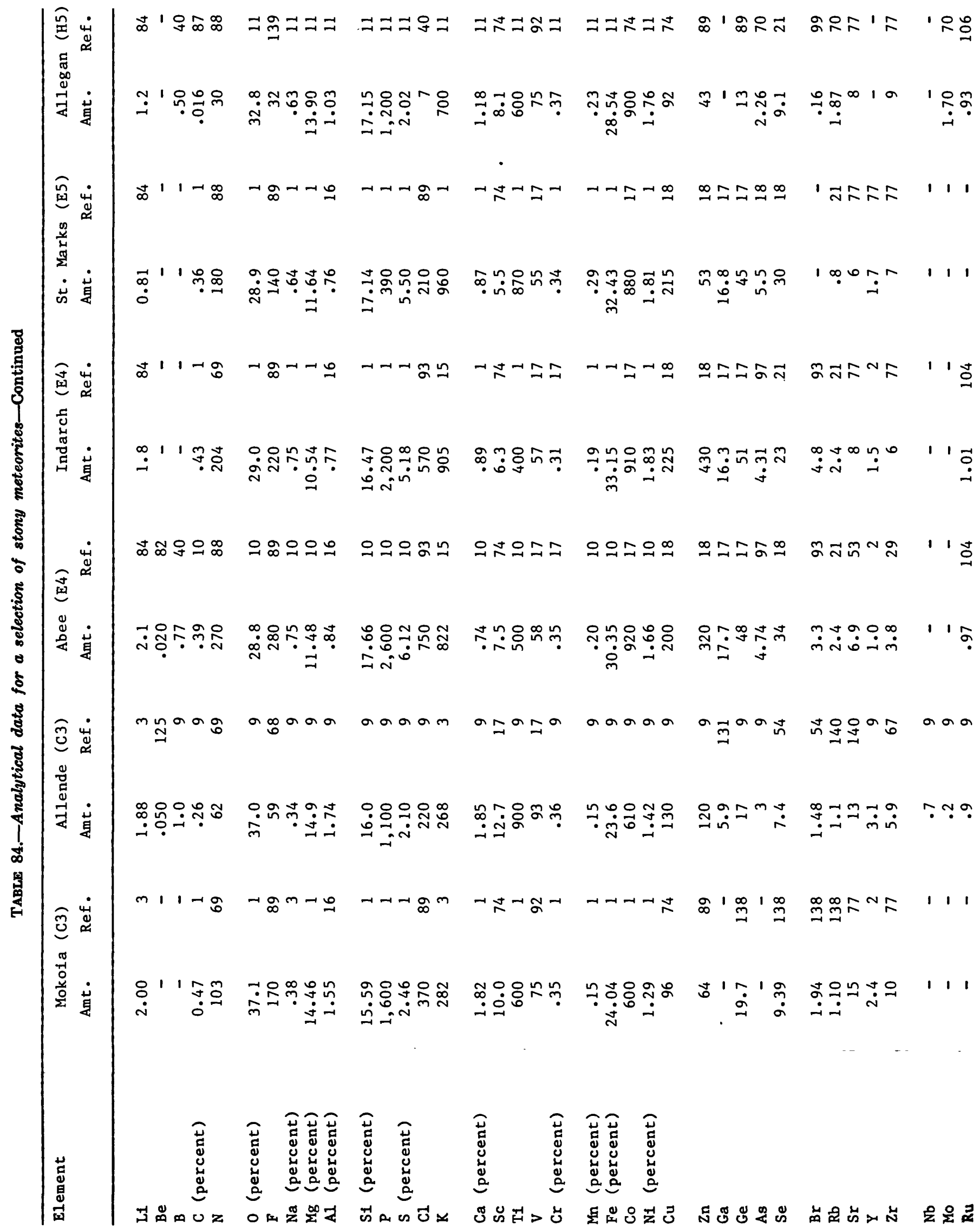




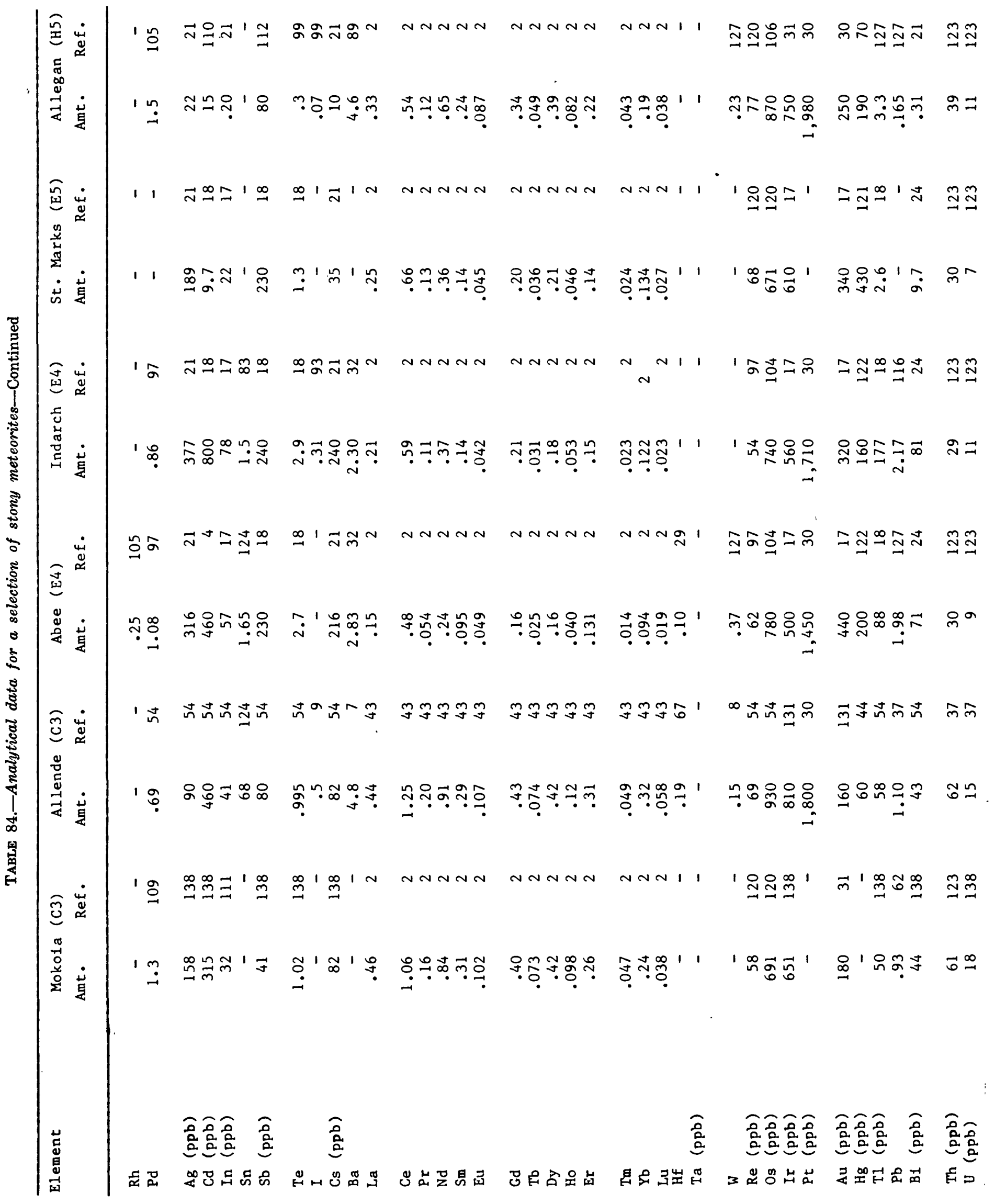




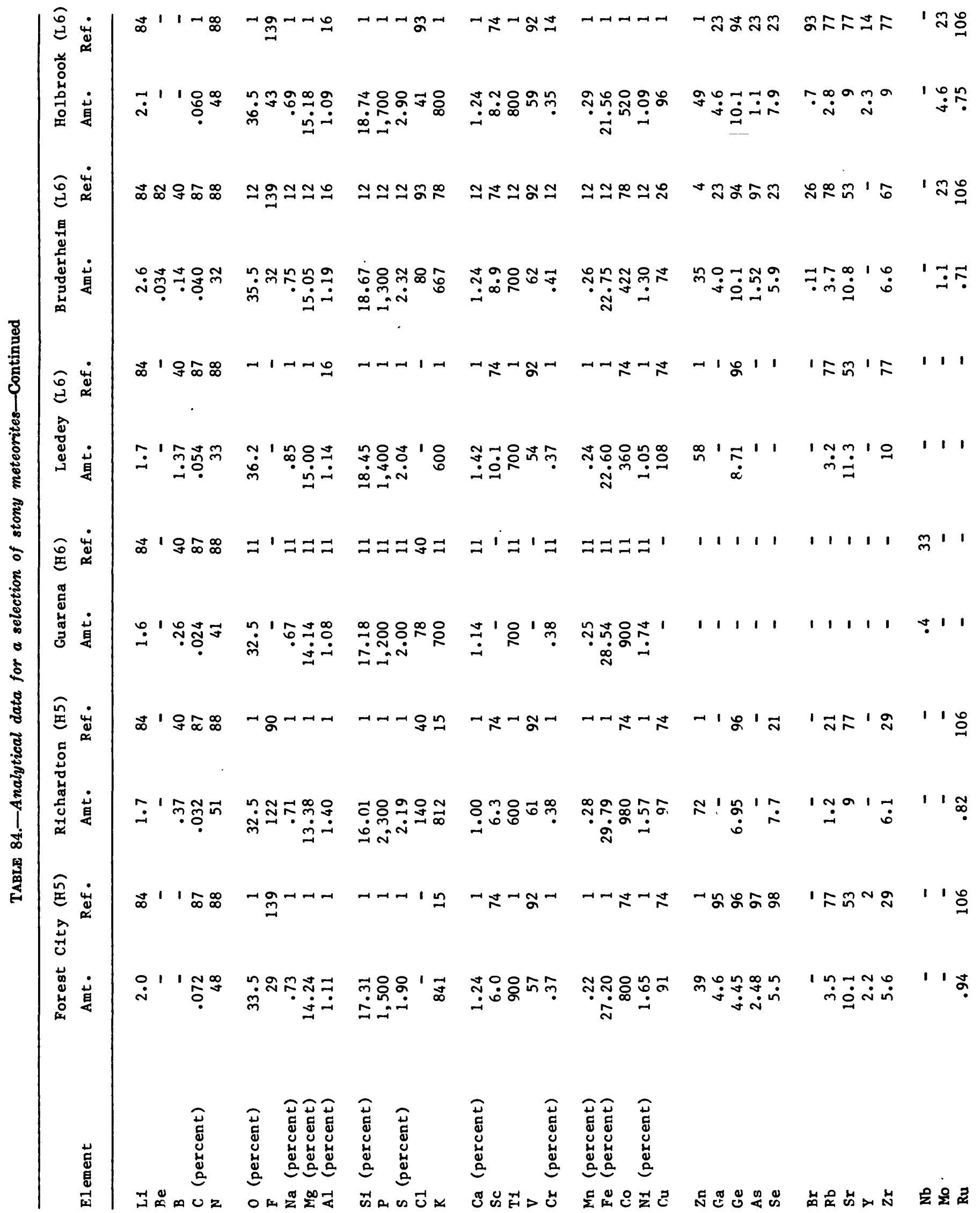




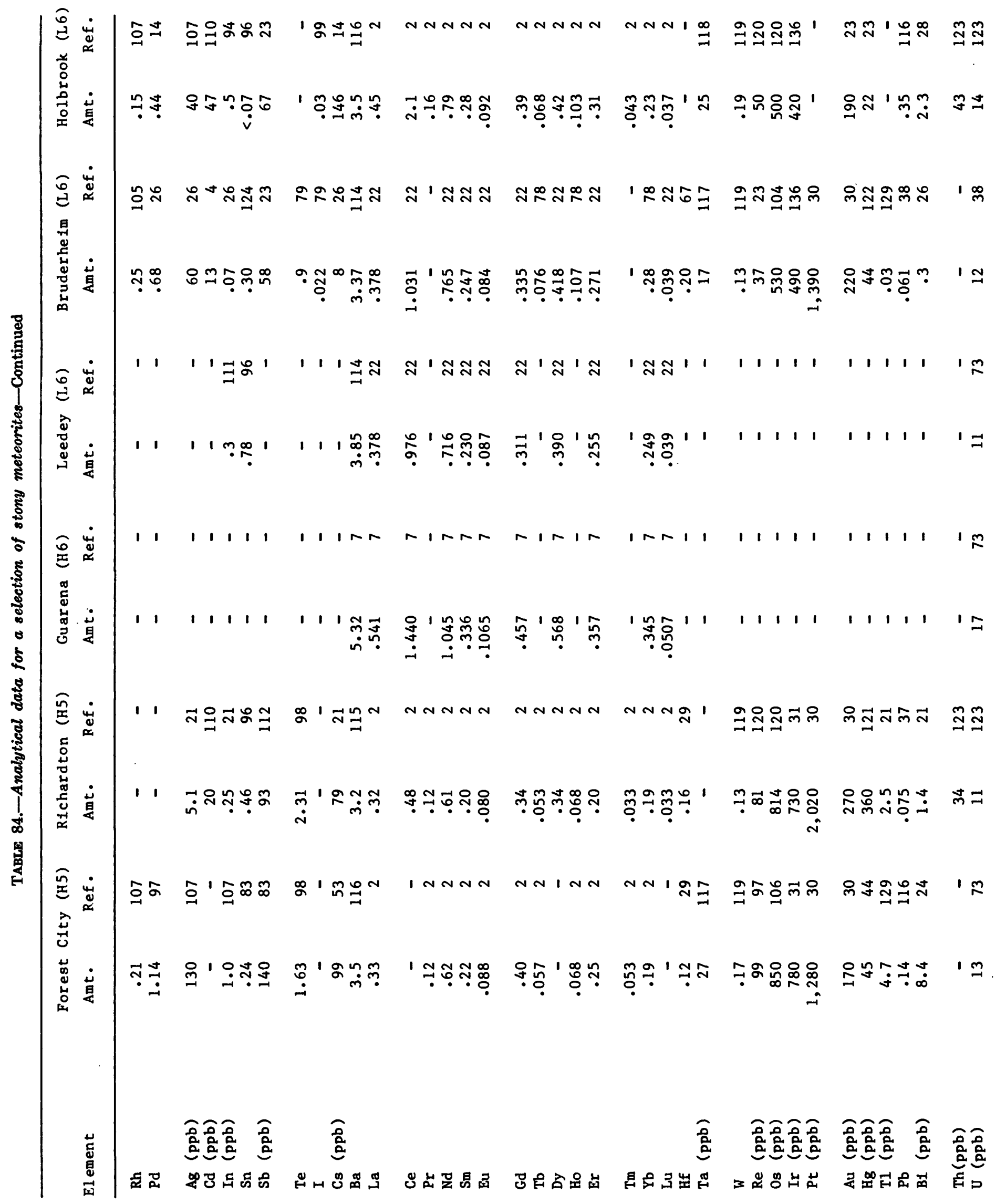




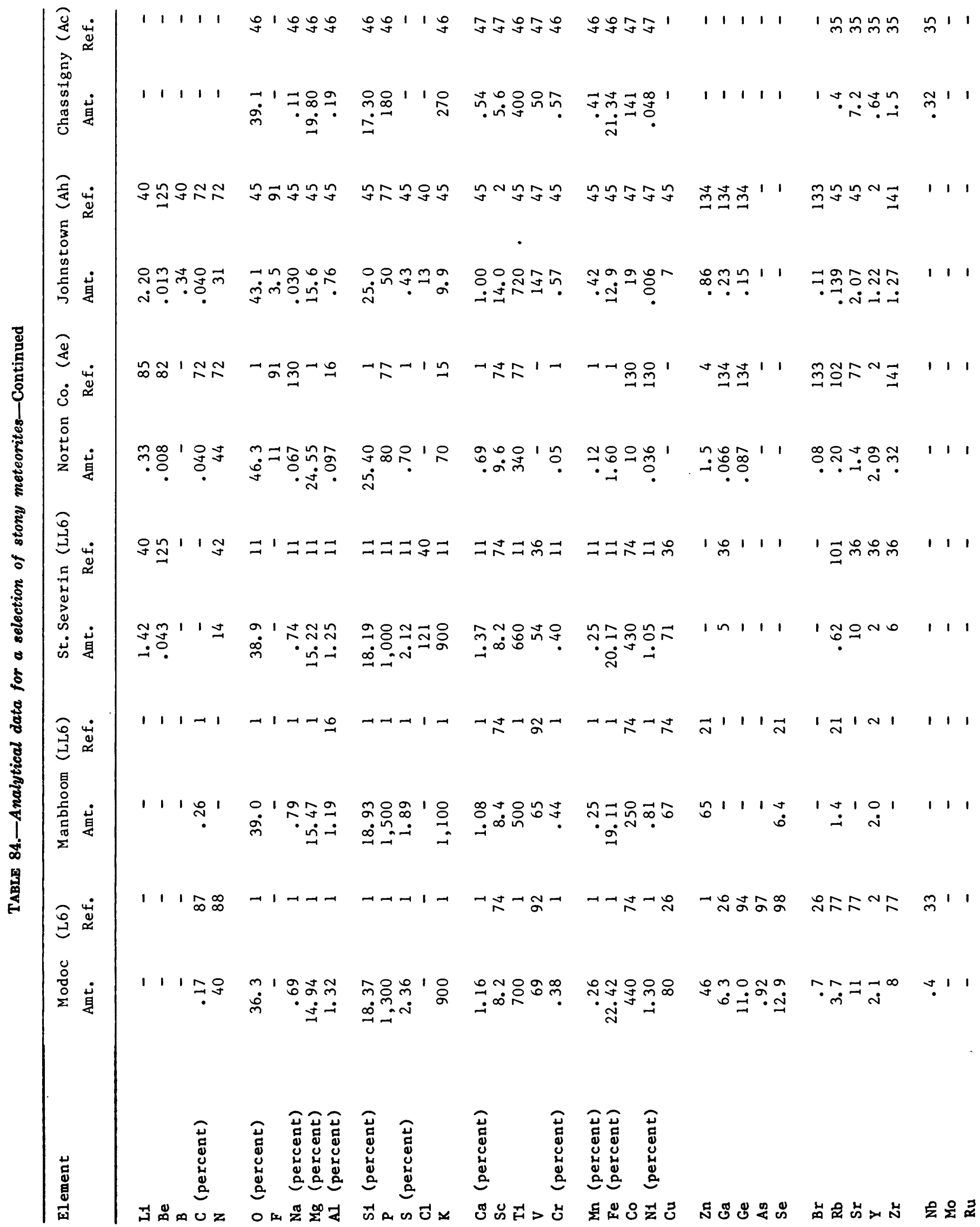




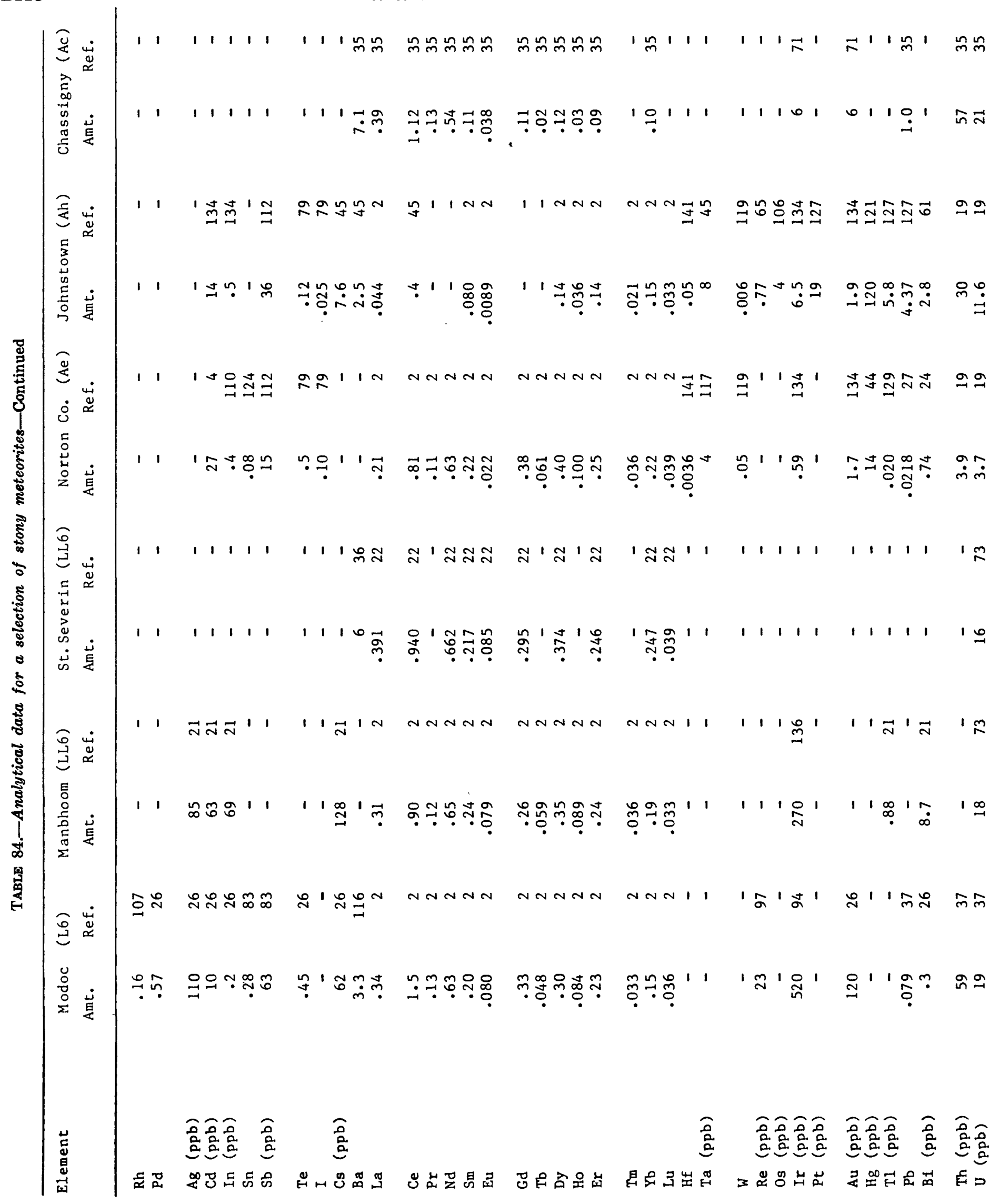




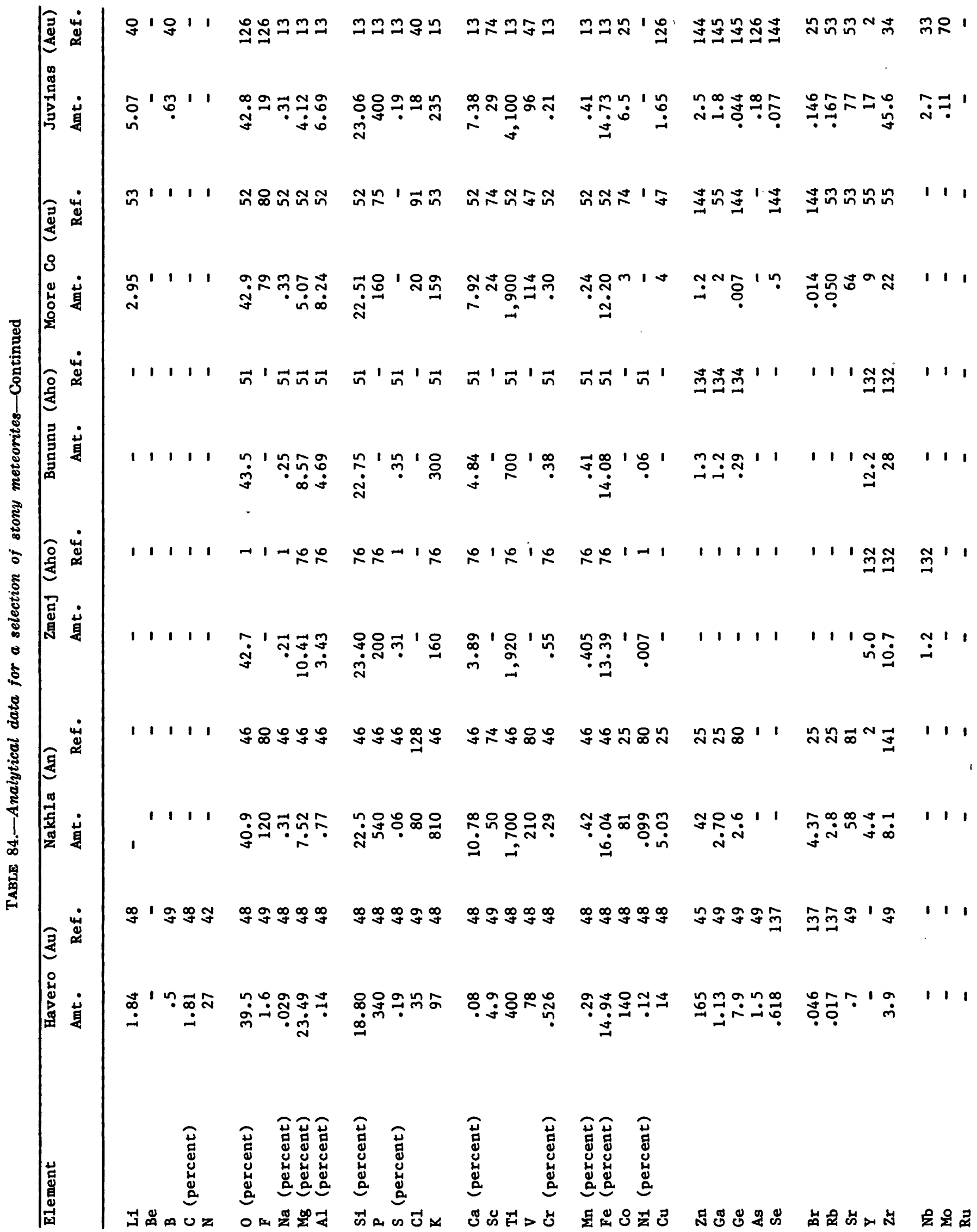




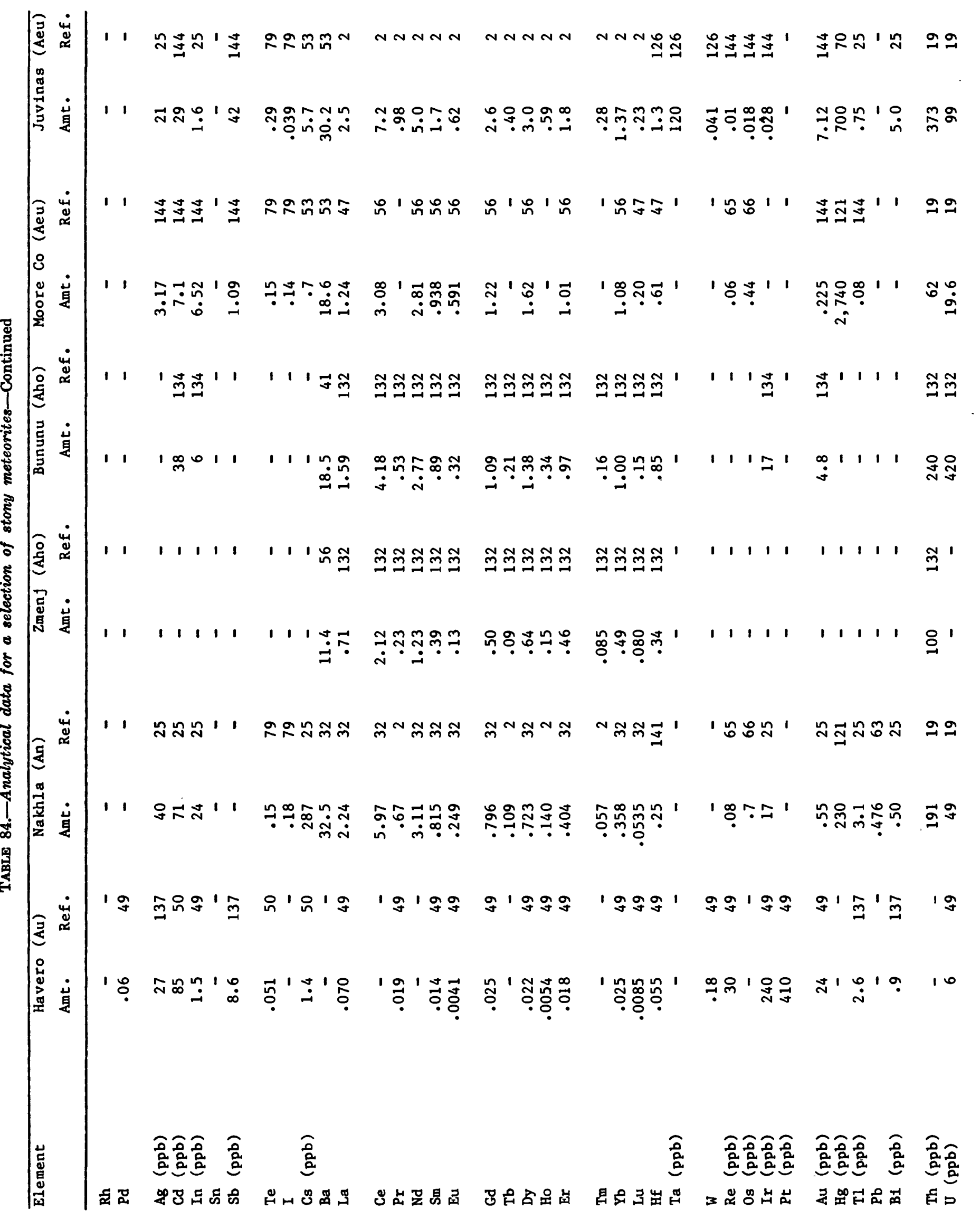




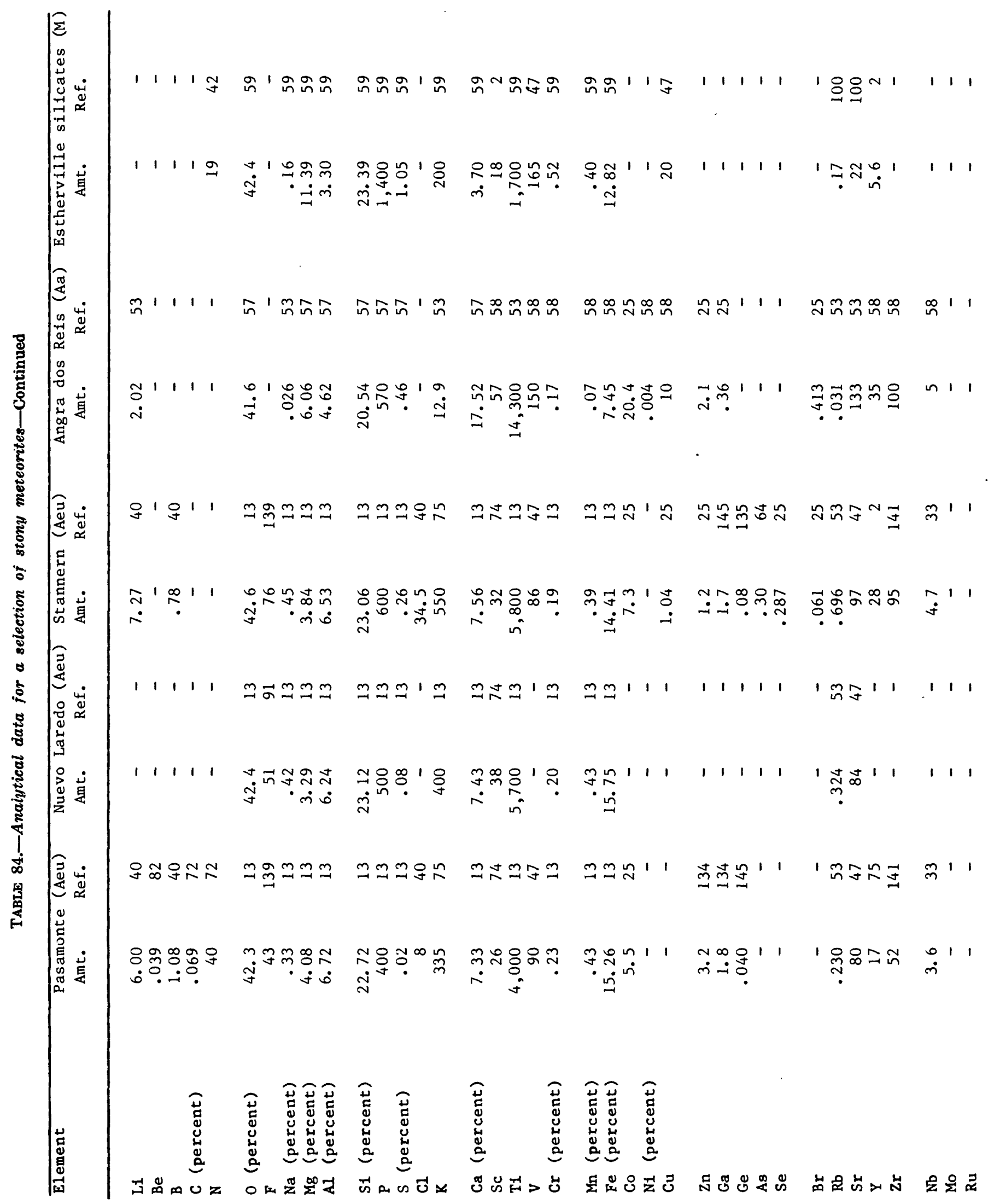




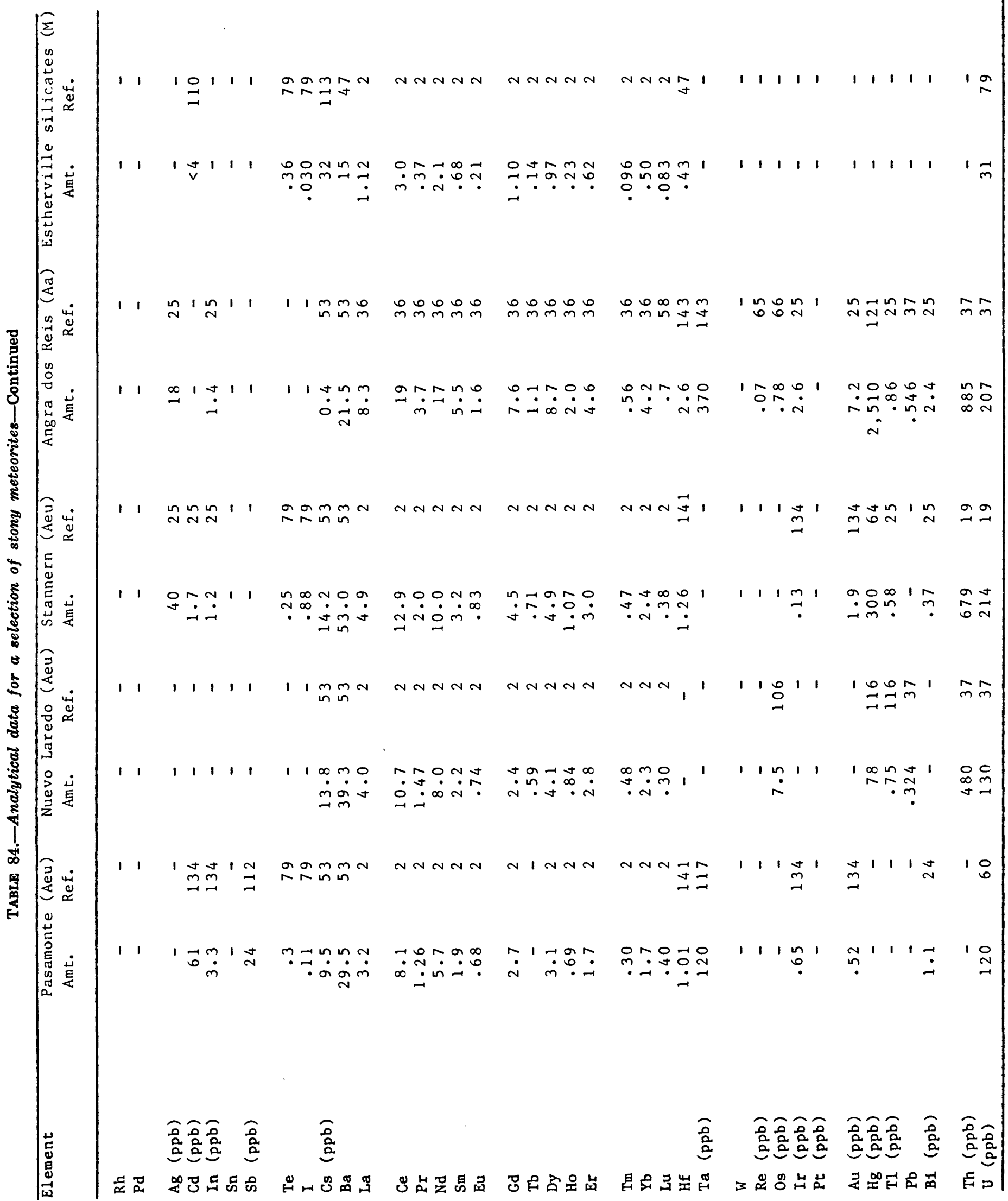


1. Wiik, 1969

2. Haskin and others, 1966

3. Nichiporuk and Moore, 1974

4. Rosman and de Laeter, $\mathbf{1 9 7 4}$

5. Jarosewich, 1971

6. Showalter, Wakita, and Schmitt, 1972

Nakamura, 1974

Ehmann, Gillum, and others, 1970

9. Mason, 1975

10. Dawson, Maxwell, and Parsons, $\mathbf{1 9 6 0}$

11. Jarosewich and Mason, 1969

2. Baadsgaard and others, 1961

3. Duke and Silver, 1967

14. Mason and Wiik, $\mathbf{1 9 6 1}$

15. Kirsten, Krankowsky, and Zähringer, 1963

16. Loveland, Schmitt, and Fisher, 1969

17. Baedecker and Wasson, $\mathbf{1 9 7 5}$

18. Binz, Kurimoto, and Lipschutz, 1974

19. Morgan and Lovering, $\mathbf{1 9 7 3}$

20. Krähenbühl and others, 1973

21. Laul and others, 1973

2. Masuda, Nakamura, and Tanaka, 1973

Case and others, 1973

Santoliquido and Ehmann, 1972

Laul and others, 1972

Keays, Ganapathy, and Anders, 1971

Huey and Kohman, 1973

Laul, Case, and others, 1970

Ehmann and Rebagay, 1970

Ehmann and Gillum, 1972

. Ehmann, Baedecker, and MeKown, 1970

32. Nakamura and Masuda, 1973

33. Graham and Mason, 1972

34. Erlank and others, 1972

35. Mason and others, 1976

36. Mason and Graham, 1970

37. Tatsumoto, Knight, and Allegre, 1973

38. Tilton, 1973

39. Lovering, Le Maitre, and Chappell,

40. Quijano-Rico and Wänke, 1969

41. Philpotts, Schnetzler, and Thomas, 1967

42. Kothari and Goel, 1974

43. Wakita and Schmitt, 1970

44. Ozerova and others, 1973

45. Mason and Jarosewich, 1971

46. McCarthy and others, 1974

47. Jérome, 1970

48. Wlik, 1972
49. Wänke and others, 1972

50. Binz, Ikramuddin, and Lipschutz, 1975

51. Mason, 1967 a

52. Hess and Henderson, 1949

53. Tera and others, 1970

54. Anders and others, 1975

55. Allen and Mason, 1973

56. Schnetzler and Philpotts, 1969

57. Ludwig and Tschermak, 1909

58. Smales and others, 1970

59. Nelen and Mason, 1972

60. Fisher, 1969a

61. Ehmann and Hulzenga, 1959

62. Marshall, 1962

63. Hutchison, Gale, and Arden, 1975

64. Kiesl and others, 1967

65. Morgan, 1970

66. Morgan, 1965

67. Ganapathy, Papia, and Grossman, 1976

68. Goldberg and others, 1974

69. Gibson, Moore, and Lewis, 1971b

70. Hermann and Wichtl, 1974

71. Boynton, Starzyk, and Schmitt, 1976

72. Gibson, Moore, and Lewis, 1971a

73. Fisher, 1972

74. Schmitt and others, 1972

75. McCarthy, Erlank, and Willis, 1973

76. MeCarthy, Ahrens, and Erlank, 1972

77. VonMichaelis and others, 1969

78. Allen, 1970

79. Clark and others, 1967

80. Greenland, $\mathbf{1 9 6 3}$

81. Gale, Arden, and Hutchison, 1975

82. Sill and Willis, $\mathbf{1 9 6 2}$

83. Hamaguchi and others, 1969

84. Nichiporuk and Moore, 1970

85. Balsiger and others, $\mathbf{1 9 6 8}$

86. Mills, 1968

87. Moore and Lewis, $\mathbf{1 9 6 7}$

88. Gibson and Moore, 1971

89. Greenland and Lovering, 1965

90. Reed, 1964

91. Reed and Jovanovic, 1969

92. Nichiporuk and Bingham, 1970

93. Goles, Greenland, and Jérome, 1967

94. Tandon and Wasson, 1968

95. Schaudy, Kiesl, and Hecht, 1968

96. Shima, 1964

97. Fouché and Smales, $1967 \mathrm{~b}$

98. DuFresne, 1960
99. Reed and Allen, $\mathbf{1 9 6 6}$

100. Pinson and others, 1965

101. Gopalan and Wetherill, $\mathbf{1 9 6 9}$

102. Bogard and others, 1967

103. Kaushal and Wetherill, 1970

104. Crocket and others, 1967

105. Sen Gupta, 1968a

106. Bate and Huizenga, 1963

107. Schindewolf and Wahlgren, 1960

108. Rieder and Wänke, 1969

109. Greenland, 1967

110. Schmitt, Smith, and Olehy, 1963

111. Schmitt and Smith, 1968

112. Tanner and Ehmann, 1967

113. Smales and others, 1964

114. Eugster, Tera, and Wasserburg, 1969

115. Hamaguchi, Reed, and Turkevich, 1957

116. Reed, Kigosht, and Turkevich, 1960

117. Ehmann, 1965

118. Atkins and Smales, 1960

119. Amiruddin and Ehmann, 1962

120. Morgan and Lovering, 1967

121. Ehmann and Lovering, 1967

122. Reed and Jovanovic, 1967

123. Morgan and Lovering, 1968

124. De Laeter, MeCulloch, and Rosman. 1974

125. Quandt and Herr, 1974

126. Wänke, Baddenhausen, Balacescu, and others, 1972

127. Hintenberger, Jochum, and Senfert 1973

128. Podosek, 1973

129. Huey and Kohman, 1972

130. Schmitt, Linn, and Wakita, 1970

131. Chou and others, 1976 a

132. Taylor, S. R. written commun., 1976

133. Leberman and Ehmann, 1967

134. Chou and others, 1976b

135. Wasson and Baedecker, 1970

136. Müller, Baedecker, and Wasson, 197

137. Higuehi and others, 1976

138. Anders and others, 1976

139. Allen and Clarke, 1977

140. Tatsumoto, Unruh, and Desborough, 1976

141. Ehmann and others 1976

142. Mittlefehldt and Wetherill, 1977

143. Ma, Murali, and Sehmitt, 1977

144. Gros and others, 1976

145. Chou and others, $1976 \mathrm{c}$

\section{ACKNOWLEDGMENTS}

I wish to thank the following persons who helped me in the preparation of this compilation: P. R. Brett and Michael Fleischer, who read and commented on the entire manuscript; R. O. Allen, P. A. Baedecker, W. D. Ehmann, M. E. Lipschutz, C. B. Moore, G. W. Reed, M Tatsumoto, and G. W. Wetherill, who reviewed specific sections; J. T. Wasson, E. R. D. Scott, and V. F. Buchwald, who provided illustrations; and S. R. Taylor, who provided the lanthanide and some other trace element data on the Bununu and Zmenj meteorites specifically for this publication.

\section{REFERENCES CITED}

Ahrens, L. H., 1964, Si-Mg fractionation in chondrites: Geochim. et Cosmochim. Acta v. 28, no. 4, p. 411-423. 1970, The composition of stony meteorites-VII. Observations on fractionation between $L$ and $H$ chondrites: Earth and Planetary Sci. Letters, v. 9, p. 345-347.

Ahrens, L. H. and VonMichaelis, H., 1968, Fractionation of some abundant lithophile element ratios in chondrites, in Ahrens, L. H. ed., Origin and distribution of the elements: New York, Pergamon Press, p. 258-272.

Ahrens, L. H., VonMichaelis, H., Erlank, A. J., and Willis, J. P., 1969, Fractionation of some abundant lithophile element ratios in chondrites, Paper 15 in Millman, $P$. M., ed., Meteorite research: Dordrecht, Hollond, D. Reidel Publishing Co., p. 166-173. 
Allen, R. O., Jr., 1970, Multi-element neutron activation analysis-development and application of trace element study of the Bruderheim chondrite: Wisconsin Univ., $\mathrm{Ph}$. D. thesis.

Allen, R. O., and Clark, P. J., 1977, Fluorine in meteorites: Geochim. et Cosmochim. Acta, v. 41, No. 5, p. 581-585.

Allen, R. O., and Mason, Brian, 1973, Minor and trace elements in some meteoritic minerals: Geochim. et Cosmochim, Acta, v. 37, no. 6, p. 1435-1456.

Amiruddin, A., and Ehmann, W. D., 1962, Tungsten abundances in meteoritic and terrestrial materials: Geochim. et Cosmochim. Acta, v. 26, p. 1011-1022.

Anders, Edward, 1964, Origin, age, and composition of meteorites: Space Sci. Rev. v. 3, nos. 5-6, p. 583-714.

1971a, How well do we know "cosmic" abundances: Geochim, et Cosmochim. Acta, v. 35, p. 516-522.

$1971 \mathrm{~b}$, Meteorites and the early solar system: Palo Alto, Calif., Ann. Rev. Astronomy Astrophys. v. 9, p. 1-34.

Anders, Edward, Higuchi, Hideo, Gros, J., Takahashi, H., and Morgan, J. W., 1975, Extinct superheavy element in the Allende meteorite: Science, v. 190 , no. 4221, p. 12621271.

Anders, Edward, Higuchi, Hideo, Ganapathy, R., and Morgan, J. W., 1976, Chemical fractionations in meteorites -IX. C3 chondrites: Geochim. et Cosmochim. Acta, v. 40, no. 9, p. 1131-1139.

Arnold, J. R., and Suess, H. E., 1969, Cosmochemistry in Annual Review of Physical Chemistry, v. 20: Palo Alto, Calif., Annual Reviews Inc., p. 293-314.

Atkins, D. H. F., and Smales, A. A., 1960, The determination of tantalum and tungsten in rocks and meteorites by neutron activation analysis: Anal. Chim. Acta, v. 22, p. 462-478.

Baadsgaard, Halfdan, Campbell, F. A., Folinsbee, R. E., and Cumming, G. L., 1961, The Bruderheim meteorite: Jour. Geophys. Research, v. 66, no. 10, p. 3574-3577.

Baedecker, P. A., and Wasson, J. T., 1975, Elemental fractionations among enstatite chondrites: Geochim, et Cosmochim. Acta, v. 39, no. 5, p. 735-765.

Balsiger, H., Geiss, J., Groegler, N., and Wyttenbach, A., 1968, Distribution and isotopic abundance of lithium in stone meteorites: Earth and Planetary Sci. Letters, v. 5, no. 1, 17-22.

Bate, G. L., and Huizenga, J. R., 1963, Abundances of ruthenium, osmium and uranium in some cosmic and terrestrial sources: Geochim. et Cosmochim. Acta, v. 27, no. 4, p. 345-360.

Bate, G. L., Potratz, H. A., and Huizenga, J. R., 1958, Thorium in iron meteorites-a preliminary investigation: Geochim. et Cosmochim. Acta, v. 14, nos. 1/2, p. 118-125.

Bauer, R., and Schaudy, R., 1970, Activation analytical determination of elements in iron meteorites-3. Determination of manganese, sodium, gallium, germanium, copper and gold in 21 iron meteorites and 2 mesosiderites: Chem. Geology, v. 6, p. 119-131.

Berkey, E., and Fisher, D. E., 1967, The abundance and distribution of chlorine in iron meteorites: Geochim. et Cosmochim. Acta, v. 31, no. 10, p. 1543-1558.

Binz, C. M., Ikramuddin, M., and Lipschutz, M. E., 1975, Contents of eleven trace elements in ureilite achondrites: Geochim. et Cosmochim. Acta, v. 39, no. 11, p. 1576-1579.
Binz, C. M., Ikramuddin, M., Rey, P., and Lipschutz, M. E., 1976, Trace elements in primitive meteorites-VI. Abundance patterns of thirteen trace elements and interelement relationships in unequilibrated ordinary chondrites: Geochim, et Cosmochim. Acta, v. 40, no. 1, p. 59-72.

Binz, C. M., Kurimoto, R. K., and Lipschutz, M. E., 1974, Trace elements in primitive meteorites-V. Abundance pattern of thirteen trace elements and interelement relationships in enstatite chondries: Geochim. et Cosmochim. Acta, v. 38, no. 10, p. 1579-1606.

Boato, Giovanni, 1954, The isotopic composition of hydrogen and carbon in the carbonaceous chondrites: Geochim. et Cosmochim. Acta, v. 6, nos. 5/6, p. 209-220.

Bogard, D. D., Burnett, D. S., Eberhardt, P., and Wasserburg, G. J., $1967,{ }^{87} \mathrm{Rb}^{-87} \mathrm{Sr}$ isochron and ${ }^{40} \mathrm{~K}-{ }^{40} \mathrm{Ar}$ ages of the Norton County achondrite: Earth and Planetary Sci. Letters, v. 3, no. 3, p. 179-189.

Boynton, W. V., Starzyk, P. M., and Schmitt, R. A., 1976, Chemical evidence for the genesis of the ureilites, the achondrite Chassigny and the nakhlites: Geochim. et Cosmochim. Acta, v. 40, no. 12, p. 1439-1447.

Buchwald, V. F., 1975, Handbook of iron meteorites; their history, distribution, composition and structure; Berkeley, Univ. of California Press, 3 v., 1418 p.

Buddhue, J. D., 1946, The average composition of meteoritic iron: Pop. Astronomy, v. 54, no. 3, p. 149-154.

Bunch, T. E., Keil, Klaus, and Olsen, E., 1970, Mineralogy and petrology of silicate inclusions in iron meteorites: Contr. Mineralogy and Petrology, v. 25, no. 4, p. 297340.

Bunch, T. E., Keil, Klaus, and Snetsinger, K. G., 1967, Chromite composition in relation to chemistry and texture of ordinary chondrites: Geochimica et Cosmochimicha Acta, v. 31, no. 10, p. 1569-1582.

Bunch, T. E., and Olsen, E., 1975, Distribution and significance of chromium in meteorites: Geochim. et Cosmochim. Acta, v. 39, no. 6/7, p. 911-927.

Buseck, P. R., and Goldstein, J. I., 1969, Olivine compositon and cooling rates of pallasitic meteorites: Geol. Soc. America Bull., v. 80, no. 11, p. 2141-2158.

Buseck, P. R., and Keil, Klaus, 1966, Meteoritic rutile: Am. Mineralogist, v. 51, nos. 9-10, p. 1506-1515.

Cameron, A. G. W., 1973, Abundances of the elements in the solar system: Space Sci. Rev., v. 15, p. 121-146.

Case, D. R., Laul, J. C., Pelly, I. Z., Wechter, M. A., SchmidtBleek, F., and Lipschutz, M. E., 1973, Abundance patterns of thirteen trace elements in primitive carbonaceous and unequilibrated ordinary chondrites: Geochim. et Cosmochim. Acta, v. 37, no. 1, p. 19-33.

Chou, Chen-Lin, Baedecker, P. A., and Wasson, J. T., 1973 , Distribution of $\mathrm{Ni}, \mathrm{Ga}, \mathrm{Ge}$ and $\mathrm{Ir}$ between metal and silicate portions of H-group chondrites: Geochim. et Cosmochim. Acta, v. 37, no. 9, p. 2159-2171.

-1976a, Allende inclusions-volatile-element distribution and evidence for incomplete volatilization of presolar solids: Geochim. et Cosmochim. Acta, v. 40, no. 1, p. $85-94$.

-1976b, Siderophilic element evidence regarding a chondritic component in howardites: Lunar Science VII, p. 135-137.

Chou, Chen-Lin, Boynton, W. V., Bild, R. W., Kimberlin, Jerome, and Wasson, J. T., 1976, Trace element evidence 
regarding a chondritic component in howardite meteorites, in Seventh Lunar Conference, 7 th, Houston, Tex., 1976, Proc. Geochim. et Cosmochim. Supp. 7, v. 3, p. 3501-3518.

Chou, Chen-Lin, and Cohen, A. J., 1973, Gallium and germanium in the metal and silicates of L- and LL-chondrites: Geochim. et Cosmochim. Acta, v. 37, no. 2, p. 315-327.

Clark, R. S., Rowe, M. W., Ganapathy, R., and Kuroda, P. K., 1967, Iodine, uranium and tellurium contents in meteorites: Geochim. et Cosmochim. Acta, v. 31, no. 10, p. $1605-1613$.

Clayton, R. N., Grossman, Lawrence, and Mayeda, T. K., 1973, A component of primitive nuclear composition in carbonaceous meteorites: Science, v. 182 , no. 4111 , p. $485-488$.

Clayton, R. N., Onuma, Naoki, and Mayeda, T. K., 1976, A classification of meteorites based on oxygen isotopes: Earth and Planetary Sci. Letters, v. 30, no. 1, p. 10-18.

Cobb, J. C., 1967, A trace-element study of iron meteorites, Jour. Geophys. Research, v. 72, no. 4, p. 1329-1341.

Conrad, R. L., Schmitt, R. A., and Boynton, W. V., 1975, Rare-earth and other elemental abundances in Allende inclusions: Meteoritics, v. 10 , no. 4, p. 384-387.

Crockett, J. H., 1972, Some aspects of the geochemistry of $\mathrm{Ru}, \mathrm{Os}$, Ir, and $\mathrm{Pt}$ in iron meteorites: Geochim. et Cosmochim. Acta, v. 36, p. 517-535.

Crocket, J. H., Keays, R. R., and Hsieh, S., 1967, Precious metal abundances in some carbonaceous and enstatite chondrites: Geochim. et Cosmochim. Acta, v. 31, no. 10, p. 1615-1623.

Crozaz, G., U, Th, and extinct ${ }^{24} \mathrm{Pu}$ in the phosphates of the St. Severin meteorite: Earth and Planetary Sci. Letters, v. 23 , no. $2,164-169$.

Dawson, K. R., Maxwell, J. A., and Parsons, D. E., 1960, A description of the meteorite which fell near Abee, Alberta, Canada: Geochim. et Cosmochim. Acta, v. 21, p. 127-144.

De Laeter, J. R., and Jeffrey, P. M., 1967, Tin-its isotopic and elemental abundance: Geochim. et Cosmochim. Acta, v. 31, no. 6, p. 969-985.

De Laeter, J. R., McCulloch, M. T., and Rosman, K. J. R., 1974 , Mass spectrometric isotope dilution analyses of tin in stony meteorites and standard rocks: Earth and Planetary Sci. Letters, v. 22, no. 3, p. 226-232.

Doan, A. S., Jr., and Goldstein, J. I., 1969, The formation of phosphides in iron meteorites, in Millman, P. M., ed., Meteorite Research: Dordrecht, D. Reidel Publishing Co., p. 763-779.

DuFresne, Ann, 1960, Selenium and tellurium in meteorites: Geochim, et Cosmochim. Acta, v. 20, no. 2, 141-148.

Duke, M. B., and Silver, L. T., 1967, Petrology of eucrites, howardites and mesosiderites: Geochim. et Cosmochim. Acta, v. 31 , no. 10 , p. $1637-1665$.

Easton, A. J., and Hey, M. H., 1968, Minor elements present in the silicate phase of enstatite chondrites: Mineralogy Mag., v. 36, p. 740-742.

Edwards, George, 1955, Sodium and potassium in meteorites: Geochim. et Cosmochim. Acta, v. 8, nos. 5-6, p. 285-294.

Ehmann, W. D., 1965, On some tantalum abundances in meteorites and tektities: Geochim, et Cosmochim. Acta, v. 29 , no. 1 , p. $43-48$.
Ehmann, W. D., Baedecker, P. A., and McKown, D. M., 1970 , Gold and iridium in meteorites and selected rocks: Geochim. et Cosmochim. Acta, v. 34, p. 493-507.

Ehmann, W. D., and Chyi, L. L., 1974, Zirconium and hafnium in meteorites: Earth and Planetary Sci. Letters, v. 21 , no. 3 , p. $230-234$.

Ehmann, W. D., Chyi, L. L., Garg, A. N., and Ali, M. I., 1976, Solar system abundances of zirconium and hafnium [abs.]: Internat. Geol. Cong., 25th, Sydney, Austr: lia, 1976, p. 611-612.

Ehmann, W. D., and Gillum, D. E., 1972, Platinum and go? in chondritic meteorites: Chem. Geology, v. ', no. 1, ?) 1-11.

Ehmann, W. D., Gillum, D. E., Morgan, J. W., Nadkarni, R. A., Rebagay, T. V., Santoliquir. P. M., and Showalter, D. L., 1970, Chemical analyses of the Murchison and Lost City meteorites: Meteoritics, v. 5, no. 3, p. 131-136.

Ehmann, W. D., and Huizenga, J. R., 1959, Bismuth, thallium and mercury in stone meteorites by activation analysis: Geochim. et Cosmochim. Acta, v. 17, no. 1-2, p. 125-135.

Ehmann, W. D., and Lovering, J. F., 1967, The abundance of mercury in meteorites and rocks by neutron activation analysis: Geochim. et Cosmochim. Acta, v. 31, no. 3, p. 357-376.

Ehmann, W. D., and Rebagay, T. V., 1970, Zirconium and hafnium in meteorites by activation analysis: Geochim. et Cosmochim. Acta, v. 34, p. 649-658.

El Goresy, Ahmed, 1967, Quantitative electron microprobe analyses of K-feldspar grains from the Odessa iron meteorite [abs.]: Abstracts, 30th Meeting of the Meteoritical Society, Moffett Field, California.

1971, Meteoritic rutile-a niobium-bearing mineral: Earth and Planetary Sci. Letters, v. 11, p. 359-361.

Erlank, A. J., Willis, J. P., Ahrens, L. H., Gurney, J. J., and McCarthy, T. S., 1972, Inter-element relationships between the moon and stony meteorites with particular reference to some refractory elements in Lunar Science III : Lunar Sci. Inst. Contrib. 88, p. 239-241.

Eugster, O., Tera, F., and Wasserburg, G. J., 1969, Isotopic analyses of barium in meteorites and in terrestrial samples: Jour. Geophys. Research, v. 74, no. 15, p. 3897-3908.

Fireman, E. L., and Schwarzer, D., 1957, Measurement of $\mathrm{Li}^{6}, \mathrm{He}^{3}$, and $\mathrm{H}^{3}$ in meteorites and its relation to cosmic radiation: Geochim. et Cosmochim. Acta, v. 11, no. 4, p. 252-262.

Fisher, D. E., 1963, The fluorine content of some chondritic meteorites: Jour. Geophys. Research, v. 68, no. 23, p. 6331-6335.

$1969 \mathrm{a}$, Uranium content of some stone meteorites and their Pu-Xe decay interval: Nature, v. 222, p. 1156 .

$1969 \mathrm{~b}$, Silicon in iron meteorites and the Earth's core: Nature, v. 222, p. 866-867.

1972, Uranium content and radiogenic ages of hypersthene, bronzite, amphoterite and carbonaceous chondrites: Geochim. et Cosmochim. Acta, v. 36, p. 15-33.

1973, Achondritic uranium: Earth and Planetary Sci. Letters, v. 20, no. 1, p. 151-156.

Fleischer, R. L., Naeser, C. W., Price, P. B., Walker, R. M., and Marvin, U. B., 1965, Fossil particle tracks and uranium distribution in minerals of the Vaca Muerta meteorite: Science, v. 148 , no. 3670 , p. 629-631. 
Fouche, K. F., and Smales, A. A., 1967a, The distribution of trace elements in chondritic meteorites-1. Gallium, germanium and indium: Chem. Geology, v. 2, p. 5-33.

$-1967 \mathrm{~b}$, The distribution of trace elements in chondritic meteorites-2. Antimony, arsenic, gold, palladium and rhenium: Chem. Geology, v. 2, p. 105-134.

Fredriksson, Kurt, and Mason, Brian, 1967, The Shaw meteorite: Geochim. et Cosmochim. Acta, v. 31, no. 10, p. 1705-1709.

Fredriksson, Kurt, Nelen, Joseph, and Fredriksson, B. J., 1968, The LL-group chondrites in Ahrens, L. H., ed., Origin and distribution of the elements: New York, Pergamon Press, p. 457-466.

Fuchs, L. H., 1966, Djerfisherite, alkali copper-iron sulfideA new mineral from enstatite chondrites: Science, v. 153 , no. 3732 , p. $166-167$.

1969, The phosphate mineralogy of meteorites, Paper 56 in Millman, P. M., ed., Meteorite Research. D. Riedel Publishing Co., p. 683-695.

Fuchs, L. H., and Olsen, Edward, 1973, Composition of metal in Type III carbonaceous chondrites and its relevance to the source-assignment of lunar metal: Earth and Planetary Sci. Letters, v. 18 , no. 3, p. 379-384.

Fuchs, L. H., Olsen, Edward, and Jensen, K. J., 1973, Mineralogy, mineral-chemistry, and composition of the Murchison (C2) meteorite: Smithsonian Contrib. Earth Sci., no. 10,39 p.

Gale, N. H., Arden, J. W., and Hutchison, R., 1972, Uraniumlead chronology of chondritic meteorites: Nature Phys. Sci., v. 240 , no. 99 , p. 56-57.

1975, The chronology of the Nakhla achondritic meteorite: Earth and Planetary Sci. Letters, v. 26, no. 2, p. 195-206.

Ganapathy, R., Papia, G. M., and Grossman, Lawrence, 1976, The abundances of zirconium and hafnium in the solar system: Earth and Planetary Sci. Letters, v. 29, no. 2, p. 302-308.

Garz, T., and Kock, M., 1969, Experimental oscillator strengths for FeI lines: Astron. Astrophys., v. 2, p. 274-279.

Gast, P. W., Hubbard, N. J., and Weismann, H., 1970, Chemical composition and petrogenesis of basalts from Tranquillity Base in Apollo 11 Lunar Science Conference Proceedings Volume 2-Chemical and isotope analysis: Geochim. et Cosmochim. Acta Suppl. 1, p. 1143-1163.

Gibson, E. K., Jr., and Moore, C. B., 1970, Inert carrier-gas fusion determination of total nitrogen in terrestrial rocks and meteorites: Anal. Chemistry, v. 42, no. 4, p. 461-464.

1971a, The distribution of total nitrogen in iron meteorites: Geochim. et Cosmochim. Acta, v. 35, p. 877890.

-1971b, Total nitrogen content of ordinary chondrites: Chemie der Erde, v. 30, no. 1-4, p. 115-131.

Gibson, E. K., Moore, C. B., and Lewis, C. F., 1971a, Carbon and nitrogen abundances in selected achondrites: Meteoritics, v. 6, no. 2, p. 87-92.

1971b, Total nitrogen and carbon abundances in carbonaceous chondrites: Geochim. et Cosmochim. Acta, v. 35 , no. 6 , p. 599-604.

Goldberg, Edward, Uchiyama, Aiji, and Brown, Harrison, 1951, The distribution of nickel, cobalt, gallium, palla- dium and gold in iron meteorites: Geochim. et Cosmochim. Acta, v. 2, no. 1, p. 1-25.

Goldberg, L., Müller, E. A., and Aller, L. H., 1960, The abundances of the elements in the solar atmosphere: Astrophys. Jour. Suppl., Ser. 5, p. 1-138.

Goldberg, R. H., Burnett, D. S., Furst, M. J., and Tombrello, T. A., 1974, Fluorine concentrations in carbonaceous chondrites: Meteoritics, v. 9, no. 4, p. 347-348.

Goldschmidt, V. M., 1923, Geochemische Verteilungsgesetze der Elemente: Norske Vidensk. Skr. Mat.-Naturv. Kl., no. 3.

1937, Geochemische Verteilungsgesetze der Elemente. IX. Die Mengenverhältnisse der Elemente und der AtomArten: Norske Vidensk. Akad. Skr., Mat.-Naturv. K1. no. 4 .

Goles, G. G., 1969, Cosmic abundances. Chapter 5 of Wedepohl, K. H., ed., Handbook of Geochemistry, Volume I, Berlin, Springer-Verlag, p. 115-133.

1971 , A review of meteoritic abundances of sodium, potassium, rubidium and caesium: Chemie der Erde, v. 30 , no. 4 , p. $133-137$.

Goles, G. G., and Anders, E., 1962, Abundances of iodine, tellurium and uranium in meteorites: Geochim. et Cosmochim. Acta, v. 26, p. 723-737.

Goles, G. G., Greenland, L. P., and Jérome, D. Y., 1967, Abundances of chlorine, bromine, and iodine in meteorites: Geochim. et Cosmochim. Acta, v. 31, no. 10, p. 1771-1787.

Gopalan, K., and Wetherill, G. W., 1969, Rubidium-strontium age of amphoterite (LL) chondrites: Jour. Geophys. Research, v. 74 , no. 17 , p. $4349-4358$.

1970, Rubidium-strontium studies on enstatite chondrites-whole meteorite and mineral isochrons: Jour. Geophys. Research, v. 75, no. 17, p. 3457-3467.

Graham, A. L., and Mason, Brian, 1972, Niobium in meteorites: Geochim. et Cosmochim. Acta, v. 36, no. 7, p. 917922.

Gray, C. M., Papanastassiou, D. A., and Wasserburg, G. J., 1973, The identification of early condensates from the solar nebula: Icarus, v. 20, no. 2, p. 213-239.

Greenland, L. P., 1963, Minor and trace element abundances in stony meteorites: Ph.D. thesis, Canberra, Australian National Univ.

1967, The abundances of selenium, tellurium, silver, palladium, cadmium, and zinc in chondritic meteorites: Geochim. et Cosmochim. Acta, v. 31, no. 5, p. 849-860.

Greenland, L., and Lovering, J. F., 1965, Minor and trace element abundances in chondritic meteorites: Geochim. et Cosmochim, Acta, v. 29, no. 8, p. 821-858.

Gros, Jacques, Takahashi, Hiroshi, Hertogen, Jan, Morgan, J. W., and Anders, Edward, 1976, Composition of the projectiles that bombarded the lunar highlands: in Seventh Lunar Science Conference Proceedings. Geochim. et Cosmochim Acta Suppl. 7, p. 2403-2425.

Hamaguchi, H., Onuma, N., Hirao, Y., Yokoyama, H., Bando, S., and Furukawa, M., 1969, The abundances of arsenic, tin and antimony in chondritic meteorites: Geochim. et Cosmochim. Acta, v. 33, no. 4, p. 507-518.

Hamaguchi, Hiroshi, Reed, G. W., and Turkevich, Anthony, 1957, Uranium and barium in stone meteorites: Geochim. et Cosmochim. Acta, v. 12, no. 4, 337-347.

Hara, T., and Sandell, E. B., 1960, Meteoritic abundance of 
ruthenium: Geochim. et Cosmochim. Acta, v. 21, no. 1, p. 145-150.

Haskin, L. H., Frey, F. A., Schmitt, R. A., and Smith, R. H., 1966, Meteoritic, solar and terrestrial rare-earth distributions in Physics and chemistry of the Earth, Volume 7: New York, Pergamon Press, p. 167-321.

Haskin, L. A., Haskin, M. A., Frey, F. A., and Wildeman, T. R., 1968, Relative and absolute terrestrial abundances of the rare earths in Ahrens, L. H., ed., Origin and distribution of the elements, New York, Pergamon Press, p. 889-912.

Hayatsu, Ryoichi, Studier, M. H., Oda, Atsuko, Fuse, Kigono, and Anders, Edward, 1968, Origin of organic matter in early solar system-II. Nitrogen compounds: Geochim. et Cosmochim. Acta, v. 32, no. 2, p. 175-190.

Hayes, J. M., and Biemann, K., 1968, High resolution mass spectrometric investigations of the organic constituents of the Murray and Holbrook chondrites: Geochim. et Cosmochim. Acta, v. 32, no. 2, 239-267.

Hermann, F., Kiesl, W., Kluger, F., and Hecht, F., 1971, Neutronenaktivierungsanalytische Bestimmung einiger Spurenelemente in meteorischen Phasen: Mikrochim. Acta, no. 2, p. 225-240.

Hermann, F., and Wichtl, M., 1974, Neutronenaktivierungsanalytische Bestimmung von Spurenelementen in Meteoriten der Vatikanischen Sammlung in Kiesl, W., and Malissa, H., eds., Analyse extraterrestrichen Materials: Vienna, Springer-Verlag, p. 163-172.

Hess, H. H., and Henderson, E. P., 1949, The Moore County [N.C.] meteorite-a further study with comment on its primordial environment: Am. Mineralogist v. 34, nos. 7-8, p. 494-507.

Hey, M. H., 1966, Catalogue of meteorites with special reference to those represented in the collection of the British Musum (Natural History) [3rd ed.l: London, British Museum, Pub. 464, 637 p.

Hey, M. H., and Easton, A. J., 1968, Copper in various phases of several olivine-hypersthene and olivine-bronzite chondrites: Mineralog. Mag., v. 36, p. 855-858.

Higuchi, Hideo, Morgan, J. W., Ganapathy, R., and Anders, Edward, 1976, Chemical fractionations in meteorites-X. Ureilites: Geochim. et Cosmochim. Acta, v. 40, no. 12, p. 1563-1571.

Hintenberger, H., Jochum, K. P., and Seufert, M., 1973, The concentration of the heavy metals in four new Antarctic meteorites Yamato (a), (b), (c), and (d) and in Orgueil, Murray, Allende, Abee, Allegan, Mocs and Johnstown: Earth and Planetary Sci. Letters, v. 20, no. 3, p. 391-394.

Hubbard, N. J., and Gast, P. W., 1971, Chemical composition and origin of nonmare lunar basalts in Lunar Science Conference, 2d, Volume 2: Geochim. et Cosmochim. Acta Suppl. 2, p. 999-1020.

Huey, J. M., and Kohman, T. P., 1972, Search for extinct natural radioactivity of ${ }^{205} \mathrm{~Pb}$ via thallium-isotope anomalies in chondrites and lunar soil: Earth and Planetary Sci. Letters, v. 16, no. 3, p. 401-412.

Huey, J. M., and Kohman, T. P., $1973,{ }^{207} \mathrm{~Pb}-{ }^{200} \mathrm{~Pb}$ isochron and age of chondrites: Jour. Geophys. Research, v. 78, no. 17, p. $3227-3244$.

Hutchison, R., Gale, N. H., and Arden, J. W., 1975, Invalid 4.01-Gyr model U-Pb "age" of the Nakhla meteorite: Nature, v. 254, p. 678-680.
Ikramuddin, M., Binz, C. M., and Lipschutz, M. E., 1976, Thermal metamorphism of primitive meteorites-II. Ten trace elements in Abee enstatite chondrite heated at $400^{\circ}$ $1000^{\circ} \mathrm{C}$; Geochim. et Cosmochim. Acta, v. 40, no. 2, p. 133-142.

Injerd, W. G., and Kaplan, I. R., 1974, Nitrogen isotope distribution in meteorites: Meteoritics, v. 9, no. 4 , p. 352353.

Jarosewich, Eugene, 1967, Chemical analyses of seven stony meteorites and one iron with silicate inclusions: Geochim. et Cosmochim. Acta, v. 31, no. 6, p. 1103-1107.

1971, Chemical analysis of the Murchison meteorite: Meteoritics, v. 6, no. 1, p. 49-52.

Jarosewich, Eugene, and Mason, Brian, 1969, Chemical analyses with notes on one mesosiderite and seven chondrites: Geochim. et Cosmochim. Acta, v. 33, no. 3, p. 411-416.

Jérome, D. Y., 1970, Composition and origin of some achondritic meteorites: Univ. of Oregon, Ph.D. thesis, $179 \mathrm{p}$.

Kaplan, I. R., and Hulston, J. R., 1966, The isotopic abundance and content of sulfur in meteorites: Geochim. et Cosmochim. Acta, v. 30, no. 5, p. 479-496.

Kaushal, S. K., and Wetherill, G. W., 1970, Rubidium 87strontium 87 age of carbonaceous chondrites: Jour. Geophys. Research, v. 75, no. 2, p. 463-468.

Keays, R. R., Ganapathy, R., and Anders, Edward, 1971, Chemical fractionations in meteorites-IV. Abundances of fourteen trace elements in L-chondrites; implications for cosmothermometry: Geochim. et Cosmochim. Acta, v. 35, no. 4 , p. 337-363.

Keil, Klaus, 1968, Mineralogical and chemical relationships among enstatite chondrites: Jour. Geophys. Research, v. 73 , no. 22 , p. $6945-6976$.

-1969, Titanium distribution in enstatite chondrites and achondrites, and its bearing on their origin: Earth and Planetary Sci. Letters, v. 7, no. 3, p. 243-248.

Keil, Klaus, and Fredriksson, Kurt, 1963, Electron microprobe analysis of some rare minerals in the Norton County achondrite: Geochim. et Cosmochim. Acta, v. 27, no. 9, p. 939-947.

1964, The iron, magnesium, and calcium distribution in coexisting olivines and rhombic pyroxenes of chondrites: Jour. Geophys. Research, v. 69 , no. 16, p. 34873517.

Keil, K., and 15 others, 1976, Progress by the consorts of Angra dos Reis: Lunar Science VII, p. 443-445.

Kelly, W. R., and Moore, C. B., 1973, The determination of zinc in iron meteorites: Meteoritics, v. 8, no. 1, p. 49-50.

Kempe, W., and Müller, O., 1969, The stony meteorite Krähenberg, in Millman, P. M. ed., Meteorite Research: Dordrecht, Holland, D. Reidel Publishing Co., p. 418-428.

Kiesl, W., and Hecht, F., 1969, Meteorites and the hightemperature origin of terrestrial planets, in Millman, P. M. ed., Meteorite Research: Dordrecht, Holland, D. Reidel Publishing Co., p. 67-74.

Kiesl, W., Seitner, H., Kluger, F., and Hecht, F., 1967, Determination of trace elements by chemical analysis and neutron activation in meteorites of the Viennese Museum of Natural History: Monatsh. aftefür. Chemie., v. 98, p. 972-978.

Kirsten, T., Krankowsky, D., and Zähringer, J., 1963, Edel- 
gas und Kalium-Bestimmungen an einer grösseren Zahl von Steinmeteoriten: Geochim. et Cosmochim. Acta, v. 27 , no. 1, p. 13-42.

Kothari, B. K., and Geol, P. S., 1974, Total nitrogen in meteorites: Geochim. et Cosmochim. Acta, v. 38, no. 10, 1493-1507.

Krähenbühl, Urs, Morgan, J. W., Ganapathy, R., and Anders, E., 1973, Abundance of 17 trace elements in carbonaceous chondrites: Geochim. et Cosmochim. Acta, v. 37, no. 5, p. 1353-1370.

Kuroda, P. K., and Sandell, E. B., 1954, Geochemistry of molybdenum: Geochim. et Cosmochim. Acta, v. 6, no. 1, p. 35-63.

Larimer, J. W., and Anders, Edward, 1967, Chemical fractionations in meteorites-II. Abundance patterns and their interpretation: Geochim. et Cosmochim. Acta, v. 31 , no. 8 , p. $1239-1270$.

Laspeyres, Hugo, and Kaiser, Erich, 1895, Quartz and Zerkonkrystalle im Meteoreisen von Toluca in Mexico: Zeitschr. Kristallographie und Mineralogie, v. 24, p. 485-499.

Laul, J. C., Case, D. R., Schmidt-Bleek, F., and Lipschutz, M. E., 1970, Bismuth contents of chondrites: Geochim. et Cosmochim. Acta, v. 34, no. 1, p. 89-103.

Laul, J. C., Ganapathy, R., Anders, Edward, and Morgan, J. W., 1973, Chemical fractionations in meteorites-VI. Accretion temperatures of $\mathrm{H}-$, LL-, and E-chondrites, from abundance of volatile trace elements: Geochim. et Cosmochim. Acta, v. 37, no. 2, p. 329-357.

Laul, J. C., Keays, R. R., Ganapathy, R., Anders, E., and Morgan, J. W., 1972, Chemical fractionations in meteorites- $V$. Volatile and siderophile elements in achondrites and ocean ridge basalts: Geochim. et Cosmochim. Acta, v. 36 , no. 3 , p. 329-345.

Laul, J. C., Pelly, I., and Lipschutz, M. E., 1970, Thallium contents of chondrites: Geochim. et Cosmochim. Acta, v. 34 , no. 8 , p. $909-920$.

Laul, J. C., and Schmitt, R. A., 1973, Chemical composition of Apollo 15, 16, and 17 samples in Lunar Science Conference 4th, Proceedings Volume 2: Geochim. et Cosmochim. Acta, Suppl. 4, p. 1349-1367.

Lawless, J. G., 1973, Amino acids in the Murchison meteorite: Geochim. et Cosmochim. Acta, v. 37, no. 9, 2207-2212.

Lieberman, K. W., and Ehmann, W. D., 1967, Determination of bromine in stony meteorites by neutron activation: Jour. Geophys. Research, v. 72, no. 24, p. 6279-6287.

Linn, T. A., Jr., Moore, C. B., and Schmitt, R. A., 1968, Neutron activation determination of vanadium in iron meteorites and sulfide nodules: Geochim. et Cosmochim. Acta, v. 32, no. 5, p. 561-564.

Loveland, W., Schmitt, R. A., and Fisher, D. E., 1969, Aluminum abundances in stony meteorites: Geochim. et Cosmochim. Acta, v. 33, no. 3, p. 375-385.

Lovering, J. F., Le Maitre, R. W., and Chappell, B. W. 1971, Murchison C2 carbonaceous chondrite and its inorganic composition: Nature Phys. Sci., v. 230, no. 1, p. 18-20.

Lovering, J. F., Nichiporuk, W., Chodos, A., and Brown, H., 1957. The distribution of gallium, germanium, cobalt, chromium, and copper in iron and stony-iron meteorites in relation to nickel content and structure: Geochim. et Cosmochim. Acta, v. 11, no. 4, 263-278.

Ludwig, E., and Tschermak, G., 1909, Nachtrag zu der
Mitteilung über den Meteoriten von Angra dos Reis: Tschermaks Mineralog. u. Petrog. Mitt., v. 28, p. 109114.

McCarthy, T. S., Ahrens, L. H., and Erlank, A. J., 1972, Further evidence in support of the mixing model for howardite origin: Earth and Planetary Sci. Letters, v. 15 , no. 1 , p. 86-93.

MeCarthy, T. S., Erlank, A. J., and Willis, J. P., 1972, On the origin of eucrites and diogenites: Earth and Planetary Sci. Letters, v. 18, no. 3, p. 433-442.

MeCarthy, T. S., Erlank, A. J., Willis, J. P., and Ahrens, L. H., 1974, New chemical analyses of six achondrites and one chondrite: Meteoritics, v. 9, no. 3, p. 215-221.

Ma, M.-S., Murali, A. V., and Schmitt, R. A., 1977, Genesis of the Angra dos Reis and other achondrite meteorites: Earth and Planetary Sci. Letters, v. 35, no. 2, p. 331346.

Marshall, R. R., 1962, Mass spectrometric study of the lead in carbonaceous chondrites: Jour. Geophys. Research, v. 67, no. 5, 2005-2015.

Martin, P. M., and Mason, Brian, 1974, Major and trace elements in the Allende meteorite; Nature, v. 249, no. 5455, p. 333-334.

Marvin, U. B., 1975, The perplexing behavior of niobium in meteorites and lunar samples: Meteoritics, v. 10, no. 4, p. 452-454.

Marvin, U. B., and Klein, Cornelis, Jr., 1964, Meteoritic zircon: Science, v. 146, no. 3646, p. 919-920.

Mason, Brian, 1962, Meteorites: New York, John Wiley and Sons, 274 p.

1967a, The Bununu meteorite, and a discussion of the pyroxene-plagioclase achondrites: Geochim. et Cosmochim. Acta, v. 31, p. 107-115.

1967b, Meteorites: Am. Scientist, v. 55, no. 4, p. $429-455$.

-ed., 1971, Handbook of elemental abundances in meteorites: New York, Gordon and Breach Science Publishers, $555 \mathrm{p}$.

1974, Aluminum-titanium-rich pyroxenes, with special reference to the Allende meteorite: Am. Mineralogist, v. 59, no. 11-12, p. 1198-1202.

1975, The Allende meteorite-cosmochemistry's Rosetta stone? Accounts Chem. Research, v. 8, no. 7, p. 217-224.

Mason, Brian, and Graham, A. L., 1970, Minor and trace elements in meteoritic minerals: Smithsonian Contr. Earth Sci., no. 3, 17 p.

Mason, Brian, and Jarosewich, E., 1971, The composition of the Johnstown meteorite: Meteoritics, v. 6, no. 4, p. 241246.

Mason, Brian, and Martin, P. M., 1974, Minor and trace element distribution in melilite and pyroxene from the Allende meteorite: Earth and Planetary Sci. Letters, v. 22, no. 2, p. 141-144.

1977, Geochemical differences between components of the Allende meteorite: Smithsonian Contrib. Earth Sci. no. 19 , p. $22-28$.

Mason, Brian, Nelen, J. A., Muir, P., and Taylor, S. R., 1976, The composition of the Chassigny meteorite: Meteoritics, v. 11 , no. 1 , p. $21-27$.

Mason, Brian, and Wilk, H. B., 1961, The Holbrook, Arizona, chondrite: Geochim. et Cosmochim, Acta, v. 21, nos. 3-4, p. 276-283. 
1964, The amphoterites and meteorites of similar composition: Geochim. et Cosmochim. Acta, v. 28, no. 4, p. 533-538.

Masuda, Akimasa, Nakamura, Noboru, and Tanaka, Tsugoshi, 1973, Fine structures of mutually normalized rareearth patterns of chondrites: Geochim. et Cosmochim. Acta, v. 37, no. 2, p. 239-248.

Mills, A. A., 1968, Boron in carbonaceous chondrites: Nature, v. 220, p. 1113-1114.

Mittlefehldt, D. W., and Wetherill, G. W., 1977, Rb-Sr studies of carbonaceous chondrites (in press).

Moore, C. B., and Brown, Harrison, 1962, The distribution of manganese and titanium in stony meteorites: Geochim. et Cosmochim. Acta, v. 26, p. 495-502.

-1963, Barium in stony meteorites: Jour. Geophys. Research, v. 68 , no. 14 , p. $4293-4296$.

Moore, C. B., and Gibson, E. K., 1969, Nitrogen abundances in chondritic meteorites: Science, v. 163 , no. 3863, p. 174-176.

Moore, C. B., Gibson, E. K., Jr., and Keil, Klaus, 1969, Nitrogen abundances in enstatite chondrites: Earth and Planetary Sci. Letters, v. 6, no. 6, p. 457-460.

Moore, C. B., and Lewis, C. F., 1965, Carbon abundances in chondritic meteorites: Science, v. 149, no. 3681, 317-318. 1966, The distribution of total carbon content in enstatite chondrites: Earth and Planetary Sci. Letters, v. 1 , no. 6 , p. 376-378.

1967, Total carbon content of ordinary chondrites: Jour. Geophys. Research, v. 72, no. 24, p. 6289-6292.

Moore, C. B., Lewis, C. F., and Nava, David, 1969, Superior anlyses of iron meteorites Paper 60 in Millman, P. M., ed., Meteorite Research: D. Reidel Publishing Co., Dordrecht, Holland, p. 738-748.

Morgan, J. W., 1965, The application of activation analysis to some geochemical problems: The Australian National Univ., Ph. D. thesis, $339 \mathrm{p}$.

1970, Anomalous rhenium isotopic ratio in the solar wind-detection at the nanogram level: Nature, v. 225, p. 1037-1038.

Morgan, J. W., and Lovering, J. F., 1967, Rhenium and osmium abundances in chondritic meteorites: Geochim. et Cosmochim. Acta, v. 31, no. 10, p. 1893-1909.

-1968, Uranium and thorium abundances in chondritic meteorites: Talanta, v. 15, no. 11, p. 1079-1096.

-1973, Uranium and thorium in achondrites: Geochim. and Cosmochim. Acta, v. 37, no. 7, p. 1697-1707.

Moss, A. A., Hey, M. H., Elliott, C. J, and Easton, A. J., 1967 , Methods for the chemical analysis of meteoritesII. The major and some minor constituents of chandrites: Mineral. Mag. 36, p. 101-119.

Mueller, G., 1953, The properties and theory of genesis of the carbonaceous complex within the Cold Bokkeveld meteorite: Geochim. et Cosmochim. Acta, v. 4, nos. 1-2, p. 1-10.

Müller, Otto, Baedecker, P. A., and Wasson, J. T., 1971, Relationship between siderophilic-element content and oxidation state of ordinary chondrites: Geochim, et Cosmochim. Acta, v. 35 , no. 11 , p. 1121-1138.

Murthy, V. R., 1963, Elemental and isotopic abundances of molybdenum in some meteorites: Geochim. et Cosmochim. Acta, v. 27 , no. 11 , p. 1171-1178.

Nagy, B., 1975, Carbonaceous meteorites: New York, Elsevier, $747 \mathrm{p}$.
Nakamura, Noboru, 1974, Determination of REE, Ba, Fe, $\mathrm{Mg}, \mathrm{Na}$ and $\mathrm{K}$ in carbonaceous and ordinary chondrites: Geochim. et Cosmochim. Acta, v. 38, no. 5, p. 757-775.

Nakamura, Noboru, and Masuda, Akimasa, 1973, Chondrites with peculiar rare-earth patterns: Earth and Planetary Sci. Letters, v. 19, no. 4, p. 429-437.

Nelen, Joseph, and Mason, B., 1972, The Estherville meteorite in Melson, W. G., ed., Mineral Sciences Investigations, 1969-1971: Smithsonian Contrib. Earth Sci., no. 9, p. $55-56$.

Nichiporuk, Walter, 1975, The distribution of $\mathrm{Li}, \mathrm{Na}$, and $\mathrm{K}$ in the LL-group chondrites: Meteoritics, no. 4, v. 10, p. 466.

Nichiporuk, Walter, and Bingham, Elizabeth, 1970, Vanadium and copper in chondrites: Meteoritics, v. 5, no. 3, p. 115-130.

Nichiporuk, Walter, and Brown, Harrison, 1965, The distribution of platinum and palladium metals in iron meteorites and in the metal phase of ordinary chondrites: Jour. Geophys. Research, v. 70, no. 2, p. 459-470.

Nichiporuk, Walter, Chodos, Arthur, Helin, Eleanor, and Brown, Harrison, 1967, Determination of iron, nickel, cobalt, calcium, chromium and manganese in stony meteorites by X-ray fluorescence: Geochim. et Cosmochim. Acta, v. 31, no. 10, p. 1911-1930.

Nichiporuk, Walter, and Moore, C. B., 1970, Lithium in chondritic meteorites: Earth and Planetary Sci. Letters, v. 9 , no. 3 , p. $280-286$.

1974, Lithium, sodium and potassium abundances in carbonaceous chondrites: Geochim. et Cosmochim. Acta, v. 38 , no. 11 , p. 1691-1701.

Nishmura, Masakichi, and Sandell, E. B., 1964, Zinc in meteorites: Geochim. et Cosmochim. Acta, v. 28, no. 7, p. $1055-1080$.

Noddack, I., 1935, Die Haüfigkeit der seltenen Erden in Meteoriten: Zeitschr. Anorg. u. Allg. Chemie, v. 225, p. 337-364.

Olsen, Edward, and Fuchs, L. H., 1967, The state of oxidation of some iron meteorites: Icarus, v. 6, no. 2, p. 242-253.

Olsen, Edward, Huebner, J. S., Douglas, J. A. V., and Plant, A. G., 1973, Meteoritic amphiboles: Am. Mineralogist, v. 58 , nos. $9-10$, p. $869-872$.

Onishi, Hiroshi, and Sandell, E. B., 1955, Geochemistry of arsenic: Geochim. et Cosmochim. Acta, v. 7, nos. 1-2, p. 1-33.

1957, Meteoritic and terrestrial abundance of tin: Geochim. et Cosmochim. Acta, v. 12, no. 3, p. 262-270.

Osborn, T. W., Warren, R. G., Smith, R. H., Wakita, H., Zellmer, D. L., and Schmitt, R. A., 1974, Elemental composition of individual chondrules from carbonaceous chondrites including Allende: Geochim. et Cosmochim. Acta, v. 38, no. $\&$, p. 1359-1378.

Ozerova, N. A., Kvash`, L. G., Bulkin, G. A., and Aidinian, N. K., 1973, Certain peculiarities in the distribution of mercury in meteorites: Geochim. et Cosmochim. Acta, v. 37 , no. 3 , 569-582.

Palme, H., 1974, Zerstörungsfreie Bestimmung einiger Spurenelemente in Mond- und Meteoritenproben mit 14 MeV-Neutronen in Kiesl, W. and Malissa, H., eds., Analyse extraterrestrischen Materials: Vienna, SpringerVerlag, p. 147-161.

Pellas, Paul, and Storzer, Dieter, 1975, Uranium and plu- 
tonium in chondritic phosphates: Meteoritics, v. 10, no. 4, p. 471-473.

Philpotts, J. A., Schnetzler, C. C., and Thomas, H. H. 1967, Rare-earth and barium abundances in the Bununu howardite: Earth and Planetary Sci. Letters, v. 2, no. 1, p. 19-22.

Pinson, W. H., Jr., Schnetzler, C. C., Beiser, E., Fairbairn, H. W., and Hurley, P. M., 1965, Rb-Sr age of stony meteorites: Geochim. et Cosmochim. Acta, v. 29, no. 5, p. $455-466$.

Podosek, F. A., 1973, Thermal history of the nakhlites by the ${ }^{40} \mathrm{Ar}{ }^{39} \mathrm{Ar}$ method: Earth and Planetary Sci. Letters, v. 19 , no. 2 , p. $135-144$.

Poldevaart, Arie, 1947, The relationship of orthopyroxene to pigeonite: Mineral. Mag., v. 28, p. 164-172.

Prewitt, C. T., and Rothbard, D. R., 1975, Crystal structures of meteoritic and lunar whitlockites [abs.]: Lunar Science VI, pt. 2, p. 646-648.

Prior, G. T., 1916, On the genetic relationship and classification of meteorites: Mineral. Mag., v. 18, p. 26-44. 1920, The classification of meteorites: Mineral. Mag., vol. 19 , p. $51-63$.

Quandt, Ulrich, and Herr, Wilfrid, 1974, Beryllium abundance of meteorites determined by non-destructive photon activation: Earth and Planetary Sci. Letters, v. 24, no. 1, p. 53-58.

Quijano-Rico, M., and Wänke, H., 1969, Determination of boron, lithium, and chlorine in meteorites Paper 13 in Millman, P. M., ed., Meteorite Research: D. Reidel Publishing Co., Dordrecht, Holland, p. 132-145.

Ramdohr, Paul, 1963, The opaque minerals in stony meteorites: Jour. Geophys. Research, v. 68, no. 7, p. 2011-2036.

-1973 , The opaque minerals in stony meteorites: Amsterdam, Elsevier, 245 p.

Reed, G. W., Jr., 1964, Fluorine in stone meteorites: Geochim. et Cosmochim. Acta, v. 28, no. 11, p. 1729-1743.

Reed, G. W., Jr., and Allen, R. O., Jr., 1966, Halogens in chondrites: Geochim. et Cosmochim. Acta, v. 30, no. 9, p. 779-800.

Reed, G. W., Jr., Hamaguchi, Hiroshi, and Turkevich, A. L., 1958, The uranium contents of iron meteorites: Geochim. et Cosmochim. Acta, v. 13, no. 4, p. 248-255.

Reed, G. W., Jr., and Jovanovic, S., 1967, Mercury in chondrites: Jour. Geophys. Research, v. 72, no. 8, p. 22192228.

1969, Some halogen measurements on achondrites: Earth and Planetary Sci. Letters, v. 6, no. 4, p. 316-320.

Reed, G. W., Kigoshi, K., and Turkevich, A. L., 1960, Determinations of concentrations of heavy elements in meteorites by activation analysis: Geochim. et Cosmochim. Acta, v. 20, no. 2, p. 122-140.

Reed, S. J. B., 1969, Phosphorus in meteoritic nickel-iron, Paper 61 in Millman, P. M., ed., Meteorite Research: Dordrecht, D. Reidel Publishing Co., p. 749-762.

Rieder, R., and Wänke, H., 1969, Study of trace element abundance in meteorites by neutron activation, Paper 8 in Millman, P. M., ed., D. Reidel Publishing Co., Dordrecht, Holland, p. 75-86.

Rossman, K. J. R., and de Laeter, J. R., 1974, The abundance of cadmium and zinc in meteorites: Geochim. et Cosmochim, Acta, v. 38 , no. 11 , p. $1665-1677$.
Ross, J. E., and Aller, L. H., 1976, The chemical composition of the sun: Science, v. 191, no. 4233, p. 1223-1229.

Santoliquido, P. M., and Ehmann, W. D., 1972, Bismuth in stony meteorites and standard rocks: Geochim. et Cosmochim. Acta, v. 36, no. 8, p. 897-902.

Schaudy, R., Kiesl, W., and Hecht, F., 1967, Activation analytical determination of elements in meteorites: Chem. Geology, v. 2, p. 279-287.

1968, Activation analytical determination of elements in meteorites, 2; determination of manganese, sodium, gallium, copper, gold and chromium in 21 meteorites: Chem. Geology, v. 3, p. 307-312.

Schindewolf, U., and Walgren, M., 1960, The rhodium, silver and indium content of some chondritic meteorites: Geochim. et Cosmochim. Acta, v. 18, nos. 1-2, p. 36-41.

Schmitt, R. A., Goles, G. G., Smith, R. H., and Osborn, T. W., 1972, Elemental abundances in stone meteorites: Meteoritics, v. 7, no. 2, p. 131-213.

Schmitt, R. A., Linn, T. A., and Wakita, H., 1970, The determination of fourteen common elements in rocks via sequential instrumental activation analysis: Radiochimica Acta, v. 13, p. 200-212.

Schmitt, R. A., Mosen, A. W., Suffredini, C. S., Lasch, J. E., Sharp, R. A., and Olehy, D. A., 1960, Abundances of the rare-earth elements, lanthanum to lutetium, in chondritic meteorites: Nature, v. 186 , no. 4728 , p. 863-866.

Schmitt, R. A., and Smith, R. H., 1968, Indium abundances in chondritic and achondritic meteorites and in terrestrial rocks in Ahrens, L. H., ed., Origin and distribution of the elements: New York, Pergamon Press, p. 283-300.

Schmitt, R. A., Smith, R. H., and Olehy, D. A., 1963, Cadmium abundances in meteoritic and terrestrial matter: Geochim. et Cosmochim. Acta, v. 27, no. 11, p. 10771088.

Schnetzler, C. C., and Philpotts, J. A., 1969, Genesis of the calcium-rich achondrites in light of rare-earth and barium concentrations Paper 19 in Millman, P. M., ed., Meteorite Research: New York, Springer-Verlag, p. 206216.

Scott, E. R. D., 1972, Chemical fractionation in iron meteorites and its interpretation: Geochim. et Cosmochim. Acta, v. 36 , no. 11 , p. 1205-1235.

Scott, E. R. D., and Wasson, J. T., 1975, Classification and properties of iron meteorites: Rev. Geophys. Space Phys., v. 13 , no. 4 , p. 527-546.

Seitner, H., Kiesl, W., Kluger, F., and Hecht, F., 1971, Wetchemical analysis and determination of trace elements by neutron activation in meteorites: Jour. Radioanal. Chem., v. 7, no. 2, p. 235-248.

Sen Gupta, J. G., 1968a, Abundances of the six platinum metals in some iron and stony meteorites-Relationships to the theories of evolution of parent bodies of meteorites and the origin of these elements: Chem. Geology, v. 3, no. 4, p. 293-305.

$1968 \mathrm{~b}$, Determination of fluorine in silicate and phosphate rocks, micas, and stony meteorites: Anal. Chim. Acta, v. 42, no. 1 , p. 119-125.

Shima, Masako, 1964, The distribution of germanium and tin in meteorites: Geochim. et Cosmochim. Acta, v. 28, no. 4 , p. 517-532.

Shima, M., and Honda, M., 1967, Distributions of alkali, alkaline earth and rare earth elements in component minerals of chondrites: Geochim. et Cosmochim. Acta, v. 
31, no. 10, p. 1995-2006.

Showalter, D. L., Wakita, H., and Schmitt, R. A., 1972, Rare earth and other abundances in the Murchison carbonaceous chondrite: Meteoritics, v. 7, no. 3, p. 295-301.

Sill, C. W., and Willis, C. P., 1962, The beryllium content of some meteorites: Geochim. et Cosmochim. Acta, v. 26, p. 1209-1214.

Smales, A. A., Hughes, T. C., Mapper, D., McInnes, C. A. J., and Webster, R. K., 1964, The determination of rubidium and caesium in stony meteorites by neutron activation analysis and by mass spectrometry: Geochim. et Cosmochim. Acta, v. 28, no. 2, p. 209-233.

Smales, A. A., Mapper D., and Fouché, K. F., 1967, The distribution of some trace elements in iron meteorites, as determined by neutron activation: Geochim. et Cosmochim. Acta, v. 31, p. 673-720.

Smales, A. A., Mapper, D., Webb, M. S. W., Webster, R. K., and Wilson, J. D., 1970, Elemental composition of lunar surface material in Apollo 11 Lunar Science Conference Proceedings, Volume 2: Geochim. Cosmochim. Acta, Suppl. 1, p. 1575-1582.

Snetsinger, K. G., and Keil, Klaus, 1969, Ilmenite in ordinary chondrites: Am. Mineralogist, v. 54, no. 5-6, p. 780-786.

Snetsinger, K. G., Keil, Klaus, and Bunch, T. E., 1967, Chromite from "equilibrated" chondrites: Am. Mineralogist, v. 52, nos. 9-10, p. 1322-1331.

Tanaka, Tsuyashi, and Masuda, Akimasa, 1973, Rare-earth elements in matrix, inclusions and chondrules in the Allende meteorite: Icarus, v. 19 , no. 4 , p. 523-530.

Tandon, S. N., 1967, Mercury, thallium and bismuth in metal and troilite phases of iron meteorites by neutron activation analysis: U.S. Atomic Energy Comm. Rept. NYO844-71, $35 \mathrm{p}$.

Tandon, S. N., and Wasson, J. T., 1968, Gallium, germanium, indium and iridium variations in a suite of L-group chondrites: Geochim. et Cosmochim. Acta, v. 32, no. 10, 1087-1109.

Tanner, J. T., 1968, Mercury and bismuth abundances in iron meteorites by neutron activation: U.S. Atomic Energy Comm. Rept. NYO-844-75, p. 37-41.

Tanner, J. T., and Ehmann, W. D., 1967, The abundance of antimony in meteorites, tektites and rocks by neutron activation analysis: Geochim. et Cosmochim. Acta, v. 31, no. 10 , p. 2007-2026.

Tatsumoto, Mitsunobu, Knight, R. J., and Allegre, C. J., 1973, Time differences in the formation of meteorites as determined from the ratio of lead-207 to lead-206: Science, v. 180, no. 4092, p. 1279-1283.

Tatsumoto, Mitsunobu, Unruh, D. M., and Desborough, G. A., 1976, U-Th-Pb and Rb-Sr systematics of Allende and U-Th-Pb systematics of Orgueil: Geochim. et Cosmochim. Acta, v. 40, no. 6, p. 617-634.

Taylor, H. P., Jr., Duke, M. B., Silver, L. T., and Epstein, Samuel, 1965, Oxygen isotope studies of minerals in stony meteorites: Geochim. et Cosmochim. Acta, v. 29, no. 5, p. 489-512.

Tera, F., Eugster, O., Burnett, D. S., and Wasserburg, G. J., 1970, Comparative study of $\mathrm{Li}, \mathrm{Na}, \mathrm{K}, \mathrm{Rb}, \mathrm{Cs}, \mathrm{Ca}, \mathrm{Sr}$, and $\mathrm{Ba}$ abundances in achondrites and in Apollo 11 lunar samples in Apollo 11 Lunar Science Conference Proceedings Volume 2: Geochim. et Cosmochim. Acta Suppl. 1, p. 1637-1658.
Tilton, G. R., 1973, Isotopic lead ages of chondritic meteorites: Earth and Planetary Sci. Letters, v. 19, no. 3, p. 321-329.

Urey, H. C., 1961, Criticism of Dr. B. Mason's paper on "The origin of meteorites": Jour. Geophys. Research, v. 66 , no. 6 , p. $1988-1991$.

1967, The abundance of the elements with special reference to the problem of the iron abundance: Royal Astron. Soc. Quart. Jour., v. 8, no. 1, p. 23-47.

Urey, H. C., and Craig, Harmon, 1953, The composition of the stone meteorites and the origin of the meteorites: Geochim. et Cosmochim. Acta, v. 4, nos. 1-2, p. 36-82.

Van Schmus, W. R., and Ribbe, P. H., 1968, The composition and structural state of feldspar from chondritic meteorites: Geochim. et Cosmochim. Acta, v. 32, no. 12, p. 1327-1342.

1969 , Composition of phosphate minerals in ordinary chondrites: Geochim. et Cosmochim. Acta, v. 33, no. 5, p. 637-640.

Van Schmus, W. R., and Wood, J. A., 1967, A chemicalpetrologic classification for the chondritic meteorites: Geochim. et Cosmochim. Acta, v. 31, no. 5, p. 747-765.

Vinogradov, A. P. Lavrukhina, A. K., Ganiyev, A. G., Silvanovich, Y. A., and Rakhimov, K. R., 1972, Partition of platinum metals and gold between phases in meteoritic material, Part 1: Geochem. Internat., v. 9, no 6, p. 967-974.

1973, The distribution of the platinoids and gold between phases in meteoritic material, Part 2: Geochem. Internat., v. 10, no. 4, p. 719-730.

Vogt, J. R., and Ehmann, W. D., 1965, An automated procedure for the determination of oxygen using fast neutron activation analysis; oxygen in stony meteorites: Radiochimica Acta, v. 4, p. 24-28.

VonMichaelis, H., Ahrens, L. H., Willis, J. P., 1969, The composition of stony meteorites-II. The analytical data and an assessment of their quality: Earth and Planetary Sci. Letters, v. 5, no. 6, p. 387-394.

Wakita, Hiroshi, and Schmitt, R. A., 1970, Rare earth and other elemental abundances in the Allende meteorites: Nature, v. 227, no. 5257, p. 478-479.

Wänke, H., Baddenhausen, H., Balacescu, A., Teschke, F., Spettel, B., Dreibus, G., Palme, H., Quijano-Rico, M., Kruse, H., Wlotzka, F., and Begemann, F., 1972, Multielement analyses of lunar samples and some implications of the results in Lunar Science Conference, 3rd, Proceedings: Geochim. et Cosmochim. Acta, Suppl. 3, p. 12511268.

Wänke, H., Baddenhausen, H., Palme, H., and Spettel, B., 1974, On the chemistry of the Allende inclusions and their origin as high temperature condensates: Earth and Planetary Sci. Letters, v. 23, no. 1, p. 1-7.

Wänke, H., Baddenhausen, H., Spettel, B., Teschke, F., Quijano-Rico, M., Dreibus, G., and Palme, H., 1972, The chemistry of the Haverö ureilite: Meteoritics, v. 7, no. 4, p. 579-590.

Wark, D. A., and Lovering, J. F., 1976, Refractory platinum metal grains in Allende calcium-aluminum-rich clasts (CARC's): possible exotic presolar material: Lunar Science VII, p. 912-914. 
Wasson, J. T., 1974, Meteorites-classification and properties: New York, Springer-Verlag, 360 p.

Wasson, J. T., and Baedecker, P. A., 1970, Ga, Ge, In, Ir, and $\mathrm{Au}$ in lunar, terrestrial and meteoritic basalts im Apollo 11 Lunar Science Conference Proceedings: Volume 2: Geochim. Cosmochim. Acta, Suppl. 1, p. 17411750 .

Wasson, J. T., Chou, Chen-Lin, Bild, R. W., and Baedecker, P. A., 1976, Classification of and elemental fractionation among ureilites: Geochim. et Cosmochim. Acta, v. 40, no. 12 , p. $1449-1458$.

Wetherill, G. W., 1964, Isotopic composition and concentration of molybdenum in iron meteorites: Jour. Geophys. Research, v. 69 , no. 20 , p. $4403-4408$.

Wilk, H. B., 1956, The chemical composition of some stony meteorites: Geochim. et Cosmochim. Acta, v. 9, nos. 5-6, p. 279-289.

1969, On regular disconiinuities in the composition of meteorites: Societas Scientiarum Fennica, Commentationes Physics-Mathematical, v. 34, p. 135-145.
1972, The chemical composition of the Haverö meteorite and the genesis of the ureilites: Meteoritics, v. 7, no. 4 , p. 553-557.

Winchester, J. W., and Aten, A. H. W., Jr., 1957, The content of tin in iron meteorites: Geochim. et Cosmochim. Acta, v. 12, nos. 1-2, p. 57-60.

Wing, James, 1964, Simultaneous determination of oxygen and silicon in meteorites and rocks by nondestructive activation analyses with fast neutrons: Anal. Chemistry, v. 36 , no. 3 , p. $559-564$.

Wyttenbach, A., von Gunten, H. E., and Scherle, W., 1965, Determination of bromine content and isotopic composition of bromine in stony meteorites by neutron activation: Geochim. et Cosmochim. Acta, v. 29, no. 5, p. 467474.

Yavnel, A. A., 1950, Spectrographic analysis of the SikhoteAlin meteorite: Meteoritika, v. 8, p. 134-148.

Zähringer, J., 1968, Rare gases in stony meteorites: Geochim. et Cosmochim. Acta, v. 32, no. 2, p. 209-238. 